UNIVERSIDADE DE SÃO PAULO

INSTITUTO DE GEOCIÊNCIAS

\title{
PROCESSAMENTO DE DADOS AEROMAGNÉTICOS - APLICAÇÃO AOS PROJETOS AEROGEOFÍSICOS EXTREMO SUDESTE DO BRASIL, SERRA DO MAR SUL E SÃO PAULO/RIO DE JANEIRO
}

IRALDO BRAGGION JUNIOR

Orientador: Prof. Dr. Fabio Taioli

TESE DE DOUTORAMENTO

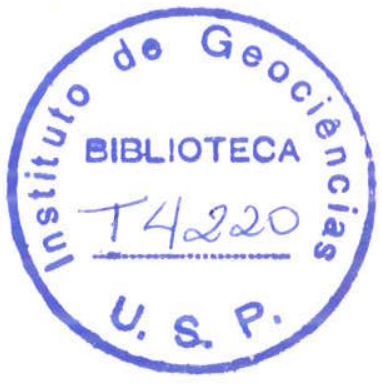

COM'SSÃO JULGADORA

Nome

Presidente: Prof. Dr. Fabio Taioli

Examinadores: Prof. Dr. Francisco José Fonseca Ferreira

Profa ${ }^{a}$ Dr $\stackrel{a}{\text {. }}$ Márcia Cristina Lopes Quintas

Prof $^{\mathrm{a}}$. Dr $\stackrel{\mathrm{a}}{ }$. Maria Irene Bartolomeu Raposo

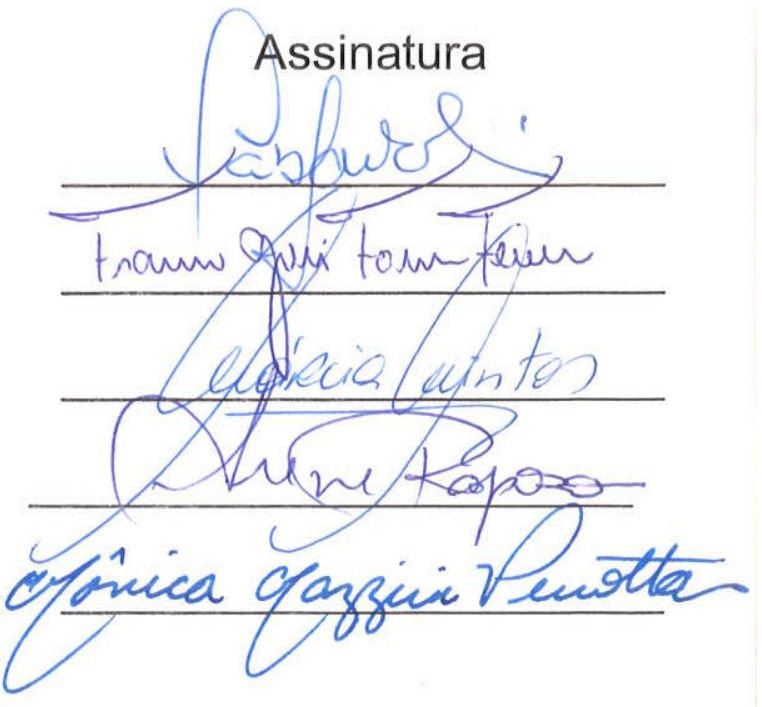

SÃO PAULO
2005 


\section{UNIVERSIDADE DE SĀO PAULO INSTITUTO DE GEOCIENCIAS}

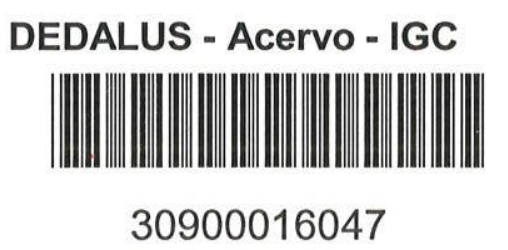

\section{PROCESSAMENTO DE DADOS AEROMAGNÉTICOS - APLICAÇÃO AOS PROJETOS AEROGEOFÍSICOS EXTREMO SUDESTE DO BRASIL, SERRA DO MAR SUL E SÃO PAULO/RIO DE JANEIRO}

Iraldo Braggion Junior

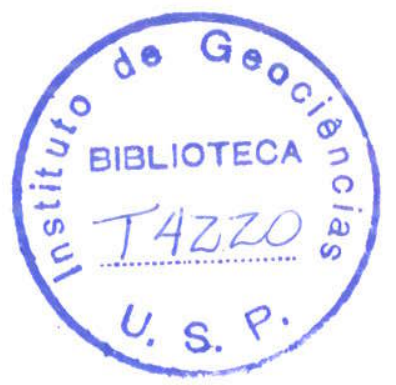

Orientador: Prof. Dr. Fabio Taioli

TESE DE DOUTORAMENTO

Programa de Pós-Graduação em Recursos Minerais e Hidrogeologia

$$
\begin{aligned}
& \text { SẢO PAULO } \\
& 2004
\end{aligned}
$$


À minha mãe, Nair 


\section{Agradecimentos}

$\mathrm{O}$ autor gostaria de expressar os seus mais sinceros agradecimentos às diversas pessoas e instituições que contribuíram para o desenvolvimento deste trabalho, seja na forma de cessão de dados, ou pelas sugestões e críticas apresentadas. Dentre estas, gostaria de agradecer especialmente:

Ao Prof. Dr. Fábio Taioli, pela orientação e pela confiança depositada durante a elaboração do trabalho;

Ao Departamento Nacional de Produção Mineral (DNPM) pela permissão de uso dos dados digitais do Projeto Aerogeofísico Serra do Mar Sul;

À Companhia de Pesquisa de Recursos Minerais (CPRM) pela permissão de uso dos dados digitais dos Projetos Aerogeofísicos Extremo Sudeste do Brasil e São Paulo/Rio de Janeiro, além do fornecimento dos mapas de posicionamento de linhas de vôo do Projeto Aerogeofísico Serra do Mar Sul;

A Minerais do Paraná S.A. (MINEROPAR), especialmente ao Mestre Donaldo Cordeiro da Silva, pela cessão de mapas de posicionamento de linhas de vôo do Projeto Aerogeofísico Serra do Mar Sul;

Ao Dr. Leonardo Castro de Oliveira (Instituto Militar de Engenharia - Ministério da Defesa -Comando do Exército), Dr. Luiz Paulo Souto Fortes (Departamento de Geodésia - IBGE) e Prof. Dr. João Francisco Galera Monico (Departamento de Cartografia - UNESP) pelas sugestões, discussões e fornecimento de parâmetros que permitiram realizar a correção cartográfica do Projeto Aerogeofísico Serra do Mar Sul;

Ao Dr. Carlos César de Araújo e ao Prof. Dr. Ginaldo Adhemar da Cruz Campanha (Instituto de Geociências da USP) pela cessão da versão digital dos contatos litológicos e lineamentos das cartas Cerro Azul e Apiai;

Ao Dr. Emanuel Giarolla (Instituto Nacional de Pesquisas Espaciais - INPE) e ao Prof. Dr. Ricardo Camargo (Departamento de Ciências Atmosféricas do IAG-USP) pela cessão de dados digitais de alta resolução de linha de costa;

Ao Dr. Martin H. S. Schimmel (Universidade de Barcelona) pela sugestão de emprego e posteriores discussões quanto ao uso de fasores para a análise de dados aeromagnéticos;

Ao Dr. Gordon R. J. Cooper (Universidade de Witwatersrand) pelas discussões sobre o emprego de camadas equivalentes para a interpolação 3-D de dados aeromagnéticos;

Aos colegas Arnaldo Roque, Douglas Bastianon, Jorge J. C. Palma, Luis E. B. Paulino, Luiz C. K. M. Ferrari, Márcia C. L. Quintas, Rinaldo M. Marques e Tereza H. Yamabe pelo apoio e amizade. 


\section{Resumo}

Este trabalho tem por objetivo efetuar uma análise crítica e comparativa das técnicas de processamento e da consistência de levantamentos aeromagnéticos executados sobre os estados de São Paulo, Paraná, Santa Catarina e Rio Grande do Sul.

Os dados oriundos dos Projetos Aerogeofísicos São Paulo/Rio de Janeiro, Serra do Mar Sul e Extremo Sudeste do Brasil foram processados segundo as técnicas e parâmetros sugeridos por seus autores (CPRM e Geofoto) e, também, utilizando procedimentos alternativos aos anteriores. A análise das malhas digitais geradas segundo os procedimentos aqui propostos indica que as técnicas de processamento sugeridas neste trabalho são capazes de produzir representações digitais do campo magnético anômalo com qualidade superior aos modelos digitais obtidos com o emprego das técnicas utilizadas anteriormente. São apresentados algoritmos inéditos para a identificação de fiduciais de controle, reposicionamento semi-automático de fiduciais de controle e determinação do cruzamento entre linhas de vôo. Foram identificados alguns tipos de erro que afetam principalmente o posicionamento dos dados ao longo das linhas de vôo, sendo propostos métodos para a sua correção. Aqui também é proposto o emprego de fasores para a análise de perfis de dados aeromagnéticos. 


\section{Abstract}

This work makes a critic and comparative analysis of the consistency and processing techniques that have been employed with airborne magnetic surveys that were carried out over São Paulo, Paraná, Santa Catarina and Rio Grande do Sul states.

Digital data from São Paulo/Rio de Janeiro, Serra do Mar Sul and Extremo Sudeste do Brasil Airborne Geophysical Projects were processed with the same techniques and parameters suggested by their contractors (CPRM and Geofoto). Also, they were processed with alternative proceedings and techniques. The analysis of the digital grids produced with the proceedings proposed in this work suggests that they are capable of producing digital grids of the anomalous magnetic field with better quality than before.

Unpublished algorithms to identify control fiducial points, to perform the semi-automatic repositioning of control fiducial points and to locate the crossover points between flight lines and tie lines are presented.

Several errors that affect the location of data along flight lines have been identified. Methods to correct these errors are presented.

At last, the phasor-walkout method is proposed to analyze airborne magnetic profiles and to identify its harmonic components. 


\section{Índice}

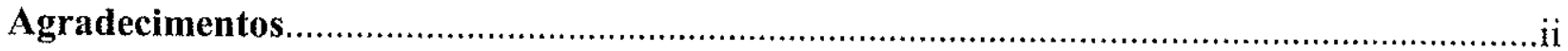

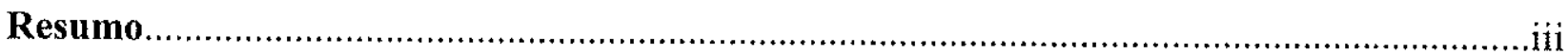

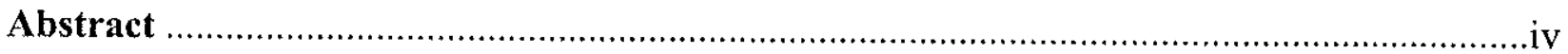

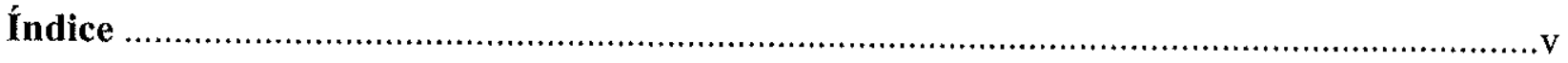

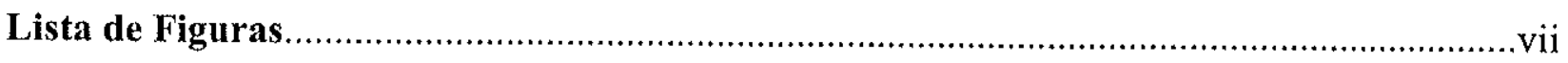

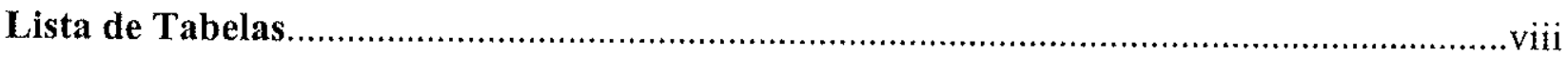

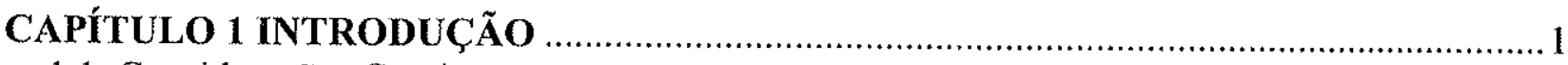

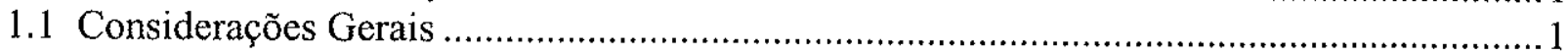

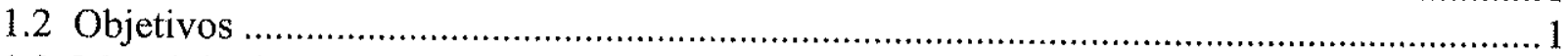

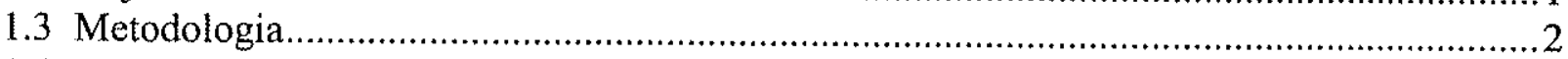

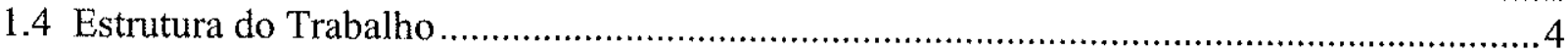

\section{CAPÍTULO 2 HISTÓRICO DOS LEVANTAMENTOS AEROGEOFÍSICOS NO} BRASIL

CAPÍTULO 3 FONTES DE ERRO EM DADOS AEROMAGNÉTICOS ........................... 10

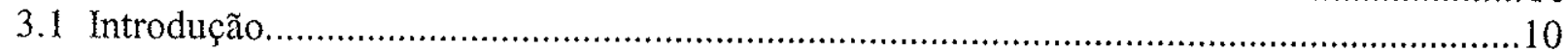

3.2 Fontes de Erro Associadas à Aeronave ................................................................... 10

3.2.1 Interferências magnéticas causadas pela operação da aeronave ............................... 11

3.2.2 Indução magnética causada pelo movimento da aeronave .....................................13

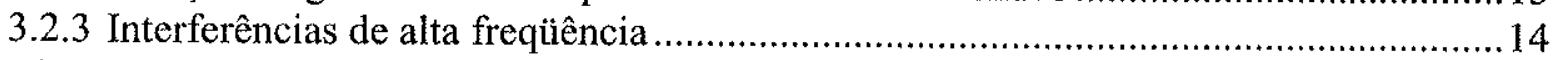

3.3 Correção das Variações Temporais .............................................................................. 14

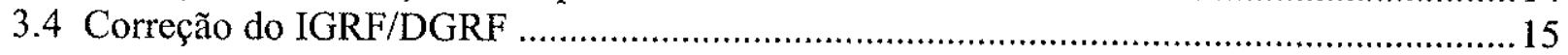

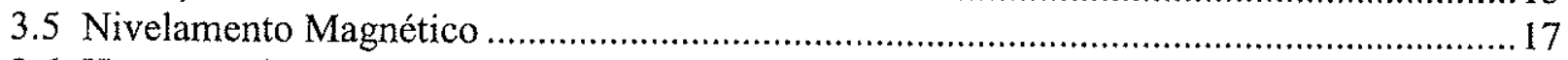

3.6 Homogeneização Espectral ................................................................................ 19

\section{CAPÍTULO 4 POSICIONAMENTO DAS FIDUCIAIS DOS PROJETOS}

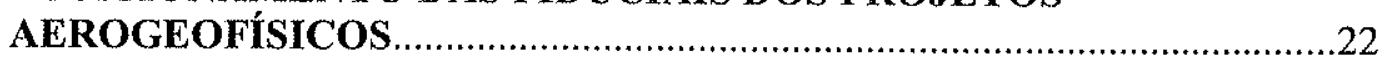

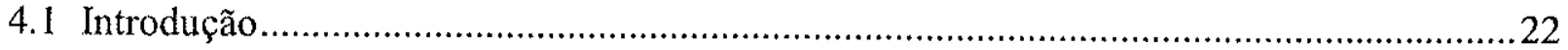

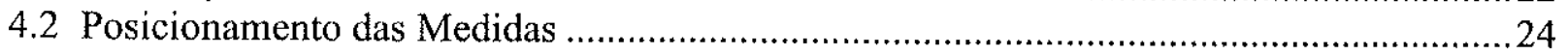

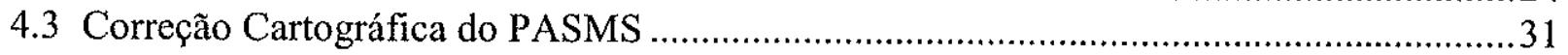

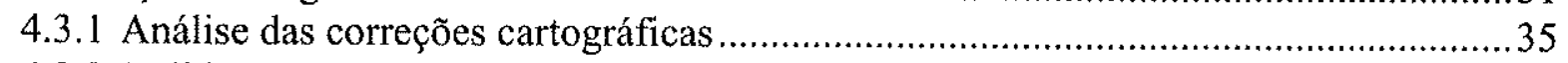

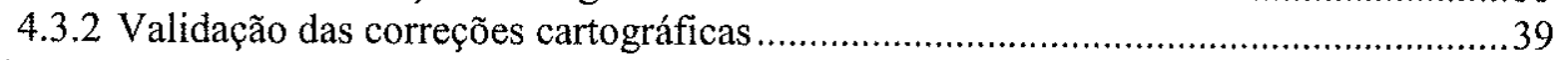

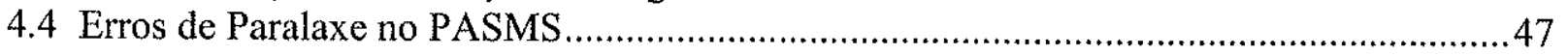

4.4.1 Correção dos erros de paralaxe do PASMS .............................................................52

4.4.2 Identificação das fiduciais de controle do PASMS .................................................53

\section{CAPÍTULO 5 TÉCNICAS DE GERAÇãO DE MALHAS DIGITAIS PARA DADOS}

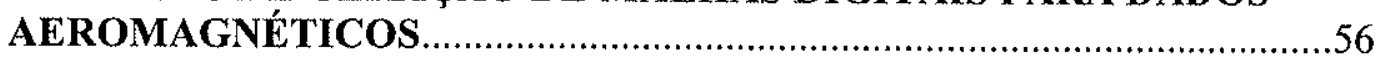

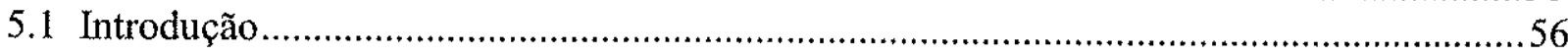

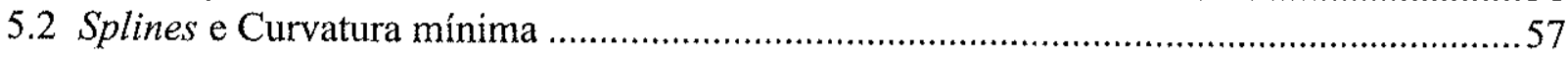




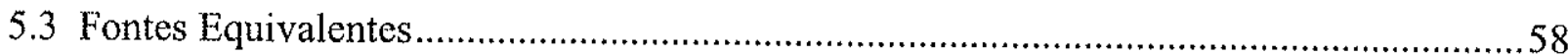

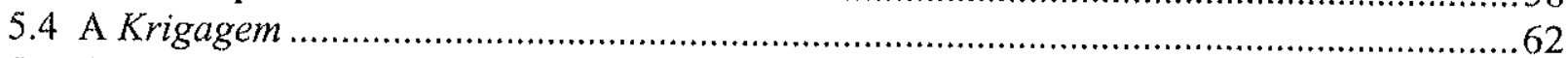

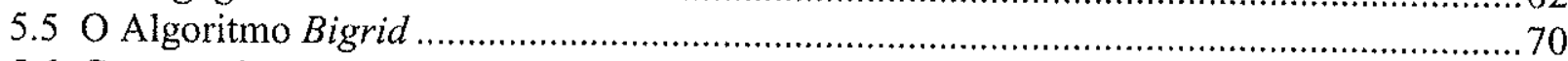

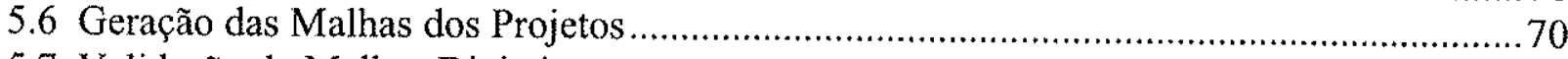

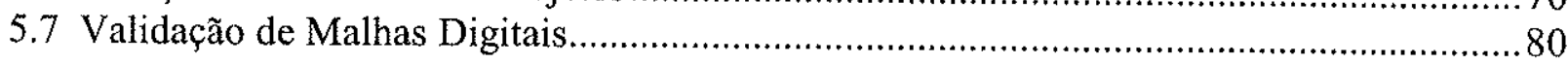

CAPÍTULO 6 FILTRAGEM LINEAR APLICADA À ATENUAÇÃO DOS ERROS DE NIVELAMENTO

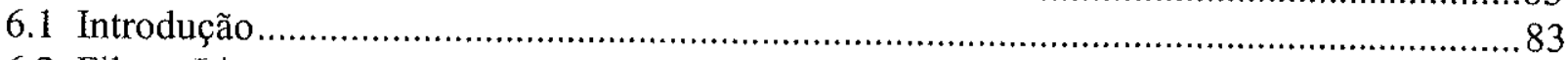

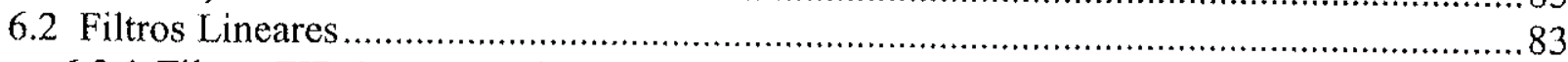

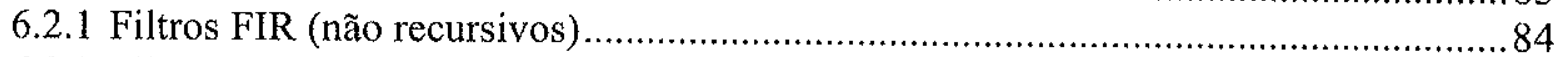

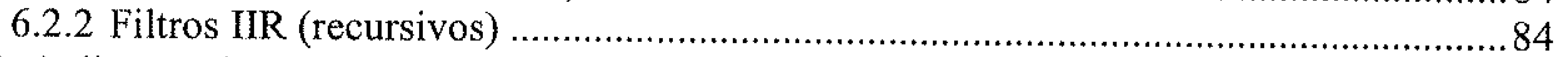

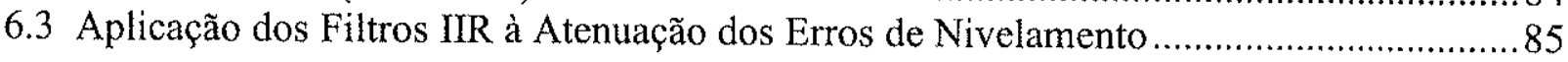

CAPÍTULO 7 NIVELAMENTO DE DADOS AEROMAGNÉTICOS.............................91

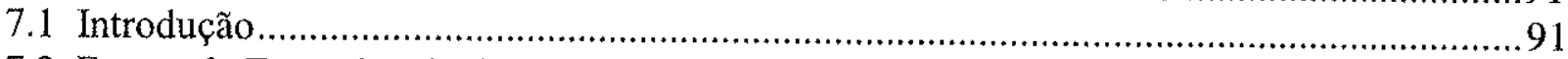

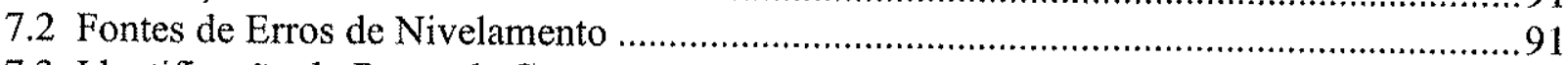

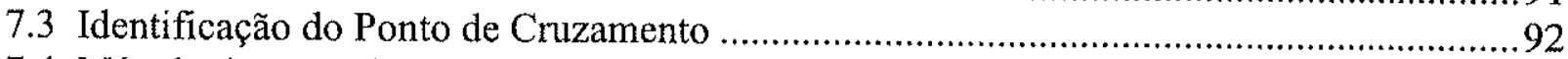

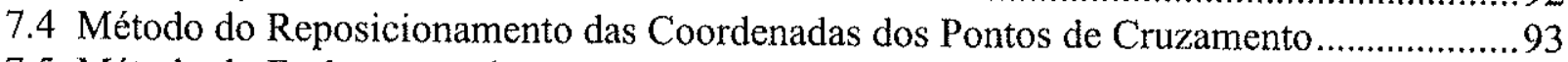

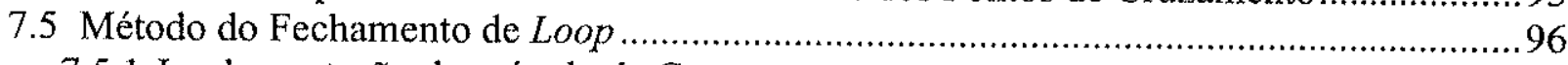

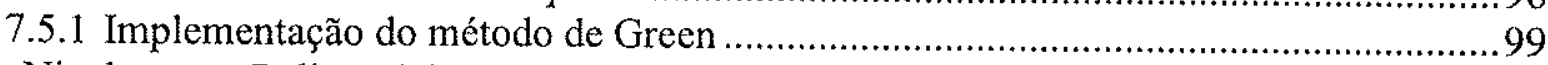

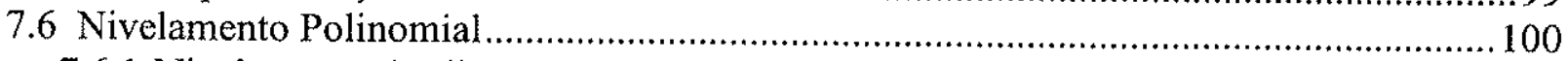

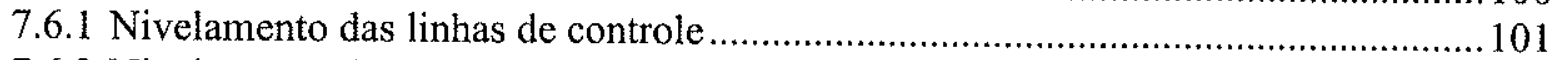

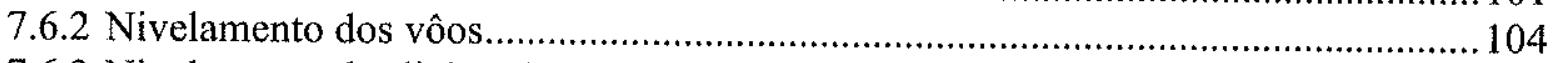

7.6.3 Nivelamento das linhas de aquisição individuais .................................................. 104

7.6.4 Nivelamento das linhas de controle com relação às linhas de aquisição........................ 104

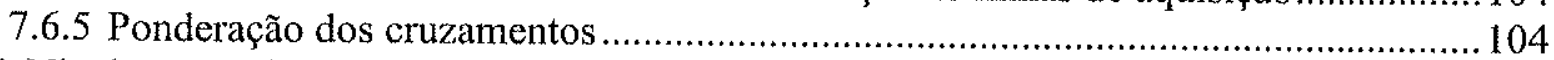

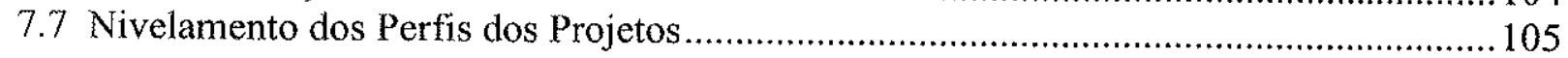

\section{CAPÍTULO 8 A DECORRUGAÇÃO E O MICRONIVELAMENTO DE DADOS}

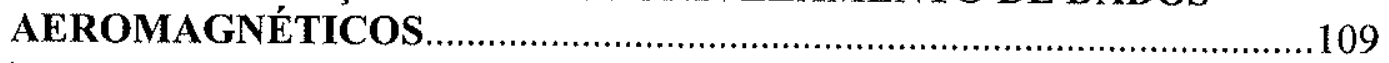

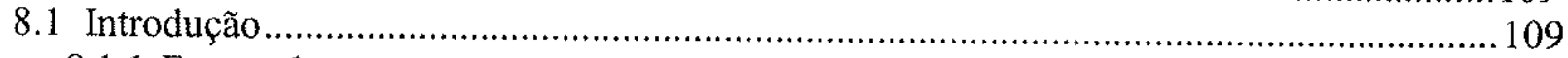

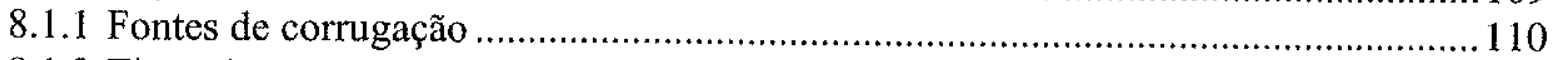

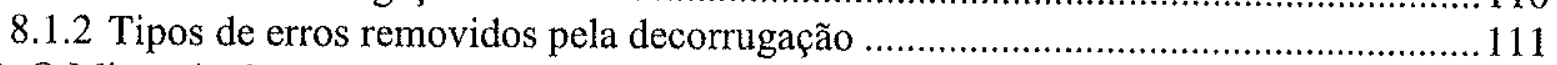

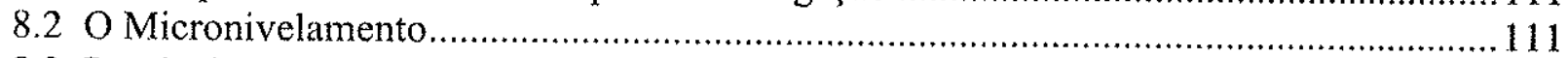

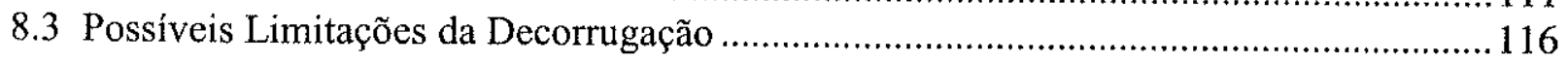

CAPÍTULO 9 O EMPREGO DE FASORES PARA A DISCRIMINAÇÃO DE COMPONENTES HARMÔNICAS E RUÍDO ..................................121

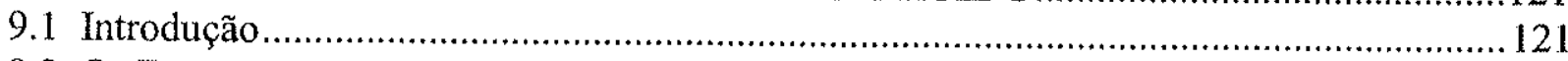

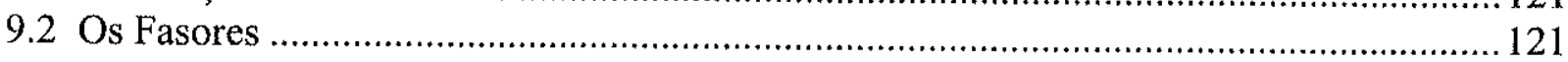

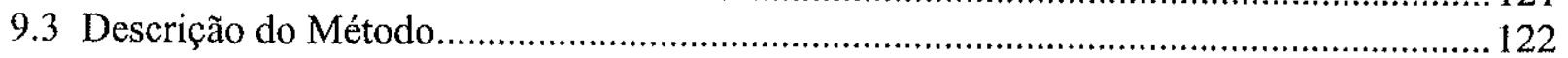

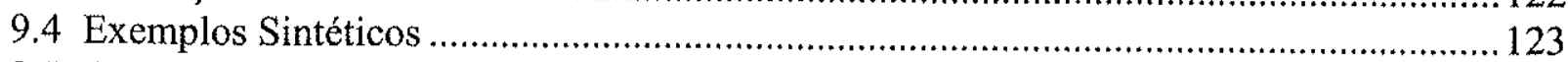

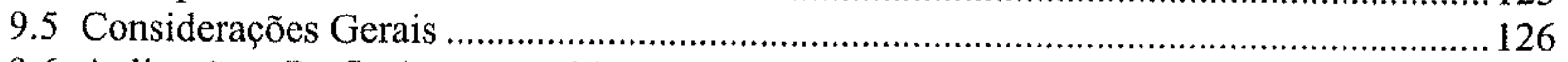

9.6 Aplicação a Perfis Aeromagnéticos do Projeto São Paulo/Rio de Janeiro............................ 126

CAPÍTULO 10 COMENTÁRIOS E CONCLUSÕES..................................................131

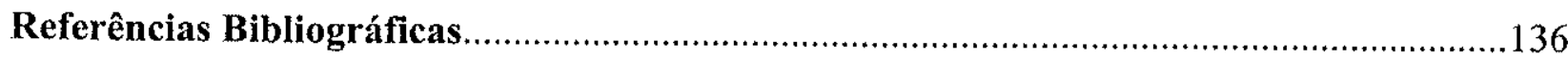


Figura 2.1 - Mapa de localização dos projetos aerogeofísicos

Figura 3.1 - Espectro aeromagnético segundo Hardwick

Figura 3.2 - Diferença entre o DGRF e o IGRF calculada para o ano de 1975 na região dos levantamentos

Figura 3.3 - Padrão de aquisição de dados aeromagnéticos

Figura 3.4 - Estimativa da distorção do espectro aeromagnético segundo Reid

Figura 4.1 - Relação entre trajetória real do vôo e fiduciais interpoladas

Figura 4.2 - Histogramas das distâncias entre fiduciais consecutivas

Figura 4.3 - Histogramas do azimute entre fiduciais consecutivas nas LP's

Figura 4.4 - Histogramas das alturas das aquisições dos dados sobre o terreno

Figura 4.5 - Efeito das linhas de vôo do PASMS condicionando a forma das anomalias

Figura 4.6 - Representação esquemática do cálculo das correções cartográficas

Figura 4.7 - Correções cartográficas medidas para efetuar o reposicionamento do PASMS

Figura 4.8 - Comparação entre as correções cartográficas medidas e modeladas para o reposicionamento do PASMS

Figura 4.9 - Decomposição das componentes do campo vetorial de correções do PASMS

Figura 4.10 - Localização dos corpos fontes de anomalia e dos lineamentos nas cartas Cerro Azul e Apiaí

Figura 4.11 - Sobreposição dos contatos geológicos e lineamentos às anomalias magnéticas

Figura 4.12 - Sobreposição dos contatos geológicos e lineamentos às anomalias de contagem total

Figura 4.13 - Sobreposição dos contatos geológicos e lineamentos às anomalias de tório

Figura 4.14 - Sobreposição dos contatos geológicos e lineamentos às anomalias de urânio

Figura 4.15 - Sobreposição dos contatos geológicos e lineamentos às anomalias de potássio

Figura 4.16 - Correção de posicionamento do PASMS na região de Florianópolis

Figura 4.17 - Simulação de erros de nivelamento e paralaxe sobre um corpo prismático

Figura 4.18 - Identificação de erro de paralaxe no PASMS na região do cráton Luis Alves

Figura 4.19 - Algoritmo para identificação automática de fiduciais de controle

Figura 5.1 - Aplicação de fontes equivalentes ao nivelamento de dados aeromagnéticos

Figura 5.2 - Exemplos de semivariogramas

Figura 5.3 - Dados aeromagnéticos processados por Hansen: mínima curvatura e krigagem isotrópica

Figura 5.4 - Dados aeromagnéticos processados por Hansen: krigagem anisotrópica

Figura 5.5 - Esquema das etapas envolvidas no algoritmo de interpolação Bigrid

Figura 5.6 - Espectros de potência das linhas de vôo do PAESB e PASPRJ

Figura 5.7 - Aplicação do algoritmo Bigrid a um trecho do PASPRJ

Figura 5.8 - Resposta espectral do filtro co-seno direcional utilizado na atenuação de erros paralelos à direção das linhas de produção

Figura 5.9 - Aplicação da krigagem e mínima curvatura a um trecho do PASPRJ

Figura 6.1 - Aplicação de filtros recursivos 1-D

Figura 6.2 - Aplicação de filtros IIR à atenuação de erros de nivelamento do PASPRJ

Figura 7.1 - Desempenho do algoritmo proposto para identificar o ponto de cruzamento entre linhas de produção e de controle

Figura 7.2 - Representação gráfica do método de nivelamento por reposicionamento das coordenadas do ponto de cruzamento

Figura 7.3 - Nivelamento pelo método de Green 
Figura 7.4 - Nivelamento polinomial - nivelamento das linhas de controle 103

Figura 7.5 - Nivelamento da subárea 4 do PASPRJ 106

$\begin{array}{lll}\text { Figura } 7.6 & \text { - Nivelamento do PAESB } & 107\end{array}$

Figura 8.1 - Fluxograma das etapas envolvidas na decorrugação e micronivelamento $\quad 110$

$\begin{array}{lll}\text { Figura } 8.2 \text { - Representação da região afetada pelas corrugações e do procedimento de } & 112\end{array}$

Figura 8.3 - Aplicação de filtros unidimensionais à decorrugação e ao micronivelamento 114

Figura 8.4 - Decorrugação da subárea 4 do PASPRJ 118

$\begin{array}{ll}\text { Figura } 8.5 \text { - Decorrugação do PAESB } & 119\end{array}$

$\begin{array}{ll}\text { Figura } 8.6 \text { - Decorrugação do PASMS } & 120\end{array}$

Figura 9.1 - Análise de fasores para um sinal sintético sem ruído $\quad 124$

$\begin{array}{ll}\text { Figura 9.2 - Análise de fasores para um sinal sintético com ruído } & 125\end{array}$

$\begin{array}{lll}\text { Figura } 9.3 \text { - Análise de fasores para um perfil aeromagnético da subárea } 4 \text { do PASPRJ } & 127\end{array}$

\section{Lista de Tabelas}

página

Tabela 1 - Informações digitais disponíveis $\quad 8$

Tabela 2 - Características dos Projetos Aerogeofísicos $\quad 8$

Tabela 3 - Variações temporais no campo magnético da Terra $\quad 15$

Tabela 4 - Estatísticas dos resíduos dos métodos de interpolação. 


\section{CAPÍTULO 1 \\ INTRODUÇÃO}

\subsection{ConsideraÇões Gerais}

O mapeamento do campo magnético terrestre tem ocupado uma importante parcela do estudo das variações petrológicas e estruturais do interior da Terra. Anteriormente à década de 1940, as observações das anomalias do campo magnético terrestre geralmente eram conduzidas em áreas de pequenas dimensões e com objetivos, quer de conhecimento geológico ou de exploração mineral, restritos. Naquele período, a aquisição de dados era essencialmente terrestre. O desenvolvimento das técnicas de condução de levantamentos magnetométricos aéreos e a maior disponibilidade desses dados, após o término da Segunda Guerra Mundial, propiciaram um mapeamento mais preciso e eficiente do campo magnético em áreas de grande extensão territorial (Hinze, 1985).

Devido aos elevados custos envolvidos na condução desses projetos, os levantamentos em escala regional foram realizados na sua maior parte por agências governamentais cujos objetivos principais eram avaliar e estimular a exploração de recursos minerais. No Brasil, o Departamento Nacional de Produção Mineral (DNPM) ficou encarregado de propiciar a execução desses levantamentos, sendo que a Companhia de Pesquisa de Recursos Minerais (CPRM) ficou com a responsabilidade de guarda dos dados de propriedade do DNPM, além de fiscalizar a execução e o processamento desses levantamentos.

O primeiro levantamento magnetométrico aéreo executado no Brasil pelo DNPM foi efetuado em 1953 na região de Poços de Caldas, MG (DNPM, 1984; CPRM, 1995). Ainda na década de 1950, foram conduzidos no Brasil mais quatro levantamentos, todos em escala de reconhecimento. Na década de 1960 não foram conduzidos levantamentos magnetométricos aéreos pelo DNPM. Estes só foram reiniciados no início da década de 1970. Em 1975, o DNPM contratou, através da CPRM, o Projeto Aerogeofísico Serra do Mar Sul (PASMS) e, em 1978, contratou os Projetos Aerogeofísicos Extremo Sudeste do Brasil (PAESB) e São Paulo/Rio de Janeiro (PASPRJ), cobrindo, desta forma, quase que a totalidade do pré-cambriano nos estados de São Paulo, Paraná, Santa Catarina e Rio Grande do Sul, além de porções da Bacia do Paraná. Com o passar dos anos, os dados magnetométricos aéreos desses organismos governamentais começaram a se tornar de domínio público, tendo as universidades e instituições de pesquisa amplo acesso a eles. $O$ interesse das universidades nesse tipo de dado reside não só no seu emprego direto na exploração mineral, mas também na possibilidade de se conduzirem estudos na área de pesquisa básica, uma vez que com eles podem ser estudadas diversas estruturas crustais.

\subsection{OBJetivos}

As anomalias magnéticas, que podem ser observadas numa configuração típica de um levantamento magnetométrico aéreo, possuem dimensões que variam de poucas dezenas de metros até várias centenas de quilômetros, apresentando uma resolução espacial menor do que 
aquela obtida com a condução de um levantamento magnetométrico terrestre e uma resolução maior do que aquela obtida com o emprego de satélites artificiais. As anomalias magnéticas obtidas através do emprego de sensores aerotransportados refletem, principalmente, estruturas e variações litológicas no interior da crosta terrestre, a configuração das rochas do embasamento cristalino, zonas de fraqueza crustal, distribuição de rochas ígneas intrusivas e extrusivas, e a geometria de bacias sedimentares.

A interpretação de perfis magnetométricos isolados presta-se ao estudo de estruturas geológicas com geometria bidimensional (2-D). Quando uma série de perfis magnetométricos é processada de modo adequado, pode-se produzir uma malha digital bidimensional útil no estudo de estruturas geológicas com geometria tridimensional (3-D).

Com a disseminação dos meios computacionais disponíveis junto às universidades brasileiras, ocorrida a partir do início da década de 1990, passou a existir a possibilidade de se empregar técnicas mais apuradas de processamento e interpretação dos dados magnetométricos aéreos. Anteriormente, a análise desse tipo de informação geralmente era do tipo qualitativa ou quando era quantitativa geralmente ocorria de forma restrita à interpretação 2-D. Devido aos limitados recursos de processamento de dados disponíveis àquela época, eram empregadas técnicas limitadas de processamento de dados aeromagnéticos, comparativamente com aquelas disponíveis atualmente.

A presente tese tem como objetivo efetuar uma análise crítica e comparativa dos dados de magnetometria aérea dos Projetos Aerogeofísicos Extremo Sudeste do Brasil (Anjos \& Mourão, 1987), Serra do Mar Sul (Geofoto, 1978b) e São Paulo/Rio de Janeiro (Anjos \& Mourão, 1988). Serão confrontadas as técnicas de processamento de dados magnetométricos empregadas nesses levantamentos com as técnicas mais recentes (Fitzgerald, 1996; Luyendyk, 1997). Serão contempladas as etapas envolvidas no pré-processamento, geração de malhas digitais, e pós-processamento de dados magnetométricos aéreos.

Com o emprego das técnicas modernas de processamento de dados magnetométricos aéreos e com a aplicação de novas metodologias que permitam a correção dos diversos tipos de erro de posicionamento do PASMS, pretende-se que as representações dos dados magnetométricos aéreos nas regiões Sul e Sudeste do Brasil, aqui geradas na forma de malhas digitais bidimensionais, sejam de qualidade superior aquelas obtidas anteriormente, maximizando o sinal de origem geológica e reduzindo as componentes de origem não geológica. Com isso, estará sendo fornecido um forte subsídio a futuros trabalhos de prospecção mineral e de estudos geológicos em geral nos estados de São Paulo, Paraná, Santa Catarina e Rio Grande do Sul.

\subsection{MEtodologia}

No que diz respeito ao pré-processamento de dados é feita uma análise das componentes de origem não crustal que afetam as medidas e que podem interferir no produto final, ou seja, a malha digital bidimensional. As variações espaciais e temporais no campo magnético, medidas durante um levantamento aerogeofísico, são causadas não apenas por corpos fontes em subsuperfície, mas, também, por componentes devidas à aeronave e pela componente do campo geomagnético que se origina no núcleo externo da Terra. Como modelo representativo do campo geomagnético, será empregado o DGRF (Definitive Geomagnetic Reference Field - 
Campo Geomagnético de Referência Definitivo) atualmente disponível em substituição ao IGRF (International Geomagnetic Reference Field - Campo Geomagnético de Referência Definitivo), disponível à época do primeiro processamento desses levantamentos (Peddie, 1983). Além disso, analisa-se a necessidade de se efetuar a homogeneização espectral dos dados aeromagnéticos, de tal forma a se reduzir a contaminação espectral durante o processo de interpolação dos perfis de dados numa malha digital bidimensional.

Tem sido amplamente divulgado na literatura que o PASMS apresenta erros de posicionamento que fazem com que as anomalias geofísicas (magnéticas e gamaespectrométricas) não se localizem próximas aos seus corpos fontes, tendo sido observados erros com magnitudes superiores a $20 \mathrm{~km}$ (Geofoto, 1978b; Silva, 1994). Estes erros originaram-se na fase de compilação dos fotomosaicos e na sua transcrição para os mapas de posicionamento de linhas de vôo, o que resultou na atribuição incorreta das coordenadas geográficas das fiduciais de controle e, por conseguinte, das coordenadas de todos os pontos de medida do PASMS. Nadal et al. (1992), desenvolveram uma técnica - baseada na transformação afim - para efetuar a correção desses erros. Essa técnica é semelhante às técnicas geralmente empregadas para a retificação de imagens de sensores remotos orbitais. Contudo, ela tem sido aplicada apenas em áreas restritas, no máximo ocupando a superfície de uma carta topográfica na escala 1:100.000. Isso tem impossibilitado o pleno aproveitamento do PASMS, quer pela comunidade acadêmica, quer por empresas que atuam na área de mineração. Neste trabalho é proposta a aplicação de uma técnica de retificação global com o objetivo de se permitir a recuperação total do PASMS. Além disso, é proposto um algoritmo semi-automático para efetuar a correção de erros de paralaxe que atingem trechos de linhas de vôo do PASMS e um algoritmo para efetuar a identificação automática das fiduciais de controle.

Anteriormente, as malhas digitais dos projetos PASPRJ, PASMS e PAESB eram geradas com o algoritmo Bigrid, pela sua simplicidade de emprego. Pretende-se, nesta tese, empregar outras técnicas de interpolação - splines e curvatura mínima, fontes equivalentes, krigagem - e efetuar a sua validação cruzada. Desse modo será possível determinar qual delas produz a melhor representação dos dados magnetométricos aéreos.

As técnicas de nivelamento empregadas anteriormente eram frágeis e propiciaram a ocorrência de fortes erros de nivelamento nas linhas de vôo. Esse problema tem sido constantemente relatado na literatura nacional por diversos autores, sem que se tentasse retrabalhar os dados originais (Ferreira, 1991; Costa et al. 1990). Atualmente, com as facilidades computacionais existentes, podem-se efetuar vários tipos de nivelamento das linhas de vôo dos projetos em questão. Particularmente, pretende-se empregar o nivelamento polinomial, $o$ nivelamento por fechamento de loop, e o nivelamento por reposicionamento das coordenadas dos pontos de cruzamento (Green, 1983; Fitzgerald, 1996; Luyendyk, 1997), objetivando reduzir as discrepâncias anteriormente existentes. Ainda com relação ao nivelamento, é proposto um algoritmo que visa otimizar a identificação da localização do ponto de cruzamento entre linhas de aquisição e linha de controle.

Não se tem conhecimento, através da consulta da bibliografia nacional, que tenham sido empregadas sistemática e comparativamente técnicas de micronivelamento e de decorrugação de dados magnetométricos aéreos aos projetos em questão. Particularmente, os principais algoritmos utilizados no micronivelamento e decorrugação existentes constituem-se de algoritmos proprietários de empresas estrangeiras (Minty, 1991). Neste trabalho, será empregada a técnica de Braggion Jr.(1998), que faz o uso de filtros recursivos do tipo elíptico para a 
atenuação desses erros residuais que afetam, sobremaneira, as porções de alta freqüência do espectro dos dados (Reid, 1980).

Rotineiramente, a identificação das componentes harmônicas (periódicas) presentes em perfis de dados magnetométricos tem sido feita através da análise do conteúdo do espectro de amplitude obtido através da transformada de Fourier dos dados. A técnica da análise dos fasores tem sido aplicada em sismologia para a investigação da presença de sinais harmônicos em séries temporais e na análise de registros de gravímetros supercondutores (Zürn \& Rydelek, 1994), e na análise de catálogos sísmicos (Rydelek \& Sacks, 1989), não se tendo conhecimento de outras aplicações desta técnica, em geofísica, fora das áreas citadas. Pretende-se que esta tese introduza o emprego da técnica de análise de fasores como instrumento de análise do comportamento espectral de perfis magnetométricos.

\subsection{Estrutura do Trabalho}

O primeiro capítulo consta da Introdução da tese. No segundo capítulo da tese Histórico dos Levantamentos Aerogeofísicos - é feito um retrospecto dos primeiros levantamentos aeromagnéticos executados no Brasil, e analisa-se como os Projetos Aerogeofísicos Extremo Sudeste do Brasil, Serra do Mar Sul e São Paulo/Rio de Janeiro se inserem no contexto dos levantamentos brasileiros.

O terceiro capítulo da tese - Fontes de Erros em Dados Aeromagnéticos - discute os erros inerentes à aquisição de dados aerotransportados, além de analisar uma série de correções que devem ser aplicadas aos dados em etapas anteriores à da geração da malha digital. Essas correções são aplicadas com o objetivo de que a malha digital gerada venha a conter o máximo de sinal devido a fontes de origem geológica e o mínimo de sinal (considerado como ruído) devido a outros tipos de fontes. Essa análise é feita baseada nas características dos procedimentos adotados para a amostragem dos dados, ou seja, nas características dos parâmetros de execução dos levantamentos aerogeofísicos empregados.

No quarto capítulo da tese - Posicionamento das Fiduciais dos Projetos Aerogeofísicos - é feita uma análise da consistência do posicionamento das medidas para os três projetos aerogeofísicos em questão. É proposta uma metodologia para o reposicionamento global das fiduciais do Projeto Aerogeofísico Serra do Mar Sul em contrapartida a metodologias anteriores que somente permitiam o reposicionamento local. Ainda quanto ao PASMS, foram identificados erros de paralaxe que afetam apenas trechos de linhas de vôo, sendo propostos algoritmos inéditos para lidar com esse tipo de erro e para identificar as fiduciais de controle.

O quinto capítulo da tese - Técnicas de Geração de Malhas Digitais para Dados Aeromagnéticos - descreve as principais técnicas de interpolação de malhas digitais empregadas com dados aeromagnéticos (splines e curvatura mínima, fontes equivalentes, krigagem, algoritmo Bigrid). Os resultados obtidos por estas técnicas são confrontados, através da análise morfológica das anomalias interpoladas e de testes de validação cruzada, objetivandose definir qual é aquela que produz os menores erros de interpolação, gerando uma malha digital mais confiável.

No sexto capítulo - Filtragem Linear Aplicada à Atenuação de Erros de Nivelamento - propõe-se o emprego de filtros recursivos do tipo elíptico (filtros de Cauer) como alternativa à 
filtragem espectral que tem sido aplicada às malhas digitais dos levantamentos utilizados nesta tese. Este tipo de filtragem tem dupla finalidade: efetuar a homogeneização espectral e atenuar os erros de nivelamento (chamados de corrugações) que afetam as malhas digitais de levantamentos aeromagnéticos.

O sétimo capítulo - Nivelamento de Dados Aeromagnéticos - analisa o emprego de três técnicas de nivelamento de dados aerogeofísicos: nivelamento polinomial, o nivelamento por fechamento de loop, e o nivelamento por reposicionamento das coordenadas dos pontos de cruzamento. Tendo em vista reduzir os erros de nivelamento originalmente existentes nos dados, os resultados obtidos com o emprego destas técnicas são comparados entre si. Além disso, é proposto um algoritmo que visa otimizar a identificação da localização do ponto de cruzamento entre linhas de aquisição e linhas de controle.

No oitavo capítulo - A Decorrugação e Micronivelamento de Dados Aeromagnéticos - são apresentadas novas técnicas que têm como objetivo atenuar os erros de nivelamento que afetam as malhas digitais dos três projetos aerogeofísicos. Estas técnicas apresentam desempenho superior com relação à técnica de filtragem espectral até então utilizada no processamento desses dados.

No nono capítulo - O Emprego de Fasores para a Discriminação de Componentes Harmônicas e Ruído - propõe-se o emprego da análise da trajetória de fasores como alternativa para a identificação de componentes harmônicas (periódicas) presentes em perfis aeromagnéticos. Esta técnica, empregada com mais freqüência nas áreas de engenharia elétrica e de sismologia, demonstrou grande potencial quanto à sua utilização com dados aeromagnéticos.

O décimo capítulo da tese contém os Comentários e Conclusões; nele também são feitas propostas para a continuidade do trabalho. 


\section{CAPITULO 2 \\ HISTÓRICO DOS LEVANTAMENTOS AEROGEOFISICOS NO \\ BRASIL}

O primeiro levantamento aerogeofísico executado pelo Departamento Nacional da Produção Mineral - DNPM - data de 1952, compreendendo um reconhecimento aerocintilométrico na região litorânea entre Macaé, RJ, e Prado, BA, com um total voado de $1.200 \mathrm{~km}$ lineares. Em 1953 foi efetuado um levantamento aeromagnético e aerocintilométrico em Poços de Caldas, MG. Neste ciclo inicial também se incluem os levantamentos nas regiões de Itabapoana, Guarapari e Norte de Vitória (1953), Ribeira do Iguape (1954), Vazante (1956) e Januária (1958) (DNPM, 1984; CPRM, 1995). Durante a década de 60 não foram executados levantamentos aerogeofísicos pelo DNPM. Os levantamentos aerogeofísicos só foram reiniciados na década de 70, através do Projeto Alto Garças, executado em 1971.

O Departamento Nacional da Produção Mineral adotou, então, a meta de "Levantar sistematicamente, em regime de reconhecimento aéreo, o máximo de área no mínimo de tempo, dentro dos recursos disponiveis. "(DNPM, 1984). Seguindo essa meta, a partir de 1970 foram desenvolvidos vários projetos, tendo o ciclo de levantamentos se encerrado em 1980, após terem sido executados 46 levantamentos. Naquele momento, o DNPM contava com $1.907 .447 \mathrm{~km}$ de levantamentos voados sobre o Escudo Brasileiro, cobrindo uma área de $2.623 .760 \mathrm{~km}^{2}$. Em 1975 o DNPM contratou, através da CPRM, o Projeto Aerogeofísico Serra do Mar Sul (PASMS), e em 1978 os Projetos Extremo Sudeste do Brasil (PAESB) e São Paulo/Rio de Janeiro (PASPRJ), cobrindo, desta forma, quase que a totalidade do pré-Cambriano nos estados de São Paulo, Paraná, Santa Catarina e Rio Grande do Sul (Figura 2.1).

O Projeto Aerogeofísico São Paulo/Rio de Janeiro, originalmente dividido em 6 subáreas, foi conduzido em duas etapas. Na primeira, foi levantado todo o estado do Rio de Janeiro (subáreas 1 e 2); na segunda, foi levantado parte do estado de São Paulo (subáreas 3, 4 e 6). A subárea 5, localizada no estado de São Paulo não foi levantada. Neste trabalho será utilizada apenas a porção paulista do projeto, ou seja, as subáreas 3, 4 e 6 .

No totall, os três projetos cobrem uma área superior a $143.000 \mathrm{~km}^{2}$, tendo sido voada uma extensão total de $152.000 \mathrm{~km}$ lineares. Foram coletadas mais de 2.052 .000 amostras ao longo de linhas de vôo espaçadas em média $1 \mathrm{~km}$ entre si. $\mathrm{O}$ espaçamento médio entre medidas ao longo das linhas de vôo foi de $58 \mathrm{~m}$ no PASMS, $65 \mathrm{~m}$ no PAESB e $100 \mathrm{~m}$ no PASPRJ. A altura média de vôo sobre o terreno foi de $150 \mathrm{~m}$ nos três projetos, tendo o PASMS sido voado na direção N30W e os outros na direção N-S. A Tabela 1 descreve todos os tipos de informação geofísica que se dispõe em meio digital para cada um dos três projetos. Conforme pode ser visto, o PASMS não possui informação disponível sobre as linhas de controle (LC), os valores de magnetometria bruta e os valores da magnetometria corrigida da variação diurna. Essas informações foram perdidas pelo executor do projeto e não podem mais ser recuperadas. A Tabela 2 resume as principais características dos três projetos, tais como: empresas executoras do levantamento e do processamento dos dados; períodos de execução e de processamento dos

\footnotetext{
'Considerando-se apenas as subáreas 3, 4 e 6 do PASPRJ, e a íntegra do PASMS e PAESB.
} 


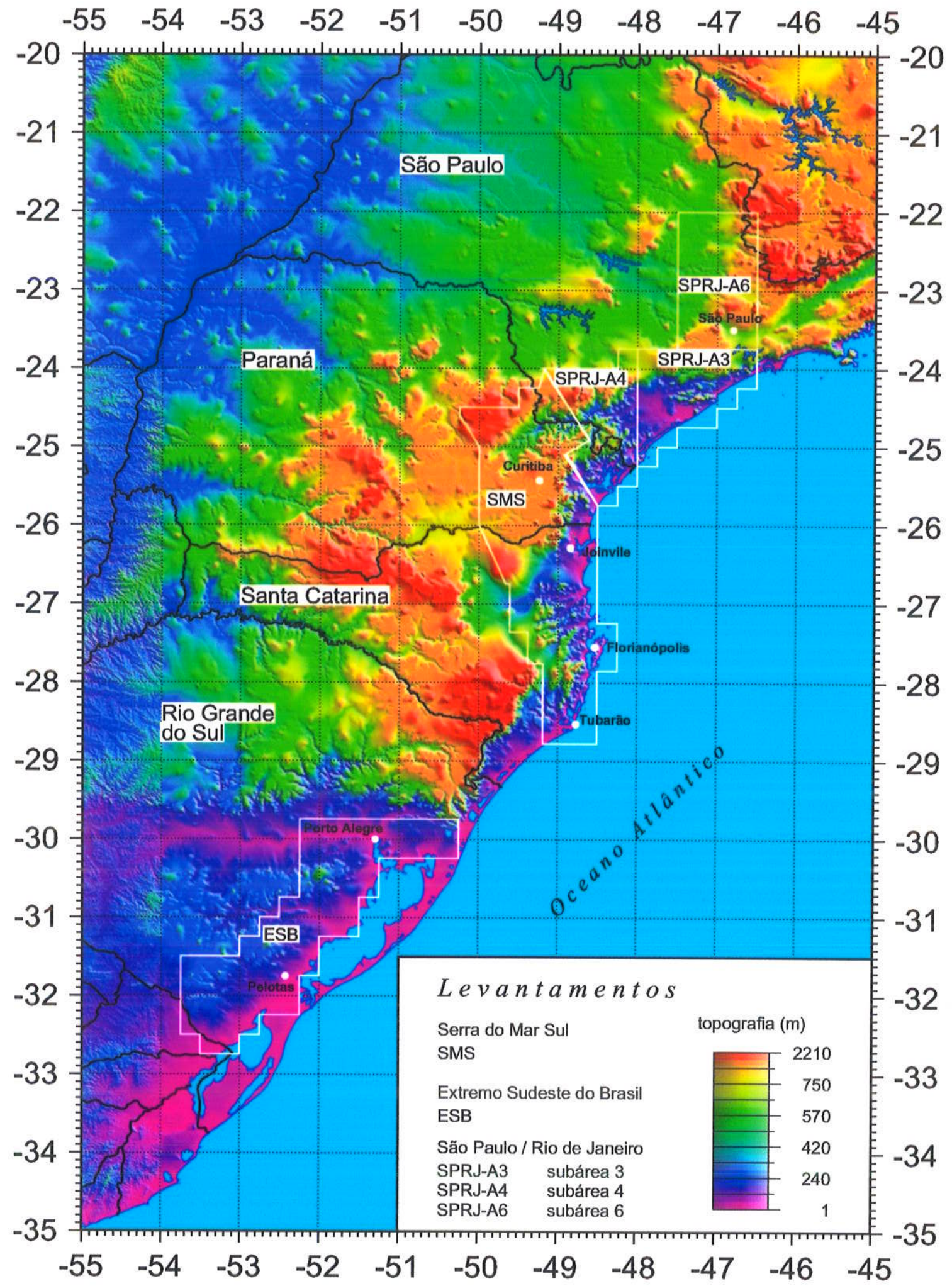

Figura 2.1 - Mapa de localização dos Projetos Aerogeofísicos Extremo Sudeste do Brasil, Serra do Mar Sul e São Paulo/Rio de Janeiro. 
Tabela 1 - Informações digitais disponiveis

\begin{tabular}{|c|c|c|c|c|c|c|c|c|c|c|c|}
\hline & \multirow{2}{*}{$\begin{array}{c}\mathrm{N}^{0} \mathrm{do} \\
\text { vôo }\end{array}$} & \multirow{2}{*}{$\begin{array}{l}\mathbf{N}^{\circ} \text { do } \\
\text { perfil }\end{array}$} & \multirow{2}{*}{$\begin{array}{l}\mathbf{N}^{\circ} \mathrm{da} \\
\text { fiducial }\end{array}$} & \multirow{2}{*}{ Horário } & \multicolumn{2}{|c|}{ Coordenada } & \multirow{2}{*}{$\begin{array}{l}\text { Altura } \\
\text { sobre o } \\
\text { terreno }\end{array}$} & \multicolumn{4}{|c|}{ Magnetometria } \\
\hline & & & & & UTM Este & UTM Norte & & Bruto & $\begin{array}{c}\text { Corrigida da } \\
\text { variação diurna }\end{array}$ & Nivelada & Residual \\
\hline SMS & $\checkmark$ & $\checkmark$ & $\checkmark$ & $\checkmark$ & $\checkmark$ & $\checkmark$ & 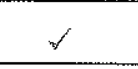 & 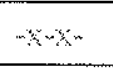 & $-x, x$ & $\checkmark$ & $\checkmark$ \\
\hline ESB & $-x-3-$ & $\checkmark$ & $\checkmark$ & $x+x$ & $\checkmark$ & $y$ & 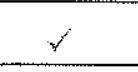 & $\checkmark$ & $\gamma$ & $\checkmark$ & $y$ \\
\hline SPRJ & $-x+x_{w}$ & $r$ & $\checkmark$ & $x-x_{-}$ & $\checkmark$ & $y$ & $\checkmark$ & $\checkmark$ & $y$ & $\checkmark$ & $v^{\prime}$ \\
\hline
\end{tabular}

\begin{tabular}{|c|c|c|c|c|c|c|c|c|c|c|c|c|c|}
\hline & \multicolumn{11}{|c|}{ Gamaespectrometria } & \multirow{3}{*}{$\begin{array}{c}\text { Linha de } \\
\text { Produção (LP) }\end{array}$} & \multirow{3}{*}{$\begin{array}{c}\text { Linha de } \\
\text { Controle (LC) }\end{array}$} \\
\hline & \multicolumn{4}{|c|}{ Bruto } & \multicolumn{4}{|c|}{ Corrigido } & \multicolumn{3}{|c|}{ Razões } & & \\
\hline & $\begin{array}{l}\text { Contagem } \\
\text { Total }\end{array}$ & $\mathrm{Th}$ & $\mathbf{U}$ & $\mathbf{K}$ & $\begin{array}{c}\text { Contagem } \\
\text { Total }\end{array}$ & $\mathrm{Th}$ & U & $\mathbf{K}$ & U/Th & $\mathbf{U} / \mathbf{K}$ & $\mathrm{Th} / \mathrm{K}$ & & \\
\hline SMS & $\checkmark$ & $\checkmark$ & 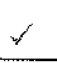 & $y$ & $\checkmark$ & $\checkmark$ & $\checkmark$ & $\checkmark$ & $\checkmark$ & $\checkmark$ & $\checkmark$ & $\checkmark$ & $-x-x$ \\
\hline ESB & $\checkmark$ & $\checkmark$ & $\checkmark$ & $\checkmark$ & $\checkmark$ & $\checkmark$ & $\checkmark$ & $\checkmark$ & $\checkmark$ & $y$ & $y$ & $\checkmark$ & $\checkmark$ \\
\hline SPRJ & $\checkmark$ & $\checkmark$ & $r$ & 4 & $\checkmark$ & $\gamma$ & $\checkmark$ & $\checkmark$ & $\checkmark$ & $\checkmark$ & $\checkmark$ & $y$ & $\checkmark$ \\
\hline
\end{tabular}

Tabela 2 - Características dos levantamentos

\begin{tabular}{|c|c|c|c|c|c|c|c|}
\hline & Executor & Ano de execução & Período de processamento & Executor do processamento & $\mathbf{N}^{a}$ de Registros & Extensão & Navegação \\
\hline SMS & Geofoto & 1975 a 1977 & 1978 & Geofoto & 808.291 & $53.924 \mathrm{~km}$ & Fotomosaico \\
\hline ESB & LASA & 1978 & 1985 a 1987 & CPRM & 704.930 & $44.023 \mathrm{~km}$ & Fotomosaico \\
\hline $\operatorname{SPR}^{1}$ & Encal & 1978 a 1979 & 1987 a 1988 & CPRM & 539.049 & $52.436 \mathrm{~km}$ & Doppler \\
\hline
\end{tabular}

\begin{tabular}{|c|c|c|c|c|c|c|}
\hline & Limites Aproximados & Altura sobre o terreno & Intervalo de amostragem & Direção das $\mathbf{P}$ & Distância entre LP & Distância entre LC \\
\hline SMS & $24,00^{\circ} \mathrm{S} / 29,00^{\circ} \mathrm{S} / 50,25^{\circ} \mathrm{W} / 48,25^{\circ} \mathrm{W}$ & $150 \mathrm{~m}$ & $1 \mathrm{~s}$ & $\mathrm{~N} 30 \mathrm{~W}$ & $1 \mathrm{~km}$ & $20 \mathrm{~km}$ \\
\hline ESB & $29,75^{\circ} \mathrm{S} / 32,75^{\circ} \mathrm{S} / 53,75^{\circ} \mathrm{W} / 50,25^{\circ} \mathrm{W}$ & $150 \mathrm{~m}$ & $1 \mathrm{~s}$ & $\mathrm{~N}-\mathrm{S}$ & $1 \mathrm{~km}$ & $10 \mathrm{~km}$ \\
\hline SPRJ ${ }^{1}$ & $22,00^{\circ} \mathrm{S} / 25,75^{\circ} \mathrm{S} / 49,25^{\circ} \mathrm{W} / 46,50^{\circ} \mathrm{W}$ & $150 \mathrm{~m}$ & $100 \mathrm{~m}$ & $\mathrm{~N}-\mathrm{S}$ & $1 \mathrm{~km}$ & $10 \mathrm{~km}$ \\
\hline
\end{tabular}

SMS - Projeto Aerogeofísico Serra do Mar Sul TSB - Projeto Aerogeofisico Extremo Sudeste do Brasil SPRJ - Projeto Aerogeofísico São Paulo - Rio de Janeiro 
dados; quantidade de dados medidos e extensão de cada levantamento $(\mathrm{km})$; tipo de navegação empregada; limites aproximados da área de cada projeto; altura sobre o terreno e intervalo de amostragem; direção das linhas de produção (LP); distância entre linhas de produção consecutivas e entre linhas de controle consecutivas.

Os dados dos três projetos foram gentilmente cedidos pelo DNPM e pela CPRM, na forma digital, perfazendo um total de 327 Mbytes de informação geofísica disposta ao longo de perfis. Quando do término do processamento de cada levantamento aerogeofísico, quer pela CPRM ou pelo executor do projeto, é publicada uma série de relatórios descrevendo as etapas de aquisição e processamento do mesmo: Anjos \& Mourão (1987) para o PAESB; Anjos \& Mourão (1988) para o PASPRJ; Geofoto (1978a) e Geofoto (1978b) para o PASMS. O conhecimento do conteúdo desses relatórios é fundamental para os usuários dos projetos, pois neles estão descritos os parâmetros de aquisição dos levantamentos, as correções que foram aplicadas aos dados, o tipo de nivelamento adotado, o método de interpolação usado na geração da malha digital, etc. 


\section{CAPÍTULO 3 \\ FONTES DE ERRO EM DADOS AEROMAGNÉTICOS}

\subsection{INTRODUÇÃO}

Antes da geração de uma malha digital a partir de dados aeromagnéticos é necessário que os mesmos passem por uma fase de pré-processamento, na qual recupera-se a trajetória do vôo e aplicam-se algumas correções aos mesmos. Os dados do campo magnético, conforme observados durante a execução de um levantamento aeromagnético, estão sujeitos a uma ampla gama de variações temporais e espaciais que se sobrepõem ao sinal proveniente das fontes de origem geológica. Essas variações, consideradas como ruído, devem ser removidas ou pelo menos minimizadas, de tal modo que os dados a serem processados contenham apenas as componentes de origem geológica.

\subsection{Fontes de Erro Associadas à Aeronave}

A assinatura magnética de uma aeronave consiste de três componentes: a sua magnetização permanente; a magnetização induzida pelo movimento da aeronave através do campo magnético da Terra; uma componente devida ao fluxo de correntes elétricas dentro da aeronave (Horsfall, 1997; Luyendyk, 1997). Essas correntes flutuam conforme o piloto varia qualquer um dos controles da aeronave, tais como: mudança na velocidade das hélices, ajuste de superfícies de controle (flapes e ailerons nas asas, leme no estabilizador vertical e profundores nos estabilizadores horizontais), etc.

A magnetização permanente da aeronave gera os erros de rumo causados pela soma vetorial do campo magnético da Terra com aquele da aeronave, resultando num deslocamento do nível de base entre linhas que foram voadas em sentidos opostos. Erros de freqüências maiores são introduzidos pelas manobras da aeronave e são chamados de erros de manobra. $O$ procedimento destinado à remoção desses erros chama-se compensação.

Os métodos passivos de compensação não são suficientemente eficientes e os sistemas ativos de compensação, que foram desenvolvidos para fins militares, não podem garantir uma compensação efetiva na freqüência zero (nível DC) ou em freqüências muito baixas (de interesse no estudo das anomalias geofísicas com longo comprimento de onda).

Essas fontes de erro são mais significantes no caso de levantamentos gradiométricos do que na execução de levantamentos que medem a intensidade do campo total. Contudo, mesmo nesse segundo caso, elas não devem ser negligenciadas, pois o produto final obtido para fins de interpretação geológica/geofisica embute, em si, a somatória de todas as fontes de erros que ocorreram ao longo de todo o processo, desde a aquisição dos dados até a sua representação final na forma de uma malha digital.

Para ilustrar os efeitos das diversas componentes que afetam a aquisição de dados aeromagnéticos, Hardwick (1984) elaborou um diagrama ilustrando as principais fontes de 
interferência nos dados aeromagnéticos e a sua relação com o espectro originado a partir de fontes de origem geológica.

Na Figura 3.1 estão representados de forma esquemática os espectros de fontes geológicas, os erros induzidos por movimentos da aeronave, os erros externos e o limite da razão sinal/ruído de um magnetômetro. O eixo inferior da figura corresponde ao eixo das frequiências, indo de 0 (nível DC) até pouco acima dos $1000 \mathrm{~Hz}$. No eixo superior, a escala de frequêencias foi convertida em comprimento de onda para uma aeronave hipotética voando a uma velocidade relativa ao solo de 160 nós (aproximadamente $280 \mathrm{~km} / \mathrm{h}$ ).

Os comprimentos de onda de maior interesse em geologia situam-se entre $200 \mathrm{~m}$ e $30 \mathrm{~km}$. As densidades espectrais de potência geológicas apresentadas são hipotéticas: as porções mais inclinadas estão associadas à distância e à magnetização das rochas do embasamento, ao passo que as porções com menor inclinação representam fontes geológicas superficiais.

\subsubsection{Interferências magnéticas causadas pela operação da aeronave}

Os vários tipos de movimentos que uma aeronave pode sofrer durante o transcurso normal de um vôo, e que interferem nas medidas aeromagnéticas, são discutidos a seguir. $\mathrm{Na}$ Figura 3.1 estão representadas as diversas faixas do espectro afetadas por esses movimentos.

Período Curto - Quando uma aeronave, voando em velocidades típicas de aquisição de dados, é perturbada, quer por comandos do piloto ou por turbulência atmosférica, a primeira resposta da plataforma sobre os eixos de arfagem (pitch), rolamento (roll) e guinada (yaw) ocorre no modo de curto período. As frequêencias envolvidas, que de certo modo dependem da velocidade relativa do ar, podem ser consideradas como aquelas nas quais a aeronave pode ser manobrada com um mínimo de força de controle.

Phugoid - Este é um modo amortecido no qual a velocidade do ar e a altitude da aeronave são intercambiadas de tal modo a gerar uma oscilação suave na arfagem. A amplitude deste movimento depende, principalmente, do mecanismo de piloto automático responsável pela manutenção da constância da velocidade e da altitude da aeronave. Hardwick (1984), ao efetuar a correlação cruzada entre o espectro aeromagnético de uma linha de aquisição, obtida a partir de uma aeronave sendo pilotada sem o auxílio de piloto automático, e a aceleração vertical da aeronave obteve uma correlação significativa com período de 40 segundos para o phugoid.

Curvas - Quando o piloto ou piloto automático efetua uma correção de rumo ou de altitude, a aeronave se move suavemente até atingir a atitude desejada. A curva no "modo 1", esquematizada na Figura 3.1, representa uma mudança de rumo de 180 graus por minuto.

Massas de ar - Corresponde a um movimento de freqüencias muito baixas. Ele está associado com mudanças de comprimento de onda muito longas na pressão barométrica que causam um movimento vertical de baixa freqüência em aeronaves cujo piloto automático segue uma altitude barométrica constante. Para levantamentos que são executados a uma altura constante com relação ao terreno, com o emprego de radioaltímetros, o movimento das massas de ar pode não ser relevante, contudo, para aqueles levantamentos conduzidos a uma altitude barométrica constante elas podem se tornar uma fonte indesejada de interferência. 


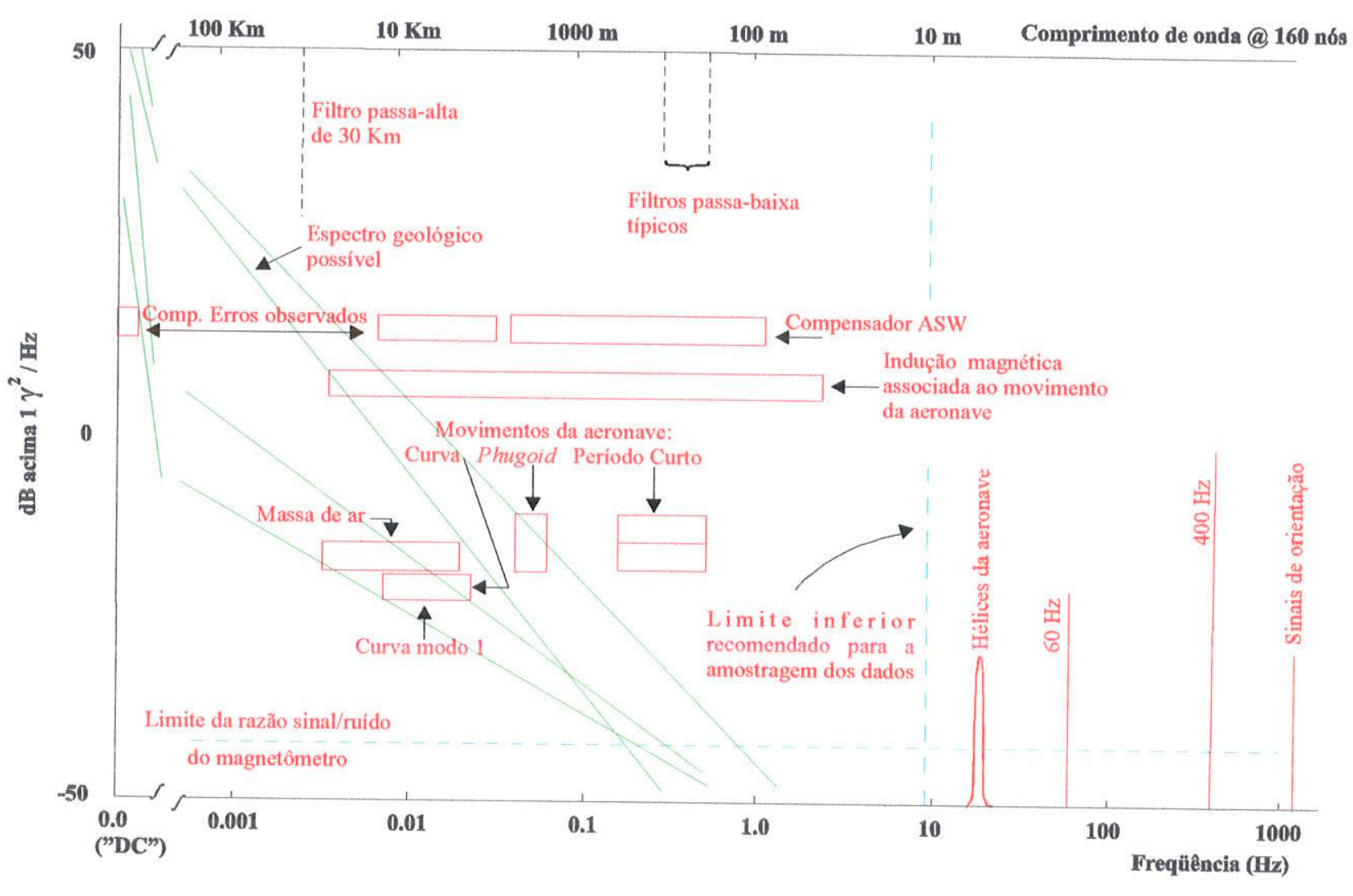

Figura 3.1 - Espectro aeromagnético segundo Hardwick (1984) 


\subsubsection{Indução magnética causada pelo movimento da aeronave}

Os movimentos descritos no item anterior produzem interferência magnética num magnetômetro de campo total mesmo que ele esteja instalado numa aeronave magneticamente limpa. O processo de se limpar magneticamente uma aeronave não é cem por cento eficiente, pois nem todas as fontes de interferência magnética podem ser removidas. Campos magnéticos permanentes estão associados inevitavelmente com os metais ferrosos presentes na estrutura e nos motores da aeronave, e com os magnetos dos motores DC. Campos magnéticos induzidos estão associados com metais não ferrosos e com componentes paramagnéticos ${ }^{2}$ de aço. Esses campos induzidos variam de acordo com o rumo da aeronave. Finalmente, grandes superfícies condutoras, como aquelas que compõem a fuselagem da aeronave, são uma fonte inevitável de interferência causada por correntes parasitas que são geradas conforme a aeronave manobra dentro do campo da Terra. A banda de freqüência na qual essa interferência ocorre está representada na Figura 3.1. Deve-se notar que ela se estende muito além da mais elevada freqüência induzida pelos movimentos da aeronave.

As interferências magnéticas originadas pelo movimento podem ser compensadas utilizando-se de métodos ativos e de métodos passivos.

Alguns magnetômetros aerotransportados de baixa sensibilidade podem ser compensados devido à presença de fontes grosseiras de interferência utilizando-se de métodos passivos: ímãs permanentes podem cancelar campos permanentes, pedaços de permalloy ${ }^{3}$ podem se opor a campos induzidos, e as fontes de correntes parasitas podem ser minimizadas através de bobinas localizadas próximo ao magnetômetro. Um inconveniente deste tipo de correção diz respeito ao fato de que a determinação da orientação e da amplitude corretas da correção passiva só pode ser obtida através de um processo demorado de tentativa e erro.

Os chamados métodos ativos de compensação produzem efeitos elétricos equivalentes às interferências magnéticas. Esses métodos foram desenvolvidos originalmente para serem utilizados com sistemas militares de deteç̧ão magnética de submarino (Compensadores ASW), e possuem uma resposta adequada para os fins para os quais foram criados. Contudo, as características dos sistemas de deteç̧ão militar são diferentes daquelas dos sistemas de aquisição geofísicos e, conseqüentemente, os compensadores ativos de origem militar podem não ser adequados à condução de levantamentos geofísicos.

Nas aplicações militares, somente as anomalias magnéticas de um submarino, cujos comprimentos de onda são menores ou iguais a cerca de $1.000 \mathrm{~m}$, são de interesse. Uma sensibilidade elevada e um intervalo dinâmico amplo são obtidos dentro de uma banda de passagem relativamente pequena ao se filtrar as baixas freqüencias associadas ao sinal de origem geológica.

\footnotetext{
${ }^{2}$ Paramagnetismo é propriedade que determinados materiais apresentam, ao serem expostos à ação de um campo magnético externo, que consiste em adquirir uma magnetização paralela ao campo e magnitude proporcional à intensidade deste.

${ }^{3}$ Permalloy são ligas compostas de níquel e ferro que apresentam elevada permeabilidade magnética.
} 


\subsubsection{Interferências de alta freqüûncia}

Além de sofrer a interferência na porção de baixas freqüências do espectro, um levantamento aeromagnético está sujeito à ocorrência de interferência causada por componentes harmônicas de alta frequiência (acima de $10 \mathrm{~Hz}$ ).

Na Figura 3.1 estão representados alguns pulsos de alta freqüência associados a fontes de energia elétrica de $60 \mathrm{~Hz}$ e $400 \mathrm{~Hz}$. As aeronaves possuem um gerador de energia elétrica próprio que geralmente trabalha na freqüência de $400 \mathrm{~Hz}$. Além disso, alguns componentes internos da aeronave trabalham com correntes $\mathrm{AC}$ de $60 \mathrm{~Hz}$. Somando-se às contribuições dos pulsos $\mathrm{AC}$ oriundos dos sistemas elétricos da aeronave, o espectro também pode ser contaminado por efeitos causados pelas hélices que podem não ser completamente nãomagnéticas. Os efeitos das hélices ocorrem entre 16 e $33 \mathrm{~Hz}$ e também dependem do número de pás. Além disso, no caso de aeronaves multimotor cujos propulsores não se encontram sincronizados em fase, podem ocorrer pulsos de baixa freqüência cujas freqüências variam muito suavemente ao longo do espectro.

O problema decorrente da presença de todas essas componentes harmônicas de alta freqüência acima da freqüência de amostragem (no máximo ela é igual a $10 \mathrm{~Hz}$ ) e com amplitude acima do limite da razão sinal/ruído do magnetômetro é que, de acordo com o Teorema da Amostragem, elas vão falsear o espectro na porção de baixas freqüências. Para contornar este problema, bastaria que a taxa de amostragem passasse a ser pelo menos duas vezes maior do que a freqüencia da maior componente considerada como ruído indesejável. Contudo, como esta se encontra na faixa de $400 \mathrm{~Hz}$, seria impraticável adotar uma freqüência de amostragem superior a $800 \mathrm{~Hz}$.

\subsection{CORREÇ̃̃o das VARIAÇÕES TEMPORAIS}

Dentre as variações temporais a que um levantamento aeromagnético está sujeito, a de maior amplitude é aquela devida à variação diurna do campo geomagnético. Elas são causadas principalmente por perturbações no campo magnético externo da Terra; essas perturbações são síncronas e de aproximadamente mesma amplitude dentro de uma área com raio entre $50 \mathrm{e}$ $80 \mathrm{~km}$ na superfície da Terra (Paterson \& Reeves, 1985; Hinze, 1990). Essas variações podem ser monitoradas através do uso de um magnetômetro fixo, numa estação base, e posteriormente descontadas dos valores observados durante o vôo. Contudo, se a condutividade elétrica da Terra não for constante dentro da área do levantamento (incluindo a região sobre a qual se localiza o magnetômetro base), este método pode não ser eficiente para efetuar a correção da variação diurna (Nelson, 1994). Contrastando com afirmações de outros autores, Milligan (1995), citado por (Horsfall, 1997), demonstra que a amplitude da variação diurna não é a mesma quando ela é registrada simultaneamente em estações base com uma separação de $100 \mathrm{~km}$ entre si. Nesses casos, sugere-se que sejam empregados vários magnetômetros base operando simultaneamente e dispostos por toda a área do levantamento. A correção da variação diurna também pode ser feita durante a etapa do nivelamento magnético do projeto, ao se adotar um modelo de variação suave dos erros no cruzamento entre os perfis de produção e os de controle (Foster et al., 1970; Ray, 1985).

As variações temporais do campo magnético da Terra podem ser aleatórias ou cíclicas. De acordo com Luyendyk (1997), elas podem ser classificadas de acordo com a seguinte Tabela: 
Tabela 3 - Variações temporais no campo magnético da Terra

\begin{tabular}{|c|c|}
\hline Classe & Características \\
\hline Pulsações & $\begin{array}{l}\text { Apresentam um período entre } 1 \text { e } 300 \text { segundos; possuem magnitude } \\
\text { geralmente abaixo de } 10 \mathrm{nT} \text { e a amplitude das pulsações diminui com a } \\
\text { frequência. Elas ocorrem aleatoriamente. }\end{array}$ \\
\hline Tempestades Magnéticas & $\begin{array}{l}\text { Possuem um início rápido e um decaimento de longa duração (de horas a } \\
\text { semanas) sendo que a sua magnitude pode chegar a dezenas de nanoteslas. } \\
\text { Elas são causadas por explosões solares que produzem uma rápida mudança } \\
\text { no fluxo de partículas cósmicas que interagem com a atmosfera terrestre. }\end{array}$ \\
\hline Variações Diurnas & $\begin{array}{l}\text { Apresentam um período de } 24 \text { horas e a sua magnitude pode chegar a } 50 \mathrm{nT} \text {. } \\
\text { São causadas pela rotação da Terra relativa ao sol. }\end{array}$ \\
\hline Variações Lunares & $\begin{array}{l}\text { Possuem um período de } 27 \text { dias. São causadas pela órbita da lua em torno da } \\
\text { Terra com relação ao sol. }\end{array}$ \\
\hline Variações Solares & Com período de 1 ano, são devidas à órbita da Terra com relação ao sol. \\
\hline Variaçóes Seculares & $\begin{array}{l}\text { Correspondem a mudanças graduais com um intervalo entre }-20 \text { e } 30 \mathrm{nT} / \mathrm{ano} \\
\text { para latitudes médias. }\end{array}$ \\
\hline
\end{tabular}

\subsection{CORREÇÃO DO IGRF/DGRF}

As variações espaciais no campo magnético são causadas não apenas por corpos fontes localizados na crosta terrestre, mas também pela componente do campo geomagnético que se origina no núcleo externo da Terra. Este campo, o IGRF, é calculado a partir de observações globais do campo magnético, e é atualizado a cada período de 5 anos. Ele inclui termos de variação temporal que tentam prever as mudanças seculares (longo período) do campo principal da Terra a partir de flutuações prévias e também corrige as variações devido à latitude, longitude e altitude do ponto de observação (Hinze, 1990). Durante a segunda revisão do IGRF, feita em 1981, estabeleceu-se o DGRF como sendo o campo de referência definitivo, e que seria obtido a partir de dados tão completos e refinados quanto possível (Peddie, 1983). Embora o IGRF e o DGRF apresentem uma variação temporal ao longo dos anos, pode-se considerar que os mesmos são estacionários dentro do intervalo de tempo em que os levantamentos aeromagnéticos são conduzidos.

Na Figura 3.2 está representada a diferença entre os modelos DGRF e IGRF, ambos calculados para uma altitude constante, para o ano de 1975. Como pode ser observado, a diferença entre os dois modelos não pode ser expressa através de uma simples mudança do nível de base, pois ela se apresenta de uma forma um pouco mais complexa. Via de regra, a diferença entre ambos os modelos pode ser expressa através de uma função polinomial de baixo grau (2 ou 3) dentro da área de cada um dos três projetos. Além de uma variação no nível de base, observa-se uma variação espacial não linear de menor amplitude entre os pontos extremos de cada levantamento. No caso do PASPRJ essa variação é da ordem de 20 nT, no PASMS é de 25 nT e no PAESB é de 30 nT.

Valores de referência típicos do IGRF dados pelo modelo de 1975 para uma altitude de $300 \mathrm{~m}$ são de 0,015 a $0,030 \mathrm{nT} / \mathrm{m}$ para o gradiente vertical enquanto o gradiente horizontal varia entre 0,002 e $0,005 \mathrm{nT} / \mathrm{m}$ (Hardwick, 1984). Assim, para uma variação da altitude da superfície de vôo da ordem de $1.000 \mathrm{~m}$, pode-se esperar variações de até $30 \mathrm{nT}$ nos valores das correções do IGRF. 


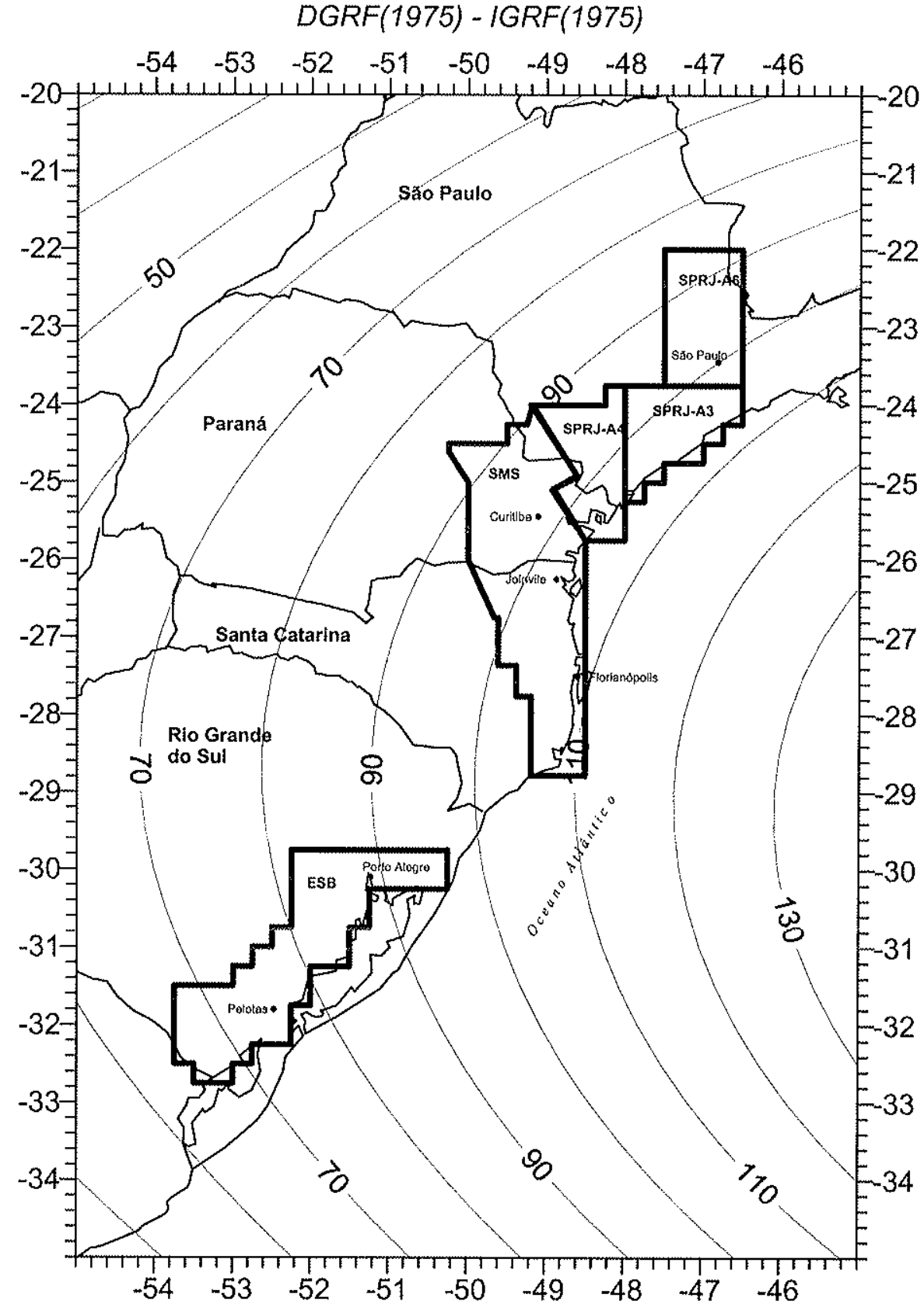

Figura 3.2 - Diferença entre o DGRF e o IGRF calculada para o ano de 1975 na região dos levantamentos aerogeofísicos Extremo Sudeste do Brasil, Serra do Mar Sul e São Paulo/Rio de Janeiro. Intervalo de contorno $10 \mathrm{nT}$. 
Quando do primeiro processamento dos dados dos projetos PASPRJ (Anjos \& Mourão, 1988), PASMS (Geofoto, 1978b) e PAESB (Anjos \& Mourão, 1987), foi empregando o IGRF como modelo de fontes de origem não crustal, desprezando-se os termos devidos às variações temporal e de altitude do ponto de observação. Como esses projetos apresentam grandes desníveis topográficos (Figura 2.1) e foram executados dentro de um longo intervalo de tempo, antecipa-se que a não remoção dessas componentes deve ter acarretado imprecisões nos produtos finais do processamento desses dados.

Nesta tese foi empregado o DGRF, atualmente disponível, em substituição ao IGRF, disponível à época do primeiro processamento dos projetos PAESB, PASMS e PASPRJ. Na sua implementação, pretendia-se incluir os termos referentes às variações temporal e de altitude, desprezadas anteriormente. Além de garantir que fossem removidas as componentes de origem não crustal melhor modeladas até o momento, com a remoção do DGRF foi possível se atenuar alguns efeitos de longo comprimento de onda que afetam principalmente as imagens digitais do PAESB.

Braggion Jr (1995) observou a presença de uma outra componente, de origem não geológica, que afeta principalmente os dados do PASMS. Naquele trabalho, pôde ser observada a existência de uma componente de longo comprimento de onda fortemente correlacionada com as variações na superfície de vôo do projeto. Naquela ocasião, constatou-se que tal superficie possui uma variação de até $2.000 \mathrm{~m}$, o que implica em correções, devidas à variação na altitude, com amplitudes que podem atingir até $60 \mathrm{nT}$ de intensidade. As correlações entre as anomalias magnéticas e as variações na superfície de vôo foram observadas em três regiões distintas: a primeira sobre a região correspondente ao Vale do Ribeira; a segunda ao longo da planície litorânea e da escarpa da Serra do Mar; a terceira no extremo sul da área coberta pelo PASMS. Como os modelos topográficos de domínio público atualmente existentes não possuem resolução espacial compatível com os projetos utilizados nesta tese, não foi possível realizar a remoção da componente do DGRF referente à variação da altitude da superfície de vôo.

\subsection{Nivelamento MAGNÉTiCo}

Os levantamentos aeromagnéticos são executados seguindo um padrão característico de amostragem em linhas de vôo (LV) que formam uma malha, de tal modo que se tenham medidas duplicadas do campo magnético em pontos de cruzamento de algumas linhas de vôo. Um levantamento característico consiste de: linhas de aquisição ou de produção (LP) voadas perpendicularmente às estruturas geológicas e que consistem na principal forma de amostragem do campo magnético na área do levantamento; linhas de controle (LC) que são voadas perpendicularmente às linhas de aquisição e que fornecem informação de controle sobre o levantamento. As interseções entre as linhas de produção e as linhas de controle recebem o nome de pontos de cruzamento. Quando da execução de um aerolevantamento com fins de reconhecimento geológico, as linhas de produção costumam apresentar uma separação entre $1.000 \mathrm{~m}$ e $2.000 \mathrm{~m}$ umas das outras (para o caso de levantamentos conduzidos sobre o embasamento exposto), contudo, em casos excepcionais, essa separação pode ser de até $4.000 \mathrm{~m}$ (quando o levantamento é executado sobre grandes bacias sedimentares). $O$ espaçamento entre as linhas de controle é bem maior; geralmente varia entre 10 e 20 vezes o espaçamento entre as linhas de aquisição. Ao longo das linhas de vôo, sejam elas de aquisição ou de controle, o espaçamento entre medidas situa-se, geralmente, entre 50 e $100 \mathrm{~m}$. A Figura 3.3 representa 


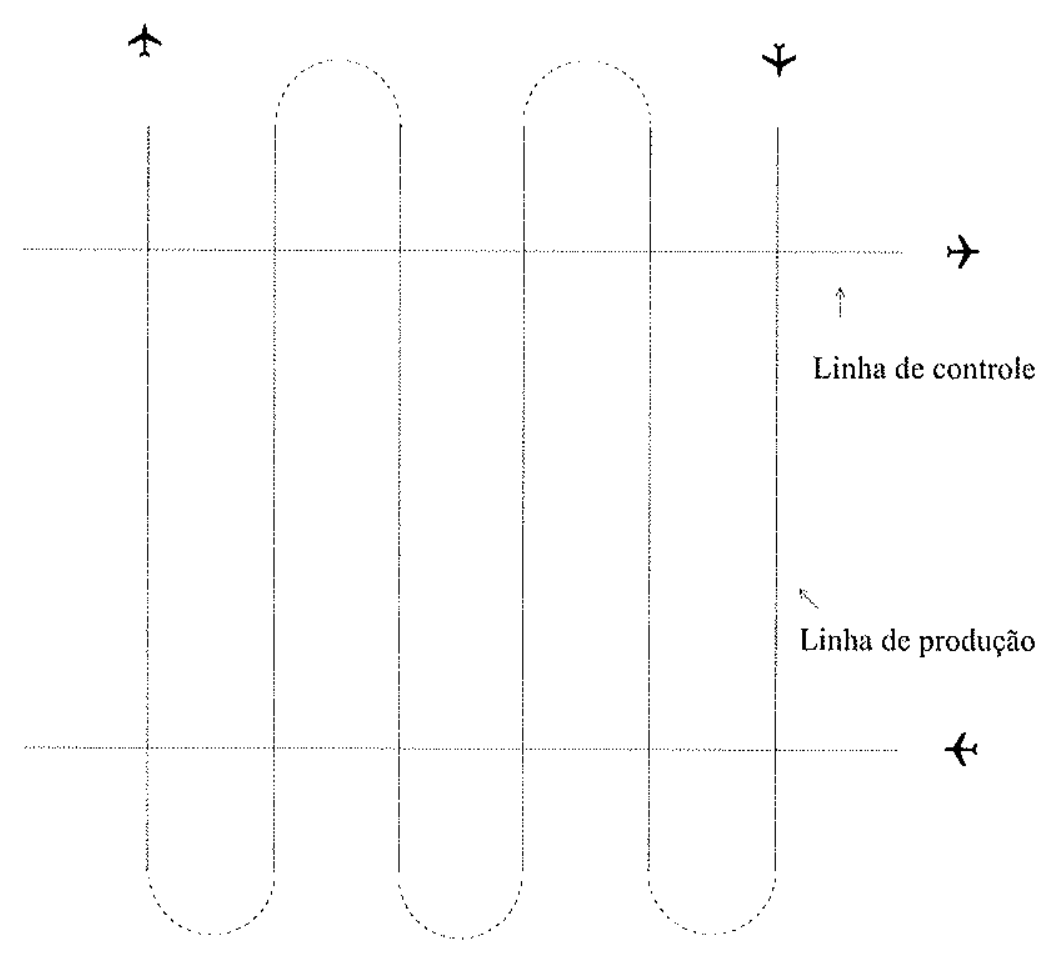

Figura 3.3 - Representação esquemática do padrão de aquisição de dados aeromagnéticos ( linhas de produção e linhas de controle).

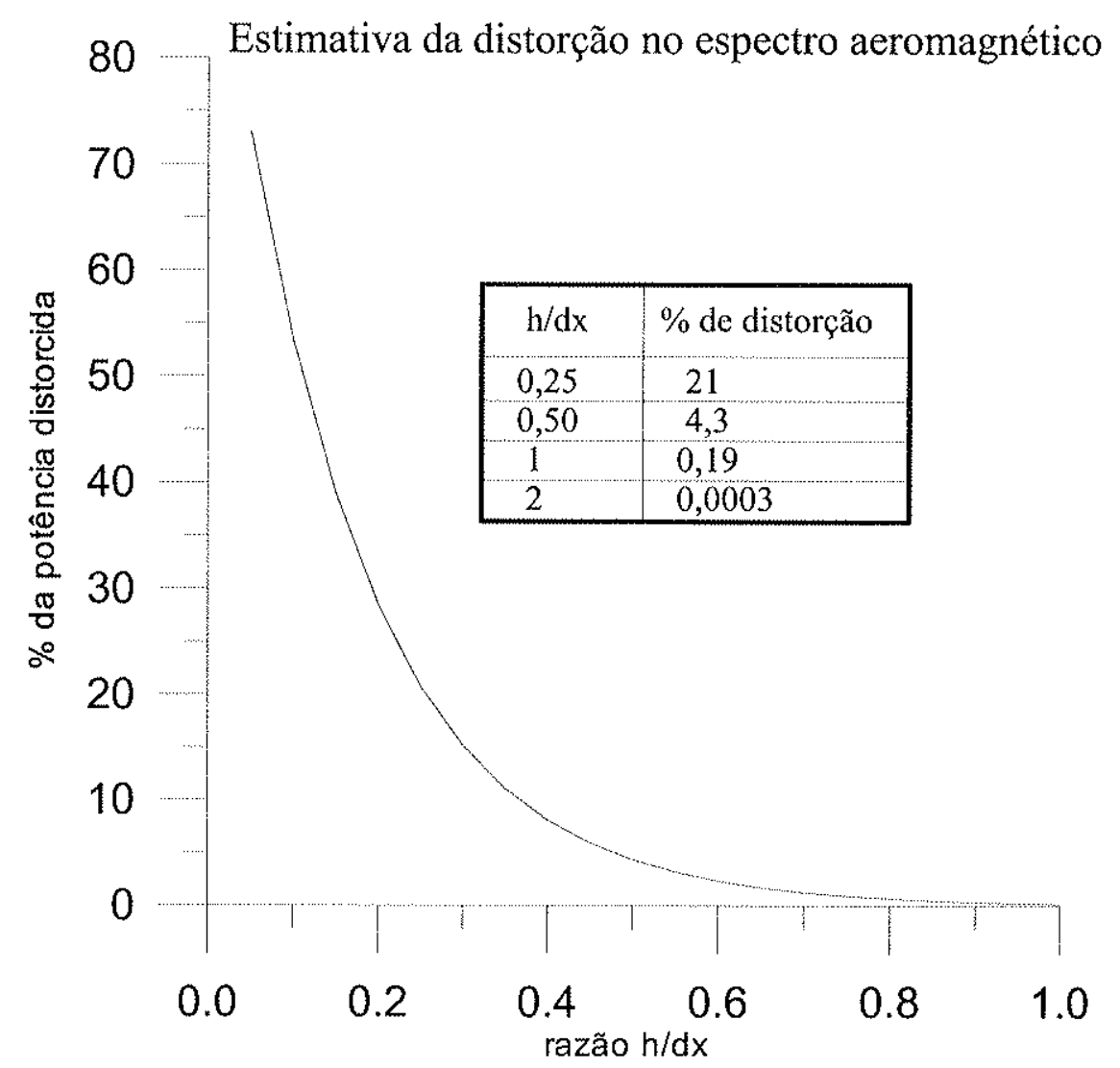

Figura 3.4 - Estimativa da distorção no espectro de potência de dados aeromagnéticos, segundo Reid (1980), onde h é a distância entre o sensor e o topo dos corpos fontes de magnetização e $\mathrm{dx}$ corresponde ao maior intervalo de amostragem $(\Delta x$ ao longo das LV e $\Delta l$ entre as LP). 
esquematicamente o padrão de aquisição de dados aeromagnéticos, com linhas de aquisição e linhas de controle.

O nivelamento magnético corresponde ao procedimento através do qual as discrepâncias entre as medidas do campo magnético em cada ponto de cruzamento são distribuídas sistematicamente entre as linhas de aquisição e as linhas de controle. Essas discrepâncias também podem receber outros nomes, tais como: diferenças de cruzamento, diferenças de fechamento, erro de nivelamento ou erro de cruzamento. Existe uma ampla variedade de métodos para se tratar as diferenças de fechamento (Foster et al., 1970; Green, 1983; Fitzgerald, 1996; Luyendyk, 1997). Esses métodos podem ser classificados em três categorias: nivelamento polinomial; fechamento de laço ou fechamento de loop; métodos que minimizam as diferenças de interseção através do ajuste dos dados de navegação ou reposicionamento das coordenadas dos pontos de cruzamento.

Pode-se constatar a presença e a intensidade da ocorrência de erros de nivelamento ao se inspecionar visualmente os mapas de contorno ou as imagens obtidas a partir da malha digital interpolada a partir dos dados aeromagnéticos. Os erros de nivelamento afetam as isolinhas e as imagens de tal forma que estas apresentam-se distorcidas na direção paralela à direção das linhas de aquisição. Essas distorções são caracterizadas por anomalias alongadas que se situam exatamente sobre as linhas de vôo. Quanto mais intensos forem os erros de nivelamento, maior será a amplitude dessas anomalias alongadas. A remoção por completo ou a atenuação dos erros de nivelamento é necessária, pois eles alteram a geometria das anomalias magnéticas prejudicando, por conseguinte, a interpretação dos dados. Além disso, o efeito danoso dos erros de nivelamento é amplificado quando se empregam determinadas técnicas de interpretação que realçam as feições de curto comprimento de onda do campo magnético anômalo, tais como: cálculo de derivadas verticais e horizontais, continuação para baixo, geração de imagens iluminadas artificialmente, etc.

Uma técnica bastante adequada para se nivelar um levantamento magnético consiste no uso de camadas ou fontes equivalentes para se continuar as observações de linhas de vôo adjacentes até um datum comum. Entretanto, esta técnica só pode ser aplicada quando são feitas medidas da altitude barométrica durante o vôo ou quando se tem um modelo topográfico digital que possa ser empregado conjuntamente com as medidas da altura radioaltimétrica.

Em capítulos futuros serão apresentadas algumas técnicas para se efetuar o nivelamento de dados aeromagnéticos bem como serão apresentadas outras técnicas destinadas à atenuação dos erros de nivelamento que, por ventura, persistam nos dados.

\subsection{HomogeneIZAÇÃo ESPECTRAL}

O campo magnético é um campo potencial contínuo, cujo conteúdo espectral estende-se de zero até infinito (Bhattacharyya, 1966). Durante a execução de um levantamento aeromagnético, o campo magnético é amostrado com um determinado espaçamento $\Delta x$ ao longo das linhas de vôo. Este espaçamento geralmente é muito menor do que o espaçamento $\Delta l$ entre linhas de vôo. Esses intervalos de amostragem definem os menores comprimentos de onda que podem ser detectados. Ao longo das linhas de vôo, o menor comprimento de onda identificável é $\lambda_{N x}=2 \Delta x$, ao passo que entre as linhas de vôo o menor comprimento de onda 
observável é igual a $\lambda_{N l}=2 \Delta l$. Tem-se, assim, uma capacidade potencialmente maior de se amostrar mais detalhes do campo magnético ao longo das linhas de vôo do que entre elas. A cada um desses comprimentos de onda está associada uma freqüência de Nyquist $f_{N}$, que corresponde à maior componente em freqüência que pode ser identificada a partir do sinal amostrado. As frequiências de Nyquist ao longo e entre as linhas de vôo são dadas, respectivamente, por $f_{N x}=(1 / 2 \Delta x)$ e $f_{N l}=(1 / 2 \Delta l)$. O procedimento de amostragem, adotado durante a execução de um levantamento aeromagnético, reproduz corretamente as componentes do sinal cujas freqüências se encontram dentro do intervalo $\left[0, f_{N x}\right]$ ao longo das linhas de vôo, e dentro do intervalo $\left[0, f_{N l}\right]$ entre linhas de vôo. De acordo com o teorema da amostragem (Press et al., 1990, Bath, 1974), as componentes espectrais presentes no campo magnético cujas freqüências forem maiores do que as freqüências de Nyquist dos intervalos dados acima serão mapeadas para dentro destes, ocasionando uma distorção do espectro, fenômeno chamado de contaminação espectral ou aliasamento. Esta distorção no espectro afeta as componentes simétricas com relação à freqüência de Nyquist. Assim, a contribuição espectral devida a uma componente igual a $f_{N}+\Delta f$, onde $\Delta f$ corresponde a um incremento positivo em freqüência, vai se somar àquela da componente $f_{N}-\Delta f$. Como o espectro magnético não é limitado em freqüência, sempre vai ocorrer a distorção espectral, independentemente dos valores adotados para $\Delta x$ e $\Delta l$. Entretanto, como o espectro de potência das anomalias magnéticas sofre um decréscimo exponencial conforme a freqüência aumenta (Spector \& Grant, 1970), a contaminação espectral vai afetar mais seriamente a porção do espectro onde estão os números de onda mais elevados. Ao se construir o gráfico do espectro de potência dos dados aeromagnéticos pode-se ter uma idéia se os dados foram contaminados de modo significativo por componentes espectrais com freqüências acima da freqüência de Nyquist. Teoricamente, o espectro de potência deve tender a zero conforme a freqüência aumenta; contudo, se o espectro de potência tender a partir de uma dada freqüência $f_{c}$ a um valor constante, então, as chances de que haja contaminação espectral acima de $f_{c}$ são grandes. Uma vez constatada a contaminação espectral, deve-se proceder à filtragem passa-baixa do sinal amostrado. A filtragem dessas componentes torna-se indispensável, principalmente quando os dados forem submetidos a determinadas técnicas de processamento, tais como a continuação para baixo, o cálculo de gradientes, etc., cuja qualidade dos resultados depende enormemente da porção do espectro associada às freqüências mais elevadas.

Reid (1980) mostra que os parâmetros $\Delta x$ e $\Delta l$ podem ser determinados criteriosamente, como função da altura de vôo sobre as fontes de magnetização, antes da execução do levantamento, de tal modo que a distorção presente no espectro seja compatível com a destinação que se pretende dar aos dados. A Figura 3.4 apresenta uma estimativa da porcentagem do espectro que vai ser distorcida, conforme se varia a razão $h / d x$, onde $h$ é a distância entre o sensor e o topo dos corpos fontes de magnetização, e $d x$ é o espaçamento entre medidas. No caso de um levantamento efetuado sobre embasamento ígneo exposto, $h$ corresponde simplesmente à altura de vôo sobre o terreno.

Conforme mencionado anteriormente, o procedimento de aquisição de dados aeromagnéticos constitui-se da amostragem do campo segundo duas direções distintas, cada qual com o seu espaçamento e freqüência de Nyquist característicos. Como $f_{N x} \gg f_{N l}$, há uma forte anisotropia na amostragem do campo magnético, ou seja, o campo magnético é amostrado dentro de uma ampla faixa espectral na direção paralela às linhas de vôo, e é amostrado dentro 
de uma faixa mais restrita na direção perpendicular a elas. Portanto, a aplicação de técnicas de geração de malhas digitais aos dados, na forma como estes se encontram, provocaria o aparecimento de inúmeras anomalias de curto comprimento de onda localizadas sobre as linhas de vôo, e que não apresentam continuidade lateral entre linhas de vôo adjacentes. Além disso, as componentes espectrais acima da freqüência $f_{N l}$ são consideradas como ruído quando da aplicação de técnicas de inversão e modelagem, uma vez que elas não apresentam componentes correspondentes que foram medidas ao longo da direção perpendicular às linhas de vôo. Elas são, portanto, feições artificiais criadas pelos algoritmos de interpolação de dados. De modo a se homogeneizar o conteúdo espectral do conjunto de dados aeromagnéticos, de tal modo que ambas as direções de amostragem apresentem os mesmos limites espectrais, deve-se proceder à filtragem dos dados. Esta filtragem é conduzida ao longo das linhas de vôo, eliminando-se destas todas as componentes cujas freqüências são maiores do que $f_{N l}$. 


\section{CAPITULO 4 \\ POSICIONAMENTO DAS FIDUCIAIS DOS PROJETOS AEROGEOFÍSICOS}

\subsection{INTRODUÇÃo}

O posicionamento correto das medidas corresponde a uma das etapas mais importantes das fases de aquisição e processamento de dados aeromagnéticos, tendo em vista que é a partir dele que se obtém as coordenadas dos pontos medidos. Ao contrário dos levantamentos efetuados no solo, nos levantamentos aéreos, a plataforma à qual o sensor está preso se encontra em movimento e em grande velocidade com relação ao solo, geralmente entre 50 e $100 \mathrm{~m} / \mathrm{s}$. Assim, devido à grande velocidade, os ajustes de navegação, que devem ser executados de modo suave, implicam em grandes mudanças no posicionamento das medidas. Hogg (1989) simula erros no posicionamento horizontal de linhas de vôo, e analisa os seus efeitos sobre a confecção de mapas de contorno.

A navegação num levantamento aerogeofísico pode ser realizada tanto de modo automático quanto visual. No modo tradicional, visual, a recuperação da trajetória percorrida pelo avião se dá através do uso de filmes de rastreio (geralmente $35 \mathrm{~mm}$ ) e fotomosaicos semicontrolados. Para posicionar as linhas de vôo nos mapas, procura-se identificar nos filmes de rastreio feições constantes nos fotomosaicos. Os pontos assim identificados são correlacionados aos registros por meio das respectivas fiduciais de controle ${ }^{4}$. Este método, utilizado até o início da década de 1970, é aceitável para levantamentos executados a cerca de $150 \mathrm{~m}$ do solo, ou mais, desde que o relevo topográfico seja moderado. Para alturas mais baixas sobre terrenos mais acidentados a velocidade do avião pode variar significativamente e embora a precisão das fiduciais de controle seja aceitável a interpolação entre elas pode ser inadequada (Hogg, 1989). Isto pode ser um problema, por exemplo, para a região da Serra do Mar ou o Vale do Ribeira.

A Figura 4.1 exemplifica o processo de interpolação de coordenadas entre fiduciais de controle. Nessa Figura, são apresentadas as trajetórias real do vôo, e aquela que é obtida através da interpolação linear de coordenadas entre duas fiduciais de controle consecutivas, simulando uma situação na qual não há fiduciais de controle em número suficiente para se recuperar de modo adequado o percurso real da aeronave quando esta sofre uma mudança de curso ao tentar se desviar de um obstáculo. Nota-se que há uma relação de correspondência de 1:1 entre as fiduciais reais e aquelas interpoladas, ou seja, não são criados nem suprimidos pontos de dados, nem tampouco os valores medidos de anomalia são alterados por qualquer processo, apenas as suas coordenadas são interpoladas linearmente entre dois pontos consecutivos de coordenadas conhecidas (fiduciais de controle). Deve-se notar que, embora na trajetória real do vôo o espaçamento entre fiduciais seja irregular, na trajetória interpolada este passa a ser constante. $\mathrm{O}$

\footnotetext{
4Fiduciais de controle são os pontos de medida identificados claramente tanto no fulme de rastreio quanto no fotomosaico, portanto, as suas coordenadas são conhecidas e comprovadas. As demais fiduciais são pontos de medida que não puderam ser identificados no filme de rastreio e no fotomosaico. As suas coordenadas são aproximadas através da interpolação linear dos pontos medidos entre duas fiduciais de controle sucessivas.
} 

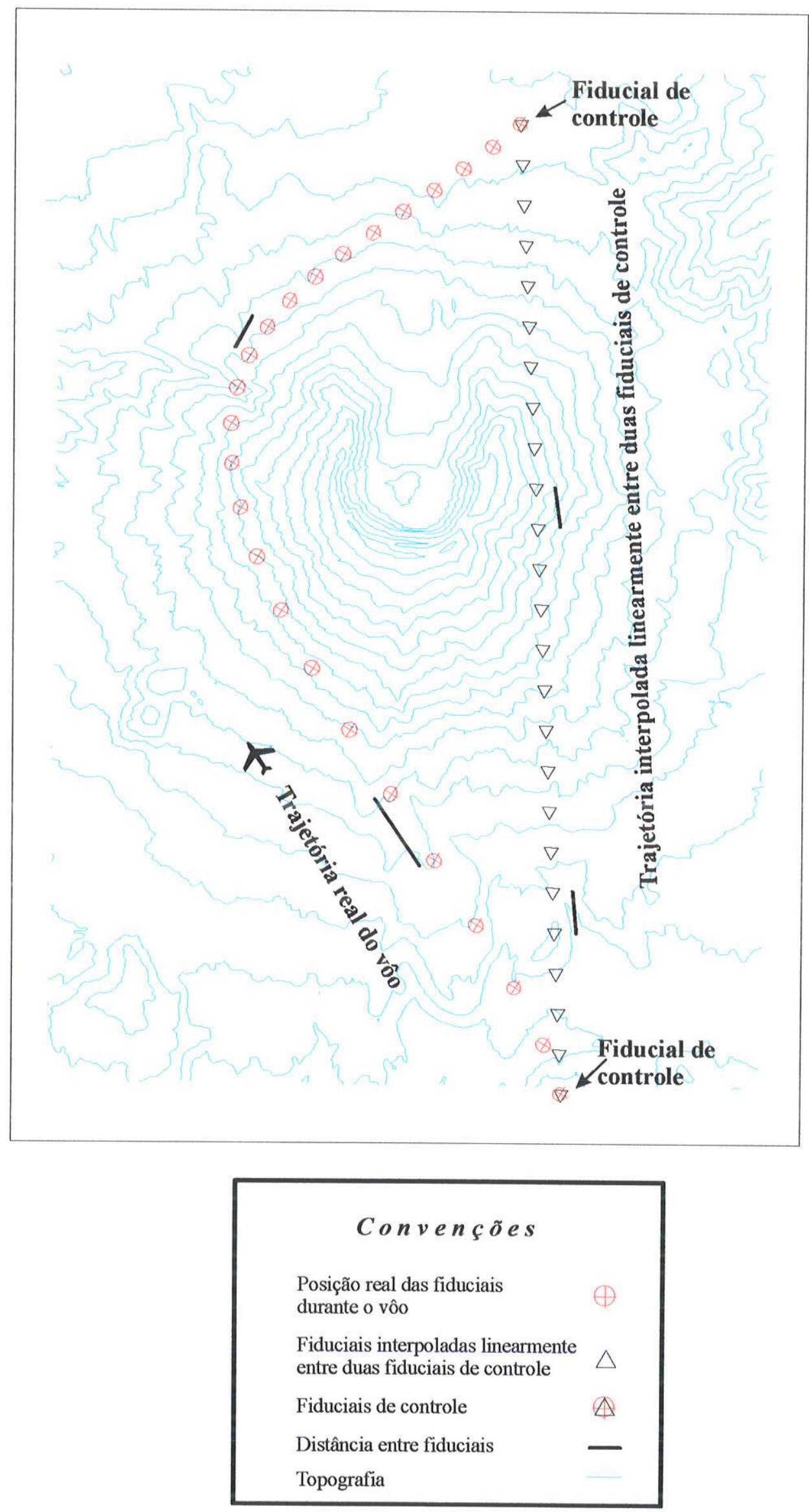

Figura 4.1 - Relação entre a trajetória real do vôo, fiduciais de medida, fiduciais de controle e fiduciais interpoladas entre as fiduciais de controle. 
efeito da má identificação das fiduciais de controle é evidente: as anomalias magnéticas passam a ter os seus valores associados a pontos com coordenadas (latitude e longitude) diferentes daqueles onde elas foram medidas originalmente.

A navegação automática ou digital, empregada rotineiramente desde meados da década de 1970, ainda não havia substituído completamente o método tradicional de se comparar os fotogramas de filmes de rastreio com fotomosaicos semicontrolados ou outras bases planimétricas, até meados da década de 1980 (Paterson \& Reeves, 1985). Através da navegação digital, a aeronave é mantida na rota preestabelecida por meio de sistemas Doppler e GPS, acoplados ao sistema de navegação da aeronave. Deste modo, o vôo segue sempre a rota preestabelecida, e a recuperação da trajetória é feita digitalmente. O radar Doppler é utilizado não só para se planejar a rota a ser seguida durante o vôo, mas também para controlar a aquisição de dados. No sistema de navegação visual as fiduciais, ou pontos de medida, eram tomadas a intervalos regulares de tempo (1 s, por exemplo). Como a velocidade do avião pode variar significativamente em levantamentos sobre terrenos muito acidentados, como é o caso do PASMS, as amostras podem ser tomadas com espaçamento irregular ao longo dos perfis. Com o uso do sistema Doppler, as fiduciais passam a ser incrementadas em função da distância percorrida pelo avião ( $100 \mathrm{~m}$, por exemplo) e não mais em tempo.

\subsection{Posicionamento das Medidas}

Os levantamentos aeromagnéticos podem ser executados variando-se uma série de parâmetros tais como: intervalo de amostragem entre medidas consecutivas, orientação das linhas de vôo, altura com relação ao solo, espaçamento entre as linhas de vôo, etc.

Durante a etapa de planejamento, deve ser dispensada uma atenção especial aos parâmetros que vão nortear a execução do levantamento. Para melhor se amostrar a forma das anomalias magnéticas, as linhas de vôo devem ser voadas perpendicularmente ao alinhamento estrutural dos corpos fontes. O intervalo de amostragem ao longo da linha de vôo deve ser escolhido de tal modo que os menores comprimentos de onda presentes na altura efetiva de vôo sejam amostrados adequadamente, caso contrário haverá uma distorção espectral das altas freqüências em direção às baixas freqüências (Bath, 1974; Reid, 1980; Press et al., 1990). A altura das linhas de vôo com relação aos corpos fontes é um parâmetro crítico que deve ser escolhido criteriosamente durante o planejamento de um levantamento aeromagnético, uma vez que a amplitude das anomalias magnéticas sofre uma atenuação que varia entre $1 / r$ e $(1 / r)^{3}$, dependendo da geometria dos corpos fontes, onde $r$ corresponde à distância fonte-sensor (Telford et al., 1986; Hinze, 1990). Portanto, a execução do levantamento dentro dos parâmetros nominais, estabelecidos previamente na etapa de planejamento, é de fundamental importância para a correta amostragem do campo magnético anômalo, evitando que sejam introduzidas distorções indesejáveis e irreversíveis nas medidas. Cabe ao sistema de posicionamento e de navegação manter o vôo dentro dos parâmetros desejados.

O sistema de posicionamento e navegação adotado tanto no PAESB quanto no PASMS foi o visual. A recuperação da trajetória do vôo e a determinação das coordenadas das fiduciais deram-se através da correlação de filmes de rastreio e mosaicos fotográficos. As medidas do campo magnético durante o vôo foram tomadas a intervalos regulares de tempo, iguais a 1 segundo. O PASPRJ adotou um sistema digital de navegação do tipo Doppler, desse modo, as medidas do campo foram feitas a intervalos regulares de distância efetivamente percorrida pelo 
avião. A Figura 4.2 evidencia a diferença entre os dois tipos de posicionamento e amostragem. Nela estão representados, para cada levantamento, os histogramas das distâncias entre fiduciais consecutivas. O PASPRJ, por ter utilizado um sistema digital de navegação e posicionamento, apresenta uma pequena dispersão com relação à distância nominal entre medidas $(100 \mathrm{~m})$, ou seja, o campo magnético foi amostrado a intervalos bastante regulares ao longo das linhas de vôo. Isso sugere que tenha ocorrido pouca contaminação espectral dos dados, partindo-se do pressuposto que o espaçamento nominal tenha sido escolhido de tal modo a se amostrar os menores comprimentos de onda presentes na altura dos vôos. Por outro lado, o PASMS, por ter utilizado um sistema de navegação visual numa área que apresenta grandes desníveis topográficos (Figura 2.1), apresenta uma grande dispersão de valores em torno do valor nominal para o intervalo de amostragem $(58 \mathrm{~m})$. Como conseqüência, o campo magnético foi amostrado a intervalos bastante variáveis ao longo da área do projeto, pressupondo-se que tenha ocorrido uma contaminação espectral mais intensa do que aquela prevista durante a etapa de planejamento do levantamento. Já o PAESB, muito embora tenha utilizado um sistema de navegação visual, apresenta uma dispersão no espaçamento entre as medidas bem menor do que aquele apresentado pelo PASMS. No caso do PAESB, a dispersão é pequena em torno do valor nominal do intervalo de amostragem $(62 \mathrm{~m})$. Essa pequena dispersão, e conseqüente melhor uniformidade na amostragem das anomalias magnéticas, deve-se ao fato da topografia ser relativamente suave na região do PAESB. Contudo, a amostragem não é tão regular quanto no caso do PASPRJ que utilizou um sistema mais adequado de navegação e posicionamento das medidas.

A combinação entre o sistema de navegação adotado, o tipo de terreno sobrevoado e a altura do vôo sobre o terreno também desempenha um papel importante na amostragem dos dados. Levantamentos conduzidos a baixa altura sobre terreno suave tendem a apresentar um pequeno desvio com relação ao azimute nominal das linhas de vôo. Quando o terreno apresenta variações topográficas abruptas e com grande amplitude, tende-se a obter um padrão de vôo divergente do azimute nominal. Novamente, o emprego de um sistema de navegação digital auxilia a manutenção do vôo no rumo preestabelecido, o que pode não ser possível ao se utilizar um sistema de navegação visual. A manutenção das linhas de vôo ao longo do rumo nominal é de extrema importância para a qualidade dos dados, haja vista que os perfís magnetométricos devem ser voados perpendicularmente às estruturas geológicas. A Figura 4.3 apresenta os histogramas dos azimutes calculados entre fiduciais consecutivas, somente nas linhas de produção, para cada um dos três projetos. O PASMS, por ter sido executado sobre uma região com fortes desníveis topográficos, por ter utilizado um sistema de navegação visual baseado em fotomosaicos cujas fotografias aéreas apresentam grandes distorções de escala, e por ter utilizado fotografias aéreas muito antigas (Geofoto 1978a; Geofoto 1978b), apresenta uma grande dispersão da orientação dos perfis em torno do azimute nominal (N30W). O PAESB, mesmo utilizando um sistema de navegação visual, apresenta uma dispersão em torno da orientação nominal dos perfis (N-S) muito menor do que aquela apresentada pelo PASMS e ligeiramente maior do que aquela do PASPRJ. A melhor qualidade da orientação dos perfis do PAESB com relação ao PASMS, haja vista que ambos utilizaram o mesmo sistema de navegação, deve-se às pequenas variações topográficas existentes na região do PAESB (Figura 2.1), o que favorece a navegação visual. Apesar do PASPRJ ter sido executado sobre uma região que apresenta desníveis topográficos quase tão intensos quanto aqueles que se observa na região do PASMS, os seus perfis apresentam uma dispersão diminuta com relação à orientação nominal dos perfis (N-S). A Melhor qualidade de amostragem do PASPRJ, comparativamente ao PASMS, deve-se ao sistema digital de navegação, que proporcionou com que o campo magnético fosse amostrado dentro dos parâmetros previamente estabelecidos. 
a)

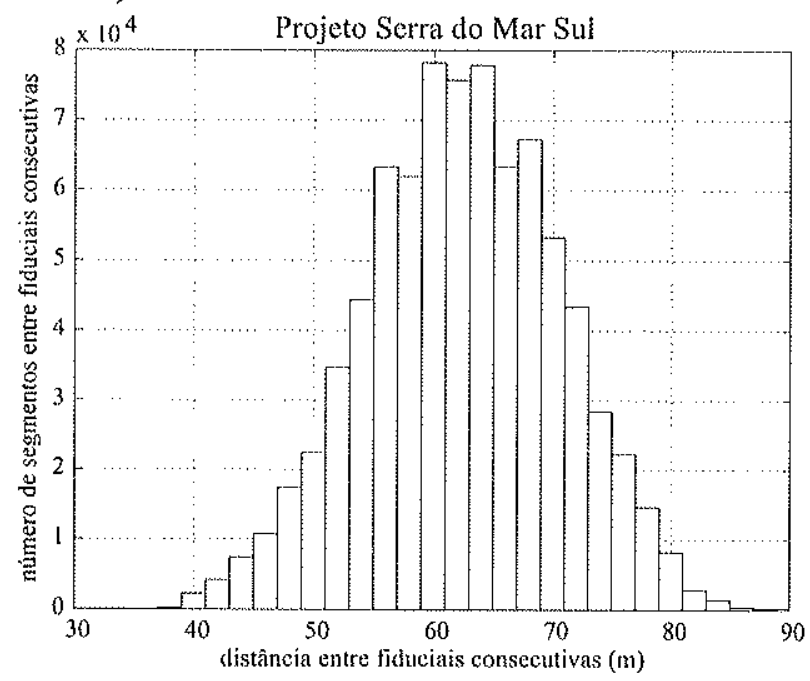

b)

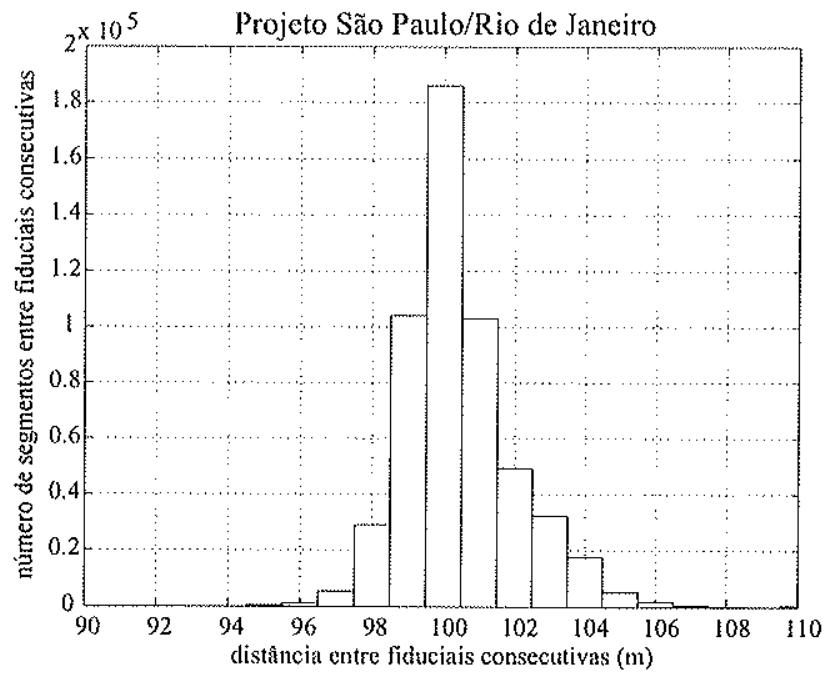

c)

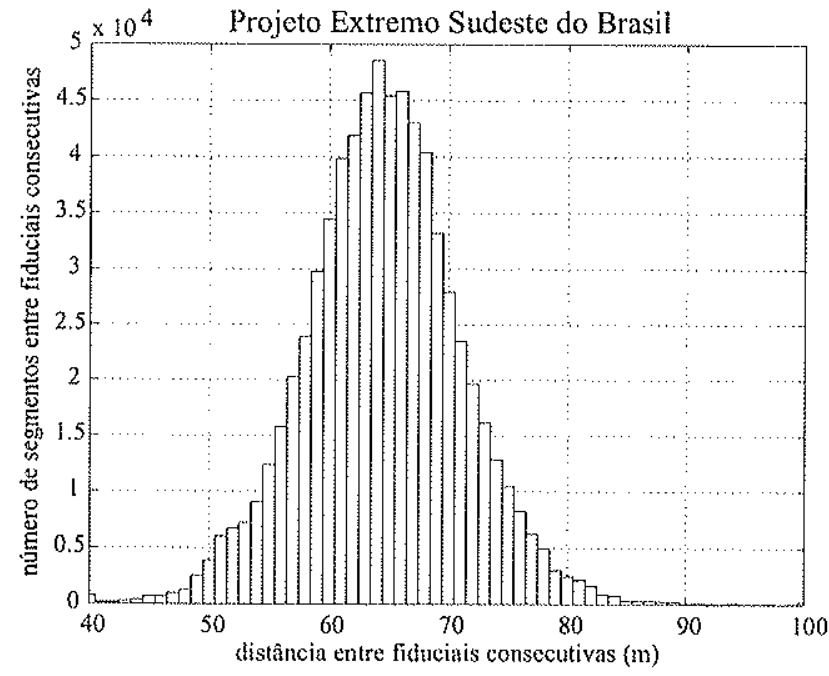

Figura 4.2 - Histogramas das distâncias entre fiduciais consecutivas:

a) Projeto Serra do Mar Sul - distância nominal $58 \mathrm{~m}$;

b) Projeto São Paulo/Rio de Janeiro - distância nominal $100 \mathrm{~m}$;

c) Projeto Extremo Sudeste do Brasil - distância nominal $62 \mathrm{~m}$. 
a)

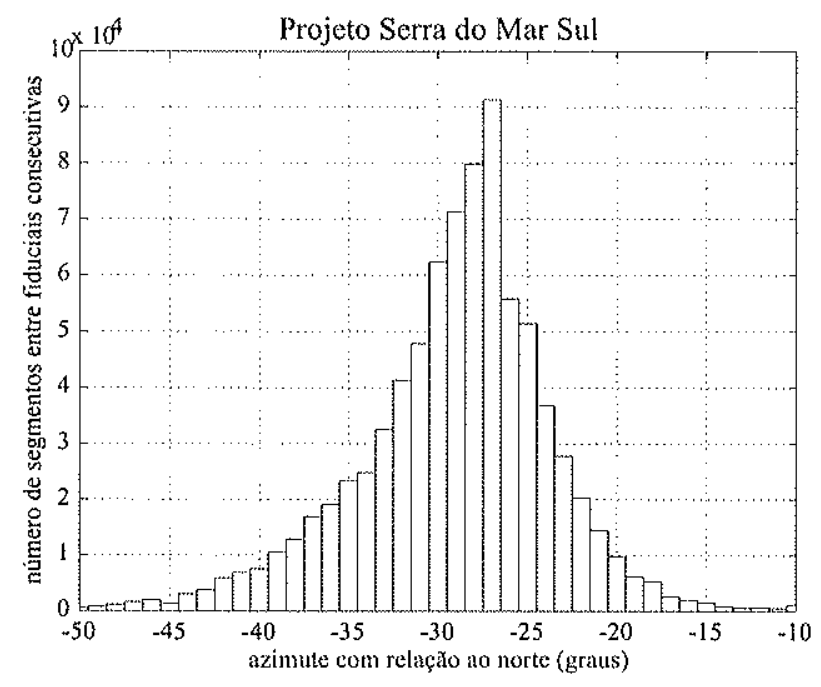

b)

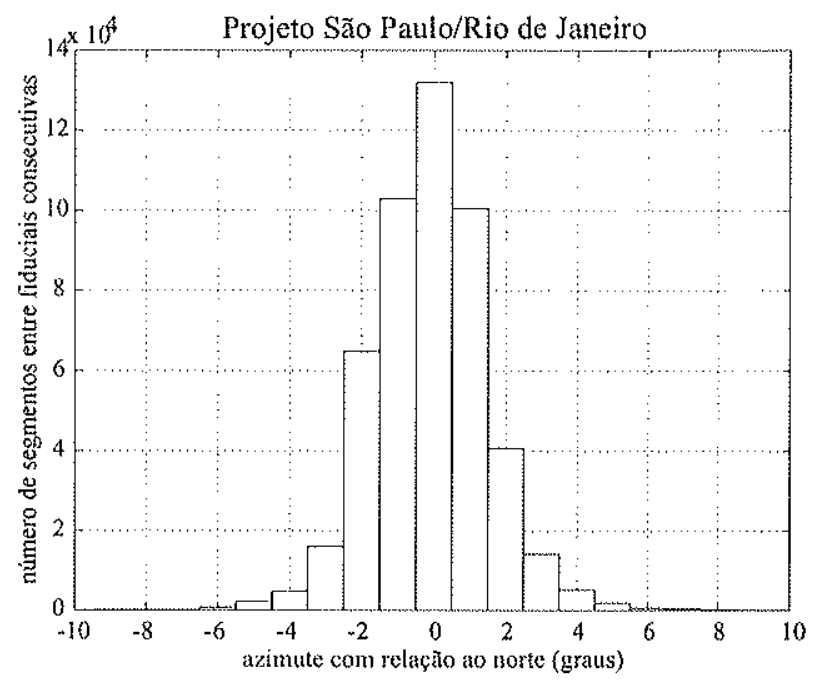

c)

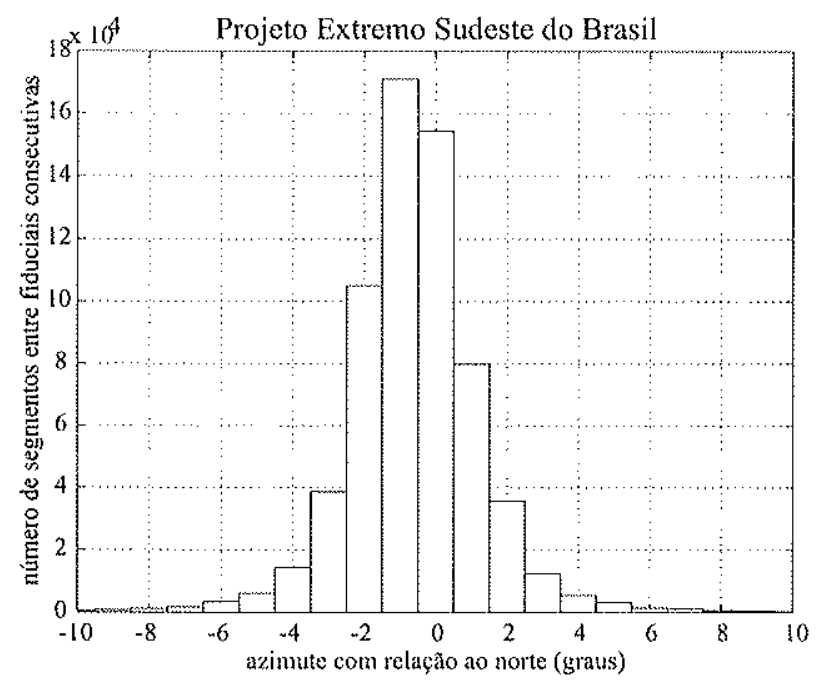

Figura 4.3 - Histogramas do azimute da aquisição de dados calculado entre fiduciais consecutivas das LP:

a) Projeto Serra do Mar Sul - azimute nominal N30W;

b) Projeto São Paulo/Rio de Janeiro - azimute nominal N-S;

c) Projeto Extremo Sudeste do Brasil - azimute nominal N-S. 
A manutenção da altura das medidas dentro dos parâmetros preestabelecidos depende, basicamente, da rugosidade do terreno sobrevoado e da altura nominal exigida. Se o terreno for monótono, a altura nominal pode ser mantida por todo o vôo, mesmo que ela seja próxima ao terreno. Nas situações em que o terreno sofre variações abruptas e intensas, a altura das medidas vai ser muito diferente da altura nominal atribuída para o levantamento. Para se transpor um obstáculo de $50 \mathrm{~m}$ de altura, uma aeronave voando a cerca de $70 \mathrm{~m} / \mathrm{s}$ deve iniciar a subida 20 segundos antes de ultrapassar o alvo (Luyendyk, 1997). Isso significa que pelo menos $1.400 \mathrm{~m}$ de perfis antes e $1.400 \mathrm{~m}$ de perfis após o obstáculo terão sido voados a uma altura superior à altura nominal, atenuando, assim, as medidas do campo magnético. A Figura 4.4 apresenta os histogramas das alturas das medidas com relação ao terreno para os três projetos. Pode-se observar que o PASMS é aquele que apresenta os maiores desvios com relação à altura nominal. Particularmente, é grande a quantidade de medidas que foram tomadas a alturas superiores a $400 \mathrm{~m}$ acima do terreno. O PAESB, mesmo tendo empregado um sistema de navegação visual, apresenta uma dispersão muito pequena da altura de vôo com relação à altura nominal. Isso pode ser explicado pelo fato do levantamento ter sido executado sobre uma região de topograficamente mais suave que o PASMS. O PASPRJ, muito embora tenha se utilizado de um sistema de navegação automática, apresenta uma dispersão das alturas de medida maior do que o PAESB, que utilizou um sistema visual. Essa maior dispersão deve-se à maior variação da topografia na área do PASPRJ, que fez com que as medidas fossem tomadas dentro de um leque maior de altura. Contudo, mesmo ele tendo sido executado sobre uma região quase tão desfavorável quanto o PASMS, a dispersão das suas alturas em torno da altura nominal é bem menor do que aquela observada no PASMS.

O paralelismo, e a manutenção do espaçamento nominal entre as linhas de vôo, são essenciais para que não se obtenham medidas que venham a distorcer a forma das anomalias magnéticas (Hogg, 1989). Tanto no PAESB quanto no PASPRJ, observa-se que as linhas de vôo foram executadas com um espaçamento entre linhas consecutivas muito próximo do espaçamento nominal $(1 \mathrm{~km})$ e que o paralelismo entre elas é excelente. Contudo, o mesmo não ocorre no PASMS. A navegação visual, auxiliada por fotos antigas, sobre uma região com grandes desníveis de relevo fez com que não se conseguisse obter o padrão característico de linhas de vôo paralelas entre si, padrão este que pode ser observado na quase totalidade dos levantamentos aeromagnéticos; ao contrário, é comum encontrar-se situações no PASMS em que ocorre o cruzamento entre duas ou mais linhas de produção, ou há um espaçamento exagerado entre estas (da ordem de 4 a $6 \mathrm{~km}$ ), conforme pode ser visto na Figura 4.5. O primeiro fator, certamente, acarretou complicações durante as etapas de nivelamento magnético e de geração da malha digital, pois os algoritmos tradicionais de nivelamento geralmente consideram que as linhas de produção e de controle formam laços retangulares (loops) entre si. Seria de se esperar que esses problemas no posicionamento ocorressem exclusivamente nas áreas de topografia bastante irregular (ao longo da Serra do Mar e do Vale do Ribeira). Contudo, ao se comparar as cartas topográficas do IBGE (Instituto Brasileiro de Geografia e Estatística), ou da DSG (Diretoria do Serviço Geográfico do Exército), com as cartas de posição de linha de vôo, não se evidencia uma associação direta e sistemática nesse sentido. Sobre algumas regiões topograficamente favoráveis, encontra-se uma má distribuição de linhas de vôo, ao passo que em outras regiões desfavoráveis há um paralelismo muito bom entre as linhas. A única explicação plausível para o mau posicionamento dos perfis reside no fato de terem sido empregadas para a navegação fotografias aéreas relativamente antigas, sobre regiões que sofreram grandes alterações culturais (Geofoto 1978a; Geofoto, 1978b). A região litorânea do 
a)

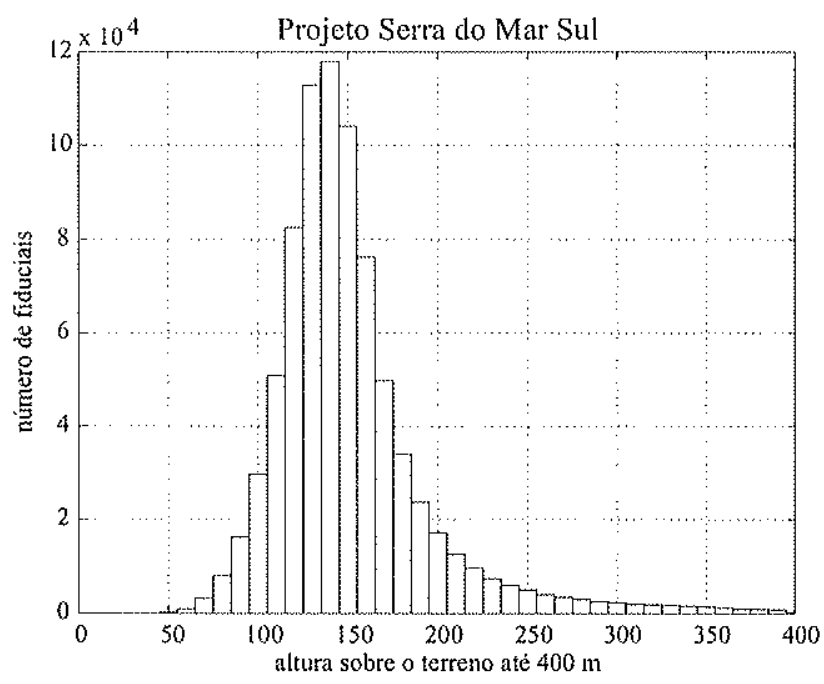

c)

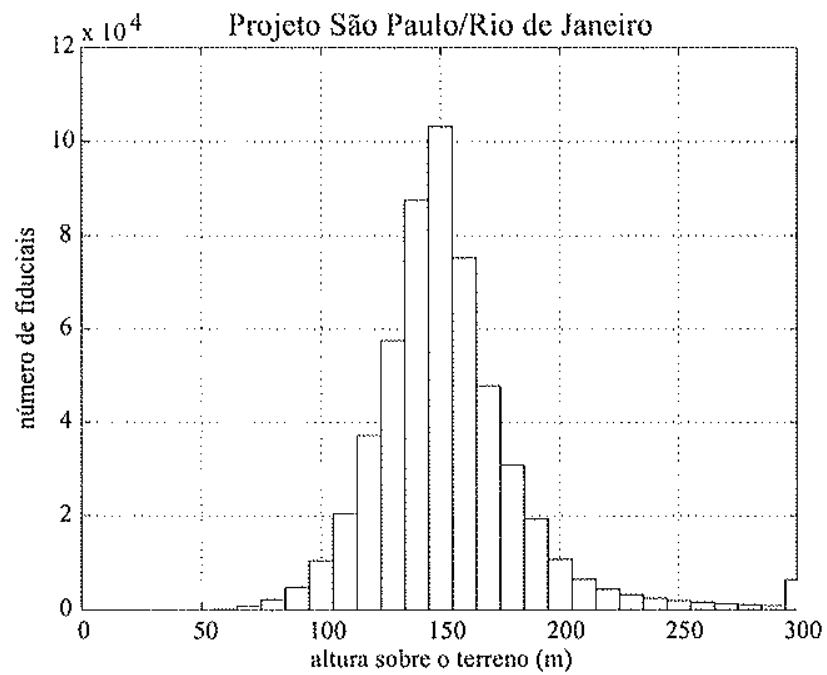

b)

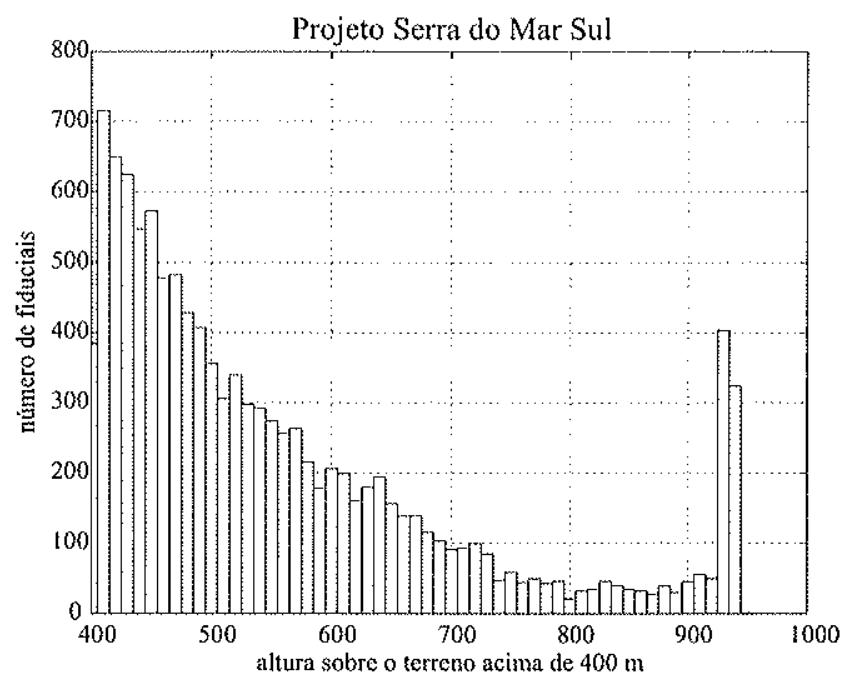

d)

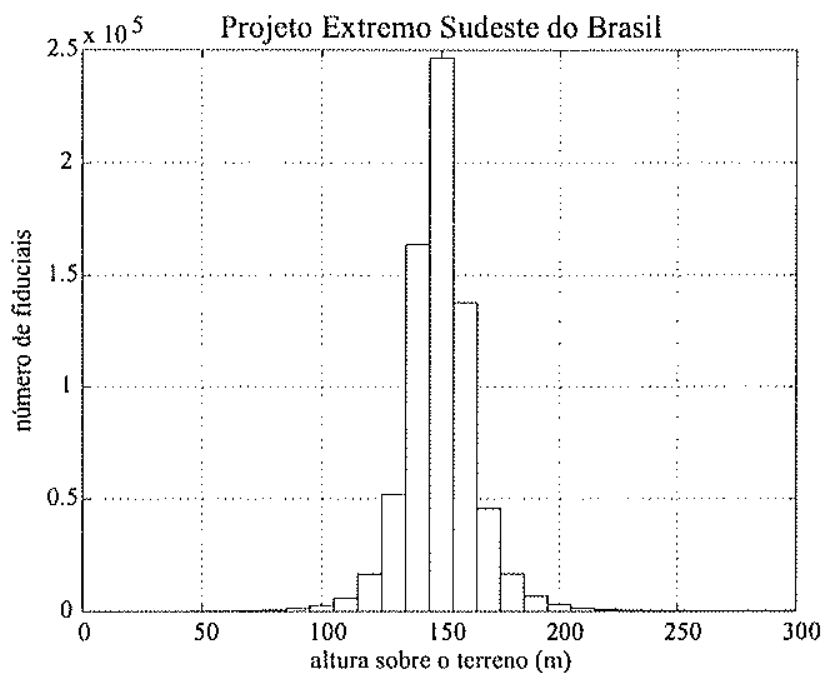

Figura 4.4 - Histogramas da altura sobre o terreno da aquisição dos dados. Todos os projetos possuem altura nominal de aquisição de dados igual a $150 \mathrm{~m}$ acima do terreno.

a) Projeto Serra do Mar Sul - histograma das fiduciais com altura entre 50 e $400 \mathrm{~m}$;

b) Projeto Serra do Mar Sul - histograma das fiduciais com altura maior do que $400 \mathrm{~m}$;

c) Projeto São Paulo/Rio de Janeiro - histograma da altura de todas as fiduciais;

d) Projeto Extremo Sudeste do Brasil - histograma da altura de todas as fiduciais. 
a)

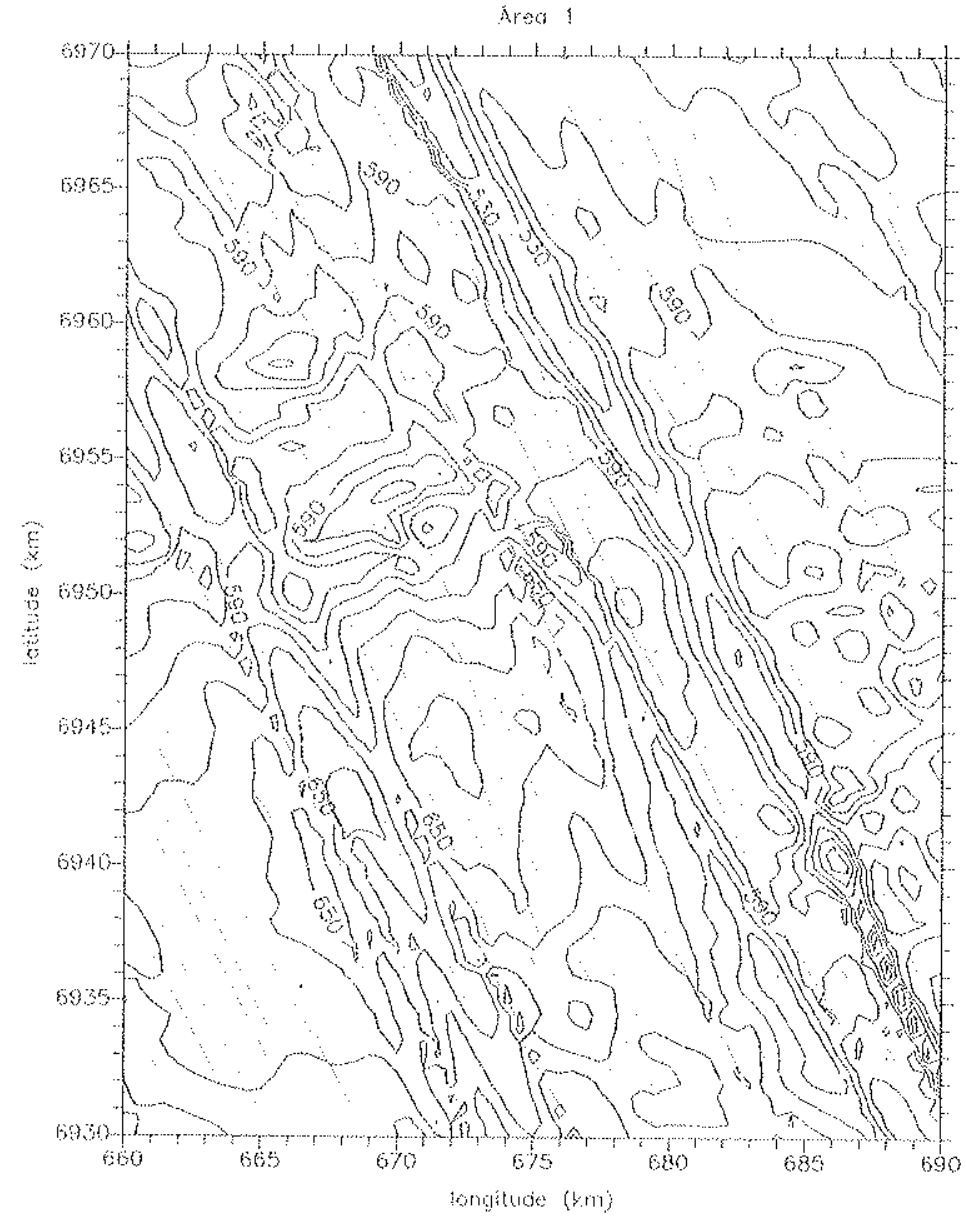

c)

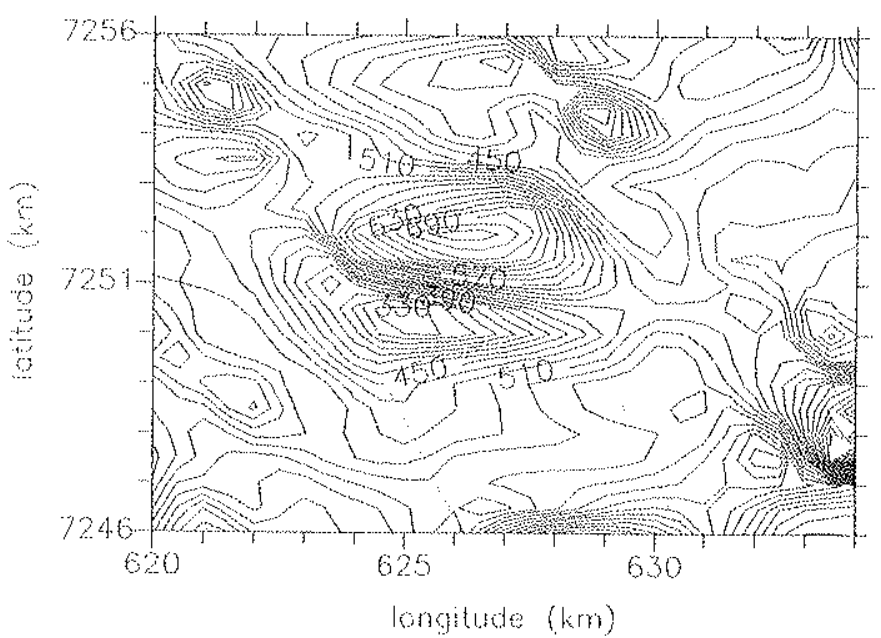

b)

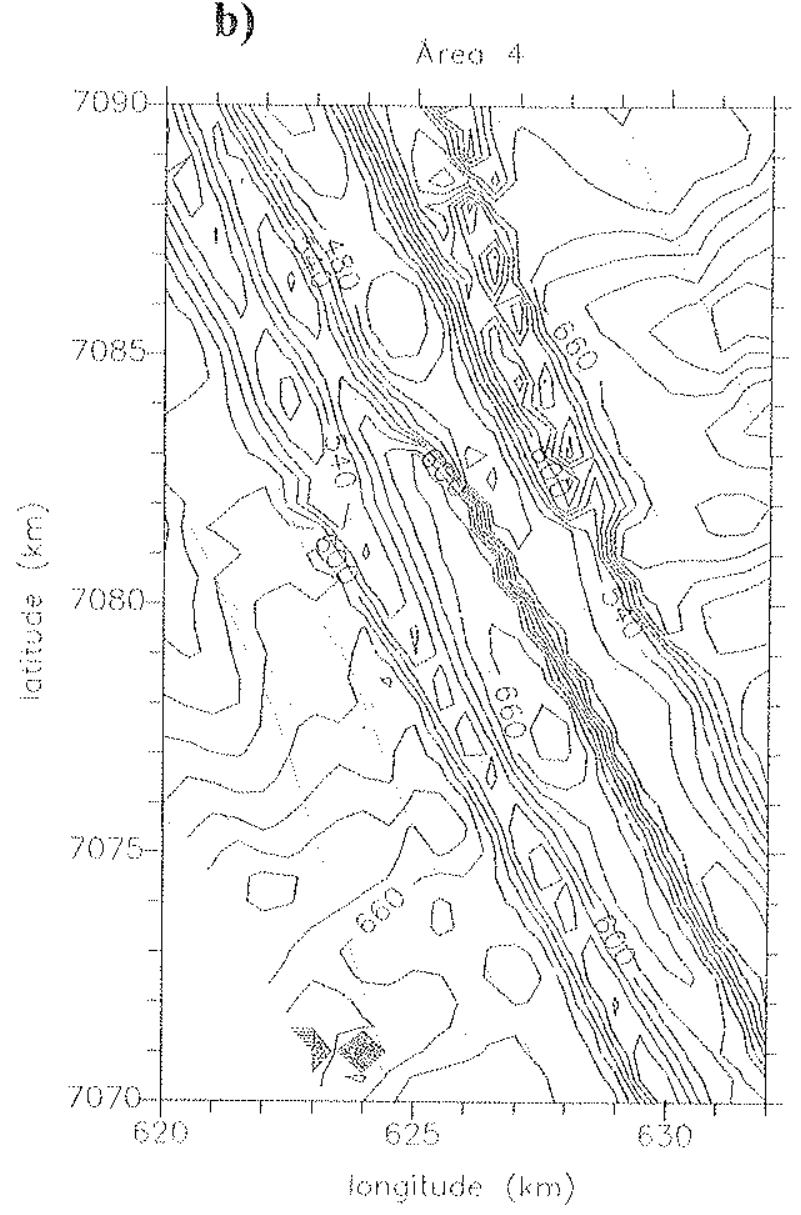

Figura 4.5 - Efeito das linhas de vôo do PASMS (em vermelho) condicionando a forma das anomalias.

a) cruzamento entre várias linhas de vôo;

b) erros de nivelamento superiores a $200 \mathrm{nT}$ deformando as anomalias na direção das linhas de vô;

c) espaçamento de $4 \mathrm{~km}$ entre linhas de vôo distorcendo as anomalias em direção às baixas freqüência. 
PASMS é uma exceção, pois nela tem-se um paralelismo muito bom entre as linhas de vôo ao longo de todo o levantamento.

A partir daquilo que foi exposto anteriormente, fica evidenciado que o emprego de um sistema automático de navegação e de posicionamento é capaz de produzir um conjunto de medidas que se encontram muito próximas das especificações nominais do levantamento, mesmo que este tenha que ser executado sobre uma região de topografia desfavorável. Por outro lado, empregando-se métodos menos sofisticados de navegação, como o visual, é possível se efetuar medidas dentro dos padrões do levantamento, desde que a topografia da região seja favorável.

\subsection{Correção CarTográfica do PASMS}

Uma das principais fontes de erro do PASMS diz respeito à base cartográfica adotada no projeto. Desde a divulgação do PASMS, tem sido constatados diversos erros de localização das anomalias geofísicas com relação à base cartográfica do IBGE (Nadal et al., 1992; Silva, 1994; Silva \& Mantovani, 1994). Como consequiência, os dados digitais do PASMS, fornecidos pela CPRM, encontram-se deslocados com relação à base cartográfica oficial adotada no Brasil. Tais deslocamentos, que atingem até $20 \mathrm{~km}$ ou mais, não são constantes dentro da área do levantamento, nem tampouco previsíveis através de uma única equação determinística. Portanto, o processamento e a geração de malhas digitais a partir dos dados do PASMS, na forma atual, fornecem anomalias geofísicas distorcidas que se encontram deslocadas com relação à base cartográfica oficial, impossibilitando a sua correlação com mapas geológicos, inversão numérica dos dados, em suma, impossibilitando que os mesmos venham a ter aplicação prática.

Nadal et al. (1992) desenvolveram uma técnica - baseada na transformação afim - para efetuar a correção desses erros. Essa técnica é semelhante às técnicas geralmente empregadas para a retificação de imagens de sensores remotos orbitais. Ela consiste na determinação de pontos de controle homólogos nos mapas de posição de linhas de vôo e nas cartas topográficas oficiais. A partir desses pontos, define-se uma transformação - a transformação afim - que mapeia as coordenadas dos pontos do sistema de coordenadas adotado no PASMS para o sistema de coordenadas adotado nas cartas topográficas oficiais do IBGE. Os pontos de controle adotados devem corresponder a feições notáveis e cujas coordenadas são bem definidas em ambos os sistemas de coordenadas. Tais pontos podem ser, por exemplo: cruzamentos entre rodovias, cruzamentos rodo-ferroviários, cruzamentos ferroviários, cabeceiras de pontes (rodoviárias ou ferroviárias) sobre rios, confluência de rios e/ou córregos, etc.

A equação matemática que exprime a transformação afïm pode ser representada matricialmente da seguinte forma:

$$
\left[\begin{array}{l}
x^{\prime} \\
y^{\prime}
\end{array}\right]=\left[\begin{array}{l}
x_{0} \\
y_{o}
\end{array}\right]+\left[\begin{array}{ll}
a & b \\
c & d
\end{array}\right] \cdot\left[\begin{array}{l}
x \\
y
\end{array}\right]
$$

onde: 
os pares $\left(x^{\prime}, y^{\prime}\right)$ e $(x, y)$ representam, respectivamente, as coordenadas de pontos homólogos nos sistemas de coordenada oficial adotado pelo IBGE, e no sistema de coordenadas adotado no PASMS;

$x_{o}, y_{o}, a, b, c$ e $d$ representam os parâmetros envolvidos na transformação dos sistemas de coordenadas.

Uma restrição quanto ao emprego da transformação afim, pelo fato dela fazer uso de um polinômio de primeiro grau, é que ela só pode ser aplicada apenas em áreas restritas, no máximo ocupando a superfície de uma carta topográfica na escala 1:50.000. Em casos excepcionais, ela pode ser aplicadas em regiões maiores, com uma área equivalente àquela encontrada nas cartas topográficas na escala 1:100.000. A transformação afim é uma boa solução para efetuar localmente a correção cartográfica do PASMS, contudo, ela se constitui de uma abordagem simplista em face da complexidade observada nos padrões das distorções que afetam o posicionamento das medidas do PASMS como um todo. Assim, ao se tentar uma solução capaz de efetuar a correção de posicionamento global do PASMS, deve-se buscar por outro tipo de metodologia de transformação. A solução adotada nesta tese consiste no ajuste de uma superfície de curvatura mínima ao conjunto de correções cartográficas que foram medidas em pontos homólogos espalhados ao longo de todo o PASMS. Essa solução, por se tratar de uma superfície suave, é capaz de acomodar as discrepâncias que não podiam ser representadas adequadamente pela transformação afim. Além disso, não há nenhuma restrição quanto à dimensão da área na qual ela pode ser aplicada.

A Figura 4.6 exemplifica esquematicamente o processo de determinação da correção cartográfica que deve ser aplicada a um único ponto do PASMS. Essa correção é calculada a partir da determinação das coordenadas de pontos de controle homólogos em ambos os sistemas de coordenadas. Nesse exemplo, foi escolhido como ponto de controle um cruzamento bem definido entre uma rodovia e uma ferrovia. As coordenadas desse ponto foram medidas no sistema de coordenadas do PASMS (ponto A) e no sistema de coordenadas cartográficas oficiais do IBGE (ponto B). Uma vez definidas as coordenadas do ponto de controle em ambos os sistemas, calcula-se o vetor correção $\overrightarrow{\mathrm{AB}}$ que deve ser aplicado ao ponto $\mathrm{A}$ de tal modo que as suas coordenadas estejam de acordo com a base cartográfica oficial brasileira.

Na Figura 4.7 estão representados de forma vetorial, na mesma escala da Figura, as correções que devem ser aplicados aos dados do PASMS para reposicioná-los corretamente sobre a base cartográfica oficial. Estes deslocamentos foram obtidos ao se digitalizar as coordenadas de pontos de controle homólogos, conforme descrito e exemplificado anteriormente, nos mapas de posição de linhas de vôo e em cartas topográficas oficiais (IBGE, DSG) na escala 1:50.000. Nessa Figura, cada quadrícula de dimensão $0,25^{\circ} \times 0,25^{\circ}$ corresponde a uma carta topográfica na escala 1:50.000. A quadrícula hachurada corresponde a um único mapa de posição de linhas de vôo dentro do qual não foi possível se identificar nenhum ponto de controle bem definido. A interpretação ou o processamento dos dados do PASMS, seja na forma de uma malha digital ou na forma de perfis, só poderá ser feita após a aplicação das correções cartográficas aqui identificadas. A não aplicação das correções anteriormente calculadas aos dados geofísicos (sejam eles magnetométricos ou gamaespectrométricos) do PASMS tem duas implicações diretas: a primeira é que as anomalias geofísicas estariam deslocadas da sua posição verdadeira; a segunda é que, devido ao fato das correções não serem constantes dentro da área do levantamento, ocorre uma distorção da forma das anomalias. Caso essas correções não sejam 
(a) Fotomosaico e mapas de posição de linhas de vôo

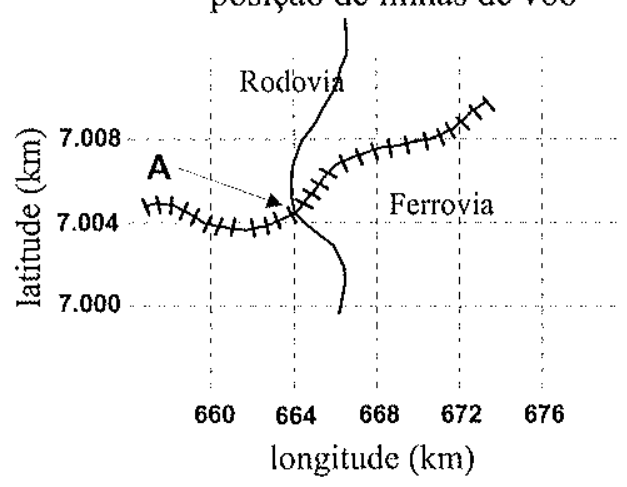

longitude $(\mathrm{km})$ (b) Mapa topográfico

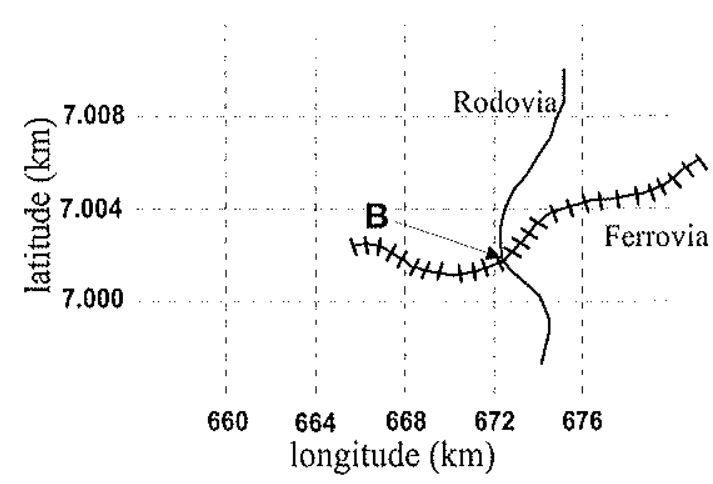

(c) Vetor correção

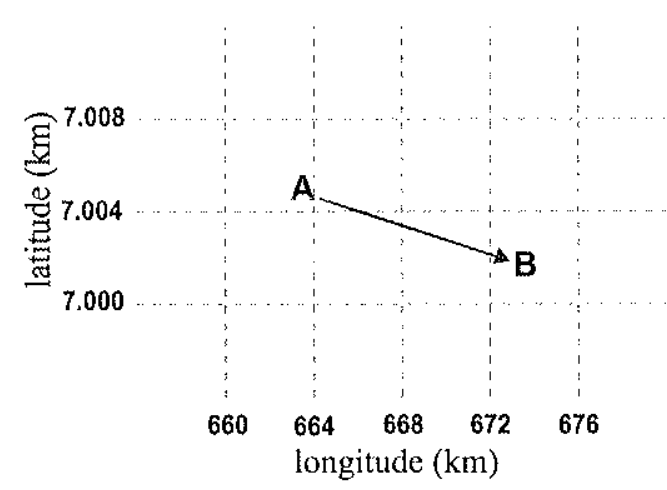

Figura 4.6 - Representação esquemática das etapas envolvidas no cálculo das correções cartográficas (c) a serem aplicadas aos dados do PASMS. Essas correções são calculadas a partir de pontos de controle homólogos identificados claramente no sistema de coordenadas adotado no PASMS (a) e na base cartográfica oficial (b). 


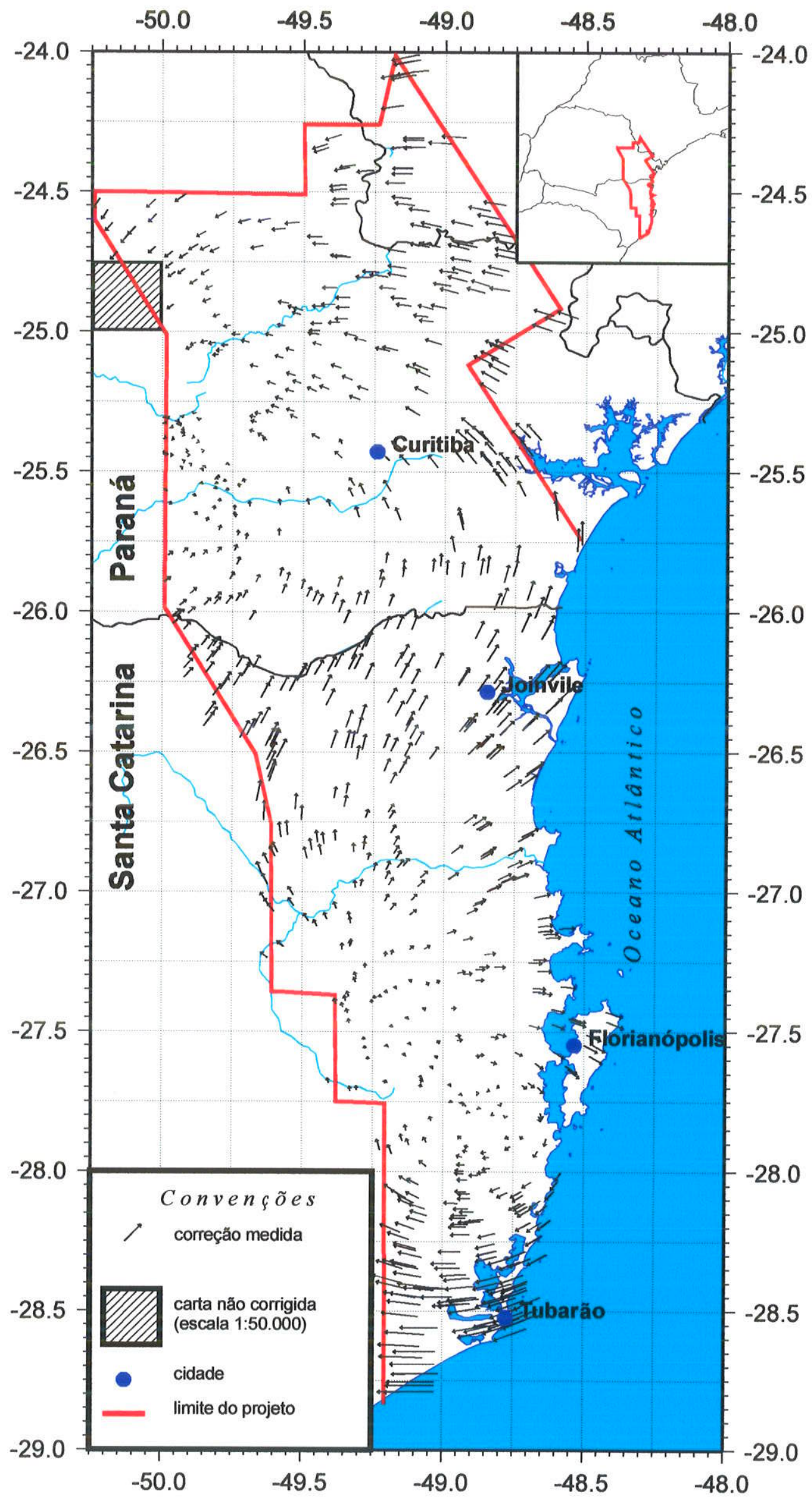

Figura 4.7 - Correções medidas para o reposicionamento das fiduciais do Projeto Aerogeofísico Serra do Mar Sul. 
aplicadas, estará se lidando com dados geofísicos que não são representativos dos corpos fontes de anomalia em subsuperfície.

Uma vez definido o campo vetorial das correções medidas, Figura 4.7, os seus valores são ajustados através do emprego de uma superfície de curvatura mínima e interpolados numa malha regular, de tal modo a produzir um campo vetorial de correções modeladas. A Figura 4.8 compara os dois campos vetoriais: o das correções medidas (vetores em preto) e o das correções modeladas (vetores em magenta). Conforme pode ser observado, o campo vetorial modelado reproduz adequadamente as correções medidas, seja em azimute, seja em magnitude.

Os valores do campo vetorial das correções modeladas são, então, calculados nas coordenadas de cada fiducial do PASMS. A aplicação dessas correções às coordenadas das fiduciais de cada medida reposiciona o PASMS de acordo com a base cartográfica oficial brasileira. Após esta correção cartográfica, os valores das anomalias geofísicas medidas (magnetometria e gamaespectrometria) passam a estar localizados corretamente com relação aos corpos fontes de anomalia. Além disso, as distorções na forma das anomalias são eliminadas.

\subsubsection{Análise das correções cartográficas}

Ao se analisar o padrão das correções, percebe-se que elas são suaves e coerentes, como era de se esperar, não havendo vetores próximos apontando para direções discordantes. Esta é uma informação importante a qual indica que o processo de distorção que originou os erros de posicionamento é suave e contínuo. As correções são mínimas no entorno de dois pontos: um ao norte do levantamento, de coordenadas aproximadas $\left(-49,9^{\circ},-25,3^{\circ}\right)$, e outro ao sul, próximo a ($\left.48,85^{\circ},-27,75^{\circ}\right)$. Aparentemente, estes pontos de mínimo devem corresponder aos pontos de controle que foram adotados pela Geofoto na elaboração da base cartográfica do PASMS. Observam-se, ainda, dois padrões distintos com relação às correções. Na porção norte do levantamento, acima do paralelo $-26,25^{\circ}$, estas se apresentam na forma de deslocamentos circulares no sentido anti-horário, cujas magnitudes aumentam conforme se distanciam do ponto de mínimo, para o qual elas parecem convergir. Na porção sul do levantamento, abaixo do paralelo $-26,25^{\circ}$, as correções também se apresentam na forma de deslocamentos circulares, só que no sentido horário, e divergindo do ponto de mínimo. Cada uma dessas áreas, quando analisada separadamente da outra, pode ser explicada, a grosso modo, como sendo resultante da aplicação de um polinômio de primeiro grau aos dados das cartas de posição de linhas de vôo. Assim, o deslocamento total em cada uma dessas áreas pode ser decomposto em três componentes: um deslocamento constante (responsável pela translação), uma componente antisimétrica (responsável pela rotação) e uma componente simétrica (responsável pela deformação de escala - contração ou expansão).

Sejam $(x, y)$ as coordenadas de um conjunto de pontos de controle nos mapas de posição de linhas de vôo e, sejam também, $\left(x^{\prime}, y^{\prime}\right)$ as coordenadas desses mesmos pontos na base cartográfica oficial do IBGE (tomado, por exemplo, em cartas topográficas). A relação entre $(\mathrm{x}, \mathrm{y})$ e $\left(\mathrm{x}^{\prime}, \mathrm{y}^{\prime}\right)$ pode ser expressa através de uma transformação linear de $\mathbf{R}^{2}$ em $\mathbf{R}^{2}$, ou seja, uma transformação afim, através da seguinte expressão:

$$
\begin{aligned}
& x^{\prime}=x_{o}+a x+b y \\
& y^{\prime}=y_{o}+c x+d y
\end{aligned}
$$




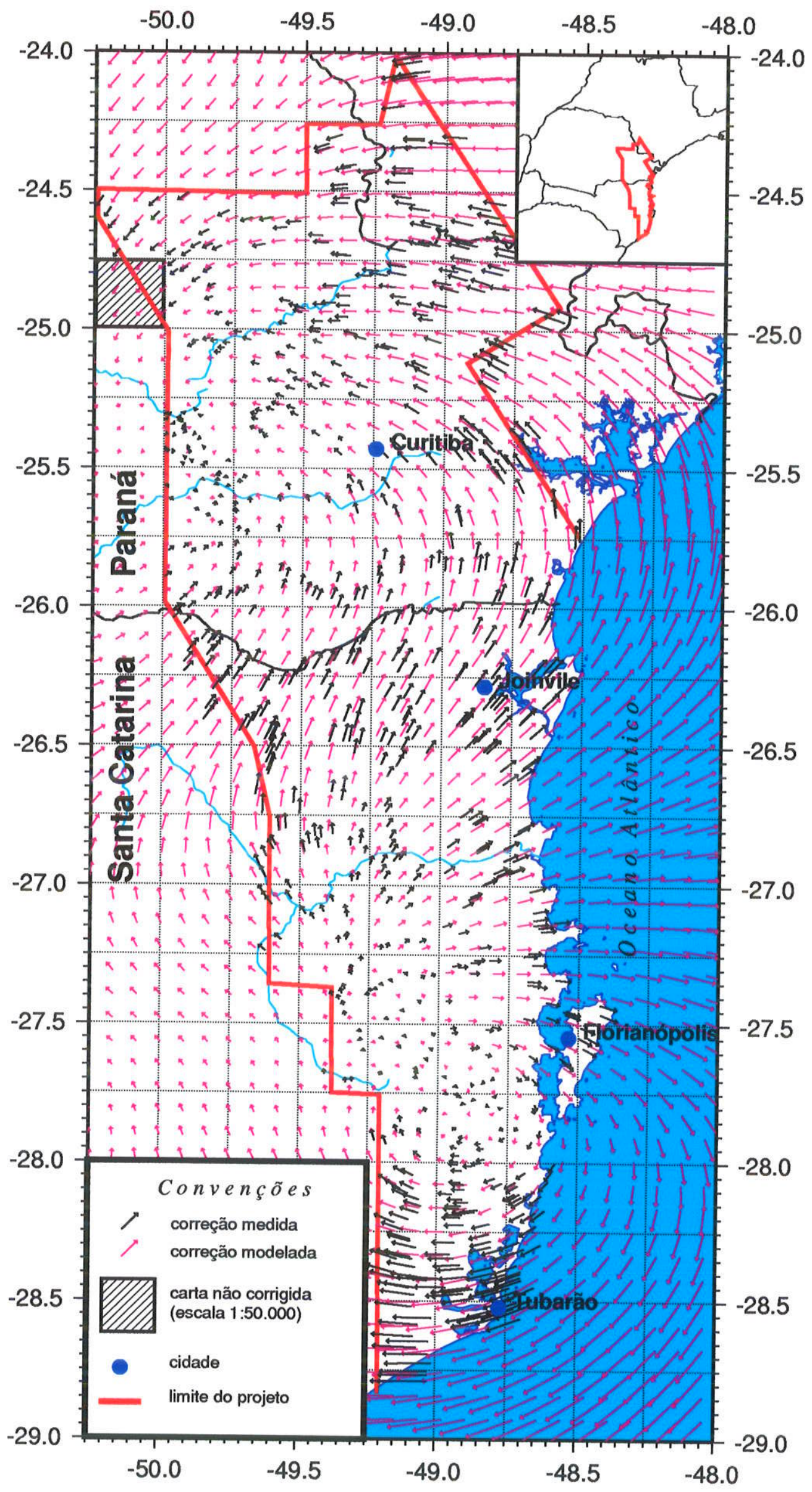

Figura 4.8 - Comparação entre as correções medidas e as correções modeladas para o reposicionamento das fiduciais do Projeto Aerogeofísico Serra do Mar Sul. 
fazendo $\mathbf{A}=\left[\begin{array}{ll}a & b \\ c & d\end{array}\right]$, escreve-se o sistema de equações anterior na forma matricial a seguir:

$$
\left[\begin{array}{l}
x^{\prime} \\
y^{\prime}
\end{array}\right]=\left[\begin{array}{l}
x_{0} \\
y_{0}
\end{array}\right]+\mathbf{A}\left[\begin{array}{l}
x \\
y
\end{array}\right]
$$

Sendo $\vec{e}$ o campo vetorial de distorção, tem-se que:

$$
\vec{e}=\left[\begin{array}{l}
x^{\prime} \\
y^{\prime}
\end{array}\right]-\left[\begin{array}{l}
x \\
y
\end{array}\right]=\left[\begin{array}{l}
x_{0} \\
y_{0}
\end{array}\right]+(\mathbf{A}-\mathbf{I})\left[\begin{array}{l}
x \\
y
\end{array}\right]
$$

onde I é a matriz identidade, $\left[\begin{array}{l}x_{0} \\ y_{0}\end{array}\right]$ corresponde à componente constante da mudança de coordenadas (translação), e $(\mathbf{A}-\mathbf{I})$ responde por uma combinação de rotação e deformação de escala.

Fazendo $\mathbf{B}=(\mathbf{A}-\mathbf{I})$ na equação anterior, tem-se que:

$$
\vec{e}=\left[\begin{array}{l}
x_{0} \\
y_{0}
\end{array}\right]+\mathbf{B}\left[\begin{array}{l}
x \\
y
\end{array}\right]
$$

A matriz B pode ser decomposta como a soma de duas outras matrizes, uma simétrica $\left(\mathbf{B}_{s}\right)$, responsável pela rotação, e outra assimétrica $\left(\mathbf{B}_{a}\right)$, responsável pela deformação de escala. Assim, tem-se genericamente que:

$$
\mathbf{B}=\mathbf{B}_{s}+\mathbf{B}_{a}
$$

onde,

$$
\mathbf{B}_{s}=\left[\begin{array}{cc}
p & \beta \\
\beta & q
\end{array}\right] \quad, \quad \mathbf{B}_{a}=\left[\begin{array}{cc}
0 & -\alpha \\
\alpha & 0
\end{array}\right] \quad \text { e } \quad \mathbf{B}=\left[\begin{array}{cc}
p & \beta-\alpha \\
\beta+\alpha & q
\end{array}\right]
$$

Finalmente, os elementos que formam a matriz $\mathbf{B}$ são expressos como função dos elementos de $\mathbf{A}$ :

$$
p=a-1, q=d-1, \beta=\frac{b+c}{2}, \alpha=\frac{c-b}{2}
$$

O conjunto de transformações anterior pode ser ajustado separadamente a cada uma das duas porções do campo vetorial de correções do PASMS. A Figura 4.9 contém as componentes de deslocamento total, componente de deslocamento constante, componente anti-simétrica, e a 
a) DESLOCAMENTO TOTAL

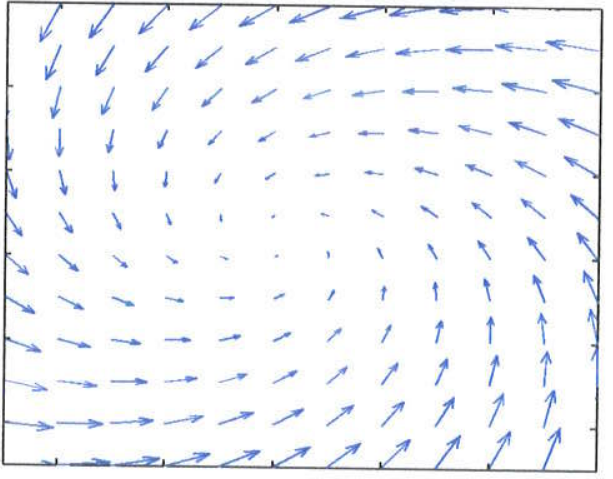

c) Componente Anti-Simétrica

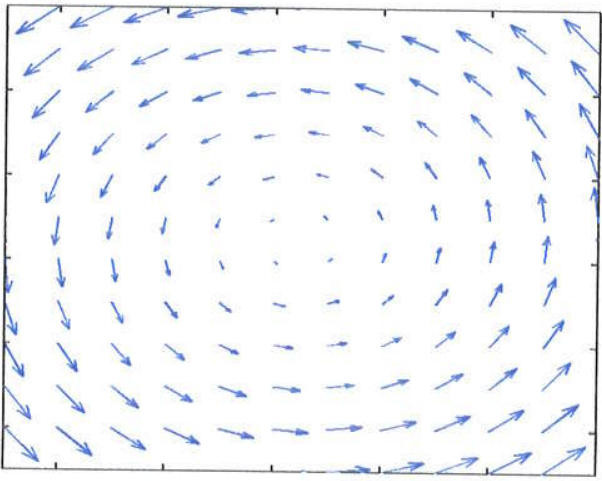

e) DESLOCAMENTO TOTAL

\begin{tabular}{|c|c|c|c|c|c|c|c|}
\hline$\uparrow$ & $\uparrow$ & 1 & 1 & 才 & 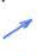 & & - \\
\hline 11 & $\uparrow$ & $t$ & 1 & , & $r$ & $\rightarrow$ & $\rightarrow \rightarrow$ \\
\hline 11 & 1 & $\uparrow$ & , & ' & - & $\rightarrow$ & $\rightarrow \rightarrow$ \\
\hline 7 & 1 & ' & ' & , & - & - & $\rightarrow \rightarrow$ \\
\hline$x>$ & ' & 、 & & - & - & $\rightarrow$ & $\rightarrow \rightarrow$ \\
\hline - & - & - & & & - & - & $->$ \\
\hline- & - & - & & & 、 & $\checkmark$ & $x>$ \\
\hline$\leftarrow$ & - & - & , & t & 1 & $\checkmark$ & $>>$ \\
\hline$\leftarrow$ & - & - & , & 1 & $\downarrow$ & 1 & $\searrow \searrow$ \\
\hline & 5 & 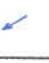 & 5 & 1 & $!$ & & 11 \\
\hline
\end{tabular}

g) Componente Anti-Simétrica

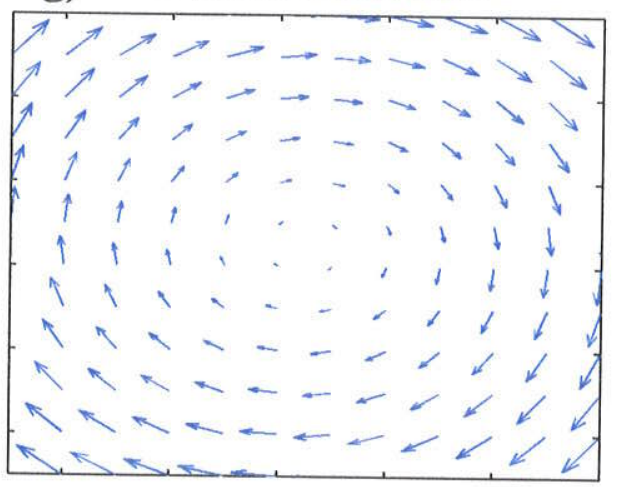

b) Componente Constante

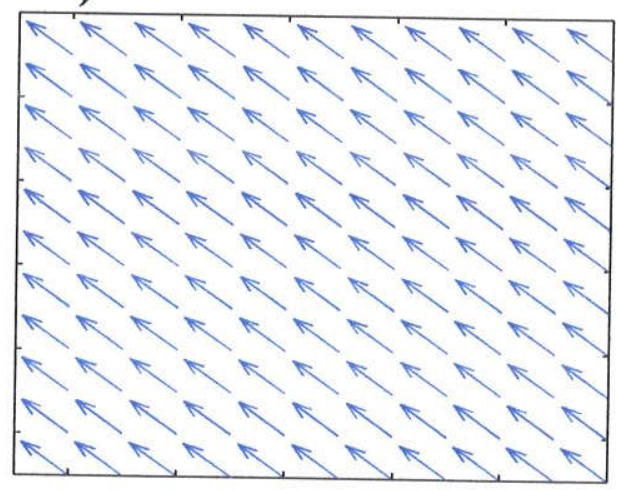

d) Componente Simétrica

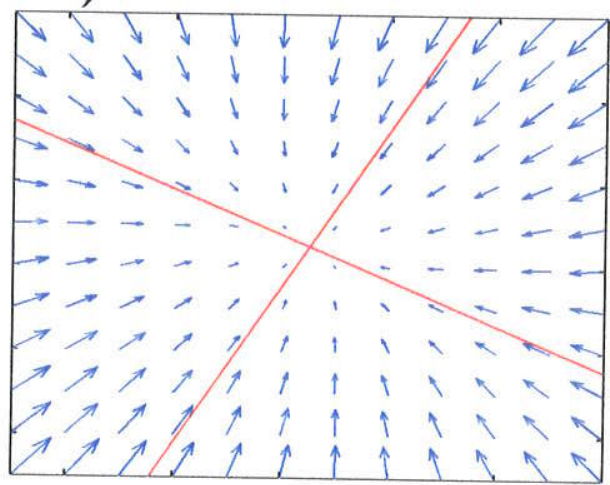

f) Componente Constante

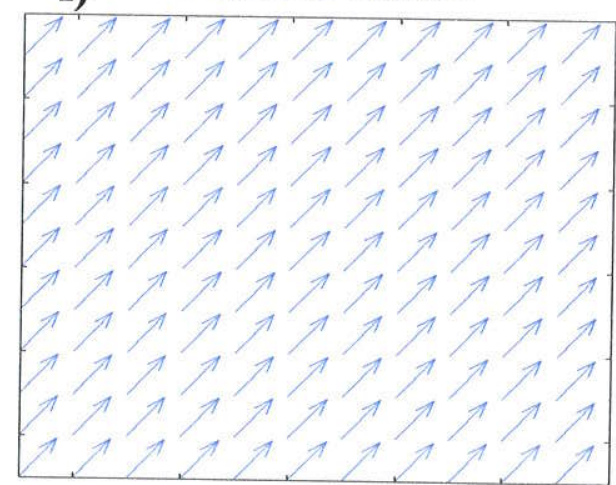

h) Componente Simétrica

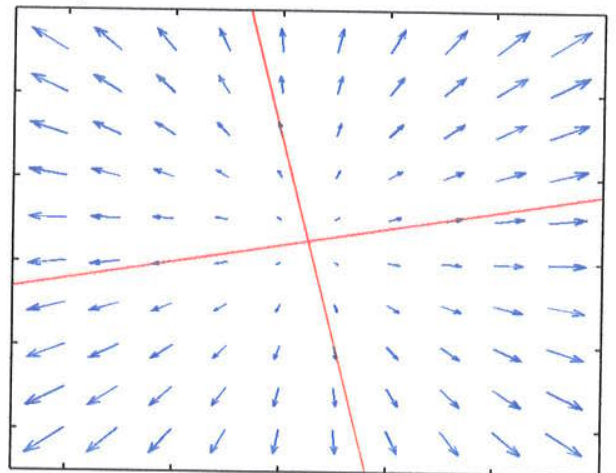

Figura 4.9 - Decomposição das componentes do campo vetorial de correções do PASMS: Deslocamento Total para as porções Norte (a) e Sul (e); Componente Constante para as porções Norte (b) e Sul (f); Componente Anti-Simétrica para as porções Norte (c) e Sul (g); Componente Simétrica para as porções Norte (d) e Sul (h). 
componente simétrica. A componente de deslocamento total foi ajustada separadamente para as porções norte e sul do PASMS. Posteriormente, ela foi decomposta nas outras três componentes. Através dessa Figura, pode-se constatar que para a porção norte do PASMS, a correção cartográfica corresponde a uma combinação de: translação para NW, rotação no sentido antihorário e contração de escala. Por outro lado, na porção sul do PASMS, a correção cartográfica pode ser compreendida como sendo produzida por uma combinação de: translação para NE, rotação no sentido horário e expansão de escala.

Deve-se ressaltar que essas componentes explicam os ajustes em grandes escalas, não sendo capazes de exprimir as variações de escala mais local no campo vetorial da correção cartográfica.

\subsubsection{Validação das correções cartográficas}

Conforme citado anteriormente, diversos autores têm relatado que as anomalias geofísicas do PASMS encontram-se deslocadas com relação à base cartográfica oficial. Um critério razoável para se validar as correções cartográficas propostas nesta tese consiste em se aplicar as correções modeladas às fiduciais do PASMS. Se as correções propostas forem capazes de posicionar as anomalias geofísicas sobre os seus respectivos corpos fontes, então as correções propostas podem ser consideradas como sendo válidas e eficientes. Foram escolhidas duas regiões para testar as correções propostas. Uma ao norte do levantamento, na região das folhas Cerro Azul (SG.22.X-B-IV) e Apiai (SG.22.X-B-V), e outra ao sul, na região de Florianópolis.

Os dados digitais dos contatos litológicos e dos lineamentos das folhas Cerro Azul e Apiaí foram gentilmente cedidos pelo Prof. Dr. Ginaldo A.C. Campanha (Instituto de Geociências da USP) e pelo Dr. Carlos César de Araújo. Os dados digitais de alta resolução da linha de costa da região de Florianópolis foram cedidos pelo Dr. Emanuel Giarolla (INPE), e pelo Prof. Dr. Ricardo Camargo (Departamento de Ciências Atmosféricas do IAG-USP).

Na primeira área de testes, a das folhas Apiaí e Cerro Azul, as fontes de contrastes de anomalias geofísicas são:

- lineamentos (Morro Agudo, Quarenta Oitava, Ribeira);

- granitóides (Três Córregos, Morro Grande, Itaoca, Barra do Chapéu);

- intrusivas alcalinas (Tunas, Mato Preto, Barra do Itapirapuã, Itapirapuã, Banhadão);

- rochas carbonáticas;

- metassedimentos.

A Figura 4.10 contém as localizações dos corpos e dos lineamentos utilizados no controle do reposicionamento das anomalias geofísicas. As Figuras subseqüentes apresentam a sobreposição dos contatos litológicos e dos lineamentos às anomalias geofísicas de magnetometria e gamaespectrometria (contagem total, tório, urânio, e potássio). Esses contatos foram sobrepostos às anomalias antes e após a correção do posicionamento. Deve-se ressaltar que os lineamentos e os corpos geológicos citados anteriormente não apresentam contrastes nítidos de propriedades para todos os dados geofisicos testados. Alguns corpos apresentam contraste de magnetometria, outros apresentam contraste de contagem total, outros de tório, etc. 


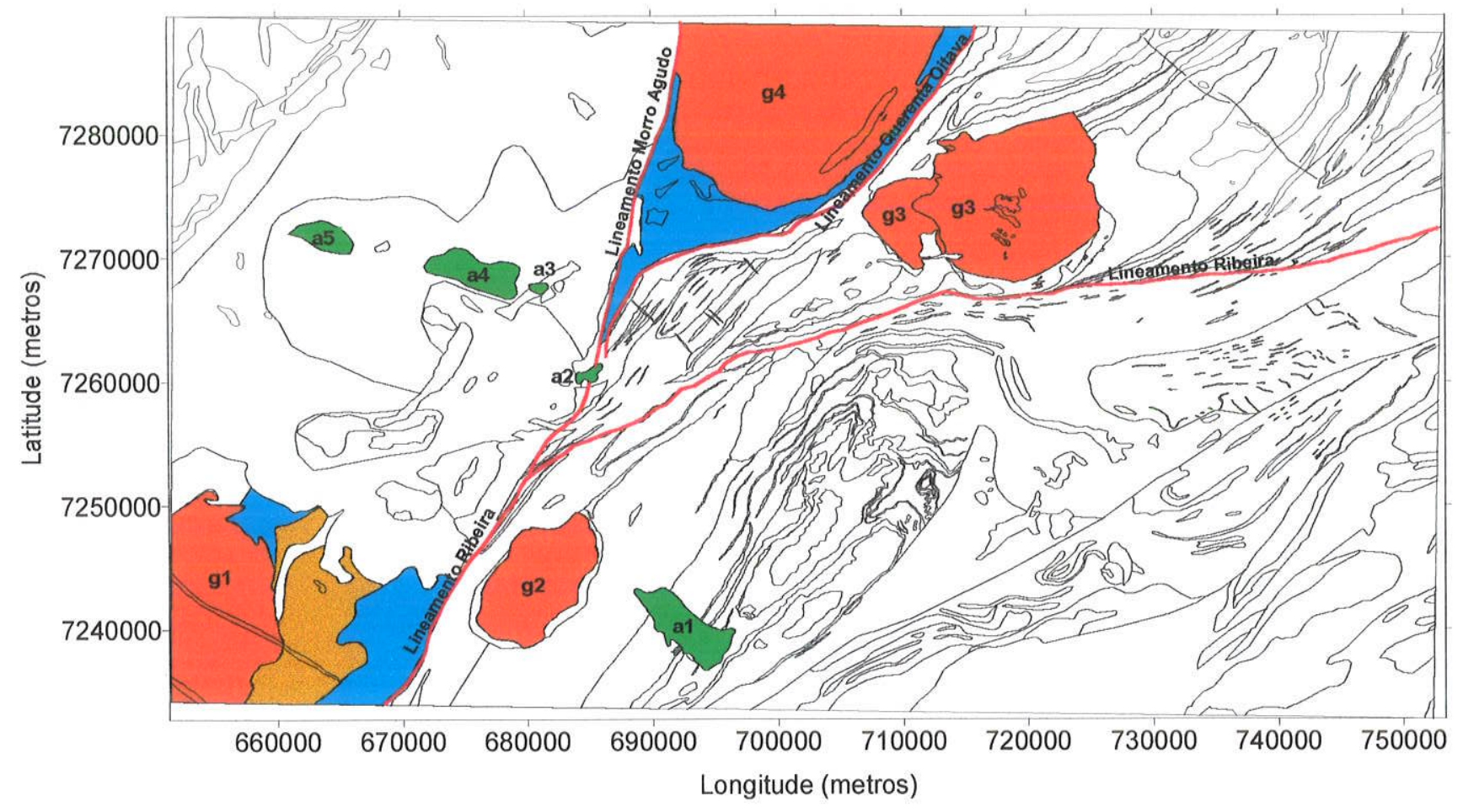

\section{LEGENDA}

Rochas Carbonáticas

Intrusivas Alcalinas

$\begin{array}{ll}\text { a1 - Tunas } & \text { a2 - Mato Preto } \\ \text { a3 - Barra do Itapirapuã a4 - Itapirapuã }\end{array}$

a5 - Banhadäo

Contato Litológico

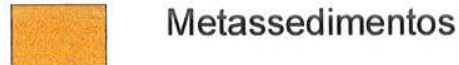

Granitóides

$\begin{array}{ll}\text { g1 - Três Córregos } & \text { g2 - Morro Grande } \\ \text { g3 - Itaoca } & \text { g4 - Barra do Chapéu }\end{array}$

Lineamentos

Figura 4.10 - Localização dos corpos fontes de anomalia e dos principais lineamentos nas cartas Cerro Azul (SG.22.X-B-IV) e Apiai (SG.22.X-B-V) 
A Figura 4.11 contém a sobreposição dos contatos litológicos e dos lineamentos às anomalias magnéticas antes e após terem sido submetidas à correção cartográfica. Antes da correção, não se nota nenhuma associação entre a geologia de superfície e as feições magnéticas. Após a correção cartográfica, observa-se que a anomalia magnética bipolar da intrusiva alcalina de Tunas, que antes se localizava a SE deste corpo, passa a se localizar imediatamente sob a alcalina. Após a correção cartográfica, também é possível se verificar que as feições magnéticas associadas aos lineamentos Quarenta Oitava e Ribeira passaram a se localizar sob esses lineamentos. Também é possível se constatar que, após a aplicação da correção cartográfica, as anomalias magnéticas associadas às auréolas de contato dos granitóides Barra do Chapéu e Itaoca passaram a coincidir com esses corpos, evidenciando os contatos desses corpos com as rochas circunvizinhas.

Devido à natureza bipolar das anomalias magnéticas, a correlação da anomalia com a forma de um corpo não é imediata. Isso já não ocorre com as anomalias gamaespectrométricas, que tendem a delimitar bem os contornos dos corpos.

A Figura 4.12 apresenta os contatos litológicos e lineamentos sobrepostos à anomalia gamaespectrométrica de contagem total. Conforme pode ser observado, antes da correção cartográfica, as anomalias geofísicas não se localizam sobre os corpos fontes de anomalia. Por outro lado, após a aplicação das correções cartográficas, fica bem nítido como essas anomalias definem bem a geometria do granitóide Barra do Chapéu e a geometria das rochas carbonáticas vizinhas a ele (formato de cunha). Após a correção cartográfica, as anomalias passaram a marcar nitidamente o contorno do granitóide Três Córregos e dos metassedimentos e rochas carbonáticas vizinhas a ele. Também é visível que após a correção cartográfica, as anomalias de contagem total associadas às alcalinas de Mato Preto e Barra do Itapirapuã passaram a se situar imediatamente sobre esses corpos.

A Figura 4.13 apresenta os contatos litológicos e lineamentos sobrepostos à anomalia gamaespectrométrica de tório. Observa-se que antes da correção cartográfica, as anomalias associadas às alcalinas Mato Preto e Barra do Itapirapuã, que são enriquecidas em terra raras, encontram-se deslocadas a SE desses corpos, assim como ocorre com a anomalia associada à alcalina Banhadão. Após a aplicação da correção cartográfica, todas as anomalias de tório passaram a se localizar exatamente sobre essas rochas alcalinas. Além disso, pode-se notar que após a correção cartográfica, a anomalia de tório também passou a coincidir com o granitóide Morro Grande.

A Figura 4.14 apresenta os contatos litológicos e lineamentos sobrepostos à anomalia gamaespectrométrica de urânio. Novamente, antes da correção cartográfica, as anomalias associadas às alcalinas Mato Preto e Barra do Itapirapuã encontravam-se a SE desses corpos. Após a correção cartográfica, as anomalias passaram a se localizar imediatamente acima desses corpos.

Por fim, a Figura 4.15 apresenta os contatos litológicos e lineamentos sobrepostos à anomalia gamaespectrométrica de potássio. Antes da aplicação da correção cartográfica, as anomalias encontravam-se deslocadas com relação aos corpos. Após a aplicação da correção, pode-se constatar que as anomalias de potássio passaram a delimitar com precisão a geometria dos granitóides Três Córregos, Itaoca e Barra do Chapéu. Elas também marcam nitidamente a localização das rochas carbonáticas delimitadas pelos lineamentos Morro Agudo, Quarenta 

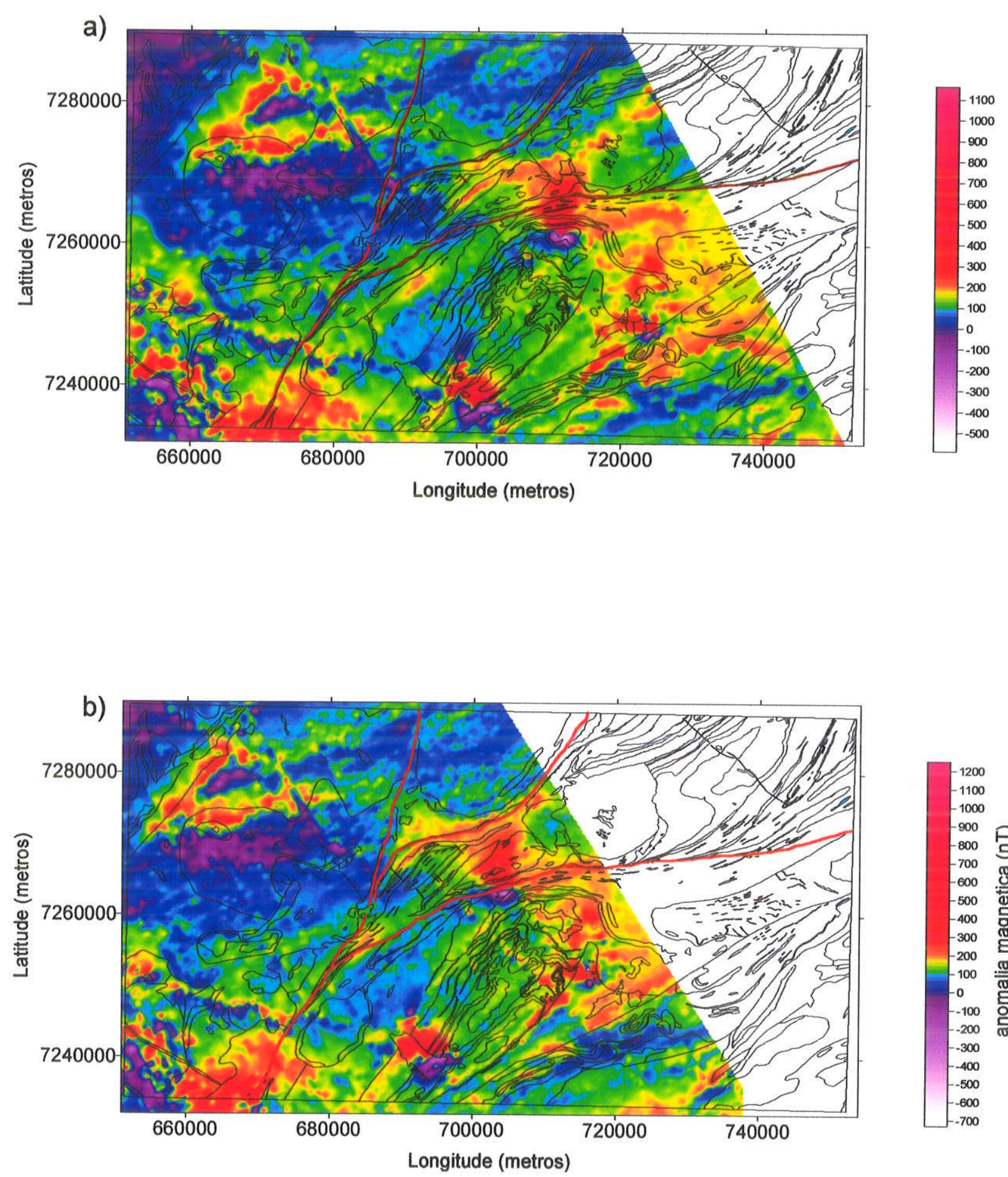

Figura 4.11 - Sobreposição dos contatos litológicos e dos lineamentos às anomalias magnéticas antes (a) e após (b) a correção do posicionamento. 

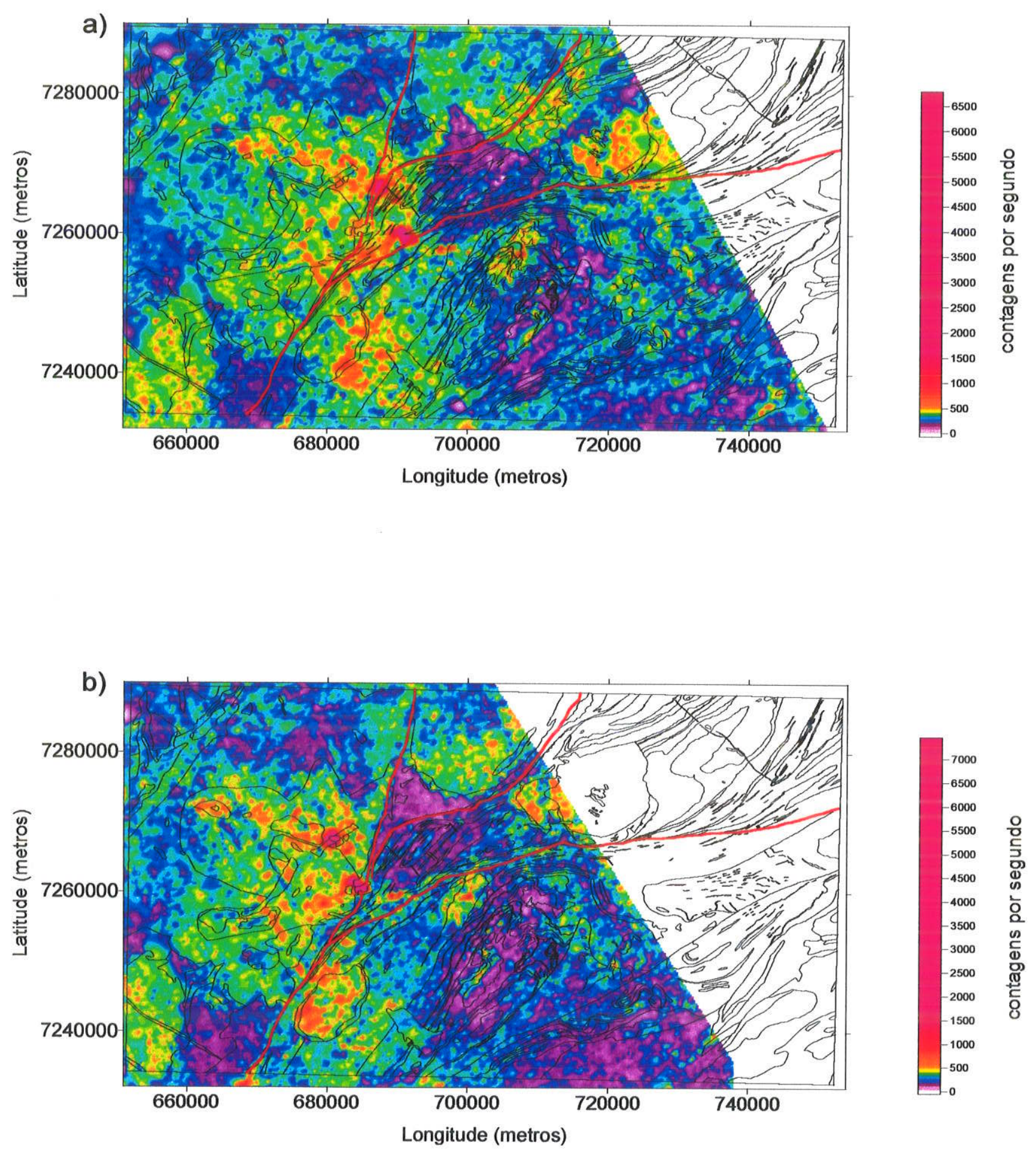

Figura 4.12 - Sobreposição dos contatos litológicos e dos lineamentos às anomalias gamaespectrométricas de contagem total antes (a) e após (b) a correção do posicionamento. 

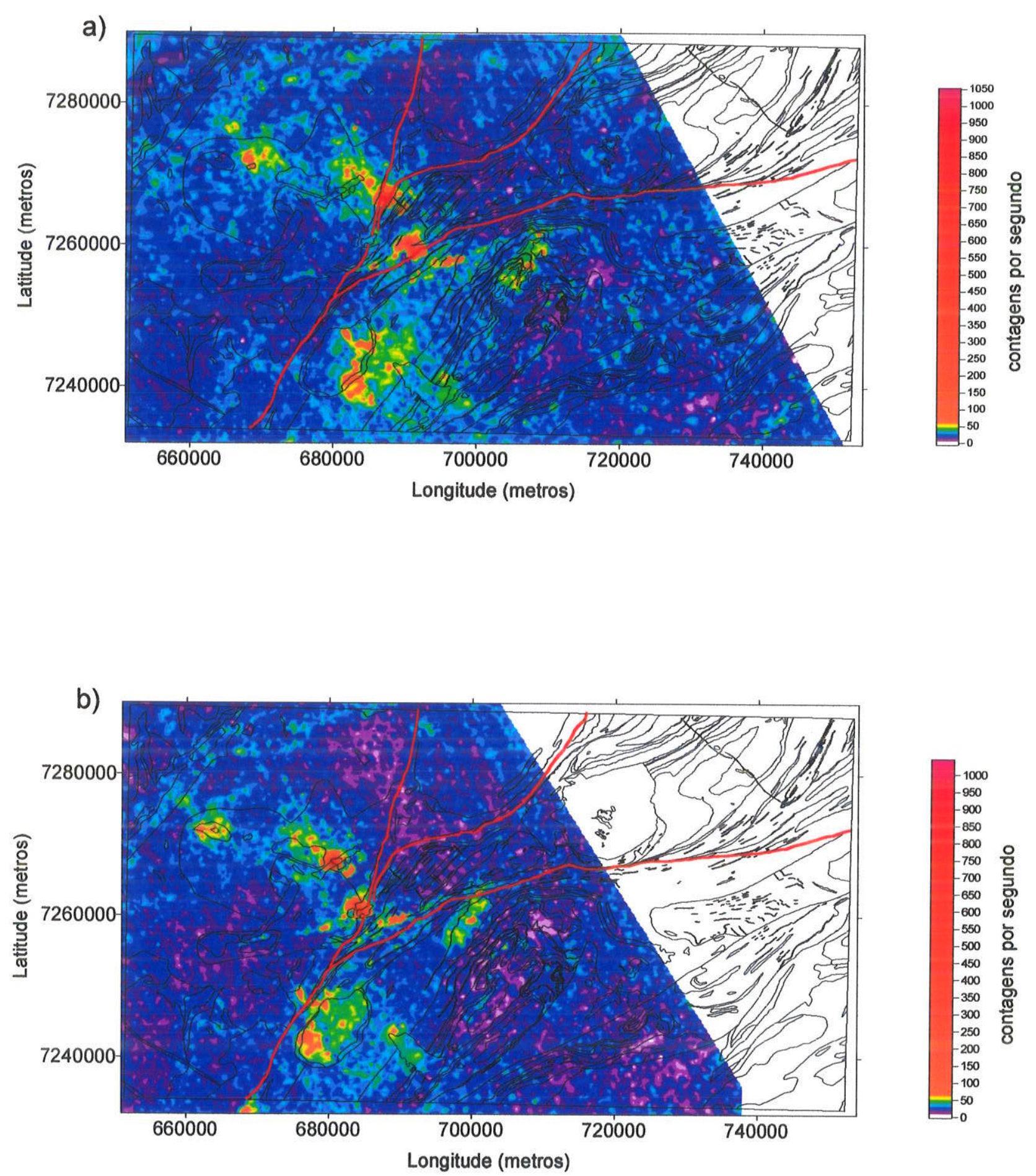

Figura 4.13 - Sobreposição dos contatos litológicos e dos lineamentos às anomalias gamaespectrométricas de tório antes (a) e após (b) a correção do posicionamento. 

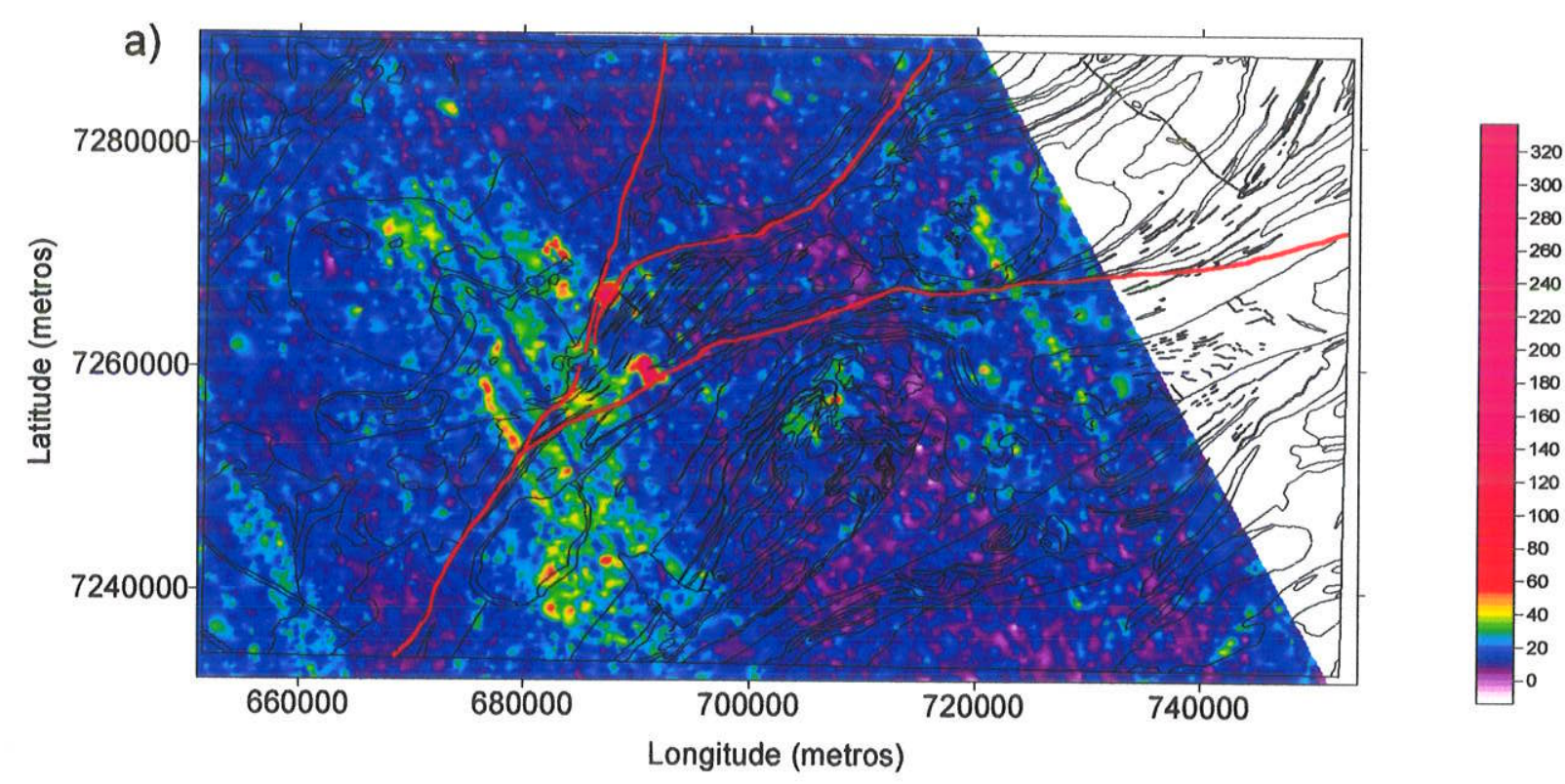

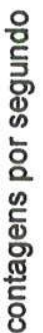
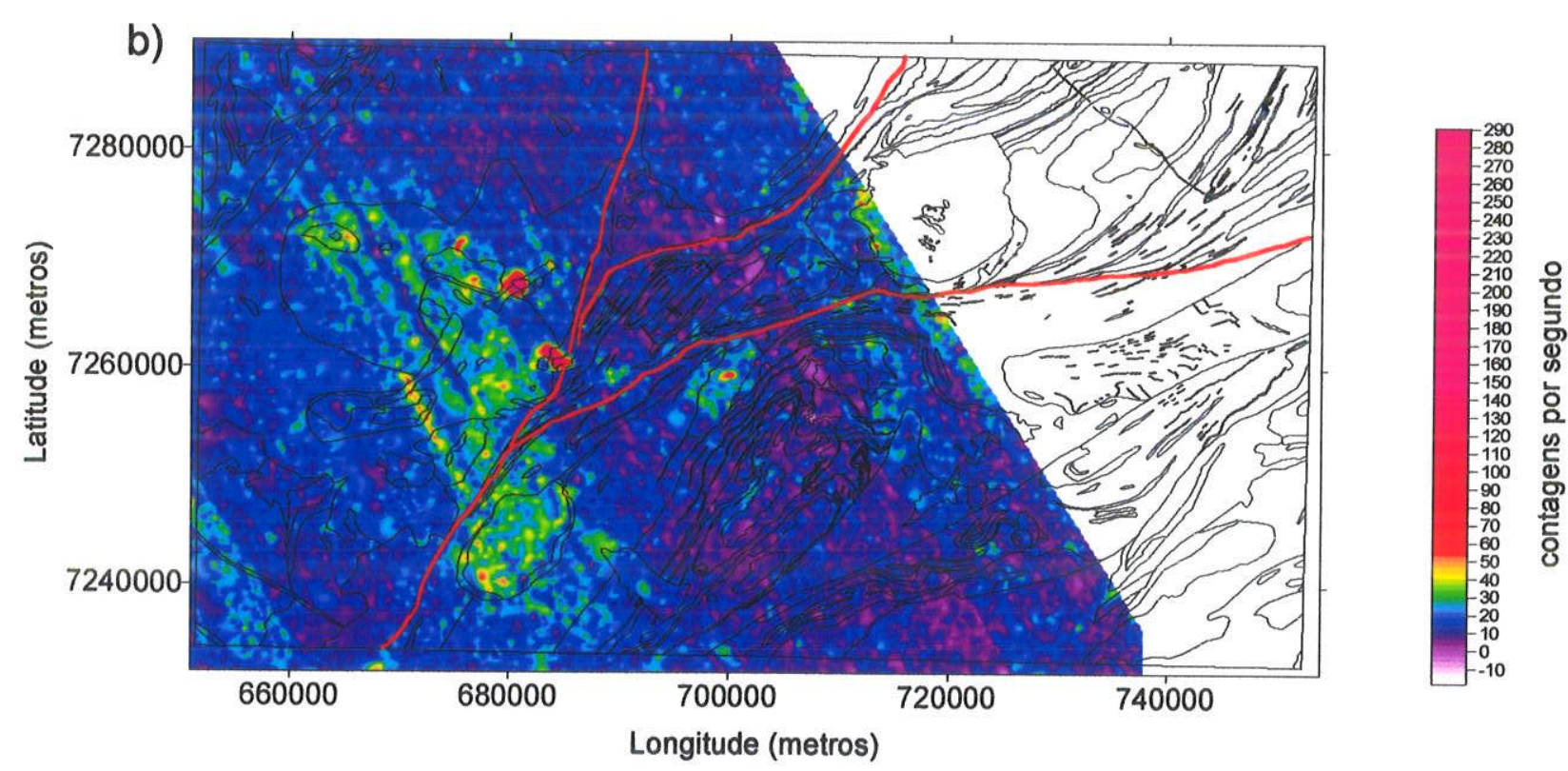

Figura 4.14 - Sobreposição dos contatos litológicos e dos lineamentos às anomalias gamaespectrométricas de urânio antes (a) e após (b) a correção do posicionamento. 

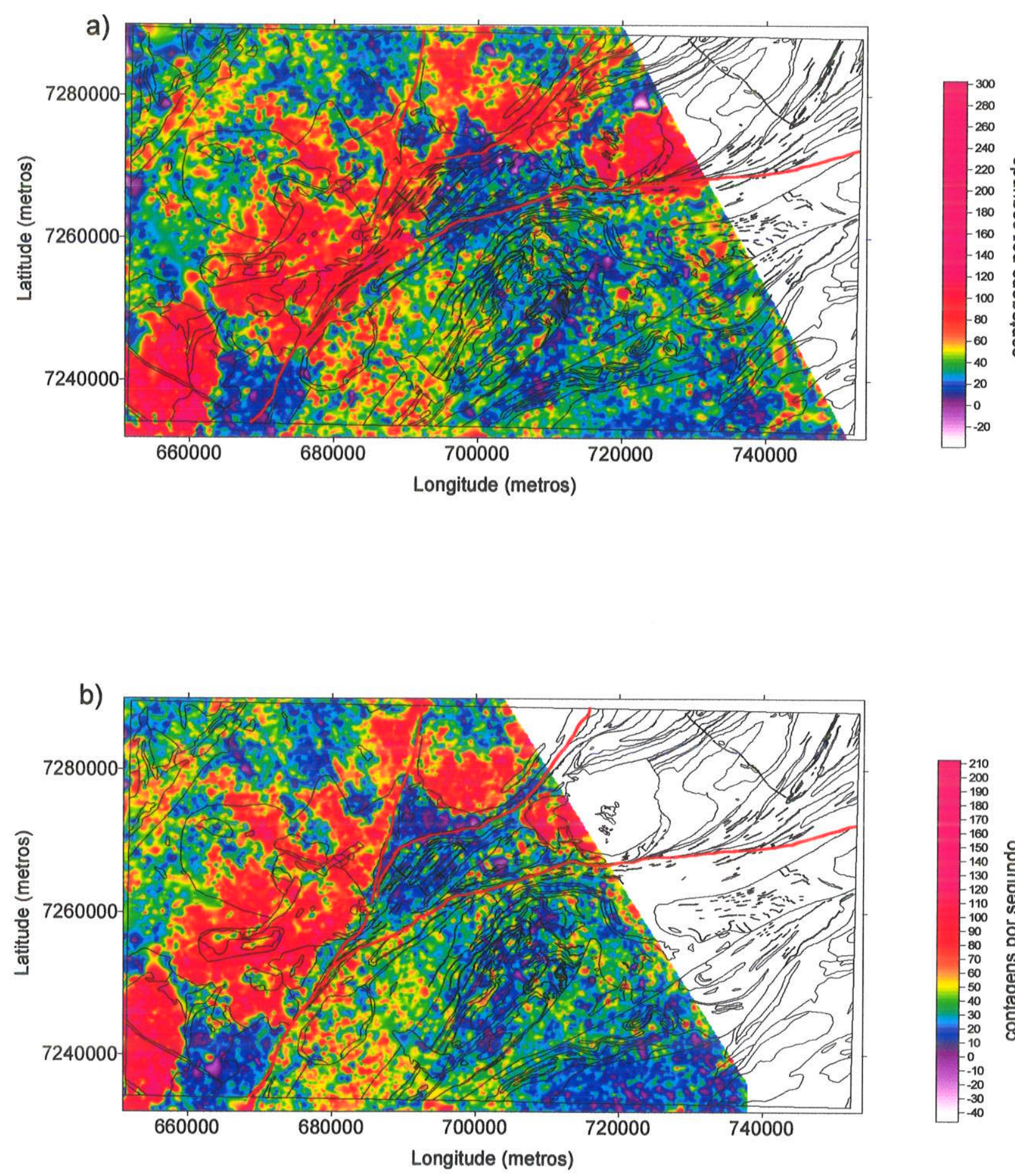

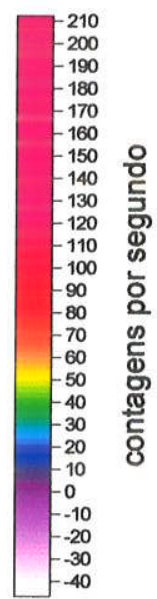

Figura 4.15 - Sobreposição dos contatos litológicos e dos lineamentos às anomalias gamaespectrométricas de potássio antes (a) e após (b) a correção do posicionamento. 
Oitava e pelo granitóide Barra do Chapéu. Após a aplicação da correção cartográfica proposta, as anomalias de potássio também passaram a coincidir com o lineamento Ribeira.

A segunda área de testes utilizada para validar as correções cartográficas situa-se na região de Florianópolis. Nela, serão empregadas somente as anomalias gamaespectrométricas para verificar a validação das correções propostas, pois não se dispõe de nenhum modelo geológico digital disponível daquela região. Ao contrário do que foi efetuado antes, quando se confrontavam os valores de gamaespectrometria com a geometria de contatos litológicos e lineamentos, aqui, a localização das fiduciais que apresentam valores de anomalia menores ou iguais aos valores de fundo serão confrontadas com a localização das grandes massas de água existentes nessa região. Sobre grandes massas de água, teoricamente, não deve ser observada nenhuma anomalia gamaespectrométrica devido à atenuação provocada por essas massas. Aliás, um critério amplamente utilizado para se medir o ruído de fundo quando da execução de um levantamento aerogamaespectrométrico consiste, justamente, em se executar uma série de sobrevôos sobre grandes massas de água. Assim, espera-se que após a aplicação da correção cartográfica proposta a este trecho do PASMS as fiduciais de gamaespectrometria cujos valores de anomalia são menores ou iguais aos valores de fundo localizem-se exatamente sobre as grandes massas de água existentes nessa região. Os valores de fundo adotados para essa região são, respectivamente: 20 contagens por segundo para o canal de contagem total; 0 (zero) contagem por segundo para o canal de tório; -1 (menos uma) contagem por segundo para o canal do urânio. O canal do potássio não foi utilizado pois ele se apresenta muito ruidoso nessa área do PASMS.

Na Figura 4.16 estão representadas as localizações das fiduciais do PASMS na região de Florianópolis antes ((a), (b), (c) e (d)) e após ((e), (f), (g) e (h)) a aplicação das correções cartográficas propostas. As Figuras (a) e (e) correspondem à localização de todas as fiduciais, independente do seu valor de anomalia. Como pode ser observado, antes da aplicação das correções (a), não há nenhuma correspondência entre o início ou fim dos vôos com a linha de costa (as medidas encontram-se deslocadas para NW). Após a aplicação das correções observase que todos os vôos iniciam-se ou terminam exatamente na linha de costa (e). As Figuras (b) e (f) apresentam a localização das fiduciais cujos valores de anomalia para o canal de contagem total são iguais ou menores que o valor de fundo. Antes da aplicação das correções cartográficas (b), essas fiduciais localizam-se parte sobre o continente, parte sobre as massas de água. Após a aplicação das correções cartográficas (f), as fiduciais passam a se localizar exatamente sobre as grandes massas de água existentes na região. Esse mesmo comportamento, também pode ser verificado para a localização das demais fiduciais de fundo dos canais de tório ((c) e $(\mathrm{g}))$ e urânio ((d) e (h)).

\subsection{Erros de Paralaxe no Pasms}

Não se encontra na literatura, até onde pôde ser pesquisado, qualquer referência sobre a existência de erros de paralaxe afetando o posicionamento das fiduciais do Projeto Aerogeofísico Serra do Mar Sul. Os relatórios técnicos de execução e processamento dos dados do projeto (Geofoto, 1978a; Geofoto, 1978b) também não citam a ocorrência desses erros. Contudo, a sua existência foi confirmada por Metelo (1996).

Como os erros de paralaxe variam entre linhas de vôo consecutivas, os seus efeitos sobre a malha digital de dados são mais pronunciados nas altas freqüuências. Isso acaba 

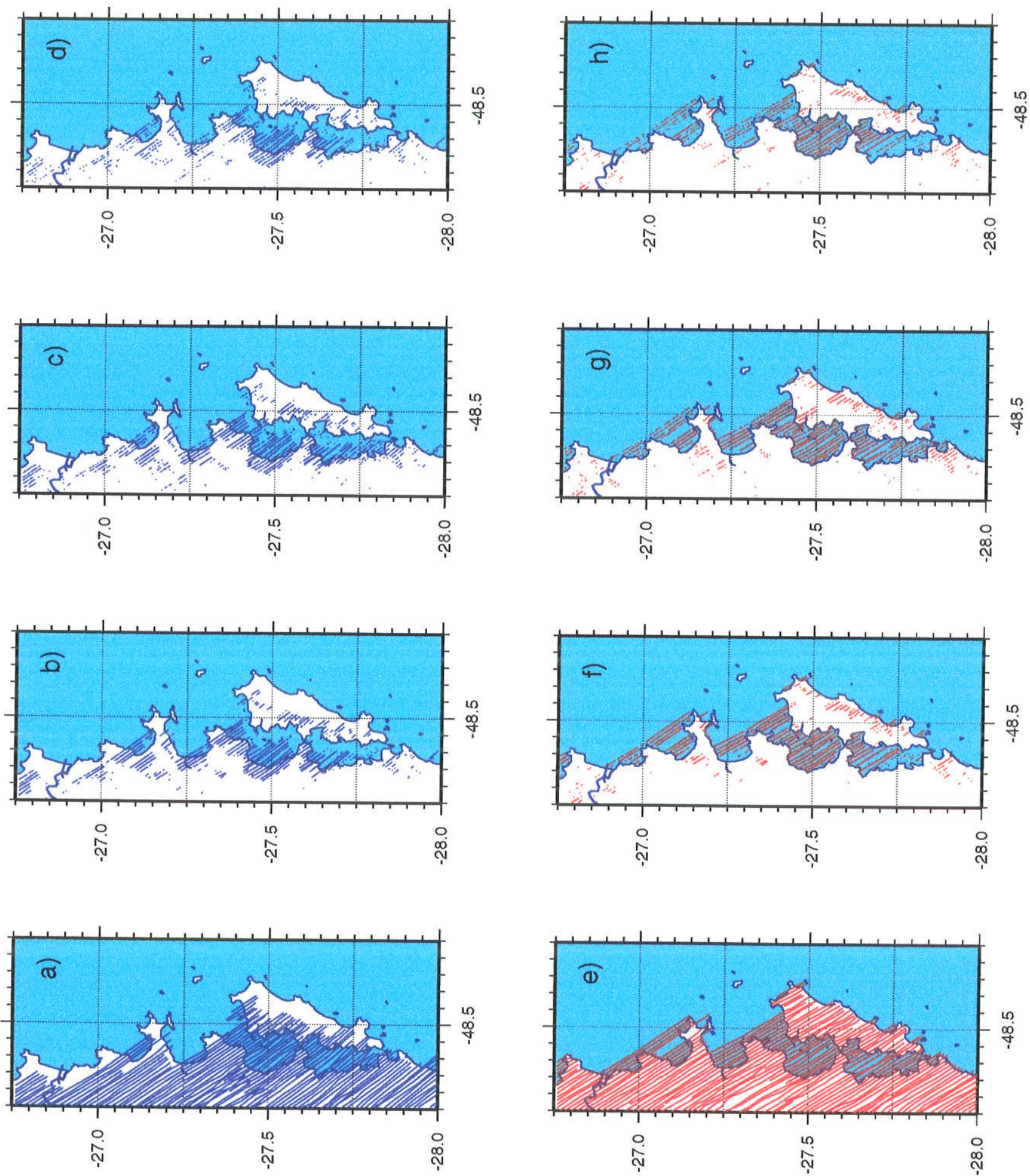

Figura 4.16 - Correção de posicionamento das fiduciais do PASMS na região de Florianópolis. Fiduciais totais (a) e de ruído de fundo nos canais de Ct (b), Th (c) e U (d) antes da correção; Fiduciais totais (e) e de ruído de fundo nos canais de Ct (f), Th (g) e U (h) após a correção. 
comprometendo o desempenho dos principais procedimentos de interpretação de dados magnéticos que, na sua maioria, fazem uso de operações de derivação. Muitas vezes os erros de paralaxe podem ser confundidos visualmente com o erro no nivelamento das linhas de vôo. A Figura 4.17 contém uma simulação dos erros de paralaxe e de nivelamento ficando evidentes as características distintas de cada um desses erros. Os erros de paralaxe nela simulados afetarn de modo uniforme todas as fiduciais de cada linha de vôo.

De acordo com Evans (1995), os erros de paralaxe podem se originar em dois momentos distintos: durante a etapa de vôo ou durante a fase de processamento dos dados. No primeiro caso, eles ocorrem quando há falta de sincronismo entre o sistema de navegação da aeronave e o sistema de registro de dados. Nesta situação, o procedimento para a correção dos dados pode ser aplicado rapidamente e de modo automático, pois os erros afetam toda uma linha de vôo de modo uniforme (Figura 4.17). No segundo caso, a sua origem se deve à determinação incorreta das coordenadas geográficas das fiduciais de controle. Esta é a causa dos erros de paralaxe identificados anteriormente. Deve-se notar que nesta situação esses erros não afetam toda uma linha de vôo, mas sim trechos de linhas de vôo. Aqui, o processo para a recuperação dos dados é mais demorado, não existindo qualquer procedimento automático conhecido para a sua execução.

A observação de anomalias magnéticas seccionadas na direção paralela à direção das linhas de vôo fornece a prova clássica da existência dos erros de paralaxe. Tal observação é favorecida se os dados forem representados na forma de uma imagem devidamente equalizada, pois mapas de contorno e imagens com contraste linear tendem a mascarar esses erros.

A elaboração de um mapa de contorno a partir de dados que contenham os erros de paralaxe que afetam somente trechos de linhas de vôo tende a gerar anomalias elípticas, com orientação oblíqua à direção das linhas de vôo, sobre corpos localizados, com dimensão da ordem do espaçamento entre linhas de produção. Desse modo, essas feições passam a ser confundidas com fontes geológicas, não podendo ser distinguidas destas. Por outro lado, ao se elaborar uma imagem digital adequadamente equalizada a partir desses mesmos dados (Figura 4.18), obtém-se anomalias seccionadas em direção paralela aquela das linhas de vôo, tornando evidente a localização dos trechos em que esses erros ocorrem.

Na Figura 4.18, as setas indicam os sentidos dos deslocamentos relativos dos trechos das linhas de vôo que geraram os erros de paralaxe. Em algumas situações, como aquela representada pelas setas na porção inferior da Figura, é possível se identificar qual linha de vôo se apresenta defeituosa, e qual trecho dentro dessa linha se apresenta mal posicionado. Nesta situação ou se elimina toda a linha de vôo ou se tenta reposicionar visualmente o trecho defeituoso, dependendo da necessidade que se tem em ter dados na área em questão. Obviamente, esse reposicionamento visual do trecho afetado é executado de modo aproximado, estimando-se um valor de deslocamento horizontal para o segmento de dados afetados de tal modo que se atenuem as discrepâncias entre a linha de vôo central e as suas vizinhas. Esse procedimento de reposicionamento pode ser adotado em situações críticas onde se tem necessidade de dados para se definir situações passíveis de serem interpretadas.

Uma segunda situação pode ocorrer, conforme representada pelas setas na porção superior da Figura 4.18. Nela, apesar do cisalhamento nas anomalias magnéticas poder ser observado e quantificado, não se sabe qual é a linha de vôo que foi deslocada. Nessa situação, 
a)

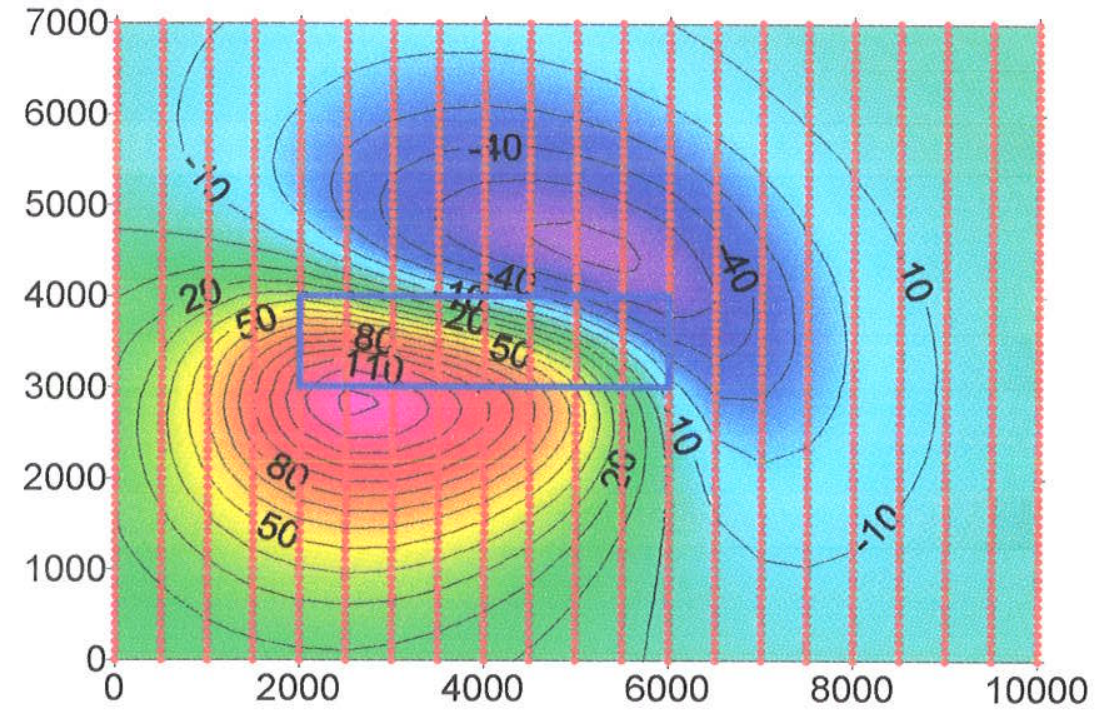

b)

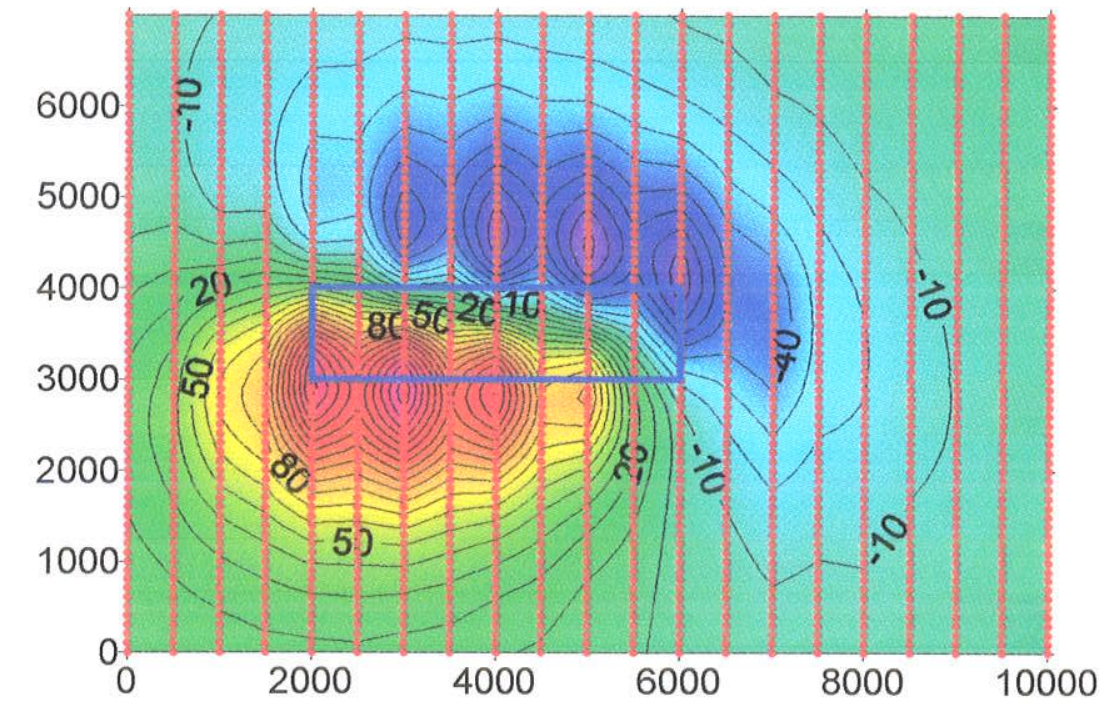

c)

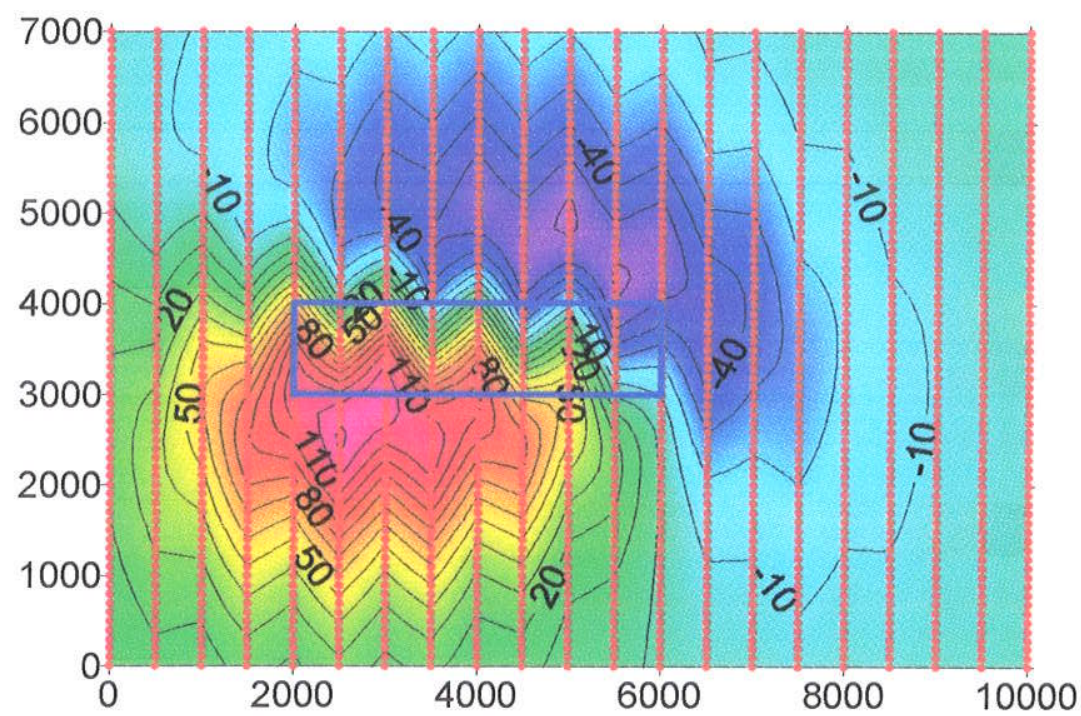

Figura 4.17 - Simulação de erros de nivelamento (b) e de paralaxe (c) sobre a forma de uma anomalia magnética (a).

Corpo fonte prismático em azul; pontos de medida em vermelho. Intervalo de contorno $10 \mathrm{nT}$, coordenadas em metros. 

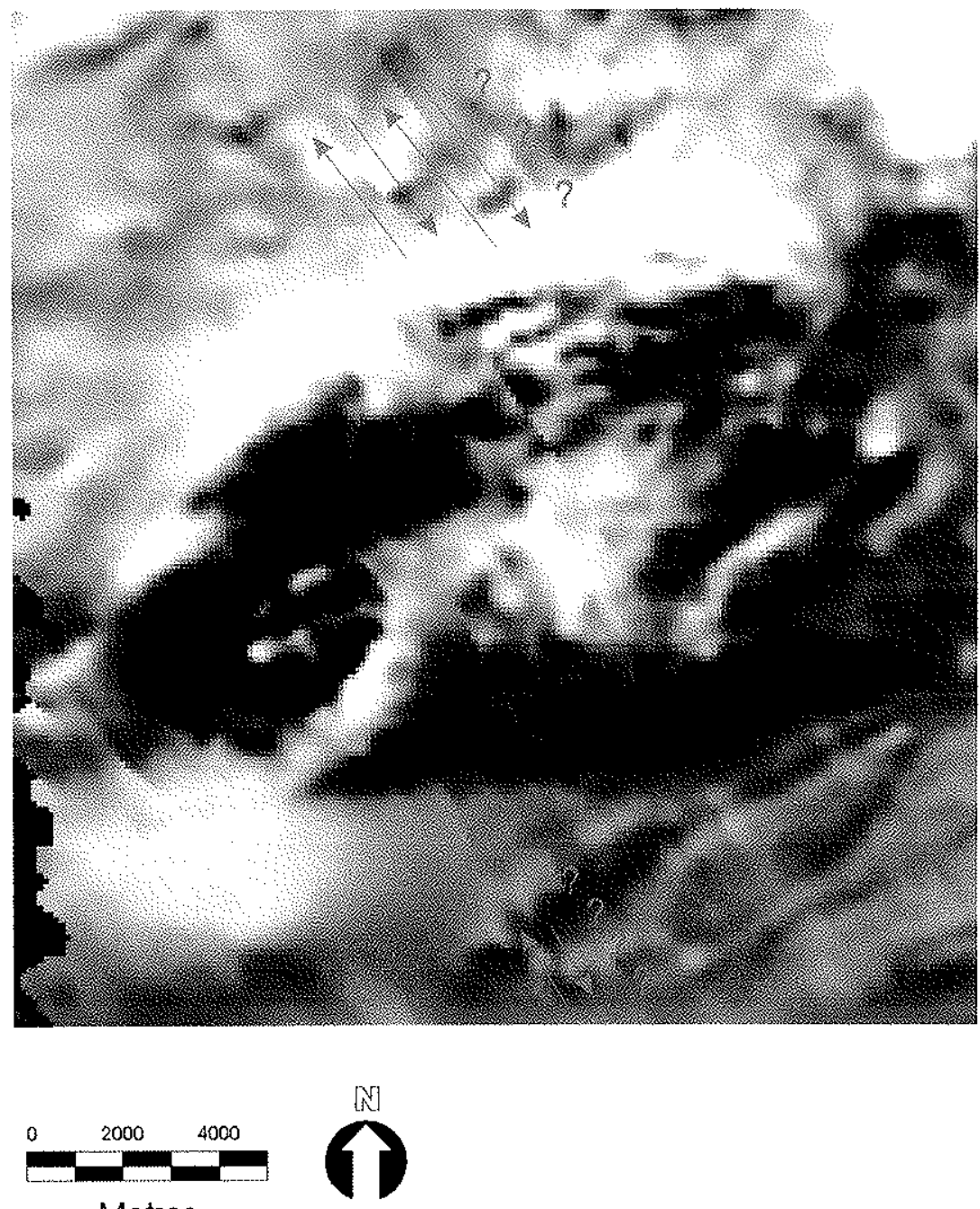

Metros

Figura 4.18 - Identificação do erro de paralaxe em trechos de linhas de vôo do PASMS, região do Cráton Luis Alves. 
ambas as linhas de vôo são consideradas defeituosas e devem ser eliminadas do conjunto de dados.

Finalmente pode ocorrer uma terceira situação, conforme indicado pelas interrogações na Figura 4.18. Nesse caso, observa-se a existência do erro de paralaxe, porém, a magnitude dele não pode ser estimada, pois não há correlação entre as anomalias presentes na linha de vôo central e aquelas das linhas de vôo adjacentes. Nesse caso, a linha de vôo central, ou o trecho em que se observa o erro de paralaxe, é eliminada.

\subsubsection{Correção dos erros de paralaxe do PASMS}

Não se encontrou na literatura a descrição de nenhum algoritmo capaz de efetuar a correção dos erros de paralaxe que afetam somente trechos de linhas de vôo. Este tipo de erro pode ser devidamente corrigido se for identificado enquanto o levantamento estiver sendo compilado/processado pela companhia responsável pela aquisição dos dados, pois ela detém, naquele momento, todo o conjunto de informações necessárias para se efetuar a correção de modo adequado. Por outro lado, se este tipo de erro passar desapercebido e só for identificado posteriormente pelos usuários, as chances de que o mesmo venha a ser adequadamente corrigido diminuem. É de praxe que os usuários, ao identificarem a ocorrência desse tipo de erro, reposicionem manualmente as fiduciais defeituosas (se elas ocorrerem em pequeno número) ou eliminem todas as fiduciais defeituosas (se elas ocorrerem em grande número).

Como no caso do PASMS o número de fiduciais associadas a erro de paralaxe é muito grande, seria inviável reposicioná-las manualmente. Por outro lado, caso as mesmas fossem eliminadas do conjunto de dados, estaria-se desprezando uma quantidade apreciável de informação sobre as anomalias magnéticas na região do PASMS. Assim, optou-se por desenvolver um algoritmo semi-automático (Braggion Jr., 2002) capaz de minimizar as distorções causadas pelo erro de paralaxe quando ele afeta apenas trechos de linhas de vôo. O algoritmo é semi-automático pois ele necessita que um operador identifique visualmente quais são as fiduciais de controle que precisam ser reposicionadas. A partir dá, o algoritmo reposiciona automaticamente as fiduciais de controle de tal modo que as discrepâncias entre os valores das anomalias magnéticas reposicionadas entre as novas coordenadas das fiduciais de controle sejam as menores possiveis com relação aos valores das anomalias magnéticas das linhas adjacentes interpolados nas coordenadas das fiduciais reposicionadas.

As principais etapas do algoritmo desenvolvido encontram-se descritas a seguir.

(a) Para cada uma das 94 cartas na escala 1:50.000 que compõem o PASMS, gerar uma imagem equalizada da anomalia magnética residual;

(b) Para cada uma dessas imagens, adotar as seguintes medidas:

(c) desenhar sobre a imagem o traçado das linhas de vôo e a localização das fiduciais de controle;

(d) identificar as fiduciais de controle que precisam ser reposicionadas dentro dos segmentos que apresentam erro de paralaxe;

(e) aplicar um incremento às coordenadas da fiducial de controle dentro do segmento e recalcular as coordenadas das demais fiduciais dentro do trecho; 
(f) aplicar um spline na direção perpendicular à direção das linhas de vôo para, a partir das linhas de vôo adjacentes, se obter um conjunto de novos valores de anomalia no segmento reposicionado em (e);

(g) calcular a somatória do quadrado dos resíduos entre os valores de anomalia interpolados e os valores de anomalia das fiduciais reposicionadas;

(h) retornar a (e), aplicando um incremento maior às coordenadas da fiducial de controle;

(i) o procedimento acima é repetido enquanto o reposicionamento da fiducial de controle, em (e), se encontrar dentro de limites previamente estabelecidos.

A posição final, atribuída à fiducial de controle e às fiduciais de medida, é aquela para a qual a somatória do quadrado dos resíduos, obtida em (g), foi a menor dentre todas.

Este procedimento reposiciona as fiduciais de controle de tal modo que as discrepâncias entre a linha de vôo que se está processando e as linhas de vôo vizinhas sejam reduzidas. Contudo, nem todas as fiduciais defeituosas podem ser reposicionadas, pois, em determinadas situações não se consegue determinar visualmente qual a linha de vôo está mal posicionada com relação às linhas vizinhas. Nesses casos, os trechos com erro de paralaxe devem ser eliminados do conjunto de dados.

Para que esse algoritmo possa ser implementado, é necessário que se discrimine as fiduciais de controle das demais fiduciais de medida. A determinação das fiduciais de controle só foi possível pois foi desenvolvido um algoritmo específico para a sua identificação. Esse algoritmo encontra-se descrito no próximo item.

\subsubsection{Identificação das fiduciais de controle do PASMS}

Para que o algoritmo de correção dos erros de paralaxe que afetam somente trechos de linhas de vôo, descrito anteriormente, possa ser implementado, é necessário que se identifique quais são as fiduciais de controle que compõem cada linha de vôo que se está tentando corrigir. Os arquivos digitais com os dados do PASMS não possuem nenhum campo discriminando quais são as fiduciais de controle conforme pode ser visto na Tabela 1. Por outro lado, os mapas de posição de linhas de vôo identificam a localização das fiduciais de controle para cada linha de vôo. Neles, sobre cada linha de vôo são desenhados símbolos nas coordenadas das fiduciais de controle; ao lado de cada símbolo encontra-se o número da fiducial para aquela linha de vôo (Tabela 1). Una vez que se conhece o número do vôo e o número da fiducial consegue-se associar àquele ponto toda a informação geofísica necessária para se reposicionar as fiduciais de controle. Contudo, como o número de fiduciais de controle que compõem o PASMS é muito grande (superior a 11.000), a identificação manual destas, a partir dos mapas de posição de linhas de vôo, torna-se impraticável. Assim, foi desenvolvido um algoritmo inédito capaz de identificar automaticamente a localização das fiduciais de controle que compõem o PASMS.

A Figura 4.19 apresenta o fluxograma das principais etapas do algoritmo desenvolvido para efetuar a identificação automática das fiduciais de controle do PASMS. O algoritmo desenvolvido possui os seguintes parâmetros de entrada: $\mathbf{V}$ (número do vôo), $\mathbf{P}$ (número do perfil), npt (número de pontos no perfil em questão), fidi (número da fiducial inicial do perfil), fidf (número da fiducial final do perfil), nperf (número de perfis que se deseja analisar), dx1 e dx2 (distância ao longo do eixo das abscissas entre duas fiduciais consecutivas), dy1 e dy 2 
(distância ao longo do eixo das ordenadas entre duas fiduciais consecutivas), fid1 e fid2 (número das fiduciais associadas a $(\mathbf{d x} \mathbf{1}, \mathbf{d y 1})$ e a $(\mathbf{d x} \mathbf{2}, \mathbf{d y} \mathbf{2})$, respectivamente). Esse algoritmo possui uma sub-rotina (detsxsy) que, ao analisar a curvatura das distâncias entre duas fiduciais consecutivas, devolve, como saída: os números do vôo (V), perfil (P) e identifica a fiducial de controle.

A eficácia do algoritmo proposto foi testada ao se comparar o resultado da sua saída com as fiduciais de controle identificadas nos mapas de posição de linha de vôo do PASMS. O algoritmo foi capaz de identificar com cem por cento de precisão a localização e o número das fiduciais de controle empregadas no teste. 


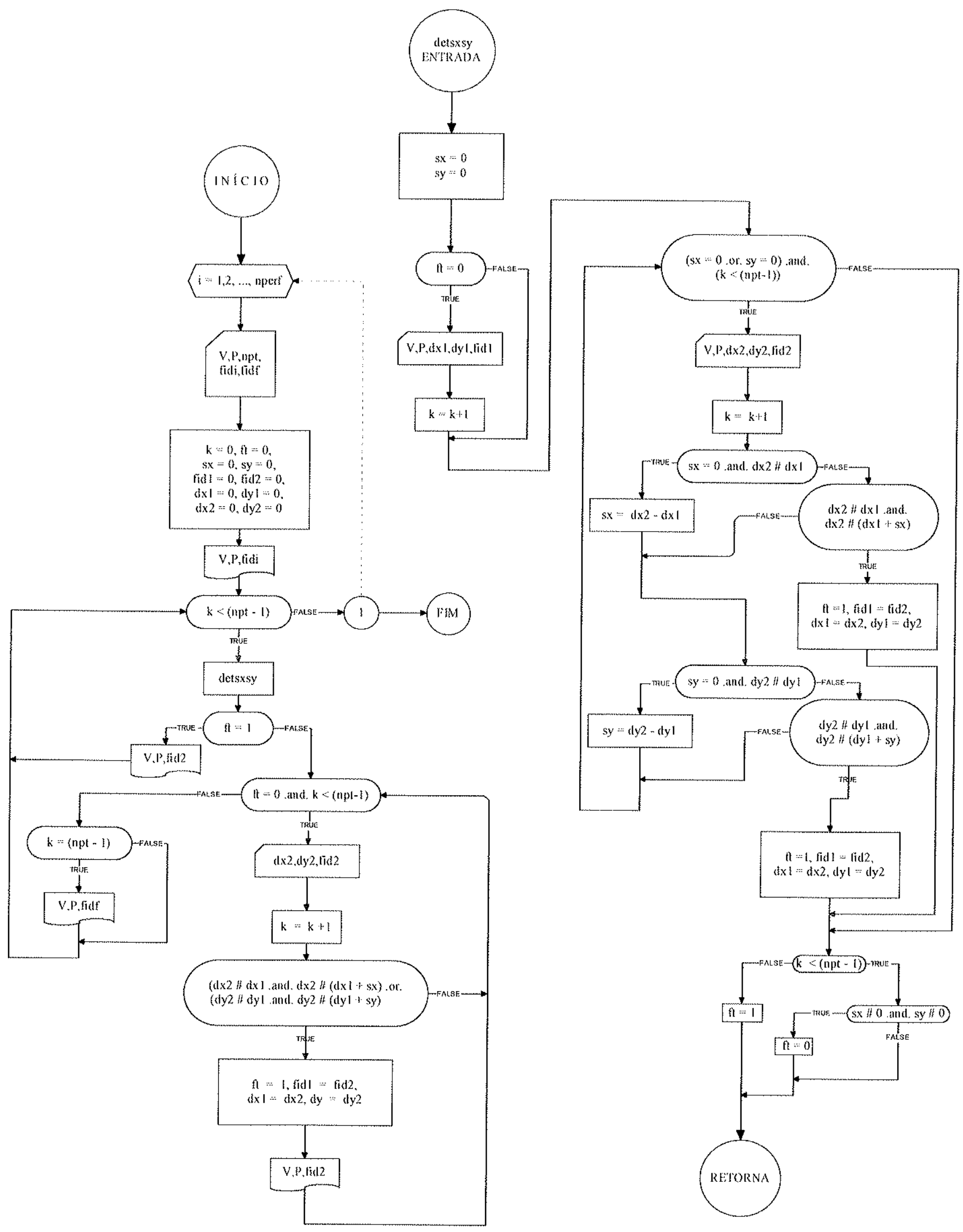

Figura 4.19 - Representação esquemática das principais etapas que compõem o algoritmo de identificação automática das fiduciais de controle do PASMS. 


\section{CAPÍTULO 5 \\ TÉCNICAS DE GERAÇÃO DE MALHAS DIGITAIS PARA DADOS AEROMAGNÉTICOS}

\subsection{INTRODUÇÃO}

O campo magnético, conforme medido durante a execução de um levantamento aerogeofĩsico, é resultante da amostragem de uma função contínua num determinado número de pontos discretos. O objetivo principal de todas as técnicas de geração de malhas digitais consiste em se estimar o valor dessa função num conjunto de pontos nodais, que não foram amostrados, a partir dos pontos de controle originalmente amostrados. Esses pontos nodais devem estar dispostos na forma de uma malha regular, pois esta é uma exigência de várias técnicas de representação de dados (mapas de contorno, imagens) e de inversão. Além disso, a malha resultante deve representar o campo num mesmo datum altimétrico, mesmo que as medidas tenham sido feitas em altitudes diferentes.

O problema de se interpolar satisfatoriamente dados do campo magnético numa malha regular a partir da distribuição original de pontos amostrados não é trivial. Particularmente no caso de dados aeromagnéticos, os pontos medidos encontram-se muito próximos uns dos outros ao longo de linhas paralelas entre si, as quais, por sua vez, estão distantes umas das outras. Este procedimento de amostragem faz com que a distribuição espacial das medidas do campo magnético seja altamente anisotrópica. Tendo em vista a grande quantidade de dados envolvida num único levantamento aeromagnético, e o elevado número de nodos da malha a ser gerada, alguns algoritmos para interpolação desse tipo de dado geralmente assumem um compromisso entre o rigor matemático necessário para se representar o campo magnético, e a economia conseguida no tempo de processamento computacional.

O campo magnético apresenta um conjunto de características que tentam ser reproduzidas por alguns métodos de interpolação: a técnica da curvatura mínima, por exemplo, faz uso do fato que o campo magnético é uma superfície suave; a técnica da krigagem faz uso de certas características estatísticas do campo amostrado e da sua continuidade; as técnicas que empregam fontes equivalentes valem-se do fato do campo magnético ser um campo harmônico. Outras técnicas de interpolação, como, por exemplo, a interpolação ponderada pelo inverso da distância ou a interpolação polinomial, são mais subjetivas e não fazem uso de qualquer propriedade da variável que está sendo interpolada. As malhas digitais geradas a partir de um mesmo conjunto de pontos de controle não são únicas: podem-se obter diferentes representações do campo magnético variando o método de interpolação ou alterando os parâmetros de ajuste de um mesmo método. Além disso, o emprego inadequado de um algoritmo de interpolação pode gerar feições irreais, que não têm qualquer significado físico (Krajewski \& Gibbs, 1994).

A malha digital gerada, independentemente do método de interpolação empregado, deve refletir o comportamento do campo magnético dentro de certos limites espectrais. Esses limites, definidos durante a fase de planejamento do levantamento, são determinados pelo espaçamento adotado entre medidas ao longo das linhas de vôo, pelo espaçamento entre as linhas de vôo, e pela altura do vôo com relação às fontes de magnetização. As malhas digitais geradas, portanto, 
não devem possuir um conteúdo espectral maior do que aquele permitido pelo espaçamento entre medidas e entre linhas de vôo. Além disso, elas devem representar os dados observados de modo contínuo e suave, assim como o é o campo magnético.

Nas próximas seções é feita a descrição das principais técnicas aplicadas à interpolação de dados aeromagnéticos em malhas regulares.

\subsection{Splines e Curvatura mínima}

Os interpoladores do tipo spline são funções suaves, que apresentam continuidade não só da função em si nos pontos amostrados, mas também das suas derivadas horizontais primeira e segunda. Casanova \& Alvarez (1985) classificam as funções de interpolação do tipo spline em três categorias: unidimensionais, quase-bidimensionais e estritamente bidimensionais. Para a interpolação de dados distribuídos irregularmente em $\mathbf{R}^{2}$ (plano cartesiano), apenas os dois últimos tipos são de interesse.

A base do método quase-bidimensional consiste em se obter uma superfície bidimensional, cúbica, a partir de splines unidimensionais. Considera-se que os dados amostrados encontram-se distribuídos irregularmente ao longo de linhas paralelas entre si, como ocorre no caso dos levantamentos aeromagnéticos, por exemplo. O método consiste em se aplicar, numa primeira etapa, splines cúbicos unidimensionais ao longo de cada linha, interpolando os dados em intervalos regulares nessa direção. A seguir, trabalhando com os pontos interpolados na etapa anterior, aplica-se um spline cúbico unidimensional na direção normal às linhas de vôo, gerando valores equi-espaçados dentro de uma malha, uma linha por vez. Como as linhas de vôo não são rigorosamente retas, nem tampouco paralelas entre si, os dados devem ser projetados sobre retas, ajustadas por mínimos quadrados às linhas de vôo, antes da primeira etapa de interpolação (Bhattacharyya, 1969).

Os splines estritamente bidimensionais foram introduzidos por Briggs (1974), e podem ser aplicados a dados que não obedecem a qualquer distribuição espacial preestabelecida. A solução encontrada por Briggs, chamada de curvatura mínima, é aquela que minimiza o funcional curvatura de uma função contínua $u$, dado por:

$$
C(u)=\iint\left(\frac{\partial^{2} u}{\partial x^{2}}+\frac{\partial^{2} u}{\partial y^{2}}\right)^{2} d x d y
$$

Como a solução encontrada também satisfaz a equação bi-harmônica:

$$
\frac{\partial^{4} u}{\partial x^{4}}+2 \frac{\partial^{4} u}{\partial x^{2} \partial y^{2}}+\frac{\partial^{4} u}{\partial y^{4}}=0
$$

as suas derivadas horizontais primeira e segunda também são contínuas. Escrevendo o funcional na forma discreta dentro de uma malha de dimensão $I \times J$, tem-se que: 


$$
C=\sum_{i=1}^{I} \sum_{j=1}^{j}\left(C_{i, j}\right)^{2}
$$

onde a curvatura da função no nó da malha de coordenadas $\left(x_{i}, y_{j}\right)$ é aproximada por diferenças finitas. Assim,

$$
C_{i, j}=\frac{\left(u_{i+1, j}+u_{i-1, j}+u_{i, j+1}+u_{i, j-1}-4 u_{i, j}\right)}{h^{2}}
$$

onde $h$ corresponde à distância entre dois nós consecutivos da malha, e $u_{i, j}$ é o valor da função num determinado nó. Para minimizar a curvatura total, tomam-se as derivadas de $(5.2 .3) \mathrm{com}$ relação ao valor da função em todos os nós, assim:

$$
\frac{\partial C}{\partial u_{i, j}}=0 \quad, \text { para } \mathrm{i}=1,2, \ldots, \mathrm{I} \text { e } \mathrm{j}=1,2, \ldots, \mathrm{J}
$$

Combinando as equações (5.2.3), (5.2.4) e (5.2.5) chega-se à relação:

$$
\begin{aligned}
& u_{i+2, j}+u_{i, j+2}+u_{i-2, j}+u_{i, j-2}+2\left(u_{i+1, j+1}+u_{i-1, j+1}+u_{i+1, j-1}+u_{i-1, j-1}\right) \\
& -8\left(u_{i+1, j}+u_{i-1, j}+u_{i, j-1}+u_{i, j+1}\right)+20 u_{i, j}=0
\end{aligned}
$$

para um nó situado no interior da malha. Expressões análogas a esta podem ser encontradas em Briggs (1974) para as situações em que os nós se encontram na borda da malha ou próximos a esta. O sistema de equações resultantes é esparso, pois apresenta tantas equações quantos forem os nós da malha, e cada equação relaciona um determinado nó $u_{i, j}$ a no máximo 12 nós vizinhos. Sistemas esparsos como este podem ser resolvidos de modo eficaz através de métodos iterativos. Se um ponto amostrado coincidir com um nó $u_{i, j}$ qualquer, então, ele terá o seu valor substituído diretamente na equação (5.2.6), caso contrário os valores dos nós são aproximados através de uma expansão em série de Taylor dos valores observados A solução assim determinada resulta na superfície mais suave possível que pode ser obtida para um dado espaçamento $h$ entre os nodos da malha.

\subsection{Fontes Equivalentes}

A representação de anomalias de campo potencial através de um conjunto de fontes equivalentes parte do princípio que as anomalias são funções harmônicas, ou seja, satisfazem a equação de Laplace. Considerando que as magnitudes das anomalias magnéticas de intensidade total são muito menores do que a magnitude do campo geomagnético, as mesmas podem ser consideradas como sendo harmônicas.

As técnicas desenvolvidas no sentido de se representar campos potenciais através de fontes equivalentes decorrem do trabalho de Dampney (1969), que determinou um conjunto de fontes pontuais, distribuídas num plano horizontal, para representar medidas de anomalia 
Bouguer amostradas numa superficie irregular. Uma desvantagem desse método é a necessidade de se resolver um sistema linear da ordem do número de dados observados para se obter os parâmetros das fontes. Isto impõe uma séria restrição computacional, uma vez que os levantamentos aeromagnéticos geralmente apresentam dezenas de milhares de observações do campo. Mendonça (1992) e Mendonça \& Silva (1994) otimizam o processo de determinação das fontes equivalentes, tornando o computacionalmente mais atraente. O princípio do método das fontes equivalentes consiste em se procurar determinar um conjunto de fontes pontuais cujo efeito conjunto representa os dados observados dentro de um certo limite preestabelecido. Uma vez determinada a localização e magnitude das fontes, calcula-se o seu efeito nas coordenadas dos nós da malha digital, e em qualquer datum, desde que externo às fontes. Assim sendo, as fontes equivalentes constituem-se de uma representação dos dados observados, que pode levar em conta os erros de observação, além de serem utilizadas na continuação de dados observados numa superficie irregular até um datum comum (Cordell, 1992; Xia et al., 1993).

A formulação apresentada a seguir é devida a Cordell (1992), e foi escolhida para exemplificar a aplicação do método devido à sua simplicidade.

Dado um conjunto de observações $f_{i}\left(x_{i}, y_{i}, z_{i}\right)$ procura se determinar um conjunto de fontes equivalentes $\left\{c_{n}\left(\xi_{n}, \eta_{n}, \zeta_{n}\right)\right\}$ tais que:

$$
\left|f_{i}\left(x_{i}, y_{i}, z_{i}\right)-\sum_{n=1}^{N} \frac{c_{n}}{\sqrt{\left(x_{i}-\xi_{n}\right)^{2}+\left(y_{i}-\eta_{n}\right)^{2}+\left(z_{i}-\zeta_{n}\right)^{2}}}\right|<\varepsilon
$$

onde $\left\{f_{i}\right\}$ representa o conjunto de observações discretas do campo magnético tomadas nos pontos $\left\{x_{i}, y_{i}, z_{i}\right\}, \varepsilon$ é o erro do ajuste, $\left\{c_{n}\right\}$ é a intensidade de fontes pontuais localizadas em $\left\{\xi_{n}, \eta_{n}, \zeta_{n}\right\}$. A função de interpolação, dada pelo termo dentro da somatória, assume a forma do potencial Newtoniano do ponto material. Devido à não unicidade da representação do campo, pode-se empregar derivadas verticais ou horizontais da função potencial, que também são harmônicas. O procedimento, iterativo, consiste em se associar uma fonte equivalente ao ponto de maior resíduo do conjunto de dados, remover o efeito dessa fonte do conjunto de dados, e repetir o processo até que seja atingido o erro máximo $\varepsilon$ preestabelecido para o ajuste ou que seja efetuado um determinado número de iterações.

As etapas envolvidas no processo são:

1. Encontrar o índice do maior valor $i_{m}$ tal que:

$$
f_{i_{m}}=\max \left\{\left|f_{i}\right|\right\}
$$

2. Impor que a primeira fonte equivalente, localizada diretamente sob este ponto, se ajuste a esse valor de anomalia. Assim, 


$$
f_{i_{m}}=\frac{c_{1}}{\left|z_{i_{m}}-\zeta_{1}\right|}
$$

deixando como incógnita apenas a profundidade em que se deseja localizar a fonte.

3. A profundidade da fonte equivalente é calculada como sendo proporcional à distância entre o ponto $i_{m}$ e o seu vizinho mais próximo. Assim,

$$
\zeta_{1}=a d_{i_{m}}
$$

onde $a$ é o fator de proporcionalidade, e

$$
d_{i_{m}}=\min \left\{\sqrt{\left(x_{i_{m}}-x_{n}\right)^{2}+\left(y_{i_{m}}-y_{n}\right)^{2}+\left(z_{i_{m}}-z_{n}\right)^{2}}\right\}
$$

para todo $n \neq i_{m}$. Desse modo, a localização e intensidade da fonte $c_{1}$ são definidos por:

$$
\begin{aligned}
& \xi_{1}=x_{i m} \\
& \eta_{1}=y_{i m} \\
& \zeta_{1}=a d_{i_{m}} \\
& c_{1}=f_{i_{m}}\left|z_{i_{m}}-\zeta_{1}\right|
\end{aligned}
$$

4. Remover o efeito da fonte equivalente de todo o conjunto de dados, formando

$$
\left\{f_{i, 2}\right\}=\left\{f_{i, 1}-\frac{c_{1}}{\sqrt{\left(x_{i}-\xi_{1}\right)^{2}+\left(y_{i}-\eta_{1}\right)^{2}+\left(z_{i}-\zeta_{1}\right)^{2}}}\right\}
$$

5. Encontrar $\max \left\{f_{i, 2}\right\}$, ajustar uma segunda fonte equivalente a este ponto, e remover o seu efeito sobre os demais.

O processo é repetido até que o erro máximo preestabelecido seja atingido ou que tenha transcorrido um determinado número de iterações, uma vez que tal procedimento não garante que haja convergência. Não existe critério definido para a escolha do fator de proporcionalidade a: um valor mais elevado força com que as fontes equivalentes se localizem a profundidades maiores, resultando numa filtragem passa-baixa; valores menores de $a$, fazendo com que as fontes se localizem mais próximas à superfície, podem amplificar os ruídos de alta frequêencia presentes nos dados (Xia \& Sprowl, 1991). Para contornar tal problema, Cordell (1992), sugere que o ajuste das fontes equivalentes não seja feito em função de $\max \left\{\left|f_{i}\right|\right\}$, mas sim dentro de um envelope no entorno do maior resíduo, ou seja, em torno de max $\left\{f_{i}\right\} \pm \varepsilon$. Desse modo, levam-se em conta não só os erros a que as medidas estão sujeitas, mas também efetua-se a filtragem não linear dos dados. 
(a)

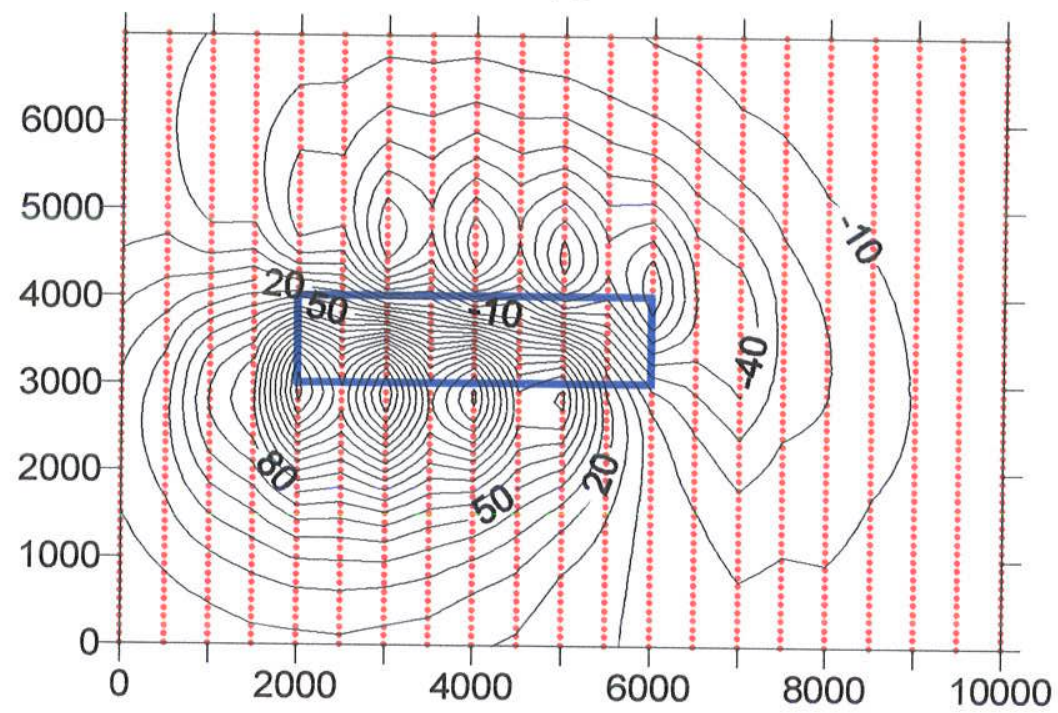

(b)

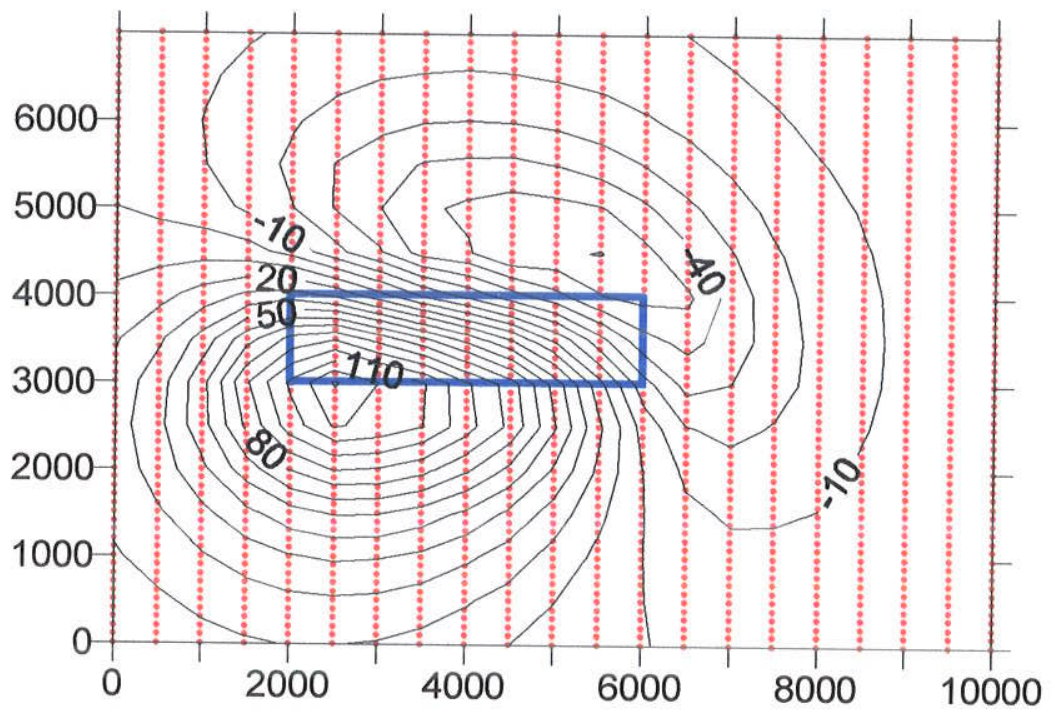

(c)

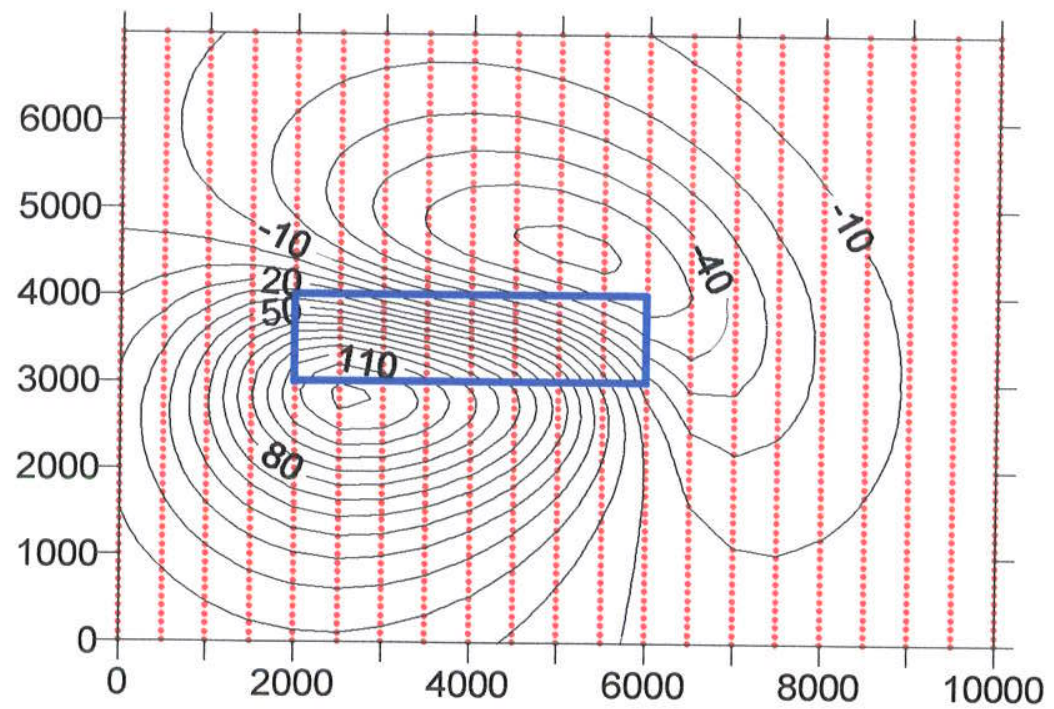

Figura 5.1 - Aplicação de fontes equivalentes ao nivelamento de dados aeromagnéticos. Intervalo de contorno $10 \mathrm{nT}$, coordenadas em metros. Corpo fonte prismático em azul. Pontos de medida de anomalia em vermelho.

(a) mapa de contorno obtido a partir de linhas de vôo desniveladas $(1,0$ e 1,3 km acima do topo do prisma); (b) anomalias niveladas através de fontes equivalentes, datum 1,3 km; (c) anomalia teórica para todas as linhas a 1,3 km acima do prisma. 
As fontes equivalentes têm a sua principal aplicação na interpolação de dados potenciais que não foram medidos no mesmo datum, como é o caso dos levantamentos aeromagnéticos que acompanham a topografia. A continuação dessas medidas para um mesmo datum reduz a influência da topografia sobre o sinal (Grauch \& Campbell, 1984; Naidu \& Mathew, 1998), e pode substituir com vantagens as técnicas tradicionais de nivelamento magnético.

A Figura 5.1 exemplifica a aplicação desta técnica ao nivelamento e interpolação 3-D de dados aeromagnéticos. A anomalia magnética foi calculada para um prisma de dimensões $4 \times 1 \times 1 \mathrm{~km}$, cuja magnetização é de 0,003 oersteds. Foram simuladas medidas a cada $100 \mathrm{~m}$, ao longo de linhas de vôo equi-espaçadas de $500 \mathrm{~m}$. A altura das linhas de vôo foi variada alternadamente, de modo que elas se encontram a 1,0 ou 1,3 km acima do topo do prisma. Variações desta ordem, $30 \%$ da altura nominal sobre o terreno, são freqüentemente encontradas em levantamentos aeromagnéticos. A Figura 5.1a corresponde ao mapa de contorno, obtido a partir das medidas desniveladas. A Figura 5.1 b corresponde ao mapa obtido ao se ajustar um conjunto de fontes equivalentes aos dados observados e continuá-los até um mesmo datum $(1,3 \mathrm{~km}$ acima do topo do prisma). A Figura $5.1 \mathrm{c}$ corresponde à anomalia teórica que seria observada se todas as linhas de vôo fossem executadas no mesmo nível, a $1,3 \mathrm{~km}$ acima do prisma. A aplicação das fontes equivalentes resulta, portanto, num mapa de contorno livre dos efeitos devidos à variação da altura das linhas de vôo.

\subsection{A KRIGAGEM}

A krigagem é um procedimento de estimativa originado a partir da teoria das variáveis regionalizadas, e que foi desenvolvido por geoestatísticos cujo objetivo era a avaliação de jazidas. A teoria das variáveis regionalizadas, desenvolvida por Matheron (1970) apud Olea (1974), procura determinar a correlação espacial entre variáveis aleatórias dependentes chamadas de variáveis regionalizadas. Uma variável regionalizada é aquela cujo comportamento se situa entre o de uma variável determinística e o de uma variável estocástica (Olea, 1975). A variável regionalizada pode ser entendida como tendo uma natureza determinística dentro de regiões de pequenas dimensões, passando a ter um comportamento crescentemente aleatório com o aumento da região. Entretanto, o caráter determinístico da variável regionalizada não pode ser expresso por qualquer função matemática.

Ao contrário de outras técnicas de interpolação, a krigagem não resulta numa função analítica que pode ser avaliada num intervalo no entorno de um ponto $\vec{x}_{0}$. A krigagem fornece uma estimativa, o valor mais provável que a variável regionalizada pode assumir no ponto $\vec{x}_{0}$. Ao contrário dos outros métodos de interpolação, que só fornecem uma estimativa do valor interpolado, a krigagem também fornece o intervalo de confiança associado ao processo de
interpolação.

A krigagem é um procedimento de interpolação ponderada. Nesse sentido, o valor estimado $Z_{\mathfrak{c}}(\vec{x})$ da variável regionalizada $Z(\vec{x})$ é dado por:

$$
Z_{e}\left(\vec{x}_{0}\right)=\sum_{i=1}^{N} w_{i} Z\left(\vec{x}_{i}\right)
$$


onde $\vec{x}_{0}$ corresponde ao ponto a ser interpolado, $Z\left(\ddot{x}_{i}\right)$ são $N$ pontos de controle dentro de um raio $r$ no entorno do ponto a ser estimado, e $w_{i}$ são os pesos a serem determinados. A krigagem se preocupa, portanto, em determinar os valores dos ponderadores $w_{i}$ que serão empregados na
interpolação.

A medida do grau de continuidade de uma variável regionalizada $Z(\vec{x})$ é dada pela função semivariograma $\gamma(\overrightarrow{\mathrm{h}})$. Experimentalmente, o semivariograma $\gamma(\overrightarrow{\mathrm{h}})$ de uma variável regionalizada é calculado a partir de amostras tomadas a intervalos regulares ao longo de linhas
ou perfis. Desse modo:

$$
\gamma(\vec{h})=\frac{1}{2 n} \sum_{k=1}^{n}\left(Z\left(\ddot{x}_{k}\right)-Z\left(\vec{x}_{k}+\vec{h}\right)\right)^{2}
$$

onde $\gamma(\vec{h})$ é a semivariância para a distância $\vec{h}, n$ corresponde ao número de pares de amostras tomadas a intervalos regulares iguais a $\vec{h}$.

O semivariograma (Figura 5.2a), ou gráfico da função semivariância $\gamma(\vec{h})$ versus a distância $\vec{h}$, contém toda a informação estrutural sobre a variável regionalizada: o tamanho da zona de influência em torno da amostra; a natureza isotrópica ou anisotrópica da variável regionalizada; a continuidade espacial da variável (Olea, 1975; Journel \& Huijbregts, 1978).

O patamar corresponde ao valor da variância na qual o semivariograma se estabiliza. A amplitude corresponde à distância dentro da qual as amostras são espacialmente correlacionadas entre si (Figura 5.2a). Todas as amostras cujas distâncias ao ponto a ser interpolado são menores ou iguais a $\vec{L}$ fornecem informação sobre o ponto. Todas as amostras fora da vizinhança definida por $\vec{L}$ são observações espacialmente independentes com relação ao ponto a ser interpolado e devem ser descartadas, uma vez que elas não fornecem qualquer informação a respeito do ponto. Matematicamente, a amplitude é definida como a menor distância $\vec{L}$ para a qual a diferença entre a semivariância e a variância da variável regionalizada é considerada desprezível. Assim, $\ddot{L}$ corresponde à menor distância para a qual (Olea, 1974):

$$
\operatorname{var}(Z(\vec{x}))-\gamma(\vec{L}) \leq \varepsilon
$$

onde $\varepsilon$ é um número pequeno. O efeito pepita corresponde ao valor do semivariograma próximo à origem, ou seja, para $\vec{h} \cong 0$. Teoricamente esse valor é igual a zero, pois duas amostras medidas no mesmo ponto têm valores idênticos. Contudo, quando se observa a existência do efeito pepita, ele é atribuido a erros de amostragem ou análise.

A anisotropia é revelada pelo comportamento distinto do semivariograma, quando este é calculado segundo direções de amostragem diferentes, quer quanto à sua forma ou quanto ao raio de influência (Figura 5.2b). Assim, a semivariância depende não só do espaçamento entre amostras, mas também da sua orientação. Quando a variável regionalizada é isotrópica, o 
(a)

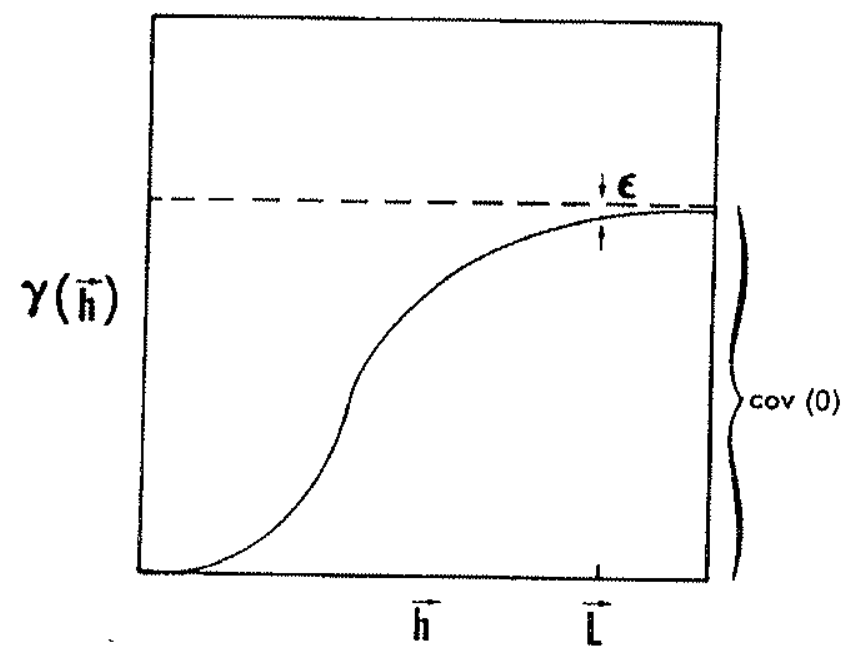

(c)

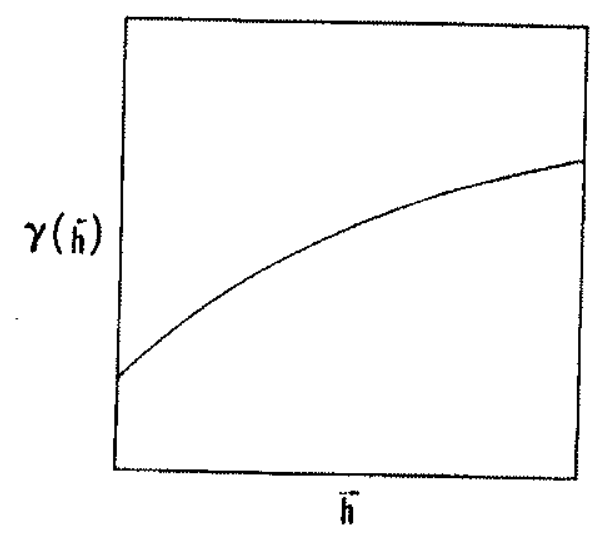

(b)

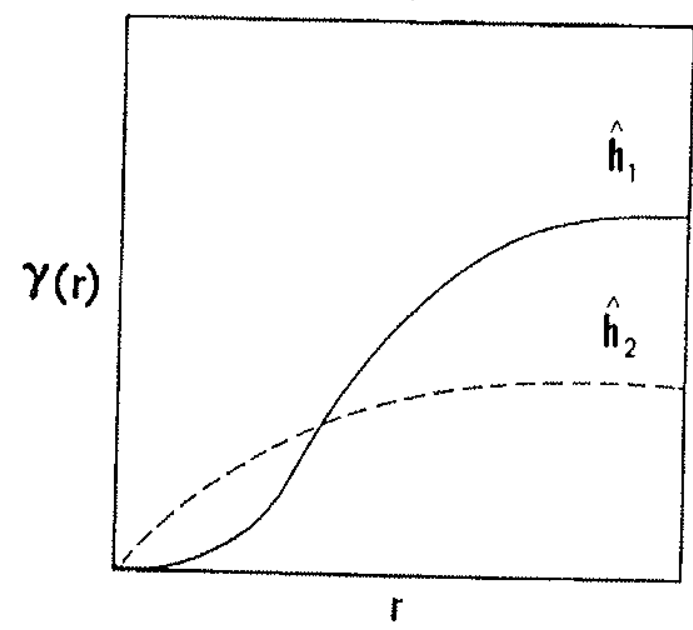

(d)

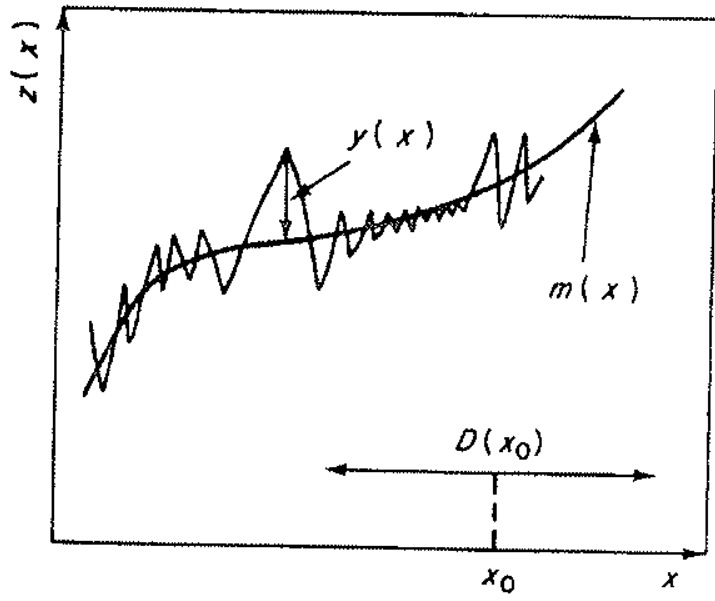

Figura 5.2 - Exemplos de semivariogramas: (a) ideal com zona de influência L (Olea, 1975), (b) apresentando anisotropia segundo duas direç̃os (Olea, 1975), (c) efeito pepita (Olea, 1975); (d) exemplo de uma variável regionalizada apresentando deriva (Journel \& Huijbregts, 1978). 
semivariograma não depende da orientação, e a semivariância pode ser escrita como $\gamma(h)$, ou seja, dependendo apenas da distância. Quando existe anisotropia, o semivariograma depende também da orientação, nesse caso, a semivariância é escrita como $\gamma(\vec{h})$.

A continuidade da variável regionalizada é caracterizada pelo comportamento do semivariograma próximo à origem (Figura 5.2c). Quando ele descreve uma curva parabólica próximo à origem, é indicativo de uma variável regionalizada com alto grau de continuidade (Yamamoto, 2001). Se o semivariograma for caracterizado por um comportamento linear próximo à origem, a variável regionalizada possui uma continuidade média, ou seja, as amostras possuem uma homogeneidade elevada para pequenas distâncias e uma perda progressiva de homogeneidade conforme a distância aumenta. Semivariogramas que não tendem a zero quando a distância $\vec{h}$ tende a zero, podem ser interpretados como indicativos da presença de ruído branco (ruído gaussiano não correlacionado) contaminando a variável regionalizada. Essa descontinuidade do semivariograma próximo à origem é chamada de efeito pepita.

A krigagem está fundamentada, além da análise do semivariograma, em dois conceitos: o de estacionariedade e o da deriva. Uma variável regionalizada $Z(\vec{x})$ é dita estacionária dentro de um dado domínio $D$, se:

$$
\int_{D} Z(\vec{x}) d \vec{x}=0
$$

A deriva $m(\ddot{x})$ da variável regionalizada num ponto $\vec{x}$ é definida como sendo a esperança matemática da variável regionalizada $Z(\vec{x})$ no ponto $\vec{x}$. Desse modo:

$$
m(\vec{x})=E(Z(\vec{x}))
$$

Fisicamente, a deriva representa a tendência local da função sobre o espaço, não devendo conter informação de detalhe sobre a mesma, Figura 5.2d, (Journel \& Huijbregts, 1978). Definese, ainda, o resíduo $Y(\vec{x})$ como sendo a diferença entre a variável regionalizada $Z(\vec{x})$ e a deriva $m(\vec{x})$, calculada no ponto $\vec{x}$.

$$
Y(\vec{x})=Z(\vec{x})-m(\vec{x})
$$

Pode-se mostrar que $E(Y(\vec{x}))=0$. Esta é uma propriedade importante dos resíduos, uma vez que é a partir deles que se obtém os semivariogramas. Como a deriva varia continua e suavemente, $m(\vec{x})$ pode, pelo menos localmente, ser aproximada por uma expressão analítica da forma:

$$
m(\vec{x})=\sum_{i=1}^{M} \lambda_{i} f^{i}(\vec{x})
$$


onde $\lambda_{i}$ são incógnitas e $f^{i}(\vec{x})$ são funções arbitrárias de $\vec{x}$. A deriva geralmente é representada na forma de um polinômio de primeiro ou segundo grau no entorno do ponto a ser interpolado, desse modo, as funções $f^{i}(\vec{x})$ são potências de $\vec{x}$ (Olea, 1975).

$O$ procedimento da krigagem, conforme mencionado anteriormente, consiste em se calcular os ponderadores $w_{i}$ da equação (5.4.1) e aplicá-los aos $N$ pontos de controle $Z\left(\vec{x}_{i}\right)$ que se situam dentro de um raio $\mathbf{r}$ no entorno do ponto $\vec{x}_{0}$ a ser estimado. $O$ raio $\mathbf{r}$ é tomado como sendo igual à distância $\vec{L}$ (equação (5.4.3)), obtida a partir do semivariograma. Impondose que a estimativa não é tendenciosa e que a variância do erro de estimativa é mínima (Olea, 1975; Journel \& Huijbregts, 1978), chega-se à equação matricial a seguir, cuja solução fornece os ponderadores $w_{i}$ :

$$
\left[\begin{array}{ccccccccc}
\gamma\left(\vec{h}_{11}\right) & \gamma\left(\vec{h}_{12}\right) & \ldots & \gamma\left(\vec{h}_{1 N}\right) & 1 & f^{\prime}\left(\vec{x}_{1}\right) & f^{2}\left(\vec{x}_{1}\right) & \ldots & f^{M}\left(\vec{x}_{1}\right) \\
\gamma\left(\vec{h}_{21}\right) & \gamma\left(\vec{h}_{22}\right) & \ldots & \gamma\left(\vec{h}_{2 N}\right) & 1 & f^{\prime}\left(\vec{x}_{2}\right) & f^{2}\left(\vec{x}_{2}\right) & \ldots & f^{M}\left(\vec{x}_{2}\right) \\
\ldots & \ldots & \ldots & \ldots & \ldots & \ldots & \ldots & \ldots & \ldots \\
\gamma\left(\vec{h}_{N 1}\right) & \gamma\left(\vec{h}_{N 2}\right) & \ldots & \gamma\left(\vec{h}_{N N}\right) & 1 & f^{1}\left(\vec{x}_{N}\right) & f^{2}\left(\vec{x}_{N}\right) & \ldots & f^{M}\left(\vec{x}_{N}\right) \\
1 & 1 & \ldots & 1 & 0 & 0 & 0 & \ldots & 0 \\
f^{\prime}\left(\vec{x}_{1}\right) & f^{\prime}\left(\vec{x}_{2}\right) & \ldots & f^{1}\left(\vec{x}_{N}\right) & 0 & 0 & 0 & \ldots & 0 \\
f^{2}\left(\vec{x}_{1}\right) & f^{2}\left(\vec{x}_{2}\right) & \ldots & f^{2}\left(\vec{x}_{N}\right) & 0 & 0 & 0 & \ldots & 0 \\
\ldots & \ldots & \ldots & \ldots & \ldots & \ldots & \ldots & \ldots & \ldots \\
f^{M}\left(\vec{x}_{1}\right) & f^{M}\left(\vec{x}_{2}\right) & \ldots & f^{M}\left(\vec{x}_{N}\right) & 0 & 0 & 0 & \ldots & 0
\end{array}\right]\left[\begin{array}{c}
w_{1} \\
w_{2} \\
\ldots \\
w_{N} \\
\lambda_{0} \\
\lambda_{1} \\
\lambda_{2} \\
\ldots \\
\lambda_{M}
\end{array}\right]=\left[\begin{array}{c}
\gamma\left(\vec{h}_{10}\right) \\
\gamma\left(\vec{h}_{20}\right) \\
\ldots \\
\gamma\left(\vec{h}_{N 0}\right) \\
1 \\
f^{1}\left(\vec{x}_{0}\right) \\
f^{2}\left(\vec{x}_{0}\right) \\
\ldots \\
f^{M}\left(\vec{x}_{0}\right)
\end{array}\right]
$$

onde

$\gamma\left(\vec{h}_{i j}\right)$ é a semivariância dos resíduos estimados, calculada para a distância $\vec{h}_{i j}=\left(\vec{x}_{i}-\vec{x}_{j}\right)$ entre o i-ésimo e o j-ésimo pontos de controle;

$\gamma\left(\vec{h}_{i 0}\right)$ é a semivariância dos resíduos estimados, calculada para a distância $\vec{h}_{i 0}=\left(\vec{x}_{i}-\vec{x}_{0}\right)$ entre o i-ésimo ponto de controle e o ponto $\vec{x}_{0}$ a ser estimado;

$f^{i}\left(\vec{x}_{j}\right)$ é o i-ésimo termo da deriva (equação (5.4.7)), $1 \leq i \leq M$, calculado para o j-ésimo ponto de controle $\vec{x}_{j}$ ou para o ponto $\vec{x}_{0}$ a ser interpolado;

$\lambda_{0}$ é o multiplicador de Lagrange, que garante que a soma $\operatorname{dos} N$ pesos $w_{i}$ é unitária;

$\lambda_{i}$ são as incógnitas da equação (5.4.7).

Uma vez obtidos os ponderadores $w_{i}$, aplica-se a equação (5.4.1) aos $N$ pontos de controle que se situam dentro de um raio $\mathbf{r}$ no entorno do ponto $\vec{x}_{0}$ a ser estimado. Na situação em que vale o sistema (5.4.8), ou seja, a variável regionalizada apresenta deriva, a krigagem é chamada de krigagem universal. 
Escrevendo-se o sistema (5.4.8) na forma $C . V=F$, pode-se calcular a variância do erro de interpolação da variável regionalizada no ponto $\vec{x}_{0}$. Assim, tem-se que a variância do erro de interpolação é dada por (Olea, 1975):

$$
\operatorname{var}\left(Z_{e}\left(\ddot{x}_{0}\right)-Z\left(\vec{x}_{0}\right)\right)=V^{T} F
$$

onde $Z_{e}\left(\vec{x}_{0}\right)$ é o valor interpolado da variável regionalizada, segundo a equação (5.4.1), no ponto $\vec{x}_{0}$, e $Z\left(\vec{x}_{0}\right)$ é o valor verdadeiro, mas desconhecido, da variável regionalizada em $\vec{x}_{0}$.

Quando a variável regionalizada a ser interpolada é estacionária de segunda ordem e livre de deriva, krigagem recebe a denominação de krigagem ordinária, e aplica-se a equação
$(5.4 .10)$ para obter os ponderadores $w_{i}$ :

$$
\left[\begin{array}{ccccc}
\gamma\left(\vec{h}_{11}\right) & \gamma\left(\vec{h}_{22}\right) & \ldots & \gamma\left(\vec{h}_{1 N}\right) & 1 \\
\gamma\left(\vec{h}_{21}\right) & \gamma\left(\vec{h}_{22}\right) & \ldots & \gamma\left(\vec{h}_{2 N}\right) & 1 \\
\ldots & \ldots & \ldots & \ldots & \ldots \\
\gamma\left(\vec{h}_{N 1}\right) & \gamma\left(\vec{h}_{N 2}\right) & \ldots & \gamma\left(\vec{h}_{N N}\right) & 1 \\
1 & 1 & \ldots & 1 & 0
\end{array}\right] \cdot\left[\begin{array}{c}
w_{1} \\
w_{2} \\
\ldots \\
w_{N} \\
\lambda_{0}
\end{array}\right]=\left[\begin{array}{c}
\gamma\left(\vec{h}_{10}\right) \\
\gamma\left(\vec{h}_{20}\right) \\
\ldots \\
\gamma\left(\vec{h}_{N 0}\right) \\
1
\end{array}\right]
$$

Uma vez que a deriva é igual a zero, a semivariância $\gamma\left(\vec{h}_{i j}\right)$ na equação (5.4.10) é obtida a partir do semivariograma da variável regionalizada $Z\left(\vec{x}_{i}\right), 1 \leq i \leq N$, e não a partir dos resíduos.

Vários são os argumentos favoráveis à aplicação da krigagem para a interpolação de dados (Olea, 1975; Journel \& Huijbregts, 1978):

- a krigagem é um procedimento de interpolação exato, ou seja, $Z_{e}\left(\vec{x}_{i}\right)=Z\left(\vec{x}_{i}\right)$ (desde que não haja efeito pepita);

- a variância do erro de estimativa é mínima;

- a estimativa não é tendenciosa, ou seja, na média o erro de interpolação é zero;

- não existe o critério subjetivo de escolha dos pontos de controle que devem fazer parte da interpolação, uma vez que a krigagem utiliza apenas pontos de controle que se situam dentro do raio de influência no entorno do ponto a ser estimado;

- a krigagem fornece uma estimativa da variância do erro de interpolação.

Como a krigagem é um procedimento de interpolação extremamente dependente da forma do semivariograma, principalmente quando há anisotropia, a adoção de um modelo impróprio de semivariograma pode ser prejudicial. Isto fica claro ao se comparar os resultados obtidos por Hansen (1993), que ao processar um levantamento aeromagnético conduzido sobre o mar, na área da Cordilheira Juan de Fuca, empregou a curvatura mínima (Figura 5.3a) e dois modelos de krigagem: o primeiro isotrópico (Figura 5.3b), e o segundo anísotrópico (Figura 5.4a). Fica evidente que o modelo anisotrópico, além de eliminar as anomalias centradas sobre as linhas de vôo presentes nos mapas gerados pela curvatura mínima e krigagem isotrópica, tornou mais claros os lineamentos magnéticos, realçando a continuidade das anomalias entre as 
(a)

$128^{\circ} 30^{\circ} \mathrm{W}$

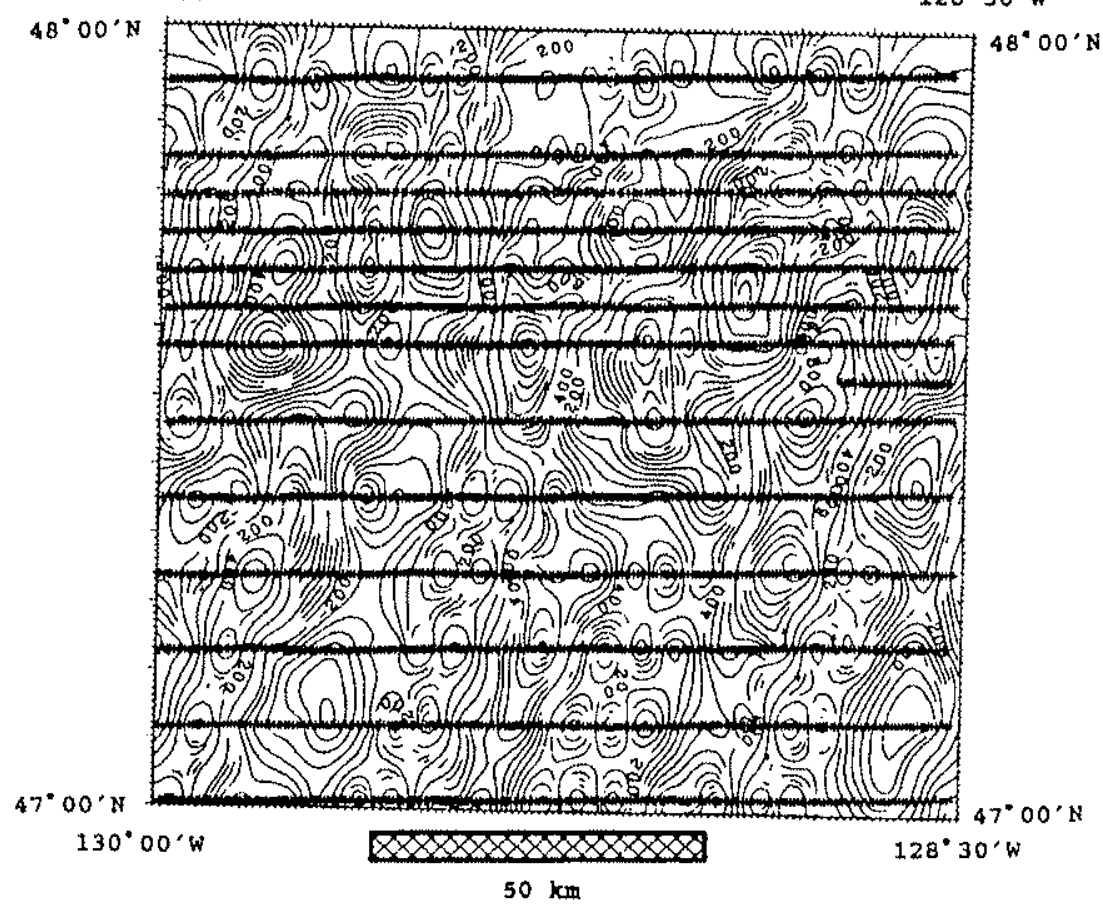

(b)

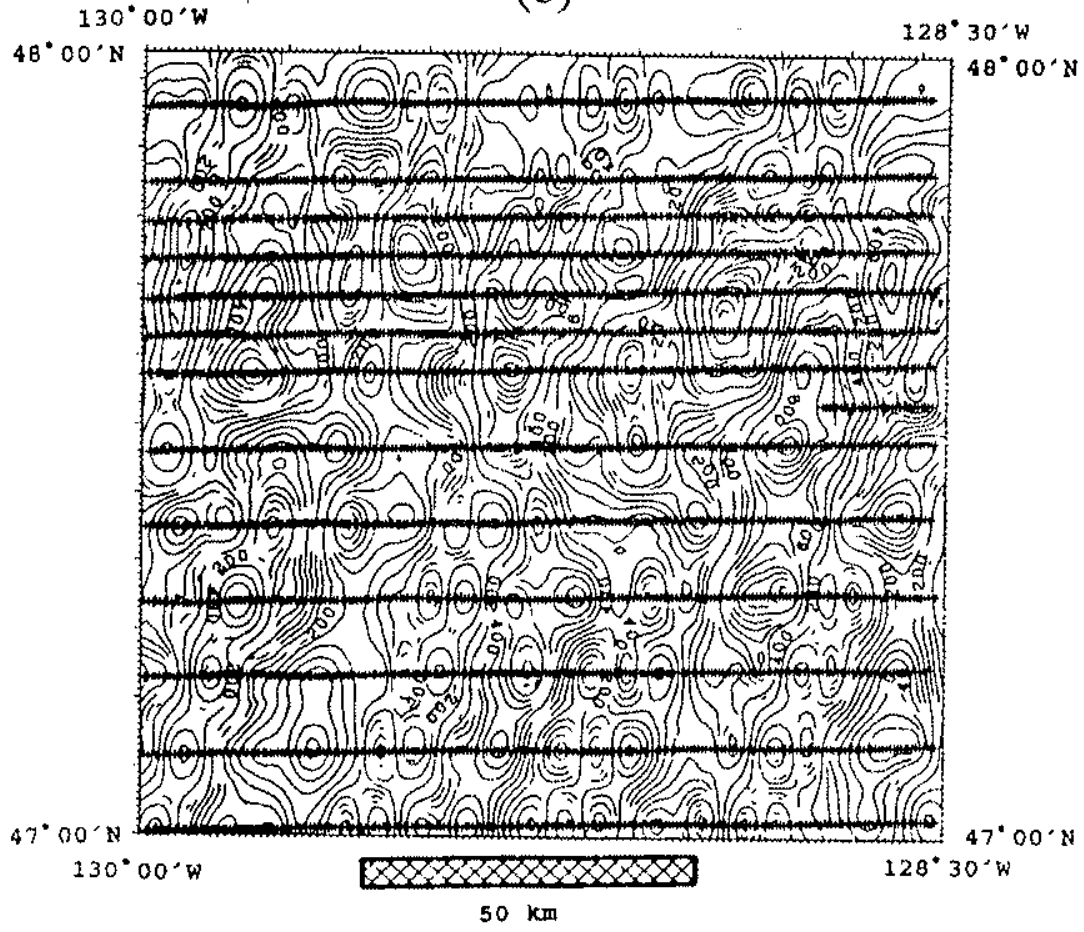

Figura 5.3 - Dados aeromagnéticos processados por Hansen (1993) empregando: (a) curvatura mínima; (b) krigagem isotrópica. 


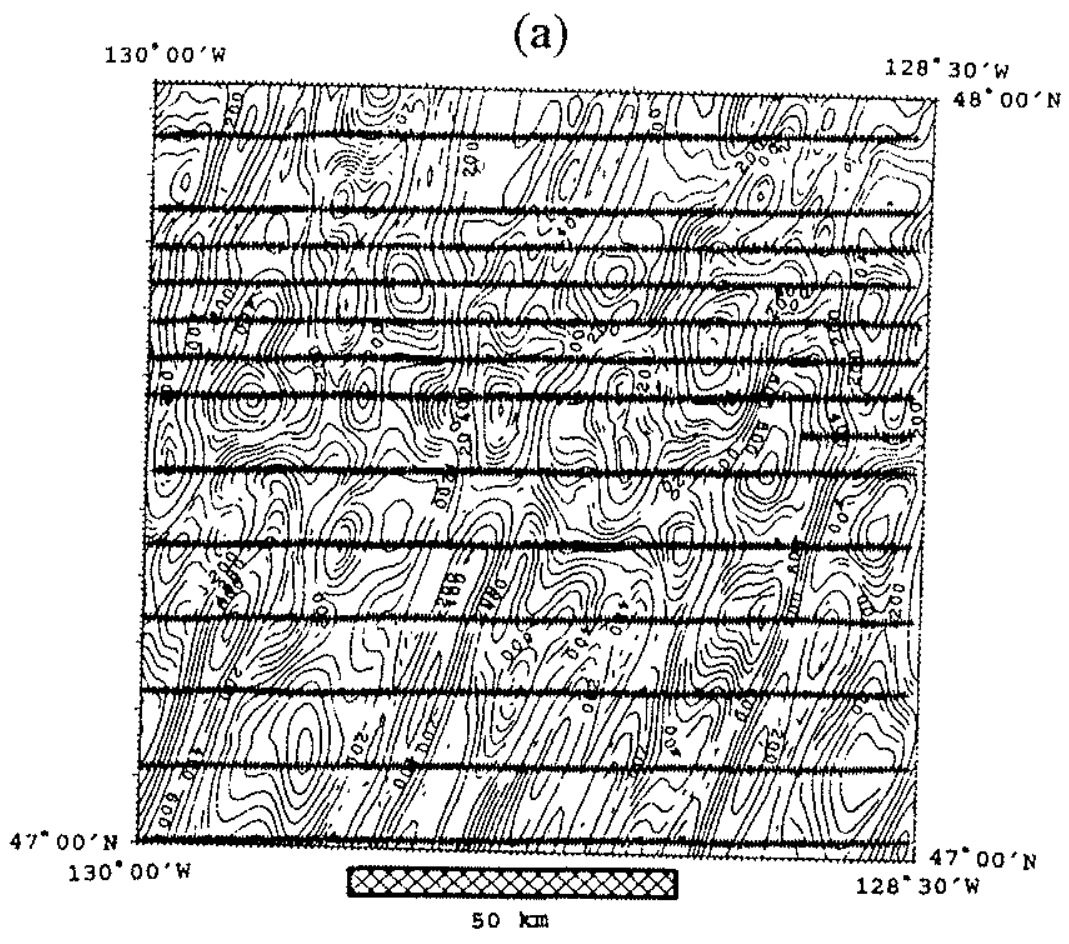

(b)

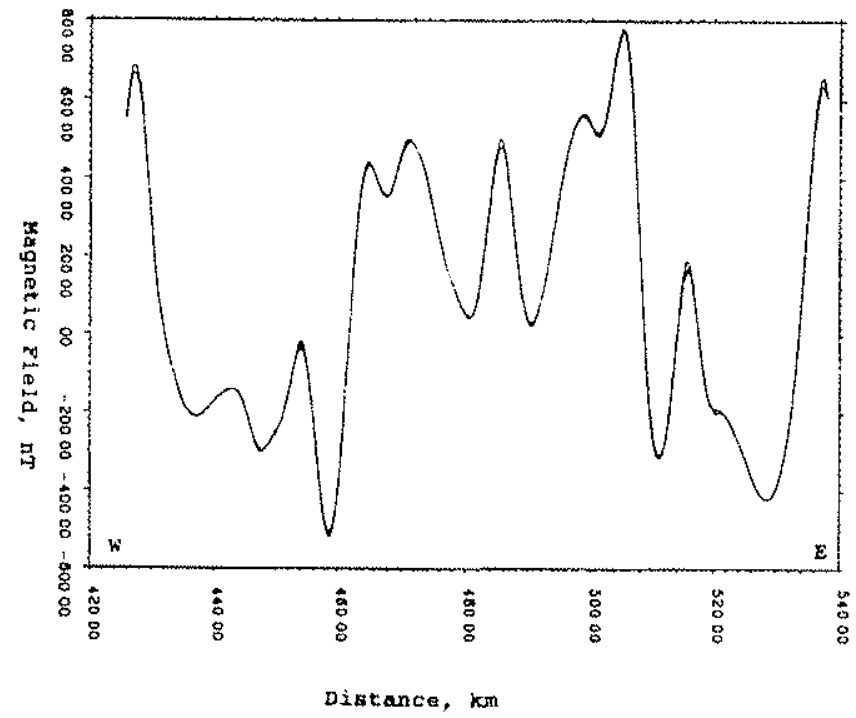

Figura 5.4 - Dados aeromagnéticos processados por Hansen (1993) empregando (a) krigagem anisotrópica; (b) perfis interpolados com curvatura mínima e krigagem anisotrópica sobrepostos a uma linha de vôo. 
linhas de vôo. Hansen (1993), também destaca que os resultados obtidos diferem entre si apenas nos locais onde não há dados amostrados. Ao comparar um perfil medido com aqueles obtidos através da interpolação por curvatura mínima e krigagem anisotrópica (Figura 5.4b) fica evidente que ambos os métodos respeitam os dados observados, onde estes existem. Curiosamente, apesar desse autor ter considerado os resultados obtidos através da krigagem anisotrópica como sendo superiores àqueles obtidos através dos outros métodos de interpolação, Hansen \& Simmonds (1993), em um trabalho posterior, efetuam a interpretação geofísica dessa região utilizando as malhas digitais interpoladas pela curvatura mínima, e não pela krigagem anisotrópica, como era de se esperar.

\subsection{O ALGORITMO BIGRID}

Um outro procedimento de interpolação, criado para ser aplicado a dados aeromagnéticos, é o Bigrid. Desenvolvido pela Paterson, Grant \& Watson, companhia de geofísica canadense, tal procedimento tem tido ampla aceitação devido à sua simplicidade e qualidade dos resultados obtidos (Lewis, 1993; Barritt, 1993; Anjos \& Mourão, 1988).

A Figura 5.5 exemplifica a seqüência de três etapas envolvidas no procedimento, descritas a seguir:

1. Estabelece-se o espaçamento entre os nós da malha digital, de tal modo que as linhas e colunas da malha sejam aproximadamente paralelas aos perfis de controle e de produção, respectivamente.

2. Trabalhando ao longo das linhas de produção, determina-se o valor da anomalia magnética na intersecção das linhas de vôo com as linhas da malha através da interpolação linear de duas fiduciais consecutivas.

3. Os pontos de intersecção, calculados na etapa 2, são interpolados ao longo das linhas da malha, gerando um valor para cada nó da malha. Esta interpolação é feita utilizando-se splines do tipo cúbico ou de Akima (Akima, 1970).

Dentre todos os procedimentos apresentados, este é o mais rápido. Os resultados obtidos com a sua aplicação são satisfatórios, embora os perfis de controle não sejam empregados na interpolação. Contudo, deve-se ter atenção especial na fase de pré-processamento dos dados, principalmente no que diz respeito ao nivelamento dos perfis de produção e à homogeneização espectral. O Bigrid é o procedimento de interpolação de dados que foi adotado pela CPRM para produzir as malhas digitais dos levantamentos PASPRJ e PAESB, e por (Barritt, 1993) na confeç̧ão do mapa de anomalias magnéticas do continente africano.

\subsection{Geração das Malhas dos projetos}

Diversos têm sido os autores que processaram os dados dos projetos aerogeofísicos PASPRJ (Anjos \& Mourão (1988); Ferreira (1991)) e PAESB (Anjos \& Mourão (1987); Costa et al. (1990)). Todos eles apresentam duas características em comum: em primeiro lugar, empregaram o algoritmo Bigrid para a interpolação da malha digital; em segundo lugar, procederam uma filtragem, para evitar a contaminação espectral da malha, que se considera ser 

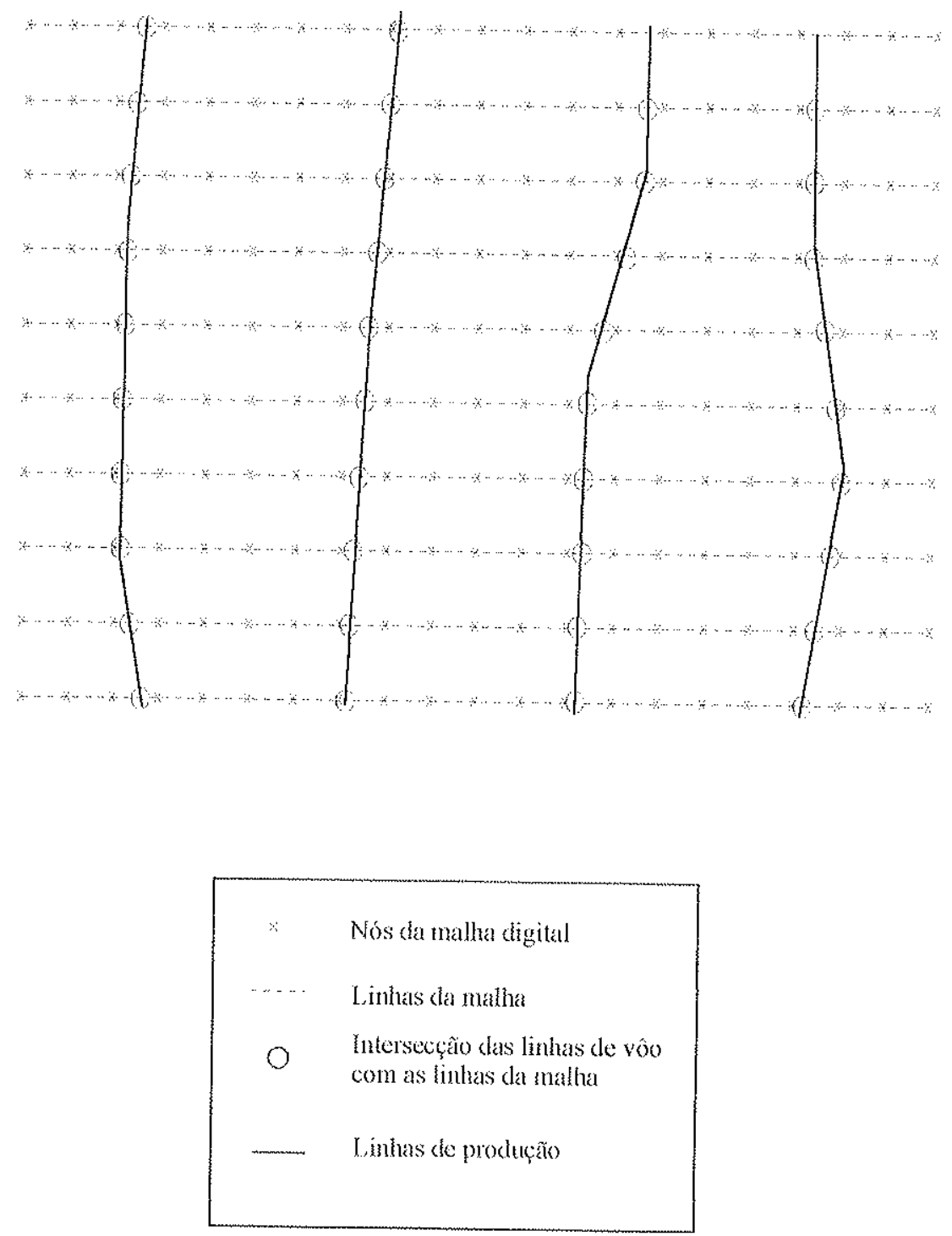

Figura 5.5 - Representação esquemática das etapas envolvidas no algoritmo Bigrid de interpolação de malhas digitais. 
inadequada para atenuar a contaminação espectral. Quanto ao PASMS, não se tem nenhuma informação (Geofoto 1978a; Geofoto, 1978b) a respeito dos métodos empregados na geração da sua malha digital.

Anjos \& Mourão (1987) descrevem do seguinte modo os parâmetros empregados na interpolação dos dados do Projeto Extremo Sudeste do Brasil:

"... Neste projeto os principais parâmetros de controle para a geração do "grid" foram:

a) Tamanho da célula do "grid" $=250 \times 250 \mathrm{~m}$

b) Direção das linhas do "grid" = paralelo ao eixo dos $X$

c) Freqüencia de corte para ofiltro anti-aliazamento $=0,002$

d) Interpolação linear ao longo das linhas de vôo

e) Interpolação tipo "akima" ao longo das linhas do "grid"... "

Costa et al. (1990), ao processarem os dados do mesmo Projeto Extremo Sudeste do Brasil, citam que:

"... foi gerado um grid com células de dimensões $500 \times 500 \mathrm{~m}$. Precedendo à determinação dos valores para cada um dos "nós" do grid foi aplicado um filtro antialiasamento aos dados de cada linha de vôo, consistindo de filtragem não linear com freqüência de corte de 0,001 ciclo/metro, função da dimensão das células."

Analogamente ao que haviam feito em 1987 com o PAESB, Anjos \& Mourão (1988) descrevem do seguinte modo os parâmetros empregados na interpolação dos dados do projeto São Paulo/Rio de Janeiro:

"... Neste projeto os principais parâmetros de controle para a geração do "grid" foram:

a) Tamanho da célula do "grid" $=250 \times 250 \mathrm{~m}$

b) Direção das linhas do "grid" = paralelo ao eixo dos $X$

c) Freqüencia de corte para ofiltro anti-aliazamento $=0,002$ ciclos/unidade de amostragem

d) Interpolação linear ao longo das linhas de vôo

e) Interpolação tipo "akima" ao longo das linhas do "grid" ... "

Nesse mesmo sentido, Ferreira (1991), ao processar os dados da subárea 6 do Projeto São Paulo/Rio de Janeiro, descreve do seguinte modo os parâmetros empregados para se gerar a malha:

" - tamanho da célula - $250 \times 250 \mathrm{~m}$;

- direção das linhas da malha - paralela ao eixo $x$;

- freqüencia de corte do filtro anti alias - 0,002 ciclo/unidade de amostragem;

- interpolação linear ao longo das linhas de vôo;

- interpolação do tipo Akima Spline ortogonal às linhas de vôo; "

Pode-se estar incorrendo em grave erro ao se utilizar as malhas digitais processadas segundo as formas descritas anteriormente, pois os levantamentos contêm uma parcela importante de energia concentrada na porção do espectro associada às altas freqüuencias. Na Figura 5.6 estão representados os espectros de potência de cada uma das subáreas dos 
levantamentos PASPRJ (Figura 5.6a) e PAESB (Figura 5.6b). Estes espectros foram calculados ao se tomar a média dos espectros de potência das linhas de vôo que se localizam dentro de cada uma das subáreas. Conforme descrito na seção 3.6 (Homogeneização Espectral), a freqüência de corte que deve ser aplicada às linhas de vôo antes da geração da malha digital é função única e exclusiva do espaçamento entre as linhas de vôo e independe das dimensões das células da malha. Como o espaçamento entre linhas de vôo é igual a $1 \mathrm{~km}$ para todos os levantamentos, vide Tabela 1, a freqüência de corte do filtro passa-baixa a ser aplicado às linhas de vôo deve ser igual a $f_{N l}=0,5 \mathrm{ciclos} / \mathrm{km}$, o que equivale a $0,0005 \mathrm{ciclos} / \mathrm{m}$.

Anjos \& Mourão (1988) e Ferreira (1991) empregam uma freqüência de corte igual a $2,0 \mathrm{ciclos} / \mathrm{km}$ para filtrar as linhas de vôo do PASPRJ. Desse modo, durante a geração da malha digital, as componentes em freqüência localizadas no intervalo que vai de $f_{N l}$ até 2,0 ciclos $/ \mathrm{km}$ vão distorcer as componentes de frequiencia mais baixa, menores do que $f_{N l}$. No caso do PAESB, Costa et al. (1990) ao empregarem uma freqüência de corte igual a 1,0 ciclo/ $/ \mathrm{km}$ ao invés de 0,5 ciclos $/ \mathrm{km}$, estão produzindo uma malha digital contaminada espectralmente. $O$ $2,0 \mathrm{ciclos} / \mathrm{km}$.

É comum encontrar-se na literatura brasileira esse tipo de má interpretação com relação à freqüência de Nyquist e as dimensões das células das malhas digitais. Vasconcellos (1994), por exemplo, recomenda que se cortem os comprimentos de onda menores do que duas vezes o

Como a contaminação espectral afeta de modo mais significativo a porção do espectro imediatamente abaixo da freqüiência $f_{N l}$, a modelagem de anomalias individuais, a partir das malhas geradas com os parâmetros definidos anteriormente, fica prejudicada, uma vez que é justamente nesta parte do espectro que se concentra a maior parte da informação referente aos detalhes da forma do corpo fonte da anomalia que está sendo modelada (Reid, 1980).

Para efeito de comparação, um trecho do PASPRJ será interpolado empregando-se o algoritmo Bigrid $\mathrm{e}$ as demais técnicas de interpolação apresentadas neste capítulo. As malhas digitais serão geradas utilizando-se os mesmos parâmetros de filtragem empregados por Anjos adequados para a filtragem passa-baixa das linhas de vôo.
(19) geradas utilizando-se valores mais

A Figura 5.7a corresponde ao mapa de contorno de anomalias magnéticas de um trecho da subárea 6 do levantamento São Paulo/Rio de Janeiro. Este mapa foi gerado usando-se os mesmos parâmetros descritos por Anjos \& Mourão (1988) e Ferreira (1991), ou seja, foi utilizado o algoritmo Bigrid, com freqüência de corte igual a 2,0 ciclos $/ \mathrm{km}$ e espaçamento de $250 \mathrm{~m}$ entre os nós da malha. Como era de se esperar, há uma quantidade razoável de anomalias Também é visível que as linhas de e sem continuidade lateral entre linhas de vôo consecutivas. área, exibindo fortes inflexões exame contorno apresentam-se sistematicamente ondulas por toda a na porção oeste do mapa há uma forte ante sobre as linhas de vôo. Além disso, pode-se notar que localizada exatamente sobre uma linte anomalia magnética linear, estendendo-se de norte a sul, particular e podem ser encontradas vôo. Essas feições não são exclusivas dessa área em Particularmente, elas longo do Projeto São Paulo/Rio de Janeiro. Sul, descaracterizando por completo extremamente intenso por todo o Projeto Serra do Mar 
a)

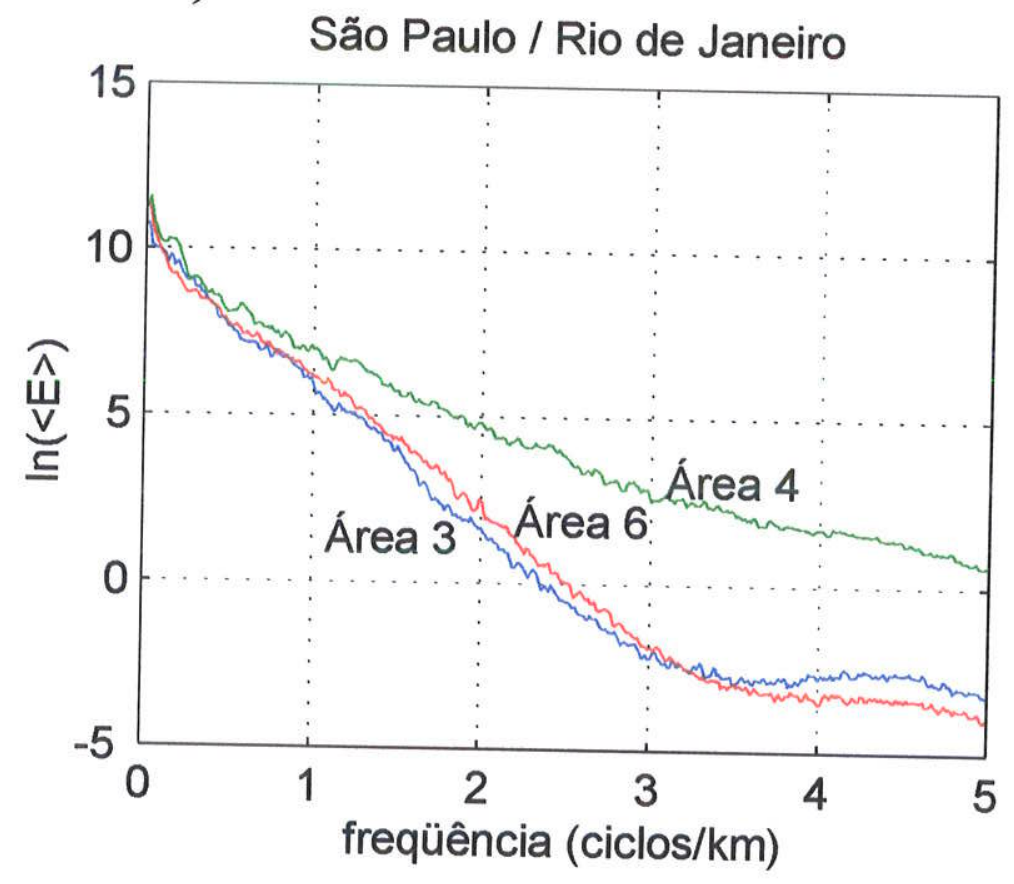

b)

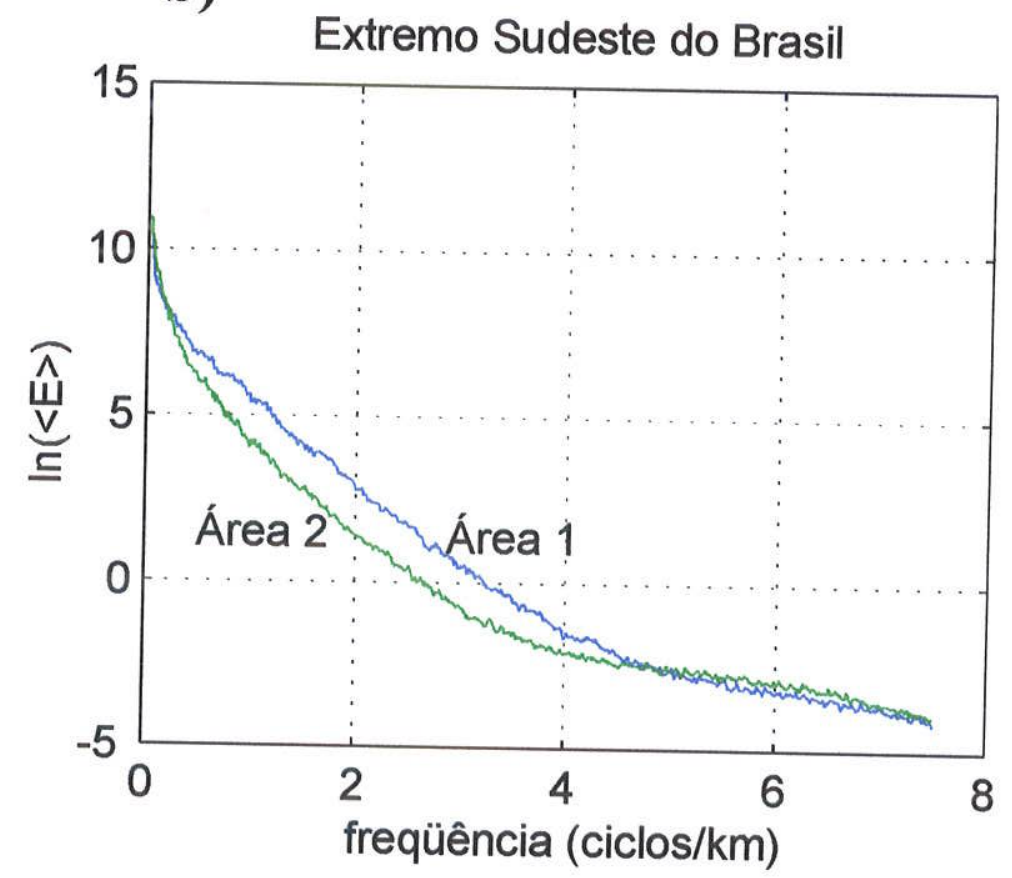

Figura 5.6 - Espectros de potência, por subárea, das linhas de vôo dos Projetos Aerogeofísicos São Paulo/Rio de Janeiro (a) e Extremo Sudeste do Brasil (b). 

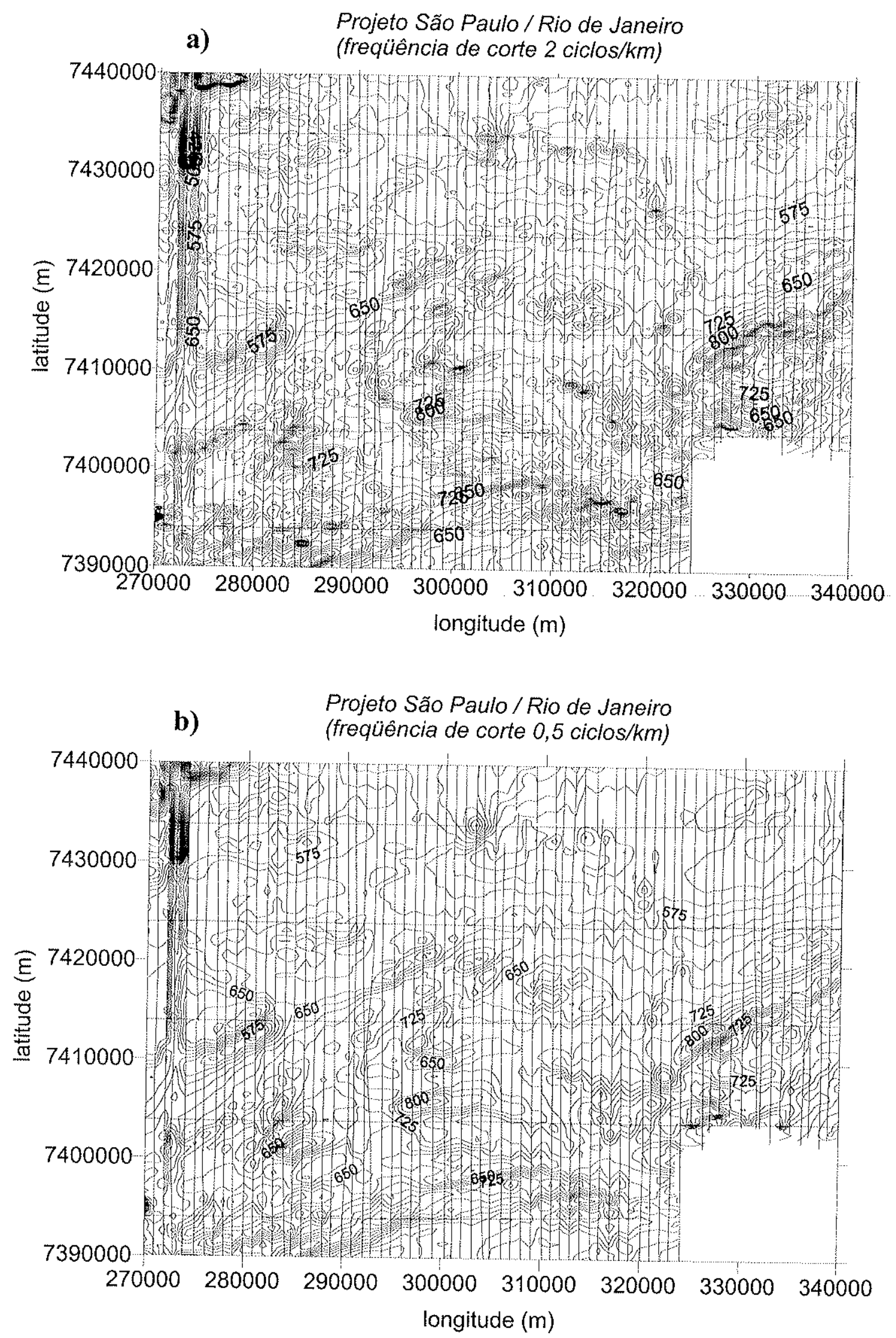

Figura 5.7 - Aplicação do algoritmo Bigrid à interpolação de um trecho da subárea 6 do PASPRJ. Intervalo de contorno $25 \mathrm{nT}$, coordenadas UTM.

(a) freqüência de corte do filtro passa-baixa igual a $2,0 \mathrm{ciclos} / \mathrm{km}$;

(b) freqüência de corte do filtro passa-baixa igual a 0,5 ciclos $/ \mathrm{km}$. 
característicos de dados que apresentam problemas de nivelamento. Esses erros de nivelam ento podem ser vistos como a adição de um ruído, próximo ao nível $\mathrm{DC}$, a todas as linhas de vôo. A ocorrência dessas distorções também foi notada por outros autores. Segundo Anjos \& Mourão (1988):

"A análise dos mapas magnéticos do PASPRJ mostrou a necessidade da adoção de medidas para eliminar alinhamentos paralelos às linhas de vôo, que normalmente ocorrem e se devem à imprecisão das correções aplicadas no tratamento geofisico dos dados. "

Foi aplicado, por esses autores, e por Ferreira (1991), um filtro direcional à malha de dados já interpolados de tal modo a se remover alinhamentos norte-sul (comprimentos de onda este-oeste). A forma do filtro empregado é dada por:

$$
L_{\theta}=\cos ^{n}(\alpha-\theta+\pi / 2)
$$

onde

$$
\begin{aligned}
& \theta=\text { direção da componente de Fourier; } \\
& \alpha=\text { direção do filtro }=90^{\circ} ; \\
& n=\text { grau da função co-seno }=0,5 .
\end{aligned}
$$

Deve-se ressaltar que a aplicação de um filtro com tais características remove não só as componentes cuja origem está associada a erros no nivelamento dos dados, mas também remove o sinal associado às componentes de origem geológica. A Figura 5.8 contém as respostas espectrais do filtro co-seno direcional, calculadas para as ordens $(n)$ iguais a $0,25,0,5,1,0$ e 2,0. As Figuras 5.8 a e $5.8 \mathrm{~b}$ representam, respectivamente, as porcentagens do espectro que são atenuadas e transmitidas versus o azimute. Conforme pode ser observado, somente as componentes espectrais que se situam a 90 graus da direção da aplicação do filtro $\left(0^{\circ}\right.$ e $\left.180^{\circ}\right)$ não serão distorcidas. As demais componentes sempre vão ser atenuadas com maior ou menor intensidade. Particularmente, deve-se notar que $1 / 3$ do espectro da malha digital (região situada entre os azimutes $60^{\circ}$ e $120^{\circ}$ ) vai sofrer uma atenuação maior ou igual a $30 \%$ quando se utiliza um filtro co-seno direcional com ordem $n=0,5$. De acordo com Vasconcellos (1994), erros de nivelamento tênues podem ser removidos utilizando-se $n=0,25$. Erros moderados podem ser atenuados $\operatorname{com} n=0,5$ e erros intensos $\operatorname{com} n=1,0$.

Os erros de nivelamento, vistos na Figura 5.7a ocorrem exclusivamente nas linhas de vôo, ou seja, onde há dados. Embora a amplitude dos erros seja variável, eles apresentam uma freqüência característica, que é igual a $f_{N l}$, e um azimute também característico, ou seja, paralelo às linhas de produção. Conforme será visto no próximo capítulo (Filtragem Linear Aplicada à Atenuação dos Erros de Nivelamento), um método possível para se atenuar os erros de nivelamento consiste em se aplicar às linhas de vôo e às linhas da malha um filtro passabaixa, com freqüência de corte ligeiramente menor do que $f_{N l}$. Reduz-se, assim, a resolução espacial e espectral da malha digital gerada, mas, por outro lado, garante-se que a mesma não contém componentes na freqüência $f_{N l}$, associada aos erros de nivelamento.

Para efeito de comparação, a mesma área representada na Figura 5.7a teve os seus dados interpolados através do algoritmo Bigrid (Figura 5.7b), do método da krigagem (Figura 5.9a) e 
a)

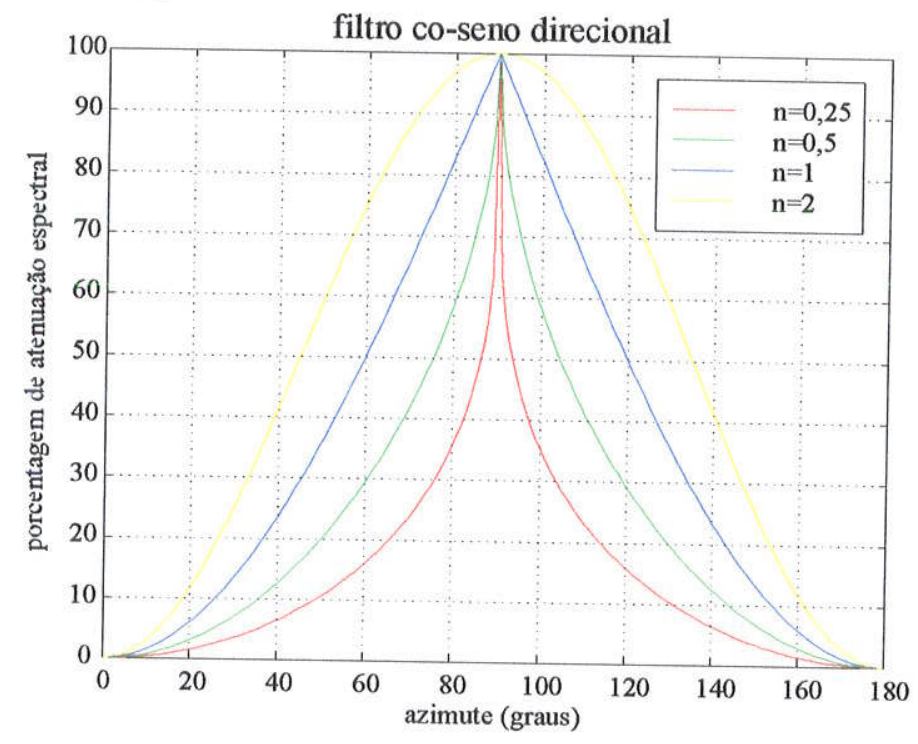

b)

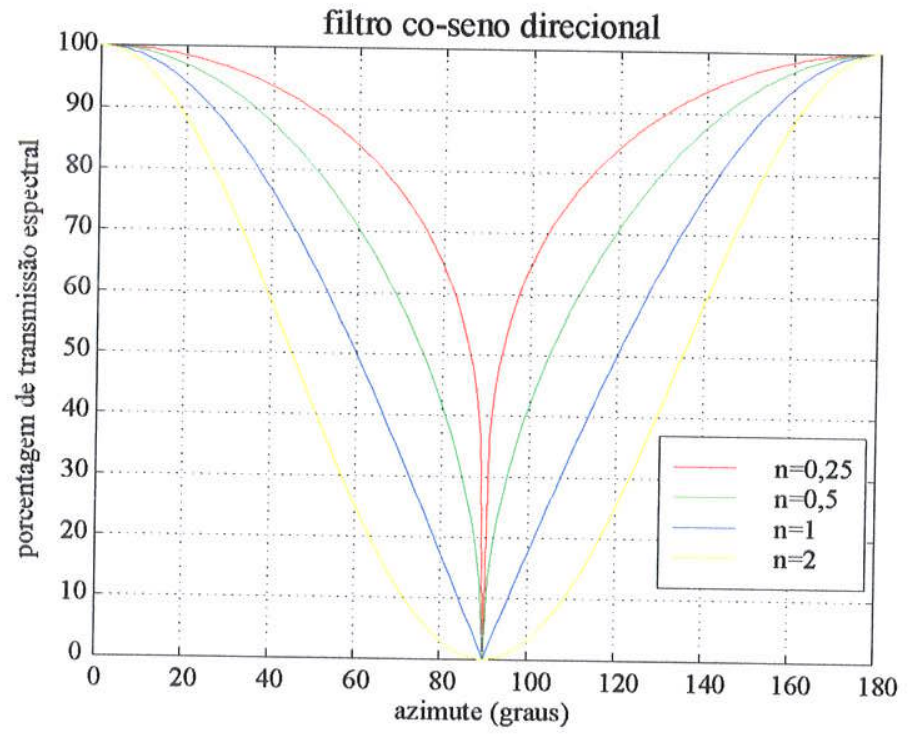

Figura 5.8 - Resposta espectral do filtro co-seno direcional utilizado na atenuação de erros paralelos à direção das LP:

a) porcentagem de atenuação espectral versus azimute para filtros com ordens iguais a $0,25,0,5,1,0$ e 2,0 ;

b) porcentagem de transmissão espectral versus azimute para filtros com ordens iguais a $0,25,0,5,1,0$ e 2,0 . 
curvatura mínima (Figura 5.9b). Durante a interpolação pelo método da krigagem o semivariograma foi aproximado por um semivariograma linear, isotrópico, cuja zona de influência apresenta tamanho $\vec{L}=5.000 \mathrm{~m}$. Desse modo, apenas as amostras situadas dentro de um raio de $5 \mathrm{~km}$ no entorno de cada nodo da malha tomaram parte na interpolação. Nestes exemplos, no que diz respeito à filtragem, os dados foram corretamente pré-processados, tendo sido aplicada uma filtragem passa-baixa às linhas de vôo com freqüência de corte $f_{N t}=0,5$ ciclos $/ \mathrm{km}$. A filtragem correta das linhas de vôo eliminou as anomalias locais, centradas sobre as linhas de vôo, que ocorrem por toda a Figura 5.7a. O padrão ondulado, associado aos erros de nivelamento, permanece nas três Figuras. Isto se deve ao fato do erro de nivelamento corresponder à adição de uma componente DC às linhas de vôo, e esse tipo de componente não é atenuada pela filtragem passa-baixa.

Visualmente não se nota qualquer diferença significativa nos mapas de contorno obtidos através dos algoritmos Bigrid, curvatura mínima e krigagem. As anomalias de pequeno comprimento de onda são bern representadas pelos três métodos, assim como as de longo comprimento. Também não há qualquer diferença na amplitude das anomalias interpoladas. Conforme citado na seção 5.5, o algoritmo Bigrid é o mais eficiente do ponto de vista computacional, podendo ser empregado facilmente no processamento de grandes quantidades de
dados.

As técnicas de interpolação da krigagem e curvatura mínima, assim como o algoritmo Bigrid, são técnicas de interpolação 2-D, ou seja, devem ser aplicadas a dados que foram amostrados numa superfície horizontal ou próxima desta, como ocorre nos levantamento aeromagnéticos conduzidos a uma altitude barométrica constante. No caso de levantamentos que acompanham a topografia, como é o caso dos projetos PAESB, PASMS e PASPRJ, pode haver constante na literatura que medidas com fortes gradientes topográficos. Tem sido uma que apresentam o menor efeito das efetuadas em superfícies paralelas ao terreno são aquelas (Wynn \& Bhattacharyya, 1977) que fez com que muitos levantamento é uma crença que prevaleceu durante a década de $1970 \mathrm{e}$ ao terreno em detrimento damentos fossem conduzidos a uma altura constante com relação (1984) mostram que, ao contráritude barométrica constante. Contudo, Grauch \& Campbell uma altura constante com ruario do que se assumia até então, os levantamentos efetuados a à geometria da topografia. Essa diferença no comportamento entre os dois tipos de levantamento anomalia, no caso de levantamentos que acompanham da componente da derivada vertical da levantamentos conduzidos a uma altitude conpanham a topografia, que está ausente no caso de levantamento PASMS apresente pelome constante. Conseqüentemente, é de se esperar que o de medida sobre os daça variaço da superfície para o fato do levantamento desníveis topográfine PASMS ter sido conduzido sobre uma região que apresenta fortes $1483 \mathrm{~m}$, enquanto $933 \mathrm{~m}$. A superfície a altura das linhas de vôo com relação à topografía varia entre $78 \mathrm{e}$ topografia (obtida a partir de gerada através da soma da altura radioaltimétrica do vôo com a nível do mar. É possív um modelo digital de terreno), varia entre 110 e $1.810 \mathrm{~m}$ acima do entre as anomalias magnéticas e a variação menos localmente possa existir alguma correlação que essa correlação existe em pelo menos três regiões de medida. Braggion Jr (1995), mostra 

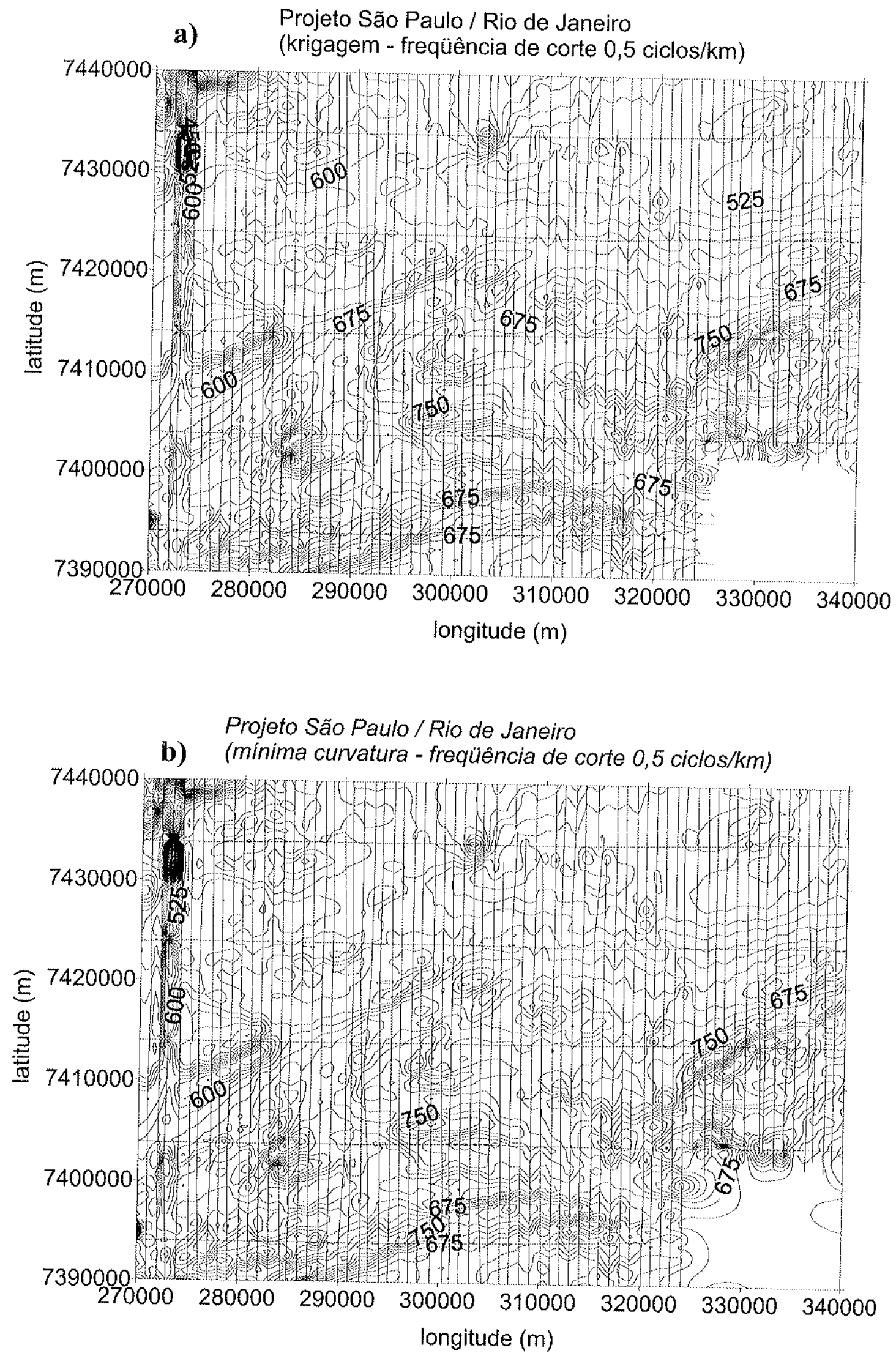

Figura 5.9 - Aplicação da krigagem e curvatura mínima à interpolação de um trecho da subárea 6 do PASPRJ. Intervalo de contorno $25 \mathrm{nT}$, coordenadas UTM.

(a) krigagem com freqüência de corte do filtro passa-baixa igual a 0,5 ciclos $/ \mathrm{km}$;

(b) curvatura mínima com freqüência de corte do filtro passa-baixa igual a $0,5 \mathrm{ciclos} / \mathrm{km}$. 
do levantamento, sobre o Vale do Ribeira; a segunda ocorre a SE, ao longo da Serra do Mar e da planície litorânea; e, finalmente, uma terceira região, ao sul da ârea abrangìida pelo PASMS.

No caso dos três projetos aerogeofísicos em questão, devido aos grandes desníveis topográficos existentes e devido à grande variação da superfície de vôo, é preferível que sejam empregadas técnicas de interpolação $3-\mathrm{D}$, tais como fontes equivalentes ou camada equivalente, ao invés das técnicas $2-\mathrm{D}$ rotineiramente utilizadas. A vantagem das técnicas de interpolação 3-D com relação às $2-\mathrm{D}$ é que elas levam em conta a natureza tridimensional dos dados que estão sendo interpolados, ou seja, a sua variação de altura. Com o emprego dessas técnicas de interpolação, consegue-se atenuar os efeitos de variação de altitude, ao se interpolar os dados numa malha digital cujos nós se encontram num mesmo datum. Também é possível, através delas, se atenuar os erros de nivelamento (Figura 5.1). No presente momento, essas técnicas de interpolação 3-D ainda não podem ser empregadas, pois ainda não existe disponível nenhum modelo topográfico digital com resolução adequada para ser utilizado com os dados dos projetos PAESB e PASPRJ. Muito embora os dados do projeto SRTM (Shuttle Radar Topographic Mission) apresentem uma resolução nominal de $90 \mathrm{~m}$, ele não se constitui de um modelo topográfico verdadeiro. Os melhores modelos topográficos digitais de domínio público, como o GTOPO30, apresentam uma resolução espacial nominal da ordem de $1 \mathrm{~km}$. Contudo, conforme pode ser visto na Figura 2.1, a resolução efetiva desse modelo, nas áreas abrangidas pelos projetos PAESB, PASMS e PASPRJ, é muito inferior à sua resolução nominal. Essa resolução é insuficiente para ser utilizada na interpolação 3-D de dados coletados a $150 \mathrm{~m}$ de altura sobre 0 terreno e com espaçamento nominal entre 58 e $100 \mathrm{~m}$ entre fiduciais consecutivas. Muito embora o PASMS seja o levantamento que apresenta os maiores desníveis topográficos e os erros de nivelamento mais pronunciados, deve-se ressaltar que ele não poderá ser alvo da interpolação 3-D. Isso ocorre, pois, segundo Metelo (1996), os dados digitais corrigidos da variação diurna desse projeto foram perdidos com o tempo. Como os dados digitais atualmente disponíveis são aqueles que já passaram pelo processo de nivelamento (vide Tabela 1), eles tiveram o seu nível de base alterado, por partes, ao longo das linhas de vôo, o que inviabiliza a
interpolação 3-D.

\subsection{Validação de Malhas digrtais}

Ao longo dos últimos anos, diversos autores conduziram análises morfológicas (forma das anomalias), estatísticas e espectrais, no sentido de determinar qual técnica de interpolação é a mais adequada para ser utilizada com dados aerogeofísicos.

Hansen (1993) avaliou o desempenho da curvatura mínima, krigagem isotrópica e krigagem anisotrópica com dados de um levantamento aeromagnético conduzido sobre o mar, na região da Cordilheira Juan de Fuca. A curvatura mínima e a krigagem isotrópica produziram resultados semelhantes entre si, com diversas anomalias espúrias centradas sobre as linhas de vôo. A krigagem anisotrópica eliminou esse efeito, gerando anomalias com direção oblíqua à direção das linhas de vôo, e que apresentavam continuidade entre várias linhas consecutivas. Deve-se ressaltar que, muito embora Hansen (1993) tenha considerado a krigagem anisotrópica como o melhor interpolador para a área em questão, Hansen \& Simmonds (1993), em um trabalho posterior, utilizam as malhas digitais interpoladas pela curvatura mínima para realizar a interpretação geofísica da região. 
Stevanato et al. (1995), ao tratarem dados de aerogamaespectrometria de um trecho do PASMS, avaliaram a morfologia e as características estatisticas das malhas digitais interpoladas com a krigagem (isotrópica e anisotrópica), a curvatura mínima e o algoritmo Bigrid. Eles mostram que a krigagem isotrópica é a técnica que menos suavizou os dados quando estes são interpolados ao longo de perfis que coincidem com uma linha de vôo. A krigagem anisotrópica foi a que mais suavizou os dados, enquanto que a curvatura mínima e o Bigrid (com resultados similares entre si), situam-se entre os dois tipos de krigagem. As estatísticas foram calculadas sobre malhas digitais residuais, obtidas a partir da diferença de uma malha interpolada na qual utilizou-se $100 \%$ dos dados amostrais, e outra obtida através da interpolação de $80 \%$ dos dados (sendo que os $20 \%$ de dados retirados foram removidos de forma aleatória da base de dados original). A krigagem isotrópica foi aquela que produziu a malha digital residual com o menor desvio padrão $(2,88)$, seguida, respectivamente, pela krigagem anisotrópica $(3,4)$, curvatura mínima $(6,65)$ e, por fim, pelo algoritmo Bigrid $(13,99)$.

Mendonça \& Silva (1995) empregaram modelos sintéticos de anomalias aeromagnéticas, originadas a partir de corpos prismáticos, para avaliar o desempenho das técnicas de interpolação por camada equivalente e curvatura mínima. A análise morfológica dos mapas de anomalias, obtidos a partir dessas técnicas, indicou que a técnica de interpolação por camada equivalente é a que produz os melhores resultados, inclusive nas situações em que os picos e flancos das anomalias são subamostrados.

Blum (1999), ao processar dados aeromagnéticos do Projeto Geofísico Brasil-Canadá, comparou o desempenho da krigagem (isotrópica e anisotrópica), do algoritmo Bigrid e da curvatura mínima. Após comparar a forma das anomalias, as estatísticas e os espectros obtidos a partir das malhas regulares interpoladas com esses métodos, chegou à conclusão que o Bigrid apresenta o melhor desempenho, sendo seguido pela krigagem anisotrópica.

Billings \& Richards (2002), ao tratarem dados aeromagnéticos de um levantamento de alta resolução (espaçamento de $50 \mathrm{~m}$ entre linhas de vôo), compararam o desempenho de quatro algoritmos de interpolação: Bigrid, curvatura mínima, curvatura mínima com tensão e triangulação. Ao compararem as imagens, espectros radiais e espectros bidimensionais das malhas interpoladas com esses métodos, concluíram que a curvatura mínima é o método que apresenta os melhores resultados, e que esta representa melhor a forma das anomalias quando o espaçamento entre as linhas de vôo é grande. A curvatura mínima com tensão apresentou o segundo melhor desempenho, resultando em distorções menores do que aquelas criadas com o Bigrid que, embora seja um algoritmo rápido, distorceu a forma das anomalias quando o espaçamento entre linhas de vôo era grande. Por fim, a triangulação foi a técnica de interpolação que mais gerou artifícios ao longo das linhas de vôo.

Nesta tese, além da análise morfológica - realizada anteriormente - das anomalias interpoladas, utilizou-se um procedimento estatístico, análogo ao empregado por Stevanato et al. (1995), para validar numericamente as malhas digitais interpoladas com a krigagem isotrópica, curvatura mínima e Bigrid.

Para cada uma das técnicas de interpolação, foram geradas duas malhas digitais: a primeira foi obtida utilizando-se $100 \%$ dos dados disponíveis, e na segunda foram empregados $80 \%$ dos dados (selecionados aleatoriamente). A segunda malha ( $80 \%$ dos dados) foi subtraída da primeira (100\% dos dados); os resíduos oriundos dessa diferença foram calculados e encontram-se resumidos na Tabela 4. 
Tabela 4 - Estatistica dos resíduos obtidos a partir da diferença entre as malkas interpoladas com $\mathbf{1 0 0 \%}$ e $\mathbf{8 0 \%}$ dos dados. K.O. - krigagem ordinária; C.Mín. - curvatura mínima.

\begin{tabular}{|c|r|r|r|r|r|r|r|r|r|}
\hline & \multicolumn{3}{|c|}{ São Paulo/Rio de Janeiro } & \multicolumn{3}{c|}{ Serra do Mar Sul } & \multicolumn{3}{c|}{ Extremo Sudeste do } \\
& Bigrid & K.O. & C.Mín. & Bigrid & K.O. & C.Mín. & Bigrid & \multicolumn{1}{c|}{ K.O. } & C.Mín. \\
\hline & 0,02 & 0,03 & 0,02 & -0.01 & 0,00 & $-0,05$ & 0,01 & 0,00 & 0,00 \\
\hline média (nT) & 0,00 & 0,00 & 0,00 & 0,00 & 0,00 & $-0,07$ & 0,00 & 0,00 & 0,00 \\
\hline mediana (nT) & $-0,61$ & $-0,61$ & $-0,62$ & $-0,35$ & $-0,37$ & $-0,33$ & $-0,28$ & $-0,32$ & $-0,23$ \\
\hline $1^{\circ}$ quartil (nT) & $-0,35$ & 0,31 & 0,23 \\
\hline $3^{0}$ quartil (nT) & 0,64 & 0,64 & 0,66 & 0,38 & 0,37 & 0,17 & 0,29 & 0,31 & 1,91 \\
\hline $\begin{array}{c}\text { desvio padrão } \\
\text { (nT) }\end{array}$ & 2,75 & 3,87 & 6,42 & 3,98 & 4,19 & 4,51 & 1,34 & 1,51 & 1,91 \\
\hline $\begin{array}{c}\text { variância } \\
\left.\text { (nT }^{2}\right)\end{array}$ & 7,56 & 14,98 & 41,21 & 15,84 & 17,56 & 20,34 & 1,79 & 2,28 & 3,65 \\
\hline
\end{tabular}

Através da análise dos resíduos descritos na Tabela 4, constata-se que o algoritmo Bigrid foi aquele que, sistematicamente, produziu os menores resíduos de interpolação, seguido, respectivamente, pela krigagem ordinária e curvatura mínima. Deve-se ressaltar que o bom desempenho do algoritmo Bigrid deve ao fato dos perfis aeromagnéticos terem sido filtrados antes da interpolação dos dados, removendo-se as componentes com frequêencia superior a $f_{N l}$. Tal procedimento atenuou a anisotropia de amostragem, eliminou as anomalias de curto comprimento de onda que não apresentam continuidade entre linhas de vôo consecutivas ( conforme pôde ser visto anteriormente na análise morfológica das anomalias interpoladas para um trecho do PASPRJ ) e preservou as anomalias com comprimento de onda compatível com o intervalo de amostragem entre linhas de vôo $\Delta l$. 


\section{CAPÍtUlo 6 \\ FILTRAGEM LINEAR APLICADA À ATENUAÇÃO DOS ERROS DE NIVELAMENTO}

\subsection{INTRODUÇÃo}

Neste capítulo é conduzido um estudo no sentido de se atenuar os fortes erros de nivelamento que afetam de modo mais intenso o projeto PASMS, e de modo menos intenso os Ferreira (1991) e Silva (1994). A solução adotada por esses por Anjos \& Mourão (1988), para atenuar os erros de nivelamento espectral, à malha de dados já interpolados, da seguinte forma:

$$
L_{\theta}=\cos ^{n}(\alpha-\theta+\pi / 2)
$$

onde $\theta=$ direção da componente de Fourier;

$\alpha=$ direção do filtro $=90^{\circ}$;

$n=$ grau da função co-seno $=0,5$.

Nota-se que a aplicação desse tipo de filtro à malha de dados remove não só as componentes cuja origem está associada a erros de nivelamento (lineamentos N-S, paralelos às linhas de vôo), mas também atenua de modo não linear as componentes de origem geológica que se encontram dentro do intervalo $10^{\circ}, 180^{\circ}$ [ (Figura 5.8).

A solução desenvolvida neste trabalho consiste na aplicação de um filltro passa-baixa às linhas e colunas da malha de dados, com freqüência de corte menor do que a freqüência característica dos erros de nivelamento, dada por $1 / 2 \Delta l$, onde $\Delta l$ corresponde ao espaçamento entre as linhas de vôo (Braggion Jr, 1998). Foi feita uma análise do comportamento de quatro filtros, recursivos, do tipo IIR (infinite impulse response - resposta impulsiva infinita), tendo em vista determinar aquele que apresenta as características mais adequadas à solução do problema. Foram analisados os filtros de Butterworth, de Chebyshev dos tipos I e II, e o filtro elíptico (Bath, 1974; Kulhánek, 1976; Parks \& Burrus, 1987; Proakis \& Manolakis, 1988; Oppenheim \& Schafer, 1989; Press et al., 1990; Scherbaum, 1996; Ginde \& Noronha, 1998; Wachspress, 2000). A seguir, é feita uma descrição geral dos filtros lineares, comparando-se os filtros recursivos e não recursivos. Nas seções posteriores, aplicam-se alguns desses filtros à atenuação
dos erros de nivelamento.

\subsection{Filtros Lineares}

A forma mais geral de um filtro linear (Press et. al, 1990), dada pela expressão (6.2), toma uma seqüência $x_{k}$ de pontos de entrada e produz uma seqüência $y_{n}$ de pontos de saída: 


$$
y_{n}=\sum_{k=0}^{M} c_{k} x_{n-k}+\sum_{j=1}^{N} d_{j} y_{n \cdots j}
$$

Aqui, os $M+1$ coeficientes $c_{k}$ e os $N$ coeficientes $d_{j}$ são fixos e definem a resposta do filtro. O filtro (6.2) produz cada novo valor de saída a partir do valor da entrada atual e dos $M$ valores prévios de entrada, além dos seus próprios $N$ valores de saída prévios. $\mathrm{Se} N=0$, de tal modo que não exista a segunda somatória em (6.2), então o filtro é chamado de não recursivo ou de resposta impulsiva finita (FIR - Finite Impulse Response). Se $N \neq 0$, então o filtro é chamado de recursivo ou de resposta impulsiva infinita (IIR - Infinite Impulse Response).

A relação entre os $c_{k}{ }^{\prime} s$ e $d_{j}{ }^{\prime} s$ e a função de resposta do filtro $\mathrm{H}(\mathrm{f})$ é:

$$
H(f)=\frac{\sum_{k=0}^{M} c_{k} e^{-2 \pi i k(f \Delta)}}{1-\sum_{j=1}^{N} d_{j} e^{-2 \pi i j(f \Delta)}}
$$

onde $\Delta$ é o intervalo de amostragem e $f$ é a frequiência. $O$ intervalo de Nyquist corresponde a $f \Delta$ entre $-1 / 2$ e $1 / 2$. Para filtros do tipo FIR, o denominador de (6.3) é igual a um.

\subsubsection{Filtros FIR (não recursivos)}

Quando o denominador em (6.3) é unitário, o termo do lado direito corresponde a uma transformada discreta de Fourier. A transformada é facilmente inversível, fornecendo os coeficientes desejados $c_{k}$ em termos do mesmo número de valores de $\mathrm{H}\left(\mathrm{f}_{i}\right)$ para as frequiências discretas $f_{i}$. Este fato, contudo, não é muito útil. O motivo é que, para valores de $c_{k}$ calculados dessa maneira, $H(f)$ tenderá a oscilar energicamente entre as freqüências discretas para as quais fixou-se o seu valor. Os filtros desta categoria podem ser implementados facilmente quer seja com fase zero, quer seja com fase linear.

\subsubsection{Filtros IR (recursivos)}

Os filtros recursivos, cuja saída em um dado momento específico depende tanto da entrada atual e prévias, quanto das saídas prévias, geralmente podem ter um desempenho que é superior ao dos filtros não recursivos com o mesmo número total de coeficientes (ou o mesmo número de operações de ponto flutuante por ponto de entrada). A razão é clara ao se examinar a equação (6.3): um filtro não recursivo tem uma resposta em freqüência que é um polinômio na variável $1 / z$, onde:

$$
z \equiv e^{2 \pi i(f \Delta)}
$$

Por outro lado, a resposta em freqüência de um filtro recursivo é uma função racional em $1 / z$. A classe de funções racionais é especialmente adequada para ajustar funções com bordas abruptas ou com feições de detalhe estreitas, sendo que muitas das características desejáveis de 
um filtro estão nestas categorias (Oppenheim \& Schafer, 1989). Os filtros recursivos sempre apresentam uma fase diferente de zero. Contudo, através de um artifício pode-se procuzir respostas com fase zero a partir de filtros recursivos. Isto pode ser obtido filtrando-se o sinal duas vezes, em direções opostas, cancelando assim a fase da resposta (Kulhánek, 1976; Scherbaum, 1996).

Os filtros não recursivos sempre são estáveis. Se a seqüência de entradas $x_{i}{ }^{\prime} s$ for interrompida, então, após não mais do que $M$ passos a seqüencia de $y_{i}{ }^{\prime} s$ produzida por (6.2) também será interrompida (cessará). Os filtros recursivos, tendo como entrada as suas próprias saídas, não são necessariamente estáveis. Se os coeficientes $d_{j}$ forem escolhidos inadequadamente, um filtro recursivo pode ter modos homogêneos exponencialmente crescentes, que se tornam enormes mesmo após a sequêencia de entrada ter sido interrompida. $O$ problema de se projetar filtros recursivos, portanto, não é só apenas um problema inverso; ele é um problema inverso com um vínculo adicional de estabilidade.

Desta forma, para aplicações práticas, é desejável saber se um filtro representado pela forma (6.2) é estável ou não. A estabilidade do filtro depende apenas dos coeficientes $d_{j}{ }^{\prime} s$. O filtro é estável (Kulhánek, 1976; Oppenheim \& Schafer, 1989) se, e somente se, todas as N raízes complexas da equação polinomial característica:

$$
z^{N}-\sum_{j=1}^{N} d_{n} z^{N-j}=0
$$

estiverem localizadas dentro do círculo unitário, ou seja, satisfizerem

$$
|z| \leq 1
$$

\subsection{AplicaÇÃo dos Filtros IIr à AtenuaÇão dos Erros de Nivelamento}

O filtro de Butterworth apresenta ganho $\mathrm{Mb}(\mathrm{w})$ que decresce monotonicamente com o aumento da freqüência w. A resposta em amplitude não apresenta qualquer oscilação (ou ripple), quer dentro ou fora da banda passante (o que já não ocorre com os filtros de Chebyshev ou elíptico). Os filtros de Butterworth apresentam resposta em amplitude plana na freqüencia $w=0$. A resposta em amplitude dos filtros de Butterworth é dada por:

$$
M b(w)=\sqrt{\frac{1}{1+\left(w / w_{c}\right)^{2 n}}}
$$

onde $w_{c}$ é a freqüência de corte e n é um número inteiro que define a ordem do filtro (número de pólos e de zeros do filtro). Para freqüencias muito baixas, $w \rightarrow 0$, o ganho se aproxima de 1 , tendendo assintoticamente para 0 com o aumento da frequiência. Na Figura 6.1a, está representado o ganho do filtro de Butterworth para as ordens $n=5,7,10$ e 14, tendo sido adotada uma freqüência de corte de aproximadamente 0,000285 ciclos/metro. Esse valor de freqüência de corte é adequado à atenuação do erro de nivelamento de linhas de vôo que 
a)

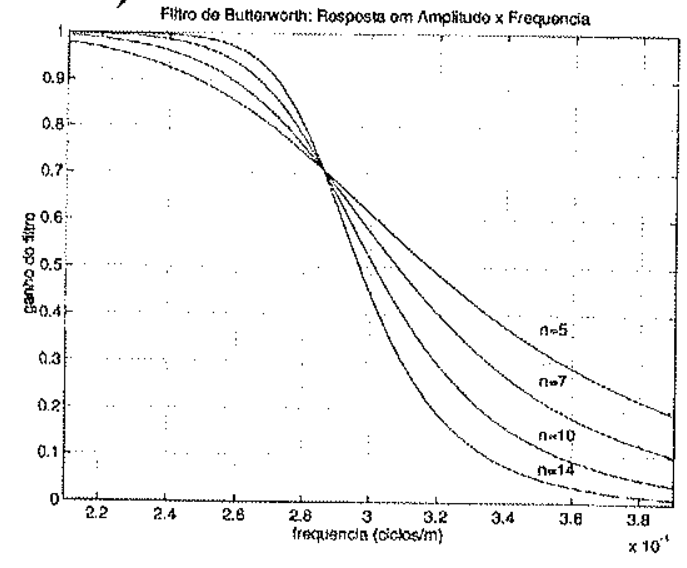

c)

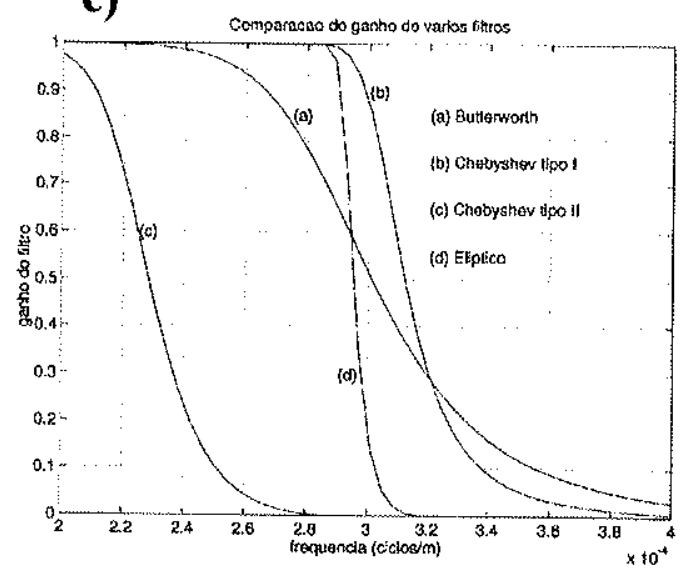

e)

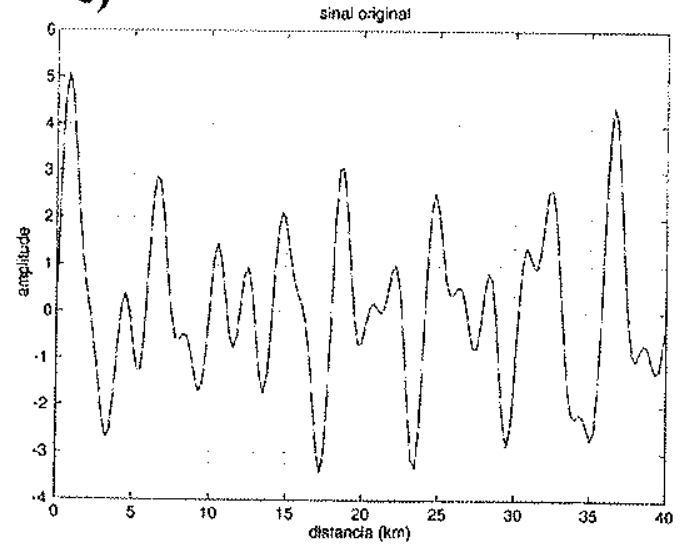

b)

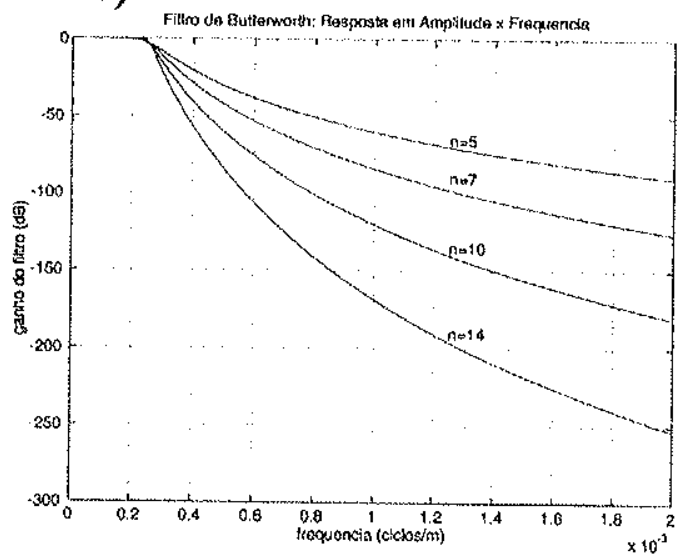

d)

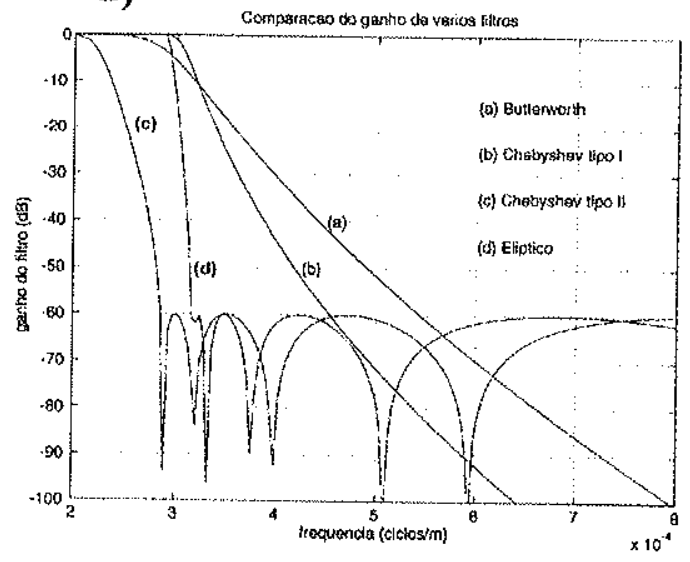

f)

Sinat Miltanto Térico x Sinzis Piltrados Reais

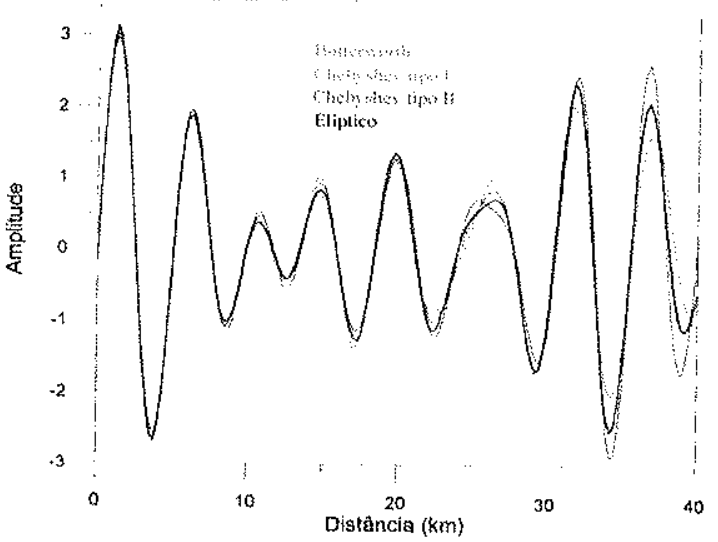

Figura 6.1 - Aplicação de filtros recursivos 1-D.

a) resposta em amplitude do filtro de Butterworth para as ordens 5, 7, 10 e 14 - escala linear de ganho;

b) resposta em amplitude do filtro de Butterworth para as ordens 5, 7, 10 e 14 - ganho em dB;

c) comparação do ganho dos filtros de Butterworth, Chebyshev (tipos I e II) e Elíptico - escala linear de ganho;

d) comparação do ganho dos filtros de Butterworth, Chebyshev (tipos I e II) e Elíptico - ganho em dB;

e) sinal sintético formado pela sobreposição de senóides com comprimentos de onda de: $2,0,3,0,3,5$, $4,55,0$ e $6,0 \mathrm{~km}$;

f) comparação da aplicação dos filtros IIR ao sinal sintético versus o sinal sintético teórico. 
apresentam um espaçamento médio de $1 \mathrm{~km}$ entre si. Nota-se que para ordens maiores, a resposta em amplitude do filtro se aproxima mais da resposta retangular de um filtro ideal. Para $w=w_{c}$ o ganho do filtro atinge o valor $1 / \sqrt{2}=0,707$ (cerca de $3 \mathrm{~dB}$ de atenuação), independentemente do valor de $n$. A escolha da ordem n do filtro é feita com base na atenuação que se deseja ter nas bandas passante e de rejeição. A Figura $6.1 \mathrm{~b}$ apresenta as resposta em amplitude dos mesmos filtros apresentados na Figura 6.1a, só que, agora, a escala adotada para representar o ganho dos filtros está em dB. O emprego dessa escala fornece um modo mais adequado para se analisar o ganho dos filtros nas altas frequiências.

Os filtros de Chebyshev do tipo I apresentam oscilação com amplitude constante na banda de passagem e comportamento monotonicamente decrescente na banda de rejeição. A resposta em amplitude $M c_{1}(w)$ de um filtro de Chebyshev do tipo I é dada por:

$$
M c_{1}(w)=\sqrt{\frac{1}{1+\varepsilon^{2} C_{n}^{2}\left(w / w_{c}\right)}}
$$

onde $\varepsilon$ é o parâmetro que controla a amplitude da oscilação na banda passante, e $C_{n}(w)$ é um polinomio de Chebyshev de grau n. A resposta em amplitude dos filtros de Chebyshev do tipo I, na banda de transição, decresce mais rapidamente do que a resposta dos filtros de Butterworth de mesma ordem, fazendo com que eles sejam mais adequados quando se quer separar freqüências próximas umas das outras. $O$ preço que se paga por essa maior capacidade de discriminar freqüências é o surgimento da oscilação na banda de passagem.

Os filtros de Chebyshev do tipo II, ao contrário daqueles do tipo I, apresentam uma resposta assintótica nas bandas de passagem e transição, e oscilação com amplitude constante na banda de rejeição. A resposta em amplitude $M c_{2}(w)$ de um filtro de Chebyshev do tipo II é dada por:

$$
M c_{2}(w)=\sqrt{\frac{1}{1+\left[\varepsilon^{2} C_{n}^{2}\left(w_{c} / w\right)\right]^{-1}}}
$$

A resposta em amplitude dos filtros elípticos $M e(w)$, por sua vez, apresenta oscilação com amplitude constante nas bandas de passagem e de rejeição, e comportamento monotonicamente decrescente na banda de transição. A resposta em amplitude dessa classe de filtros é dada por (Proakis \& Manolakis, 1988):

$$
\operatorname{Me}(w)=\sqrt{\frac{1}{1+\varepsilon^{2} U_{n}^{2}\left(w / w_{c}\right)}}
$$

onde $U_{n}$ é a função Jacobiana elíptica de ordem $n$.

Pode ser mostrado que para valores fixos da ordem $\mathrm{n}$ e da freqüência de corte $w_{c}$ os filtros do tipo elíptico são aqueles que apresentam a zona de transição mais estreita possível (Parks \& Burrus, 1987; Oppenheim \& Schafer, 1989), ou seja, a mudança da banda de passagem 
para a banda de rejeição é feita do modo mais rápido possível. Por outro lado, também pode ser mostrado que fixando-se os valores da freqüência de corte $w_{c}$ e do ganho nas bandas de passagem e de rejeição, os filtros do tipo elíptico são aqueles que fornecem a menor ordem $n$ entre todos. Tal fato tem extrema relevância prática, pois o número de coeficientes do operador de convolução espacial que descreve os filtros do tipo IIR é dado por $(n+1)$. Desse modo, ao se empregar filtros do tipo elíptico, pode-se ter a mesma resposta em amplitude que se tem com os demais tipos de filtros, porém, com um número menor de coeficientes do filtro (o que implica em menor tempo de processamento).

Nas Figuras 6.1c e 6.1d, estão representadas as respostas em amplitude dos filtros de Butterworth, Chebyshev dos tipos I e II, e elíptico, para uma freqüência de corte de 0,000285 ciclos/metro, e $n=10$. A primeira Figura, em escala linear, ressalta o comportam ento dos filtros nas bandas de passagem e transição (baixas freqüências); a segunda Figura, cujos ganhos estão em $\mathrm{dB}$, ressalta as respostas dos filtros nas bandas de transição e rejeição (altas freqüências). Os filtros de Chebyshev do tipo II e elíptico possuem ganho máximo de -60 dB na banda de rejeição, e os filtros de Chebyshev do tipo I e elíptico possuem ganho mínimo de $0,0087 \mathrm{~dB}$ na banda de passagem. Fica evidenciado, principalmente pela Figura $6.1 \mathrm{c}$, que os filtros de Butterworth e elíptico são aqueles que apresentam, respectivamente, a maior e menor zona de transição.

Para exemplificar a eficácia desses filtros, eles foram aplicados a um sinal sintético (Figura 6.1e), formado pela sobreposição de senóides com comprimento de onda de 2,0,3,0, $3,5,4,5,5,0$ e $6,0 \mathrm{~km}$. Os filtros foram projetados de modo a eliminar os comprimentos de onda menores do que $4,0 \mathrm{~km}$. A Figura $6.1 \mathrm{f}$ contém o sinal filtrado teórico, ou seja, aquele que é formado pela sobreposição das senóides com 4,5,5,0 e 6,0 km (curva amarela), sobreposto ao resultado da aplicação dos filtrus de Butterworth (curva vermelha), Chebyshev do tipo I (curva verde), Chebyshev do tipo II (curva azul) e elíptico (curva preta).

Visualmente, os filtros apresentam resultados muito semelhantes entre si. Contudo, o sinal filtrado com o filtro elíptico é aquele que apresenta o menor resíduo com relação ao sinal filtrado teórico, como era de se esperar. Os sinais filtrados com os filtros de Chebyshev apresentam praticamente o mesmo resíduo, e o sinal filtrado com o filtro de Butterworth é aquele que apresenta o maior resíduo. Tal comportamento é explicado pela menor banda de transição do filtro elíptico, seguido por uma banda de transição moderada dos filtros de Chebyshev, e por uma banda de transição ampla do filtro de Butterworth.

Esses filtros também foram aplicados a um trecho do projeto PASPRJ, Figura 6.2a, adotando-se um valor de $0,000285 \mathrm{ciclos} / \mathrm{m}$ para a freqüência de corte $w_{c}$, e $\mathrm{n}=10$ para a ordem dos filtros (o intervalo de contorno adotado nessa Figura, bem como nas seguintes, é de $25 \mathrm{nT}$ ). Essa área foi escolhida como exemplo por apresentar dois tipos de erros distintos. O primeiro é uma grande feição linear, de extensão norte-sul, localizada na longitude de $23 \mathrm{~km}$, que se deve a duas linhas de vôo consecutivas mal niveladas, produzindo um desnivelamento de até $125 \mathrm{nT}$. O segundo, de amplitude moderada (até $75 \mathrm{nT})$, alta freqüência $(0,001 \mathrm{ciclo} / \mathrm{metro}) \mathrm{e}$ extensão leste-oeste, ocorre por volta da latitude de $12 \mathrm{~km}$, local da transição da subárea 3 , ao sul, para a subárea 6 , ao norte, do projeto. Este segundo tipo de erro deve-se ao fato das subáreas 3 e 6 terem sido levantadas em épocas diferentes. 
As Figuras $6.2 \mathrm{~b}, 6.2 \mathrm{c}, 6.2 \mathrm{~d}$ e $6.2 \mathrm{e}$ apresentam, respectivamente, o resultado da aplicação dos filtros de Butterworth, Chebyshev do tipo I, Chebyshev do tipo II e elíptico, à malha de dados da Figura 6.2a. Notamse que todos os filtros foram capazes de eliminar o erro que ocorre na transição da subárea 3 para a subárea 6, embora tenham apenas atenuado o forte erro de nivelamento de extensão norte-sul. Além dos erros de nivelamento, a aplicação desses filtros eliminou o sinal de curto comprimento de onda dos corpos de origem geológica de pequena extensão lateral e pequena profundidade, como era de se esperar.

Para efeito de comparação com técnicas tradicionais de filtragem, foi gerada a Figura 6.2f, resultado da aplicação de um filtro espectral isotrópico à malha de dados da Figura 6.2a. Tal filtro apresenta uma banda passante que vai de 0 a 0,000285 ciclos/metros, eliminando as frequêencias maiores do que 0,000333 ciclos/metro, e tendo sido aplicado um arco de co-senóide para atenuar as freqüências que se situam entre 0,000285 e $0,000333 \mathrm{ciclos} /$ metro. A aplicação desse tipo de filtro produz, visualmente, resultados extremamente semelhantes à aplicação dos filtros de convolução espacial (Figuras 6.2b, 6.2c, 6.2d e 6.2e).

A grande vantagem da filtragem espacial, quando comparada com a filtragem espectral, reside no fato dela poder ser aplicada a malhas de dados incompletas, como é o caso dos três projetos aerogeofísicos empregados nesta tese. Nesses projetos, os limites dos levantamentos são irregulares, não constituindo bordas retangulares. Caso se deseje aplicar qualquer tipo de filtragem espectral a esses projetos, é necessário seccioná-los em subáreas retangulares, as quais, obviamente, não respeitam limites geológicos. Outra vantagem da filtragem espacial diz respeito ao fato de não ser necessária a remoção de qualquer superfície de tendência antes da filtragem, ao contrário do que ocorre com a filtragem espectral.

Pelos resultados obtidos, e de acordo com as características expostas anteriormente, o filtro do tipo elíptico parece ser o mais adequado para efetuar a atenuação dos erros de nivelamento, não só pelo fato dele possuir a menor zona de transição, mas também pela fácil seletividade do ganho que se deseja ter em ambas as bandas de passagem e de rejeição. Além disso, através de uma escolha criteriosa da frequiência de corte do filtro, pode-se efetuar a homogeneização espectral dos dados aeromagnéticos das linhas de vôo (Reid, 1980; Braggion Jr., 1995) atenuando-se as componentes harmônicas que podem vir a gerar uma contaminação espectral.

O filtro do tipo elíptico foi aplicado às linhas de vôo e às malhas de dados digitais dos projetos PAESB, PASMS e PASPRJ, promovendo a homogeneização do espectro dos dados e atenuando com sucesso os erros de nivelamento. 
a)

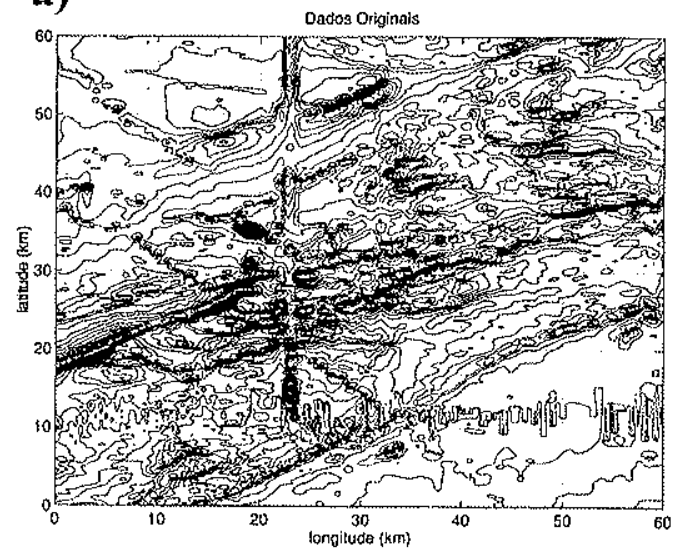

c)

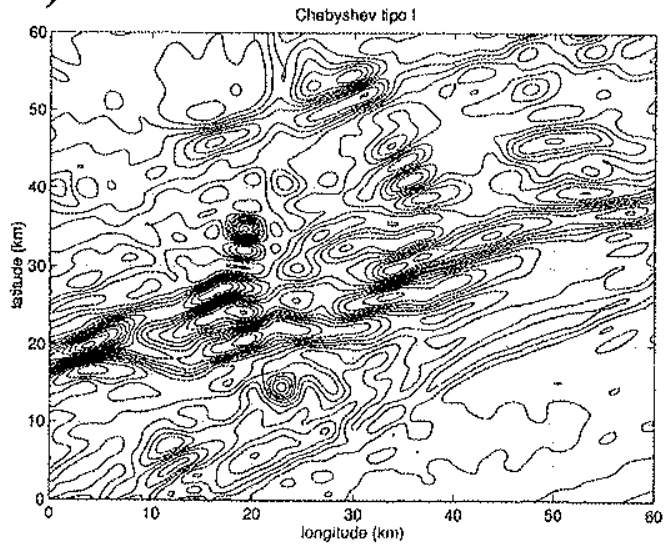

b)

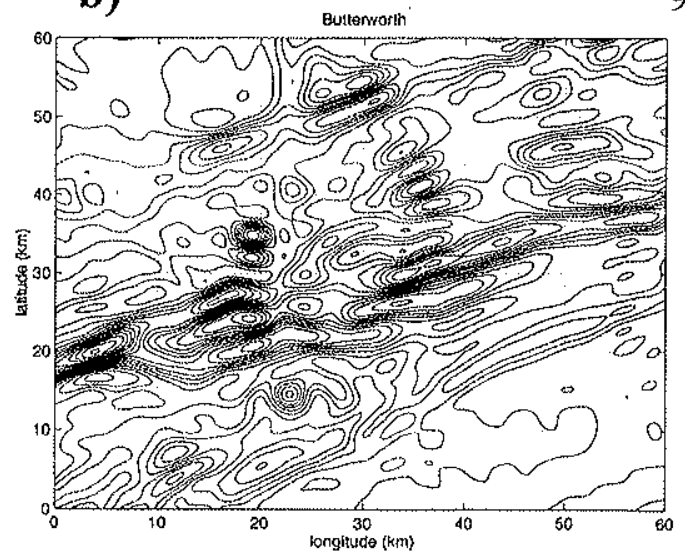

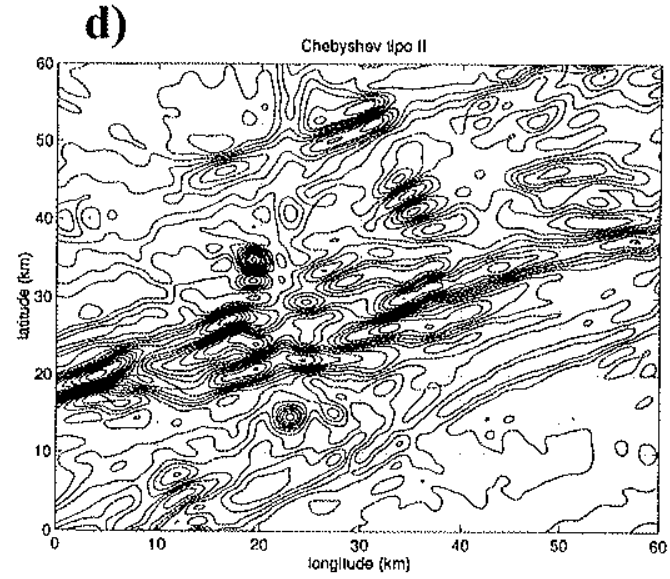

e)
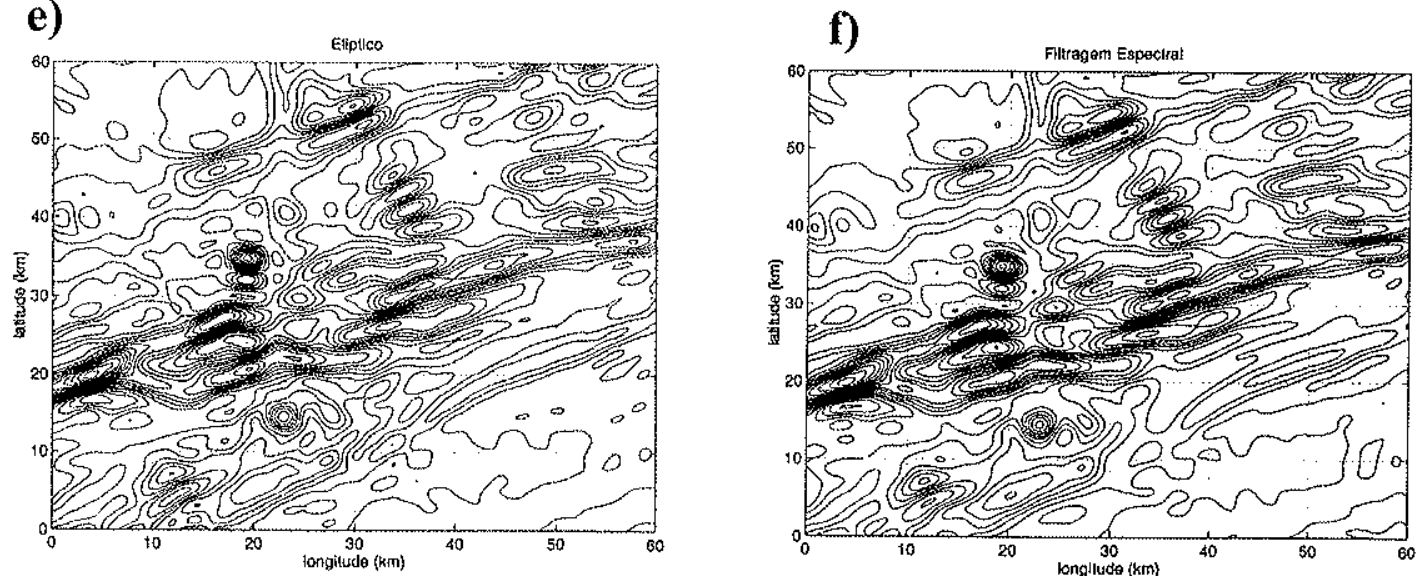

Figura 6.2 - Aplicação dos filtros IIR à atenuação dos erros de nivelamento de um trecho das subáreas 3 e 6 do PASPRJ (intervalo de contorno 25 nT).

a) dados originais;

b) resultado da aplicação do filtro de Butterworth;

c) resultado da aplicação do filtro de Chebyshev do tipo I;

d) resultado da aplicação do filtro de Chebyshev do tipo II;

e) resultado da aplicação do filtro elíptico;

f) resultado da filtragem espectral. 


\section{CAPITULO 7 \\ NIVELAMENTO DE DADOS AEROMAGNÉTICOS}

\subsection{INTRODUÇÃO}

No ponto de cruzamento entre os perfis de produção com os de controle, uma vez tendo sido feitas as correções da variação diurna e do IGRF/DGRF, os valores da anomalia magnética deveriam ser iguais. Na prática, entretanto, sempre ocorrem diferenças atribuídas principalmente às diferenças de altitude com que os perfis de produção e de controle são voados, embora também influenciam as imprecisões com que se identificam as intersecções e as fiduciais de controle em regiões com forte gradiente magnético. Diversas técnicas de nivelamento de dados têm sido desenvolvidas, todas elas tentam minimizar os erros no cruzamento entre perfis, segundo algum critério particular (Foster et al., 1970; Green, 1983; Fitzgerald, 1996; Luyendyk, 1997; Mauring et al., 2002). Basicamente, há três grupos de técnicas de nivelamento: fechamento de loop, nivelamento polinomial, e reposicionamento das coordenadas dos pontos de cruzamento.

\subsection{Fontes de Erros de Nivelamento}

As medidas de magnetometria, quando realizadas ao longo de perfis aéreos, estão sujeitas a uma série de erros e interferências que fazem com que as diferenças de cruzamento sejam diferentes de zero:

a) As linhas de produção e de controle podem ter sido voadas com alturas diferentes sobre o terreno no ponto de cruzamento. Quanto maior for a distância da aeronave com relação à fonte, menor será o valor medido para a anomalia magnética;

b) Podem ocorrer erros ao se registrar a posição e/ou altitude da aeronave quando se efetua uma medida. Erros de posição maiores ou iguais a $50 \mathrm{~m}$ são encontrados freqüentemente em levantamentos mais antigos;

c) Os magnetômetros mais antigos, incluindo alguns utilizados na década de 1970, apresentam uma deriva instrumental que varia exponencialmente com o tempo. Segundo Luyendyk (1997), essa variação pode ser de até $10 \mathrm{nT}$ por hora;

d) O campo magnético sofre uma variação temporal que pode ser cíclica ou aleatória (pulsações; tempestades magnéticas; variações diurna, lunar, solar e secular). Como as medidas ao longo das linhas de produção e de controle são feitas em instantes diferentes, essas variações afetam as medidas realizadas;

e) A posição da aeronave é medida usando-se um instrumento localizado dentro da aeronave, mas alguns tipos de magnetômetros podem estar localizados na extremidade de um cabo a uma certa distância da aeronave ou na ponta de um stinger na cauda da aeronave. Assim, as medidas magnéticas teriam as suas coordenadas registradas incorretamente. Esse fenômeno recebe o nome de erro de paralaxe sistemática;

f) A aeronave pode produzir campos induzidos que vão afetar as medidas. Esses campos podem se originar: na interação entre o campo magnético da aeronave e o campo magnético da Terra; no fluxo de corrente elétrica $(60 \mathrm{~Hz}$ e $400 \mathrm{~Hz})$ dentro da aeronave; 
g) Alguns dos movimentos a que a aeronave está sujeita no transcurso de um perfil podem afetar as medidas do campo magnético, tais como: período curto, phugoid, curvas, massas de ar.

\subsection{IdentificaÇão do Ponto de CruZamento}

As diversas técnicas de nivelamento de perfis aerogeofísicos aplicam correções aos valores de anomalia das linhas de produção e das linhas de controle de tal modo a se minimizar os erros de fechamento. Para que tais erros possam ser calculados é necessário que se identifique corretamente as coordenadas do ponto de cruzamento entre uma determinada linha de produção com uma eventual linha de controle que a intercepte.

Os pontos de cruzamento entre as diversas LP e LC que compõem um aerolevantamento, teoricamente, são identificados corretamente pela empresa responsável pela aquisição e processamento dos dados. Nesse caso, as coordenadas dos cruzamentos são identificadas prontamente a partir da recuperação da trajetória dos vôos ao se desenhar sobre os fotomosaicos o traçado das linhas de aquisição e de controle. Nessa etapa, a equipe responsável pela recuperação das trajetórias dos vôos gera um relatório contendo o número da linha de vôo, o número da linha de produção, as coordenadas (latitude e longitude) do ponto de cruzamento entre as linhas, e o número das fiduciais de controle localizadas imediatamente antes e após o ponto de cruzamento. A seguir, as coordenadas das demais fiduciais que se localizam entre essas fiduciais de controle são interpoladas linearmente entre as coordenadas das fiduciais de controle. Em seguida, identificam-se as fiduciais, cujas coordenadas foram interpoladas, que se localizam imediatamente antes e após o ponto de cruzamento. A partir das coordenadas dessas fiduciais, os seus valores de anomalia magnética são interpolados linearmente nas coordenadas do ponto de cruzamento identificado sobre o fotomosaico. Tomando-se a diferença entre os valores interpolados das anomalias da LP e da LC nas coordenadas do ponto de cruzamento previamente identificado, obtém-se o erro de cruzamento entre a linha de produção e a linha de controle em questão.

Um problema ocorre, posteriormente, quando usuários dos dados dos projetos desejam reprocessá-los, pois a informação sobre a localização dos pontos de cruzamento entre as linhas de controle e de produção não faz parte do produto final disponibilizado para o contratante do aerolevantamento (vide Tabela 1). Geralmente, os usuários de dados de levantamentos aerogeofísicos se utilizam de programas comerciais para reprocessar os dados. Como tais programas utilizam algoritmos proprietários para manipular os dados, os usuários não têm acesso à descrição da técnica que está sendo empregada. Quando um usuário resolve desenvolver ferramentas destinadas ao nivelamento de dados aeromagnéticos também deve desenvolver algum método que seja capaz de identificar os pontos de cruzamento entre LP e LC.

$\mathrm{Na}$ literatura não se encontrou descrito nenhum algoritmo otimizado para efetuar tal tarefa. Os poucos algoritmos publicados são otimizados para localizar o ponto de cruzamento entre perfis geofísicos (gravimétricos, magnetométricos e sísmicos) conduzidos a partir de navios (Herkommer \& Whitney, 1994; Hsu, 1995). Tais algoritmos levam em conta as peculiaridades dos levantamentos marítimos e não são eficientes para lidar com levantamentos aerogeofísicos em grande escala. 
Normalmente, ao se lidar com levantamentos aerogeofísicos, a identificação do ponto de cruzamento é feita "por força bruta", ou seja, para o primeiro par de fiduciais consecutivas de uma linha de produção verifica-se se ele possui algum cruzamento com o primeiro par de fiduciais consecutivas de uma linha de controle. Caso esse cruzamento não exista, o primeiro par de fiduciais da LP é confrontado com o segundo par de fiduciais da LC. Esse procedimento é repetido, sucessivamente, até que se identifique o ponto de cruzamento ou que se atinja o final da LC. Caso não tenha sido identificado nenhum ponto de cruzamento, passamse a comparar o segundo par de fiduciais da LP com todos os pares de fiduciais da LC. Caso o cruzamento não seja identificado, o procedimento é repetido para os demais pares de fiduciais consecutivas da LP até que se localize o ponto de cruzamento. Este é um procedimento demorado do ponto de vista computacional, pois, para uma situação em que a LP possui $\mathrm{N}$ fiduciais e a LC possui $\mathrm{M}$ fiduciais, pode ser necessário se efetuar até $(\mathrm{N}-1) \times(\mathrm{M}-1)$ comparações até se identificar o ponto de cruzamento.

Neste trabalho, foi desenvolvido um algoritmo iterativo para identificar de modo automático e eficiente o ponto de cruzamento entre linhas de produção e de controle de levantamentos aerogeofísicos. Para que a convergência do algoritmo seja a mais rápida possível, parte-se do pressuposto que as linhas de produção são aproximadamente paralelas ao eixo das ordenadas e que as linhas de controle são aproximadamente paralelas ao eixo das abscissas. A grosso modo, o algoritmo opera ao identificar um subconjunto de pares de fiduciais consecutivas da LP cujas ordenadas possuem valores que se situam entre o menor e o maior valor das ordenadas da LC. Analogamente, identifica-se na LC um subconjunto de pares de fiduciais consecutivas cujas abscissas possuem valores que se situam entre o menor e o maior valor das abscissas da LP. Esse procedimento vai sendo repetido iterativamente até que o número de fiduciais tenha sido reduzido drasticamente (para a partir delas se promover a busca direta do ponto de cruzamento) ou até que os dois pares de fiduciais consecutivas que se interceptam sejam identificados.

A Figura 7.1 exemplifica a aplicação do algoritmo proposto a um par de linhas de vôo do PAESB. A linha de produção possui 2.131 fiduciais e a linha de controle possui 2.251 fiduciais. Após a primeira iteração, o número de pares de fiduciais consecutivas, candidatos a conterem o cruzamento entre a LP e a LC, caiu drasticamente para 53 ao longo da LP e 49 ao longo da LC. Após a segunda iteração, tanto a LP, quanto a LC, apresentam apenas 3 pares de fíduciais consecutivas candidatas a conterem a interseção. Após a terceira iteração, o algoritmo foi capaz de identificar os pares de fiduciais que contêm o ponto de interseção entre as linhas de produção e de controle.

Esse procedimento foi aplicado à identificação dos pontos de cruzamento das LP e LC dos Projetos Aerogeofísicos Extremo Sudeste do Brasil e São Paulo/Rio de Janeiro. Pôde ser constatado que são necessárias, no máximo, 5 iterações do algoritmo para que se identifiquem os dois pares de fiduciais que formam o cruzamento ou para que se restrinja o número de pares de fiduciais antes que o algoritmo fique preso num laço.

\subsection{Método do Reposicionamento das Coordenadas dos Pontos de Cruzamento}

Duas medidas efetuadas no mesmo local, após aplicadas as correções da variação diurna, paralaxe e IGRF, deveriam ser idênticas. Se ocorrer uma diferença de fechamento diferente de 
a)

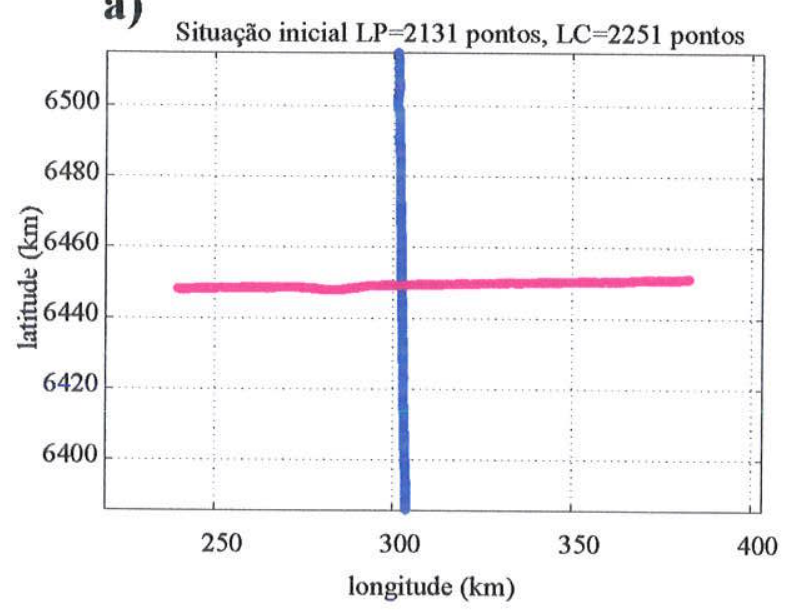

b)

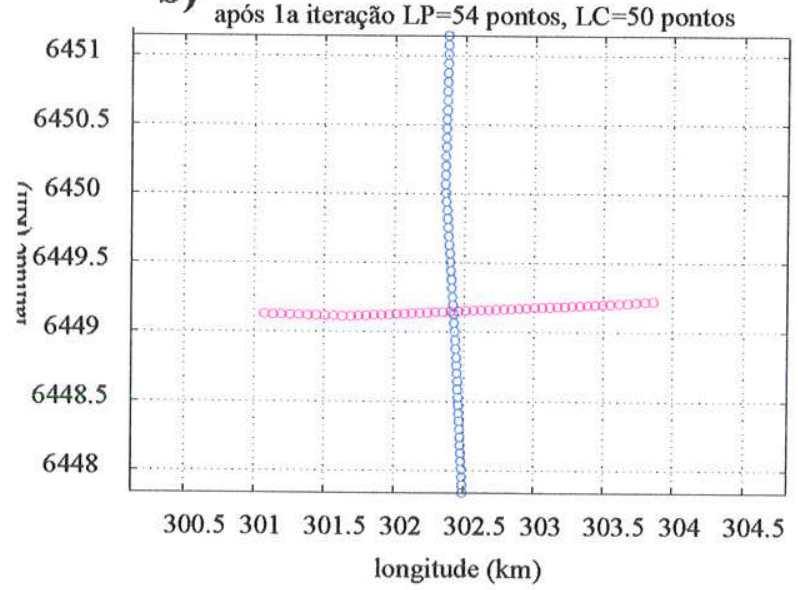

c)

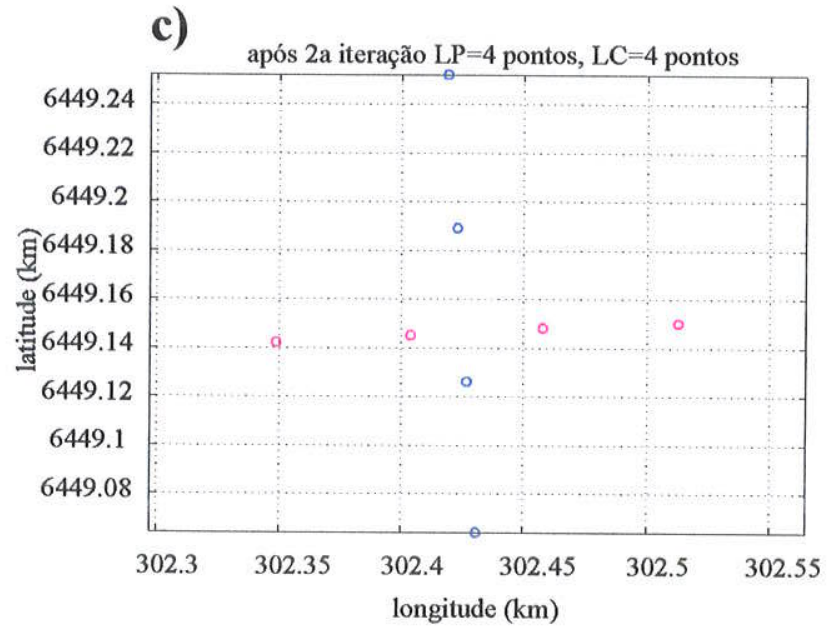

e)

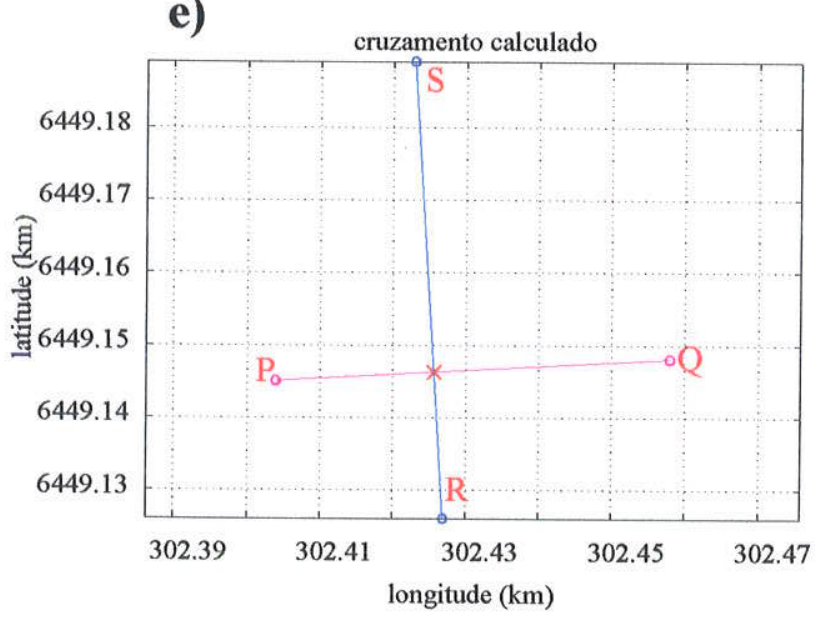

d)

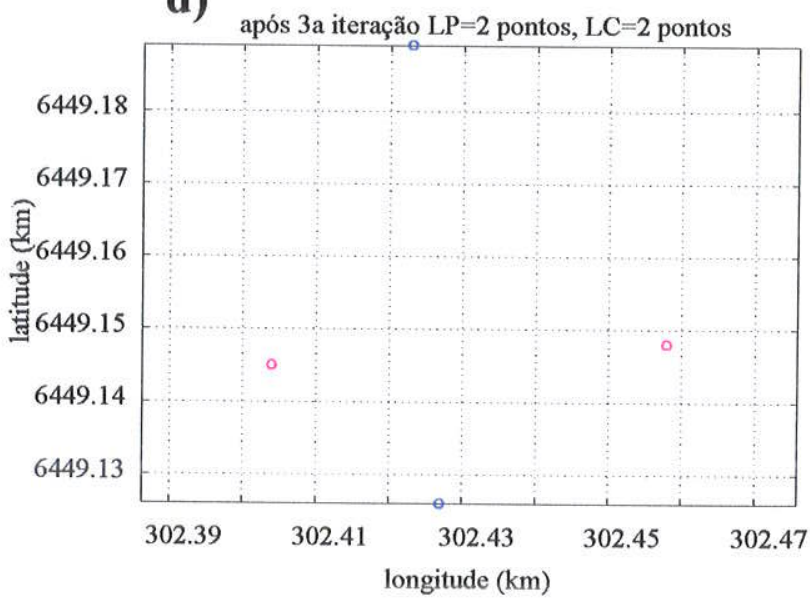

Figura 7.1 - Desempenho do algoritmo proposto para identificar o ponto de cruzamento entre linhas de produção e de controle aplicado ao PAESB.

a) situação inicial;

b) fiduciais identificadas após a primeira iteração;

c) fiduciais identificadas após a segunda iteração;

d) fiduciais identificadas após a terceira iteração;

e) ponto de cruzamento calculado a partir das fiduciais identificadas em (d). 
zero para um ponto de cruzamento, ela pode ser resultante de um erro nas medidas da pos ição geográfica das fiduciais das linhas de vôo.

Atualmente, com o emprego da navegação GPS, o grau e freqüência com que este tipo de erro ocorre é muito reduzido. Contudo, em levantamentos antigos, nos quais a navegação era feita a partir de mosaicos fotográficos, a recuperação das coordenadas corretas das fiduciais pode ser um procedimento pouco preciso, principalmente em áreas com topografia monótona, com poucos pontos de controle distinguíveis ou com grande variação topográfica.

Caso se tenha disponível uma estimativa da incerteza com que se determinam as coordenadas geográficas dos pontos de medida, então ela pode ser utilizada para se definir um círculo em torno de cada ponto de interseção dentro do qual o ponto de interseção pode ser movimentado livremente. Uma vez que se conhece o gradiente do campo magnético no ponto de interseção, assume-se que a sua posição dentro desse círculo é aquela que minimiza a diferença de cruzamento. Esse procedimento é aplicado a cada ponto de interseção dentro da área do levantamento, fornecendo, assim, um conjunto de correções que são interpoladas em todos os pontos de dados restantes.

No processo de nivelamento por reposicionamento das coordenadas dos pontos de cruzamento, procura-se a posição verdadeira do ponto de cruzamento ao tentar encontrar uma posição próxima na qual os valores do cruzamento extrapolados seriam os mesmos para a linha de aquisição e para a linha de controle. Para procurar por tal ponto, utilizam-se os gradientes calculados para a linha de controle e para a linha de aquisição no ponto de cruzamento. Em seguida, ajusta-se uma reta ao ponto da linha de controle ou da linha de aquisição que possuir o maior gradiente no cruzamento. A inclinação da reta ajustada deve ser igual ao gradiente calculado naquele ponto. Adotando-se tal procedimento, espera-se que a linha com o menor gradiente esteja correta e sirva de base para a linha com o maior gradiente. Assim, um pequeno deslocamento na fiducial da linha com o maior gradiente é capaz de exprimir uma maior variação no valor da diferença de fechamento.

O procedimento de nivelamento por reposicionamento das coordenadas dos pontos de cruzamento assume que:

1) As medidas próximas ao ponto de cruzamento na linha de maior gradiente podem ter sido atribuídas a uma posição incorreta devido a erros de navegação;

2) A posição das medidas próximas ao cruzamento na outra linha pode ser mais correta (precisa);

3) Através de um processo de extrapolação pode-se estimar valores em outras posições próximas ao ponto medido de cruzamento na linha de maior gradiente;

4) A melhor direção e método de extrapolação consistem em mudar os valores das coordenadas $X$ e $\mathbf{Y}$ da fiducial e o valor da anomalia $\mathbf{Z}$ numa direção ao longo de uma linha com as seguintes características:

- ela passa através do ponto de cruzamento com o maior gradiente;

- ela tem um gradiente igual ao gradiente de cruzamento;

- a direção adotada faz com que o valor de cruzamento $\mathbf{Z}$ com maior gradiente se aproxime do valor $\mathbf{Z}$ correspondente ao cruzamento na outra linha.

5) Dentro de um raio previamente estabelecido como limite, pode-se procurar um ponto na linha de extrapolação onde o valor $\mathbf{Z}$ é igual ao outro valor de cruzamento $\mathbf{Z}$ (diferença de fechamento igual a zero). Adotamse esse novo ponto como sendo o ponto correto para o 
cruzamento. Isso envolve mudar os valores das coordenadas $\mathrm{X}$ e $\mathbf{Y}$ do ponto de cruzamento, bem como o valor de $\mathbf{Z}$.

A Figura 7.2 ilustra graficamente o procedimento de nivelamento por reposicionamento das coordenadas do ponto de cruzamento.

O raio de influência é o raio (em metros) dentro do qual pode-se extrapolar valores de $\mathbf{Z}$ ao longo dos gradientes em busca de diferenças de fechamento iguais a zero. O seu valor é escolhido de tal forma que seja compatível com as incertezas que se têm na determinação dos valores das coordenadas geográficas dos pontos de medida. Caso essa informação não esteja disponível, pode-se adotar um valor pequeno (entre 10 e $20 \mathrm{~m}$ ), ou um valor igual à metade da distância nominal entre duas fiduciais consecutivas para o levantamento. Obviamente, só vai ser atingido um valor de diferença de fechamento igual a zero se o raio de busca for suficientemente grande. Caso isso não ocorra, ainda pode restar uma diferença de fechamento no ponto de cruzamento. Deve-se ter em mente que tal procedimento de nivelamento altera os valores das coordenadas $\mathbf{X}$ e $\mathbf{Y}$ do ponto de cruzamento, bem como altera os valores de $\mathbf{Z}$ dos dados na linha (de produção ou de controle) que apresentar o maior gradiente no ponto de cruzamento.

\subsection{MÉTodo do FechaMento de Loop}

A malha formada pelo conjunto de pontos de intersecção entre linhas de aquisição e linhas de controle pode ser considerada como uma rede de laços ou loops fechados. Assim, técnicas similares às de ajustamento de redes em levantamentos geodésicos podem ser aplicadas ao problema de nivelamento de linhas de aquisição e de controle de dados aeromagnéticos (Green, 1983; Luyendyk, 1997).

Embora a técnica proposta por Green (1983) para implementar o nivelamento por fechamento de loop seja matematicamente atrativa, pois se obtém uma solução imediata, sem intervenção manual, sabe-se que ela funciona bem apenas em áreas de gradiente magnético baixo e que apresentam pequenos intervalos dinâmicos entre as diferenças de cruzamento (Luyendyk, 1997). Devido a tais inconvenientes, é recomendável que sejam aplicados os ajustes de navegação descritos anteriormente (paralaxe, variação diurna e IGRF), de tal modo a se minimizar as diferenças de interseção, antes da aplicação deste método.

A formulação dada a seguir (Green, 1983) esboça o emprego do método de fechamento de loop de modo adequado a se tratar com as peculiaridades de levantamentos aeromagnéticos.

Considere-se uma rede de linhas de aquisição e de controle com $N$ interseções e $M$ segmentos de linha que as conectam. Deseja-se calcular um conjunto das melhores estimativas $Z_{i}$ da intensidade do campo magnético em cada ponto de interseção $(i=1,2, \ldots, N)$.

Para cada segmento de linha $\boldsymbol{k}(\mathrm{k}=1,2, \ldots, \mathrm{M})$ que une a interseção $\boldsymbol{l}$ à interseção $\boldsymbol{m}$, vale a seguinte equação:

$$
\left(Z_{l}-Z_{m}\right)-S_{k}=V_{k}
$$




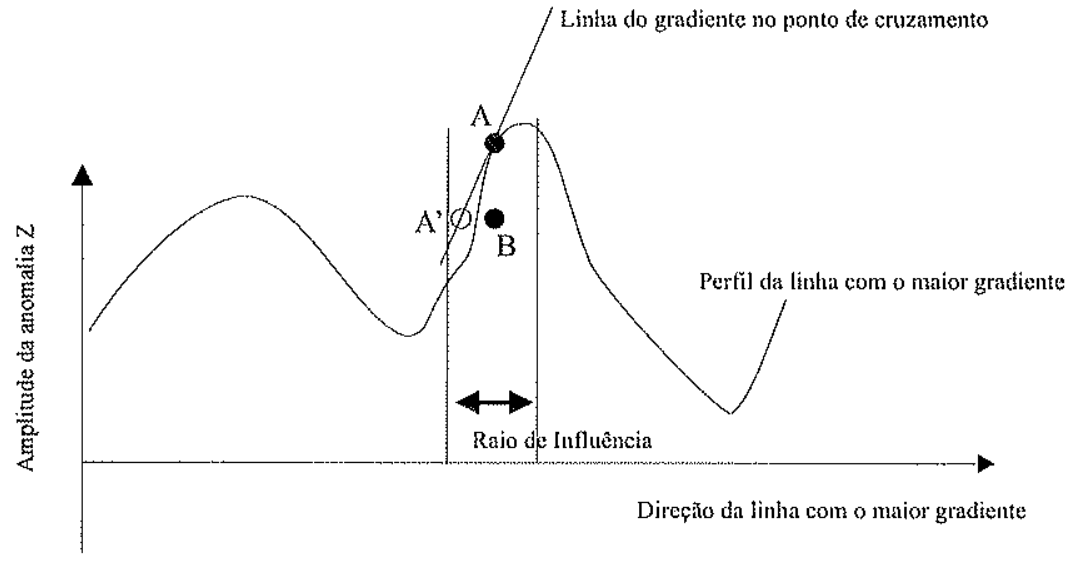

A - Ponto de cruzamento original na tinha de maior gradiente

B - Ponto de cruzamento original na outra tinha (direção perpendicutar à superfície da página neste diagrama)

A* Novo ponto de cruzamento na linha de maior crizamento com diferença de fechamento igual a zero

Figura 7.2 - Representação gráfica do procedimento de nivelamento por reposicionamento das coordenadas do ponto de cruzamento (Fitzgerald, 1996).

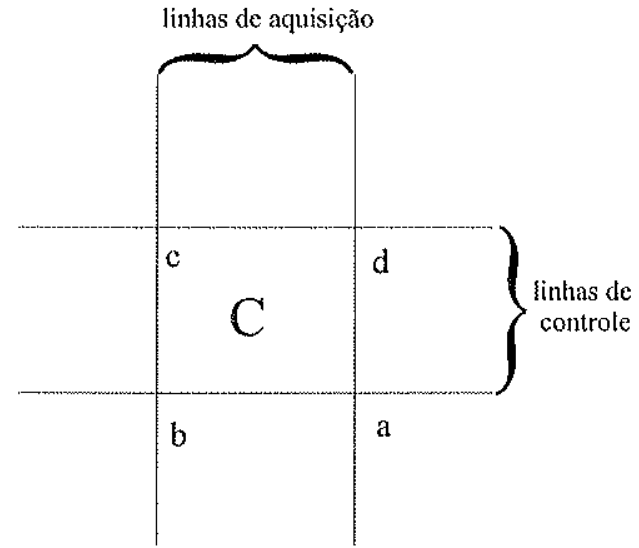

(a)

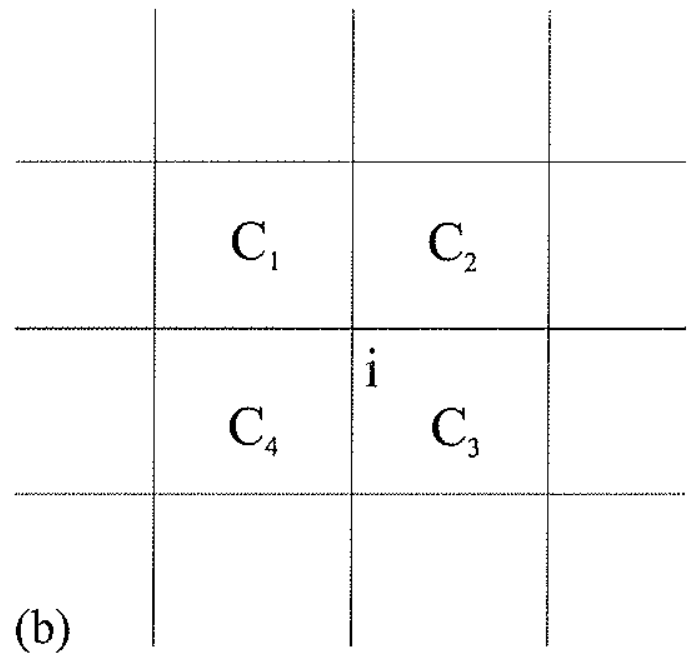

(b)

Figura 7.3 - Nivelamento pelo método de Green. Diagramas de interseção entre linhas de aquisição e de controle ilustrando o cálculo dos erros de fechamento (Green, 1983). a) relação entre o erro de fechamento $\mathbf{C}$ do loop central e as quatro interseções vizinhas $(\mathbf{a}, \mathbf{b}, \mathbf{c}, \mathbf{d})$;

b) relação entre a interseção $\mathbf{i}$ e os erros de fechamento $\left(\mathrm{C}_{1}\right.$ a $\left.\mathrm{C}_{4}\right)$ dos loops vizinhos. 
onde $V_{k}$ é a diferença entre a mudança estimada no campo $\left(Z_{l}-Z_{m}\right)$ ao longo do segmento $k$ e aquela observada durante o levantamento $S_{k}$. Assim, tem-se como requisito determinar um conjunto de $Z_{i}$ de tal modo que:

$$
\Phi=\sum_{k=1}^{M} V_{k}^{2}
$$

seja mínimo.

Rescrevendo a equação (7.2) numa forma mais apropriada, diferenciando-a com relação a $Z_{j}(j=1,2, \ldots, N)$ e igualando-se o resultado com relação a zero, chega-se a um conjunto de $\mathrm{N}$ equações simultâneas da forma:

$$
\sum_{i=1}^{N} a_{i j} Z_{i}-b_{j}=0
$$

onde: $\quad a_{i j}=\left\{\begin{array}{l}+n_{j} \text { para } i=j \\ -1 \text { se } i \text { e } j \text { são conectados por um segmento de reta } \\ 0 \text { para todos os outros casos }\end{array}\right.$

$n_{j}$ é o número de segmentos de reta que se conectam com a interseção $\mathrm{j}$

$b_{j}=\sum_{k=1}^{M} \delta_{j k} S_{k}$

e os termos da forma $\delta_{i k}=\left\{\begin{array}{l}+1 \text { quando } i=l \text { na equação (7.1) } \\ -1 \text { quando } i=m \\ 0 \text { para todos os outros casos }\end{array}\right.$

A matriz A de coeficientes $a_{i j}$ (equação (7.3)) é simétrica e com ordem $\mathrm{N}-1$ (ou seja, ela é singular e apresenta um autovalor igual a zero) onde o vínculo necessário é de que pelo menos uma interseção tenha um nível definido de modo independente.

Pode-se mostrar que a somatória em $i$ na equação (7.3) é igual à soma das mudanças estimadas no campo magnético medidas fora da interseção $j$, ao passo que $b_{j}$ é a soma das mudanças observadas fora da interseção $j$. Desta forma, o requisito para uma solução por mínimos quadrados é que a soma das diferenças observadas no entorno de cada interseção seja igual à soma obtida a partir dos valores estimados.

O conjunto de equações (7.3) pode ser resolvido através do emprego de técnicas de inversão matricial ou com o emprego de técnicas iterativas. O método de Green (1983) resolve o problema através do emprego de uma técnica iterativa, descrita a seguir. 


\subsubsection{Implementação do método de Green}

Considere um loop com quatro lados com interseções em $a, b, c$, e $d$ (Figura 7.3a) com as linhas de aquisição/produção sendo voadas na direção norte-sul e a linhas de controle na direção leste-oeste. A definição habitual do erro de fechamento em volta deste loop é:

$$
C=\left(T_{b}-T_{a}\right)+\left(F_{c}-F_{b}\right)+\left(T_{d}-T_{c}\right)+\left(F_{a}-F_{d}\right)
$$

onde, por exemplo, $T_{a}$ e $F_{a}$ são as intensidades magnéticas medidas nas linhas de controle e de aquisição, respectivamente, no ponto $a$.

Mudando a ordem dos termos na equação (7.4), tem-se:

$$
C=\left(F_{a}-T_{a}\right)-\left(F_{b}-T_{b}\right)+\left(F_{c}-T_{c}\right)-\left(F_{d}-T_{d}\right)
$$

out

$$
C=\varepsilon_{a}-\varepsilon_{b}+\varepsilon_{c}-\varepsilon_{d}
$$

onde $\varepsilon_{a}$ é o erro na interseção $a ; \varepsilon_{b}$ é o erro na interseção $b$; etc.

O procedimento adotado procura definir um novo conjunto de erros de interseção $\varepsilon_{i}^{\prime}, i=$ $1,2, \ldots N$ de tal modo que os erros de fechamento sejam reduzidos.

Conforme representado na Figura 7.3b, a interseção $i$ é rodeada por quatro loops com erros de fechamento $C_{l}, C_{2}, C_{3}$ e $C_{4}$. Pode-se mostrar que a mudança no valor de $\varepsilon_{i}$ que minimiza a somatória dos erros de fechamento é dada por:

$$
f_{i}=\left(C_{1}-C_{2}+C_{3}-C_{4}\right) / 4
$$

Quando uma interseção não estiver rodeada por quatro loops, como ocorre nas extremidades de um levantamento, a expressão anterior assume a forma:

$$
f_{i}=\left(\delta_{1} C_{1}-\delta_{2} C_{2}+\delta_{3} C_{3}-\delta_{4} C_{4}\right) /\left(\delta_{1}-\delta_{2}+\delta_{3}-\delta_{4}\right)
$$

onde $\delta_{\mathrm{i}}=1$ onde o loop existe e $\delta_{\mathrm{i}}=0$ onde o loop não existe, para $i=1,2,3$ e 4 .

O procedimento descrito a seguir (Green, 1983), implementa a técnica de nivelamento por fechamento de loop de tal modo a minimizar os erros de fechamento de um levantamento aerogeofisico:

1) Definir um deslocamento máximo permitido para a interseção ao longo das linhas de aquisição e de controle. Também definir um limite inferior (opcional) para o gradiente horizontal na região da interseção. Interseções com gradientes menores do que esse valor limite não serão ajustadas. Isso evita que o método efetue correções para pequenas variações diurnas em regiões que são magneticamente calmas. 
2) Utilizando a informação anterior, calcular os valores máximo e mínimo possíveis para o erro de cruzamento em cada interseção. Chamá-los de $\varepsilon_{i}^{u}$ e $\varepsilon_{i}^{l}$.

3) Para cada interseção $i$ estabelecer quais são as interseções adjacentes que formam os vértices dos loops adjacentes a $i$ (loops $C_{l}$ a $C_{4}$ na Figura 7.3b).

4) Para a interseção $i$, calcular os erros de fechamento $C_{1}$ a $C_{4}$ utilizando a equação (7.5) e a informação proveniente do passo (3).

5) Calcular $f_{i}$ empregando a equação (7.7).

6) O novo erro de interseção corrigido $\varepsilon_{i}^{\prime}$ é definido por $\varepsilon_{i}^{\prime}=\varepsilon_{i}-f_{i}$. Assim, se:

$$
\left\{\begin{array}{l}
\varepsilon_{i}^{\prime}>\varepsilon_{i}^{u} \text { então } \varepsilon_{i}^{\prime}=\varepsilon_{i}^{u} \\
\varepsilon_{i}^{\prime}<\varepsilon_{i}^{l} \text { então } \varepsilon_{i}^{\prime}=\varepsilon_{i}^{l}
\end{array}\right.
$$

7) Calcular o novo erro de fechamento $C_{i}^{\prime}$ associado à interseção $i$. Tomar o seu quadrado e adicioná-lo à uma somatória corrente dos quadrados $\psi$.

8) Repetir os passos (5)-(7) para $i=1, \ldots, N$ e imprimir o valor de $\psi$.

9) Repetir os passos (5)-(8) até que $\psi$ não seja reduzido significativamente por iterações adicionais.

\subsection{Nivelamento Polinomial}

O método do nivelamento polinomial assume que os erros que afetam cada uma das linhas de produção ou de controle variam suavemente e podem ser razoavelmente bem aproximados por um conjunto de polinômios locais como função do tempo. Esses polinômios são chamados de curvas de deriva e o objetivo é reconstituí-las a partir dos erros de cruzamento observados inicialmente. O erro de fechamento num dado ponto de cruzamento é formado por duas componentes: uma atribuída à linha de aquisição e outra à linha de controle. Através do nivelamento polinomial, procura-se identificar essas componentes (Fitzgerald, 1996; Luyendyk, 1997; Mauring, 2002).

$\mathrm{Na}$ sua forma mais simples, o método consiste em se ajustar um polinômio às diferenças de cruzamento em função do tempo pelo método dos mínimos quadrados. Os valores calculados pelo polinômio ajustado são, então, subtraídos dos dados originais, reduzindo-se as diferenças de cruzamento. Na literatura tem sido descritas várias implementações deste método (Yarger et al., 1978; Foster et al., 1970). Neste trabalho é adotada a implementação descrita por Luyendyk (1997) e Fitzgerald (1996), pois ela é mais elaborada do que aquela da forma mais simples descrita anteriormente.

Deve-se notar que durante um vôo são adquiridas diversas linhas, podendo-se executar mais de um vôo por dia ou passar alguns dias sem se executar nenhuma linha. As linhas que 
foram adquiridas durante o mesmo vôo podem ser relacionadas umas às outras por tempo, assim, podem-se calcular curvas de deriva para um vôo como um todo.

Segundo Luyendyk (1997), a técnica de nivelamento polinomial utilizada pelo AGSO (Australian Geological Survey Organisation - Serviço Geológico Australiano) possui quatro estágios que devem ser executados na seguinte ordem:

1) Nivelamento das linhas de controle: as linhas de controle são niveladas assumindo-se que a linha de controle principal é isenta de erros. Isso é feito através do cálculo das curvas de deriva das linhas de controle;

2) Corrigir as linhas de aquisição, por vôo, com relação às linhas de controle. Este procedimento também pode ser compreendido como sendo equivalente à correção de cada vôo assumindo-se que as linhas de controle estão corretas. Para isso, são calculadas curvas de deriva individuais para cada vôo;

3) Corrigir as linhas de aquisição individuais assumindo-se que as linhas de controle estão corretas. Para tal, calculam-se as curvas de deriva para as linhas individuais;

4) Corrigir as linhas de controle individualmente com relação às linhas de aquisição. Isto é feito calculando-se os erros residuais que afetam cada linha de controle individualmente.

Para que esse método possa ser implementado, são ajustados polinômios como função do tempo. Caso os levantamentos que estejam sendo processados não possuam a informação do instante em que as medidas foram tomadas, os polinômios passam a ser ajustados como função do número da fiducial de medida ao invés do tempo. Na hipótese de não existir informação sobre o número do vôo em que cada linha foi adquirida, o segundo estágio de nivelamento descrito anteriormente não é efetuado. Esse é o caso dos Projetos Aerogeofísicos São Paulo/Rio de Janeiro e Extremo Sudeste do Brasil, nos quais foi registrado somente o número dos perfis, não tendo sido anotado o número dos vôos (vide Tabela 1).

\section{A Linha de Controle Principal}

A primeira questão que surge durante o nivelamento polinomial consiste em se definir uma referência absoluta. Como não existe nenhuma referência absoluta, escolhe-se criteriosamente uma linha de controle, chamada de linha de controle principal, para servir como referência absoluta; isso implica em se assumir que a linha de controle principal possui, por definição, deriva igual a zero e não possui erros de nivelamento. A linha de controle principal, para ser confiável, deve ter as seguintes características: ter sido executada num período calmo, em que a variação diurna seja suave; estar localizada aproximadamente no centro da área do levantamento; estar situada sobre uma região onde o relevo magnético é suave, ou seja, ela não deve conter comprimentos de onda muito curtos com grandes amplitudes.

\subsubsection{Nivelamento das linhas de controle}

Neste estágio do nivelamento, são calculadas as curvas de deriva para cada linha de controle, nivelando-a com relação às demais. Para tal, são desempenhadas as seguintes etapas:

1) Deve-se selecionar uma linha de controle para ser a linha de controle principal; ela serve como uma referência absoluta com relação à qual todo o levantamento é nivelado. As linhas de controle serão classificadas em niveladas e não niveladas. Na primeira instância, o conjunto de 
linhas de controle niveladas consiste somente da linha de controle principal. Cada linha de controle do levantamento será nivelada, uma por vez, ajustando-a ao conjunto atual de linhas de controle niveladas.

2) Ajusta-se uma função polinomial às diferenças de cruzamento da linha de controle principal (Figura 7.4a). Uma vez que se assume que a linha de controle principal não possui erros de nivelamento, a curva ajustada representa os erros que são devidos exclusivamente às linhas de aquisição.

3) Os erros de cruzamento da segunda linha de controle são confrontados com a curva polinomial ajustada na etapa (2). Neste estágio, cada erro de cruzamento envolvendo as linhas de controle não niveladas consiste de uma componente devida à linha de controle e de outra componente devida às linhas de produção. Uma vez que a curva representa exclusivamente os erros devidos somente às linhas de aquisição, as diferenças entre os erros de cruzamento da segunda linha de controle e a curva (setas na Figura 7.4a) representam os erros devidos à linha de controle, neste caso, os erros nos valores de $\mathbf{Z}$ para a segunda linha de controle.

4) As etapas (2) e (3) são repetidas para todos os vôos que possuam linhas de produção que cruzam a linha de controle principal. Assim, forma-se um conjunto completo de correções para a segunda linha de controle.

5) Os valores de anomalia $(\mathbf{Z})$ da segunda linha de controle são corrigidos dos erros (componente devida à linha de controle) determinados na etapa (3). Isto é feito ao se ajustar uma curva por mínimos quadrados aos erros que ocorrem ao longo da linha de controle (Figura 7.4b). Os valores fornecidos pela curva ajustada são, então, subtraídos dos valores de anomalia nos pontos de cruzamento da segunda linha de controle. Assim, a segunda curva de controle passa a ser considerada nivelada.

6) Ajusta-se uma função polinomial às diferenças de cruzamento da linha de controle principal e da segunda linha de controle nivelada (Figura 7.4c). Como essa curva é calculada a partir de um conjunto de dados mais abrangente, considera-se que ela seja uma melhor estimativa dos erros que são devidos exclusivamente às linhas de aquisição.

7) Os erros de cruzamento da terceira linha de controle são confrontados com a curva polinomial ajustada na etapa (6). Uma vez que essa curva representa, agora, os erros devidos exclusivamente às linhas de aquisição, as diferenças entre ela e os erros de cruzamento (setas na Figura 7.4c) representam os erros nos valores de $\mathbf{Z}$ para a terceira linha de controle.

8) As etapas 6 e 7 são repetidas para todos os vôos com linhas de aquisição que cruzam a linha de controle principal. Assim, forma-se um conjunto completo de correções para a terceira linha de controle.

9) Os valores de $\mathbf{Z}$ da terceira linha de controle são corrigidos dos erros determinados na etapa (7). Tal correção é conduzida da mesma forma que a segunda linha de controle foi corrigida na etapa (5). Após isso, a terceira linha de controle passa a ser considerada nivelada.

10) As etapas de (6) a (9) são repetidas, incluindo a terceira linha de controle nivelada, de tal modo a se calcular uma nova curva devida exclusivamente aos erros das linhas de aquisição, 


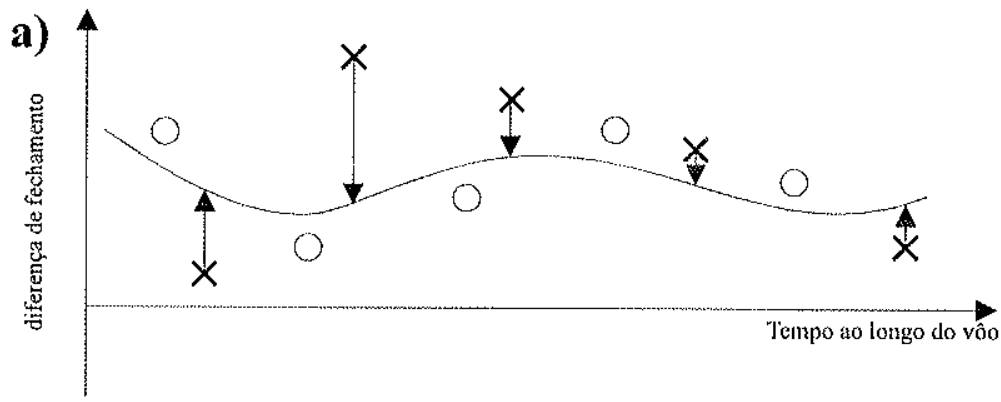

() Diferença de fechamento na linha te controle principal

$X$ Diferença de fechamento na segunda linha de controle

A Erros devido ao valor de $Z$ da linha de controle (diferenças com relação à curva dos erros exclusivos das linhas de aquisiçảo)
A curva é calculadla por ajuste de mínimos quadrados às đliferenças de fechamento na Sinha de controle principal ( pontos marcados com O)

Considerando-se que os valores de $Z$ da linha de controle principal não apresentam erro, a curva representa os erros devidos aos valores de $Z$ das linhas de aquisição.

desvio das difcrencas de fechamento da segunda linba de controle com relação essa curva dieve ser devido a erros nos valores de $Z$ da segunda linha te controle. Esses erros sito utilizaklos para corrigit os valores de $Z$ da segunda linha de controle.

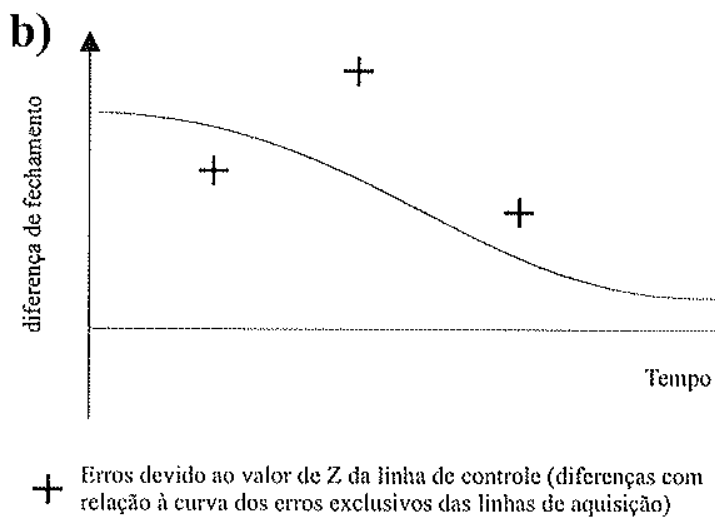

A curva é calculada através do ajuste de mínimos quadratos dos ertos da linha de controle e representa os erros devidos aos valores de $Z$ da linha de controle nessa linha de controle. Ela é a fonte de correção para o nivelamento da finha de controle.

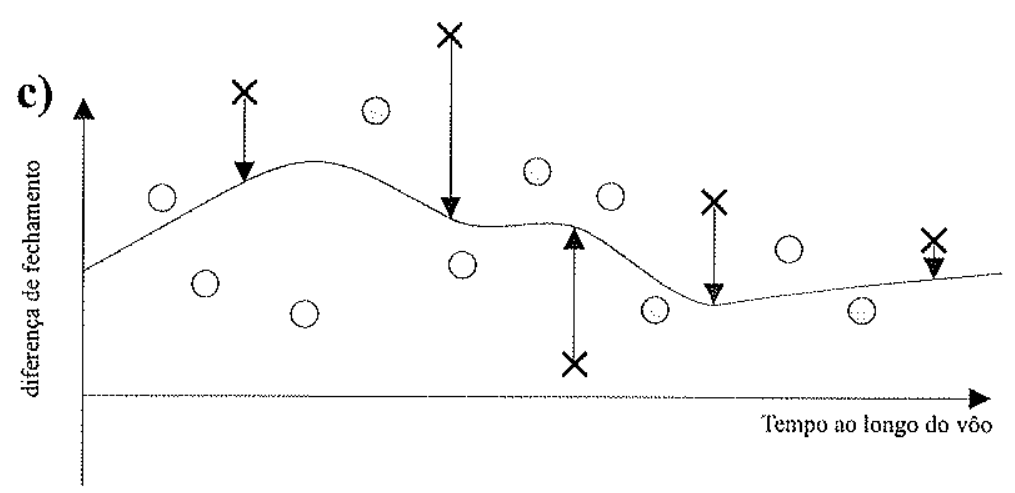

Diferença de fechamento na linha sle controle principal

Diferença de fechamento corrigida na segunda linha de controle

$X$ Diferença de fechamento na terceira linha de controle

Atros devido ao valor de $\mathrm{Z}$ da linha de controle (diferenças com relaçào à curva dos erros exclusivos das linhas de aquisição)
A curva é calculada por ajuste de minimos quadrados às diferenças de fechamento na linha de controle principal e às diferenças de fechamento corrigidas na segunda tinha de controle ( $p$ ontos marcados com $O$ e $O$ ).

Considerando-se que os valores de $\mathrm{Z}$ da linha de controle principal e da segunda linha de controle não apresentam erro, a curva representa os erros devidos aos valores de $Z$ tas linhas de aq̨uisição.

O desvio das diferenças de fechamento da terceira liıha de controle com relaçăo a essa curva deve ser devido a erros nos valores de $Z$ da terceira linha de controle. Esses erros stio utitizados para corrigir os valores de $Z$ da terceira linha de controle.

Figura 7.4 - Nivelamento Polinomial - nivelamento das linhas de controle.

a) primeira estimativa da curva dos erros devidos exclusivamente às linhas de aquisição;

b) curva de correção para os valores de anomalia da segunda linha de controle;

c) segunda estimativa da curva dos erros devidos exclusivamente às linhas de aquisição. 
calculando-se correções para a quarta linha de controle e corrigindo-a. Prossegue-se com todo esse procedimento até que todas as linhas de controle tenham sido corrigidas.

\subsubsection{Nivelamento dos vôos}

Uma vez que as linhas de controle encontram-se niveladas umas com relação às ou tras, considera-se que a sua deriva seja igual a zero e quaisquer discrepâncias nos pontos de cruzamento são atribuídos a erros que ocorrem ao longo das linhas de aquisição. Assim, os erros de interseção agora calculados podem ser usados diretamente para se obter uma estimativa da deriva que ocorreu durante cada vôo. Neste estágio, as linhas de aquisição são processadas por vôo. Cada vôo é processado individualmente e a sua curva de deriva é estimada ao se ajustar um polinômio aos seus erros de interseção. A seguir, emprega-se esta curva de deriva para se corrigir os valores das anomalias magnéticas $\mathbf{Z}$ nos pontos de cruzamento das linhas de produção do vôo em questão. Este procedimento é relativamente análogo à etapa (5) do item 7.4.1; graficamente, ele é semelhante à Figura 7.4b, só que agora a curva está sendo calculada ao longo de um vôo ao invés de uma linha de controle.

Esta etapa de processamento não pôde ser conduzida com os levantamentos São Paulo/Rio de Janeiro e Extremo Sudeste do Brasil, pois nenhum deles possui indicação do número dos vôos (vide Tabela 1).

\subsubsection{Nivelamento das linhas de aquisição individuais}

Após terem sido concluídos os estágios de nivelamento descritos anteriormente, ainda podem existir erros de nivelamento residuais específicos das linhas de aquisição. Neste estágio, as linhas de aquisição são processadas individualmente, ajustando-se um polinômio aos erros de fechamento de cada curva. A seguir, estes polinômios são utilizados para se corrigir os valores das anomalias magnéticas $\mathbf{Z}$ nos pontos de cruzamento da linha de produção em questão. Este procedimento é relativamente análogo à etapa (5) do item 7.4.1; graficamente, ele é semelhante à Figura 7.4b, só que agora a curva está sendo calculada ao longo de uma linha de aquisição ao invés de uma linha de controle.

\subsubsection{Nivelamento das linhas de controle com relação às linhas de aquisição}

Após ter-se nivelado as linhas de aquisição individualmente ainda podem existir alguns erros residuais nas linhas de controle. Neste último estágio de nivelamento, calcula-se uma curva de ajuste por mínimos quadrados para as diferenças de fechamento ao longo de cada linha de controle. Essa curva é utilizada para as correções dos valores de $\mathbf{Z}$ da sua respectiva linha de controle. Este procedimento é relativamente análogo à etapa (5) do item 7.4.1; graficamente, ele é semelhante à Figura $7.4 \mathrm{~b}$.

\subsubsection{Ponderação dos cruzamentos}

Yarger et al. (1978) notaram que os cruzamentos que apresentam maior gradiente horizontal geralmente estão associados às maiores diferenças de fechamento entre linhas de 
aquisição e de controle. Como a estabilidade dos dados magnetométricos nos pontos de cruzamento entre as linhas de aquisição e de controle pode variar, pode-se atribuir pesos aos dados nos pontos de cruzamento quando do ajuste do polinômio por mínimos quadrados de tal modo que os dados menos estáveis tenham menos influência no cálculo do polinômio.

Ao se atribuir pesos distintos para os cruzamentos, ponderam-se os valores de $\mathbf{Z}$ da linha que estiver sendo corrigida, seja ela de aquisição ou de controle. Um critério razoavelmente eficiente de se ponderar os cruzamentos (Fitzgerald, 1996) é aquele baseado no gradiente horizontal de $Z$. Cruzamentos com gradiente elevado vão contribuir menos do que cruzamentos com um gradiente baixo. Como o gradiente horizontal de $\mathbf{Z}$ pode estar associado à estabilidade dos dados, pode-se expressar o peso como sendo igual a:

$$
\text { Peso }=\frac{1}{e^{(0.1+\text { gradiente })}}
$$

\subsection{Nivelamento dos Perfis dos Projetos}

As três técnicas de nivelamento de perfis aeromagnéticos descritas neste capitulo foram aplicadas aos dados dos projetos aerogeofísicos PASPRJ e PAESB com o intuito de se verificar qual delas é capaz de melhor atenuar os erros de nivelamento existentes nesses projetos. Essas técnicas de nivelamento não puderam ser aplicadas aos dados do PASMS, pois os dados das linhas de controle deste projeto foram perdidas com o tempo (Metelo, 1996; Tabela 1).

A Figura 7.5 apresenta o resultado da aplicação das técnicas de nivelamento por reposicionamento das coordenadas dos pontos de cruzamento, por fechamento de loop e o nivelamento polinomial aos dados da subárea 4 do PASPRJ. Conforme pode ser visto, a técnica de nivelamento por reposicionamento das coordenadas dos pontos de cruzamento é aquela que produziu uma melhor representação dos dados, atenuando os efeitos dos erros de nivelamento (corrugações alongadas na direção N-S). Ela teve um bom desempenho tanto nas regiões onde o campo magnético é mais suave (no centro da figura) quanto nas regiões de anomalias com curtos comprimentos de onda e fortes gradientes magnéticos associadas aos lineamentos com direção NW (porções superior e inferior da figura). As técnicas de nivelamento polinomial e por fechamento de loop apresentaram um desempenho fraco comparado com a técnica anterior. Após a aplicação de ambas, persistem erros de nivelamento com amplitudes moderadas tanto nas regiōes onde o campo magnético é mais suave quanto nas regiões onde ele é mais variável. A técnica de nivelamento por fechamento de loop foi a que apresentou piores resultados, ao passo que o nivelamento polinomial teve um desempenho intermediário, quando comparado com as outras técnicas.

A Figura 7.6 apresenta o resultado da aplicação das três técnicas de nivelamento aos dados do PAESB. Aqui, as técnicas de nivelamento por reposicionamento das fiduciais do ponto de cruzamento e por fechamento de loop foram as que obtiveram os melhores resultados. Particularmente, o nivelamento por fechamento de loop produziu os melhores resultados onde predominam anomalias de curto comprimento de onda (porção central da figura), e resultados ligeiramente inferiores sobre as regiões com anomalias de longo comprimento de onda. $\mathrm{O}$ nivelamento por reposicionamento dos pontos de cruzamento, por sua vez, produziu bons resultados nas duas regiões onde predominam anomalias suaves e com longo comprimento de onda (uma ao norte e outra ao sul), apresentando um desempenho inferior onde predominam 


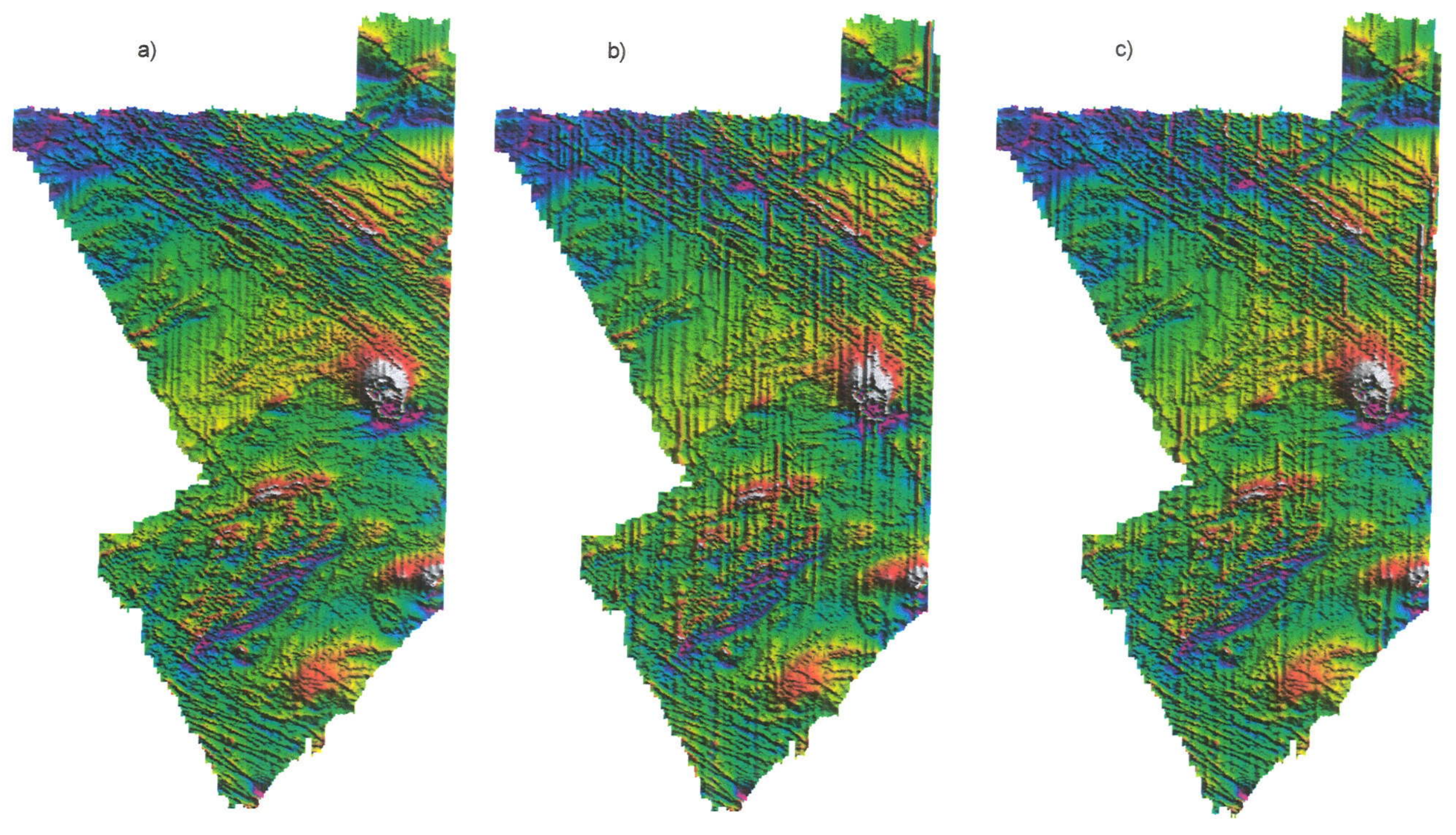

Figura 7.5 - Nivelamento da subárea 4 do PASPRJ: a) reposicionamento das coordenadas do ponto de cruzamento; b) fechamento de "loop"; c) nivelamento polinomial. 


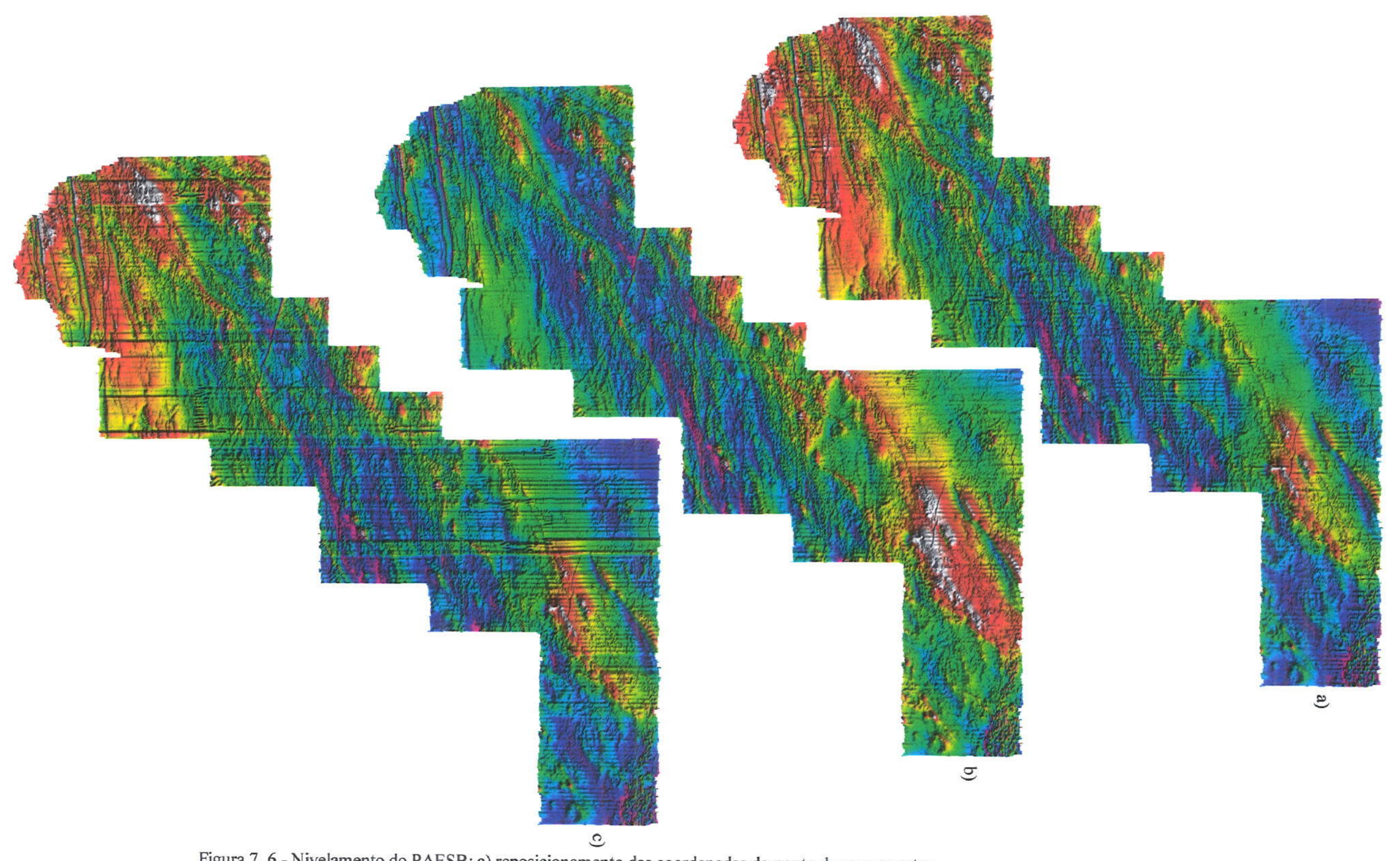

Figura 7. 6 - Nivelamento do PAESB: a) reposicionamento das coordenadas do ponto de cruzamento; b) fechamento de"loop"; c) nivelamento polinomial. 
anomalias de curto comprimento de onda (região central da figura). Com o emprego do nivelamento polinomial, persistem corrugações intensas por toda a área do PAESB, e o seu desempenho foi muito inferior àquele obtido com os demais métodos.

Muito embora a técnica de nivelamento por reposicionamento das coordenadas dos pontos de cruzamento tenha produzido bons resultados para tratar os dados das linhas de vôo do PASPRJ e PAESB, ela não foi capaz de remover por completo os erros de nivelamento, ela apenas os atenuou, sendo, assim, necessário que as malhas digitais resultantes passem por outras etapas de processamento (decorrugação e micronivelamento), antes que os dados estejam em condições de serem utilizados com técnicas de interpretação numéricas. 


\section{CAPÍTULO 8 \\ A DECORRUGAÇÃO E O MICRONIVELAMENTO DE DADOS AEROMAGNÉTICOS}

\subsection{INTRODUÇÃo}

As malhas digitais criadas a partir de dados dispostos ao longo de linhas de aquisição paralelas entre si geralmente apresentam ondulações ou listras, chamadas de corrugações, na direção das linhas de aquisição. Mesmo após a correção das variações temporais, nivelamento e geração da malha digital, ainda podem existir erros residuais com aspecto de corrugações. Constata-se a presença das corrugações através da visualização das malhas digitais geradas a partir de dados que supostamente foram nivelados corretamente. As corrugações, ao interferirem na aparência de uma malha digital, afetam a sua qualidade como um instrumento de interpretação de dados.

A remoção das corrugações que afetam as malhas digitais é feita através de técnicas de filtragem de dados. Esse procedimento recebe o nome de decorrugação. A partir de uma malha digital decorrugada, pode se aplicar correções aos perfis de vôo nivelados, tornando-os livres de diferenças de níveis. Esse procedimento recebe o nome de micronivelamento e melhora a qualidade dos perfis de vôo eliminando as corrugações que não foram removidas pelas técnicas tradicionais de nivelamento. Uma vez concluídos os ciclos de decorrugação e de micronivelamento obtêm-se, respectivamente, a melhor malha digital e os melhores perfis de vôo nivelados para a interpretação de dados aeromagnéticos.

São necessárias cinco etapas para se completar o processo de decorrugação/micronivelamento. A seguir, tem-se um resumo, passo a passo, deste processo (Fitzgerald, 1996):

1) interpolar os dados nivelados das linhas de vôo numa malha digital;

2) empregar alguma técnica de decorrugação para produzir uma malha digital de correções;

3) usar a técnica de micronivelamento para aplicar a malha digital de correções aos dados originais das linhas de vôo;

4) interpolar os dados de linha de vôo corrigidos;

5) comparar a malha digital obtida a partir dos dados das linhas de vôo originais com a malha digital produzida a partir das linhas de vôo corrigidas.

O seguinte fluxograma representa de forma esquemática as principais etapas envolvidas nos ciclos de decorrugação e micronivelamento. 
Figura 8.1 - Fluxograma das etapas envolvidas nos ciclos de decorrugação e micronivelamento.

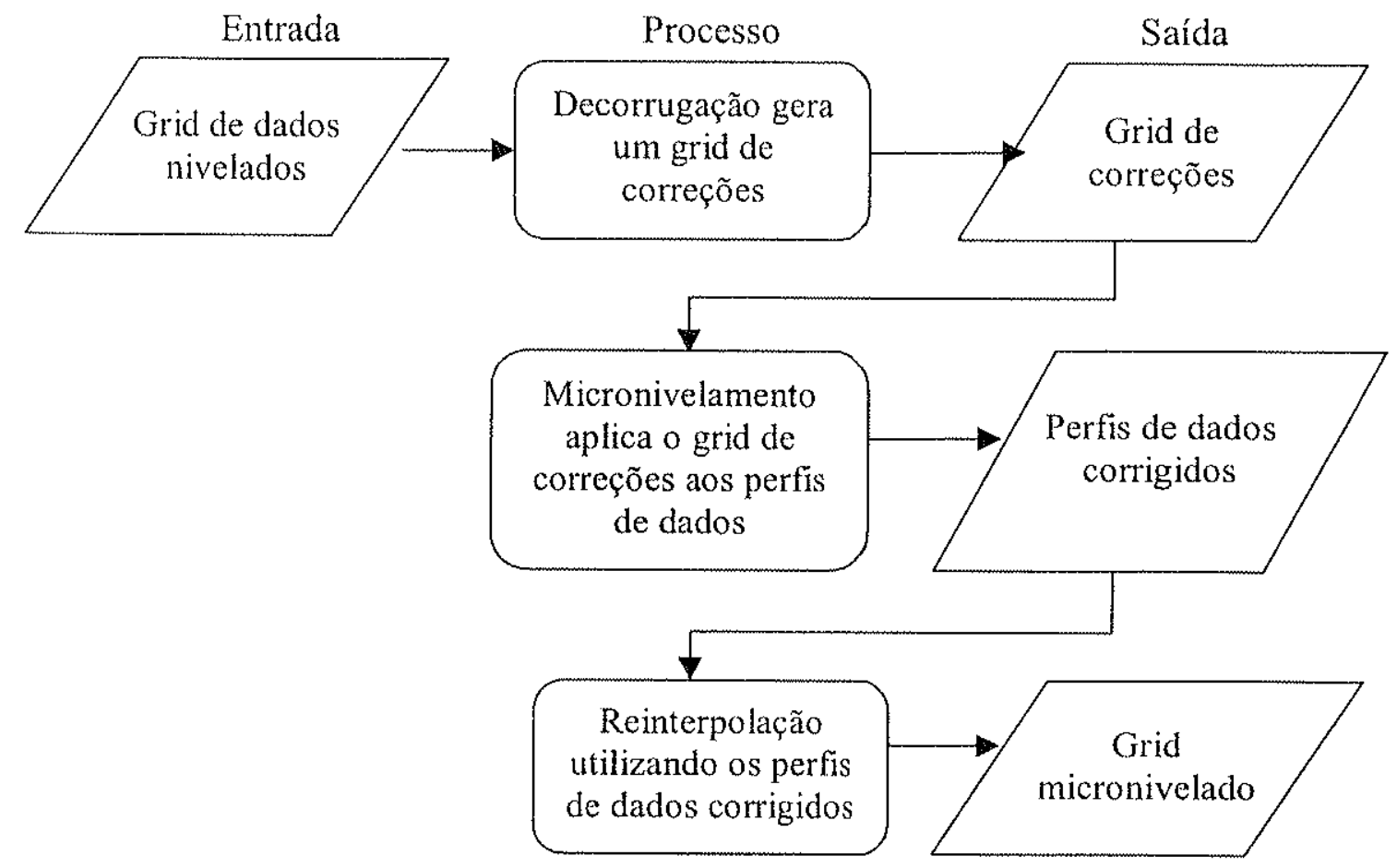

\subsubsection{Fontes de corrugação}

Não se pode ter certeza absoluta da fonte exata das corrugações num dado levantamento, mas sabe-se que entre as possíveis fontes de erro estão as seguintes (Minty, 1991; Fitzgerald, 1996; Luyendyk, 1997):

a) A posição medida de um ponto de cruzamento entre uma linha de produção e uma linha de controle pode não ser correta. Se este erro ocorrer, ele pode introduzir um erro que afeta uma região retangular que se estende por um espaçamento entre linhas em cada direção. As dimensões dessa região seriam, portanto, iguais a duas vezes o espaçamento entre linhas de produção por duas vezes o espaçamento entre as linhas de controle. Com o advento do posicionamento global por satélite (GPS), a probabilidade de ocorrência deste tipo de erro diminuiu consideravelmente. Contudo, ele está presente em boa parte dos levantamentos executados até a década de 80 .

b) Podem ocorrer flutuações na variação diurna que não foram medidas adequadamente na estação base, quer por serem localizadas ou por apresentarem um gradiente elevado. Elas poderiam afetar um conjunto de medidas ao longo de uma linha de aquisição e serem apenas parcialmente corrigidas pelos procedimentos de nivelamento de linhas de vôo.

c) Perfis adjacentes, cujas linhas de vôo apresentam sentidos opostos de aquisição, podem ser afetados por indução magnética na aeronave, o que gera um erro coerente entre perfis subseqüentes. 
d) Erros remanescentes das etapas de nivelamento das linhas de produção e de controle.

Embora esses erros residuais de nivelamento geralmente sejam pequenos, quando se empregam técnicas de processamento de imagens e de realce de visualização, eles são amplificados e reduzem a qualidade das imagens. Além disso, eles geram um ruído coerente que afeta as características espectrais da malha digital gerada.

\subsubsection{Tipos de erros removidos pela decorrugação}

A técnica da decorrugação pode remover as anomalias que apresentam as seguintes características:

- Comprimento de onda:

- Perpendicular à direção da linha de aquisição - menor ou igual a aproximadamente duas vezes o espaçamento entre as linhas de aquisição.

- Na direção da linha de aquisição - pelo menos duas vezes o espaçamento entre as linhas de controle.

Esses são comprimentos de onda mínimos próprios para as corrugações que se originam das causas citadas na seção anterior. Comprimentos de onda menores na direção das linhas de aquisição ou comprimentos de onda maiores na direção das linhas de controle aumentam o risco de se eliminar anomalias reais.

- Uma forma de onda simétrica. Esta premissa é feita de tal modo a se simplificar o procedimento da decorrugação.

- Um intervalo dinâmico relativamente pequeno. Por definição, as corrugações são erros pequenos.

As corrugações apresentam uma assinatura espectral característica, pois apresentam um pequeno comprimento de onda na direção perpendicular à direção das linhas de aquisição e um comprimento de onda longo na direção das linhas de aquisição. A Figura 8.2a ilustra a região de um levantamento que pode ser afetada pela corrugação quando esta é causada por um erro de nivelamento na interseção entre um perfil de produção e um perfil de controle.

\subsection{O MiCRONIVELAMENTO}

O micronivelamento aplica correções armazenadas em uma malha digital, geralmente oriundas da decorrugação, ao conjunto de linhas de vôo. $O$ objetivo desta etapa do processamento consiste em aplicar as correções obtidas no procedimento de decorrugação ao conjunto de linhas de vôo niveladas. Isso melhora a qualidade dos dados nos perfis, pois remove as corrugações que não foram detectadas pelos processos de nivelamento convencionais. Como o espaçamento entre os nodos da malha digital que contém as correções da decorrugação é muito maior do que o espaçamento entre fiduciais consecutivas ao longo das linhas de vôo, as correções devem ser interpoladas nas coordenadas de cada fiducial que compõem as linhas de vôo. 
a)

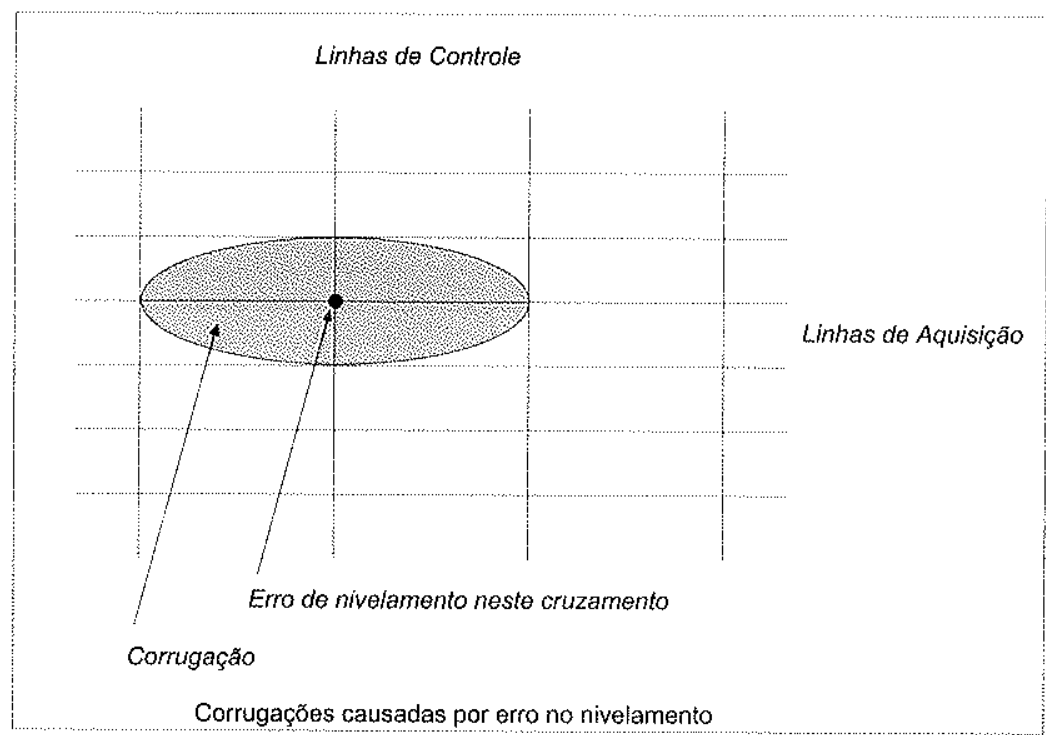

b)

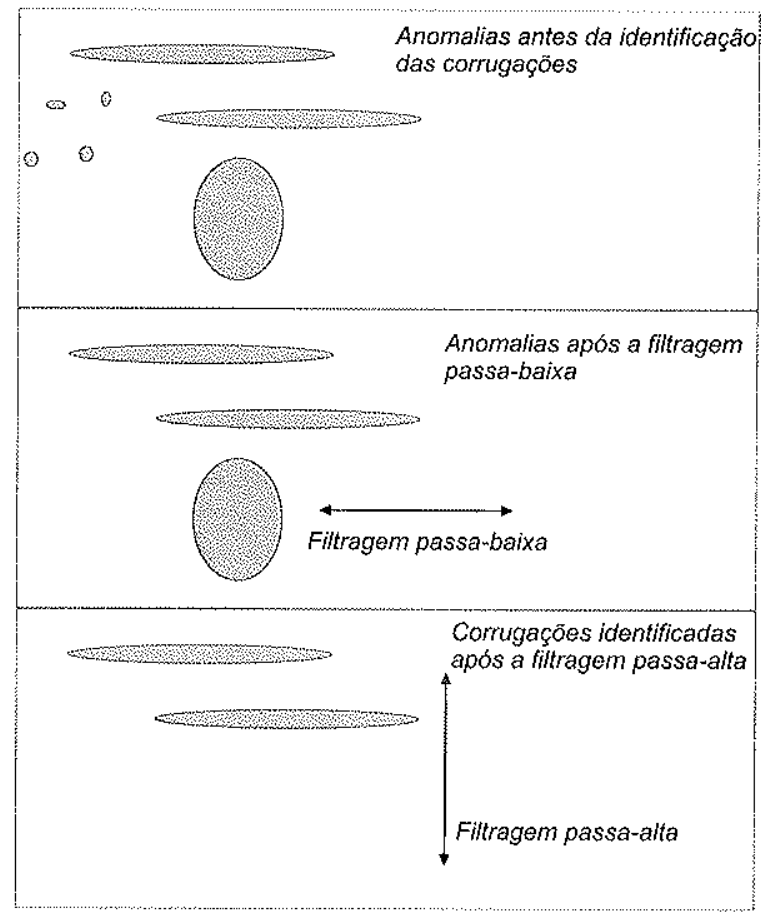

Figura 8.2 - Representação bidimensional das corrugações e do procedimento de decorrugação (Fitzgerald, 1996):

a) representação esquemática da região afetada pela corrugação causada por erro de nivelamento em um único ponto de cruzamento;

b) representação das duas etapas de filtragem envolvidas na decorrugação. 
A técnica do micronivelamento se baseia na suposição que os erros residuais nos dados são caracterizados por anomalias alongadas ao longo da direção das linhas de produção e que afetam apenas linhas individuais. Há duas restrições que devem ser feitas a respeito das características desses erros. A primeira é que, visualmente, esses erros afetam a malha digital ao longo de faixas que, teoricamente, podem ser detectadas e removidas da malha através da aplicação de filtros unidirecionais. A malha filtrada pode, então, ser usada para se corrigir os dados das linhas de vôo. A segunda restrição a respeito das características dos erros residuais é que se supõe que eles apresentam um intervalo dinâmico pequeno em torno de zero. A técnica de micronivelamento não é rigorosa e não pode distinguir entre erros de nivelamento e anomalias alongadas reais paralelas à direção das linhas de aquisição.

O procedimento de micronivelamento adotado a seguir é aquele descrito por Minty (1991). Embora existam outros algoritmos, eles não são públicos, constituindo-se de algoritmos proprietários de fabricantes de softwares para o processamento de dados aeromagnéticos ou de empresas que executam levantamentos aerogeofísicos (Luyendyk, 1997). Se for produzida uma malha digital a partir dos dados, então os erros residuais serão evidentes, assumindo a forma de anomalias espúrias alongadas caracterizadas por:

a) um comprimento de onda na direção das linhas de produção maior ou igual ao dobro do espaçamento entre as linhas de controle;

b) um comprimento de onda na direção perpendicular à direção das linhas de produção igual ao dobro do espaçamento entre as linhas de aquisição;

c) um intervalo dinâmico relativamente pequeno.

Se um dos eixos da malha digital for paralelo às linhas de produção, então as anomalias espúrias alongadas podem ser removidas da malha ao se aplicar filtros unidimensionais às linhas e colunas da malha. O procedimento (Minty, 1991; Luyendyk 1997) deve ser executado conforme descrito a seguir:

1) Criar uma malha digital $\mathbf{A}$ a partir das linhas de vôo niveladas. Aplicar um filltro passa-alta à malha digital A na direção perpendicular à direção das linhas de aquisição (Figura 8.3a).

Isso remove todos os dados, exceto aqueles com um comprimento de onda (perpendicular à direção das linhas de aquisição) menor ou igual a duas vezes o espaçamento entre as linhas de aquisição. Armazenar o resultado na malha digital B.

2) Aplicar um filltro passa-baixa à malha digital $\mathbf{B}$ na direção das linhas de aquisição (Figura $8.3 b)$.

Isso remove todos os dados, exceto aqueles com um comprimento de onda (na direção das linhas de aquisição) maior do que duas vezes o espaçamento entre as linhas de controle. Armazenar o resultado numa malha digital $\mathbf{C}$. A malha digital $\mathbf{C}$ deveria, agora, conter apenas anomalias com a forma das corrugações que se deseja remover.

3) Restringir o intervalo dinâmico da malha digital $\mathbf{C}$ de tal modo que todos os valores situemse entre dois limites predefinidos. Quaisquer valores situados fora dos limites devem ser 
a)

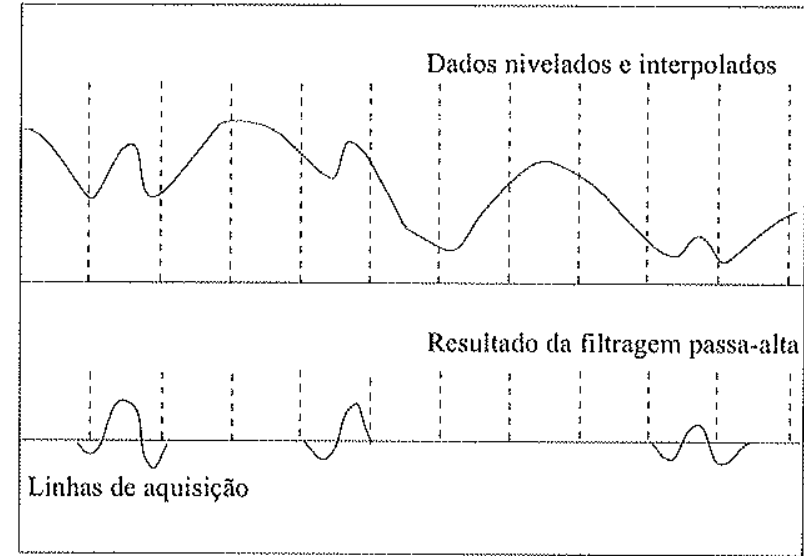

Filtragem passa-alta

b)

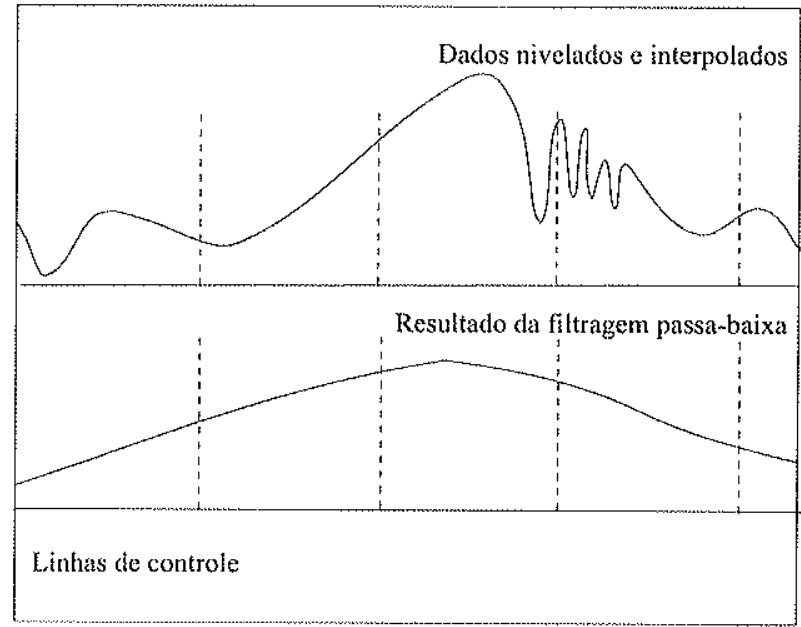

Filtragem passa-baixa

c)

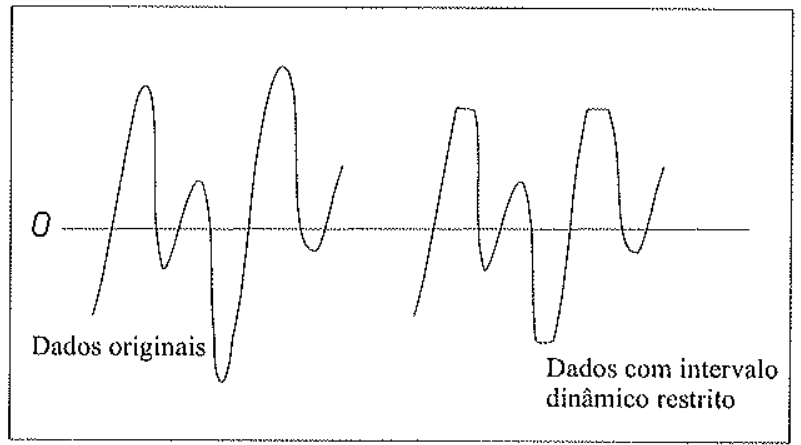

Restrição do intervalo dinâmico

Figura 8.3 - Aplicação de filtros unidimensionais à decorrugação e ao micronivelamento (Minty, 1991; Fitzgerald, 1996):

a) filtragem passa-alta na direção perpendicular à direção das linhas de aquisição;

b) filtragem passa-baixa na direção paralela à direção das linhas de aquisição;

c) restrição do intervalo dinâmico das corrugações. 
fixados como sendo iguais aos limites. A malha digital $\mathbf{C}$, agora, representa apenas os erros residuais, ou seja, as correções a serem feitas (Figura 8.3c).

4) Subtrair a malha digital $\mathbf{C}$ da malha digital $\mathbf{A}$ de tal forma a se produzir uma malha digital sem corrugações.

A Figura $8.2 \mathrm{~b}$ ilustra bidimensionalmente as duas etapas de filtragem envolvidas no processo de decorrugação.

Segundo Minty (1991), as etapas (1) e (2), descritas anteriormente, podem ser intercambiadas sem prejuízo para o resultado final. Assim, tanto faz executar primeiro a filtragem passa-alta na direção perpendicular às linhas de produção e depois a passa-baixa na direção paralela às linhas de produção ou efetuar primeiro a filtragem passa-baixa na direção paralela às linhas de produção e, em seguida, a passa-alta na direção perpendicular às linhas de produção. A malha digital $\mathbf{C}$ vai ser exatamente a mesma.

Embora conceitualmente simples, a implementação deste procedimento é complicada, devido às limitações dos filtros digitais e à amplitude sutil dos erros quando comparada com o intervalo dinâmico dos dados originais. Os filtros aplicados devem detectar todos os erros residuais, mas ao mesmo tempo devem excluir tantas anomalias reais quanto for possível, além de não introduzirem qualquer tipo de feição artificial. Ou seja, eles devem extrair os erros residuais com o comprimento de onda mais longo possivel ao longo das linhas de produção, com o menor comprimento de onda possível na direção perpendicular às linhas de aquisição, e com o menor intervalo dinâmico de tal modo que o procedimento ainda seja capaz de produzir uma malha digital que seja, visualmente, bem nivelada. Este objetivo só pode ser atingido por tentativa e erro, variando-se os comprimentos de onda de corte dos filtros, e variando-se os intervalos dinâmicos permitidos para as várias malhas digitais filtradas.

Computacionalmente, a eliminação das corrugações através da filtragem no domínio da freqüência, através do emprego de um filtro do tipo co-seno direcional, é mais simples de ser implementada do que o procedimento descrito anteriormente. Contudo, ela atenua muitas anomalias reais que não apresentam características de corrugação.

Luyendyk (1997) sugere os seguintes valores como sendo uma boa aproximação inicial para os parâmetros do procedimento de remoção das corrugações:

a) um comprimento de onda longo da ordem de 1 a 3 vezes o espaçamento entre as linhas de controle;

b) um comprimento de onda curto igual a 2 vezes o espaçamento entre as linhas de aquisição;

c) adotar valores limites para o intervalo dinâmico situados entre 5 e $10 \mathrm{nT}$.

Embora a técnica de micronivelamento seja conceitualmente simples, o desenvolvimento de filtros adequados para a sua implementação não o é. Várias técnicas de filtragem têm sido analisadas por outros autores, sendo que Luyendyk (1997) e Fitzgerald (1996) sugerem que a seguinte combinação tem apresentado os methores resultados:

a) filtro não linear de Naudy (Naudy \& Dreyer, 1968) para a filtragem passa-alta; 
b) filtro convolutivo passa-banda de Fuller (Fraser et al., 1966) para a filtragem passabaixa.

\subsection{Possíveis Limitações da Decorrugação}

A técnica da decorrugação pode eliminar anomalias reais se elas tiverem comprimentos de onda característicos de corrugações. Se existirem erros adjacentes com magnitudes similares, a decorrugação vai detectar apenas as diferenças entre esses erros (nesse caso, a decorrugação feita através de técnicas de filtragem espectral no domínio da freqüência teria desempenho superior).

Embora o filtro de Naudy não seja um filtro verdadeiro de freqüências, ele tem a sua operação baseada na deteç̧ão de anomalias de comprimento de onda mais curto do que o comprimento de onda de corte. Tais anomalias são substituídas pela interpolação dos valores de anomalias vizinhos. Este filtro é particularmente eficiente como um filtro passa-alta, geralmente empregado para detectar ruído de alta freqüência. Deve-se ressaltar que (Fitzgerald, 1996; Luyendyk, 1997):

a) ele é projetado para remover completamente as anomalias com comprimento menor do que o corte preestabelecido, enquanto que aquelas com comprimento maior do que aquele do corte mantêm a sua forma original;

b) o algoritmo de deteç̧ão de anomalias não é à prova de erros, e algumas anomalias podem não ser removidas;

c) o procedimento de interpolação vai manter alguns dados com comprimento de onda menor do que aquele pretendido para o corte.

A técnica de convolução de Fuller também não é perfeita: a resposta do filtro no entorno do comprimento de onda de corte não é abrupta, e requer-se que os perfis de dados sejam extrapolados para permitir que sejam calculados valores filtrados próximos às extremidades dos perfis. Portanto (Fitzgerald, 1996; Luyendyk, 1997):

a) vai ocorrer contaminação no entorno das anomalias cujos comprimentos de onda sejam comparáveis ao comprimento de onda do corte do filtro passa-baixa;

b) quando ocorre uma anomalia com grande amplitude e curto comprimento de onda, o nivel de base dos dados filtrados no entorno dessa anomalia é elevado, produzindo uma feição artificial semelhante aos erros residuais que se deseja remover;

c) ao se filtrar comprimentos de onda muito longos, para que o programa seja computacionalmente eficiente, é necessário que se restrinja o número de coeficientes do operador de convolução, o que faz com que os dados sejam subamostrados. Isso resulta na introdução de um ruído de alta freqüência num comprimento de onda igual àquele do intervalo subamostrado.

Para que ambos os filtros (Naudy e Fuller) possam ser aplicados, requer-se que as malhas digitais de dados sejam extrapoladas, de tal modo que valores filtrados possam ser determinados próximo aos limites das malhas. Dependendo da situação, o algoritmo de extrapolação pode introduzir dados com freqüências acima da freqüência de corte desejada. Além disso, as técnicas de extrapolação podem produzir efeitos de borda indesejáveis, 
principalmente se ocorrerem anomalias com grandes amplitudes nas extremidades dos perfis filtrados.

No Capítulo 6 foram apresentadas as versões passa-baixa dos filtros recursivos de Butterworth, Chebyshev dos tipos I e II, e elíptico. Contudo, esses mesmos filtros podem ser desenhados nas versões passa-alta, passa-banda ou rejeita-banda (Parks \& Burrus, 1987; Ginde \& Noronha, 1998), mantendo as mesmas características com relação à oscilação nas bandas de passagem e rejeição, dimensão da zona de transição, ordem do filtro, etc. que dos filtros passabaixa apresentados anteriormente. Desses filtros, o filtro do tipo elíptico é aquele que apresenta a menor largura da banda de transição, além de poder ser implementado com um menor número de coeficientes do que os demais filtros.

Como alternativa ao filtro convolutivo de Fuller para a filtragem passa-baixa, Braggion Jr. (1998) sugere o emprego de filtros recursivos do tipo elíptico, pois estes não têm os problemas apresentados pelo filtro de Fuller: eles podem ser implementados com um número pequeno de coeficientes; a largura da banda de transição é mais estreita do que aquela apresentada pelo filltro de Fuller; eles não geram feições artificiais elevando o nível de base das anomalias; os filtros elípticos não geram efeitos de borda nas extremidades dos perfis que estão sendo filtrados (conforme pode ser visto nos exemplos apresentados no Capítulo 6). Como alternativa ao emprego do filtro de Naudy para a filtragem passa-alta, também sugere-se o emprego de filtros recursivos do tipo elíptico (desenhados na versão passa-alta).

Os desempenhos de três técnicas de decorrugação de malhas digitais são comparados a seguir. Foram utilizadas: a decorrugação espectral (através da aplicação de um filtro do tipo coseno direcional no domínio da frequiência), e a decorrugação feita no domínio espacial (aplicando-se filtros unidimensionais às linhas e colunas da malha digital). Para a filtragem espacial foram empregados os filtros de Naudy e Fuller (segundo sugerido por Luyendyk (1997), Fitzgerald (1996) e Fuck (2001)), e os filtros recursivos do tipo elíptico (sugeridos por Braggion Jr (1998)).

As Figuras 8.4, 8.5 e 8.6 apresentam o resultado da aplicação dessas três técnicas de filtragem, respectivamente, às malhas digitais dos projetos PASPRJ (subárea 4), PAESB, e PASMS. Todas elas foram capazes de remover as corrugações causadas pelos erros de nivelamento que afetam esses três projetos. Contudo, conforme pode ser observado, a técnica da decorrugação espectral (filtro co-seno direcional) apresentou um desempenho indesejado, pois a sua aplicação gerou intensas distorções na direção perpendicular à direção das linhas de produção dos projetos (distorções E-W para o PASPRJ e PAESB, e distorções NE para o PASMS). A aplicação dos filtros de Naudy e Fuller também gerou distorções na direção perpendicular à das linhas de aquisição, contudo, elas são bern menos intensas do que aquelas produzidas pelo filtro co-seno direcional. A aplicação dos filtros recursivos do tipo elíptico gerou as melhores representações do campo magnético anômalo. Não são observadas distorções na direção perpendicular à direção das linhas de aquisição, e a forma das anomalias magnéticas é preservada. 


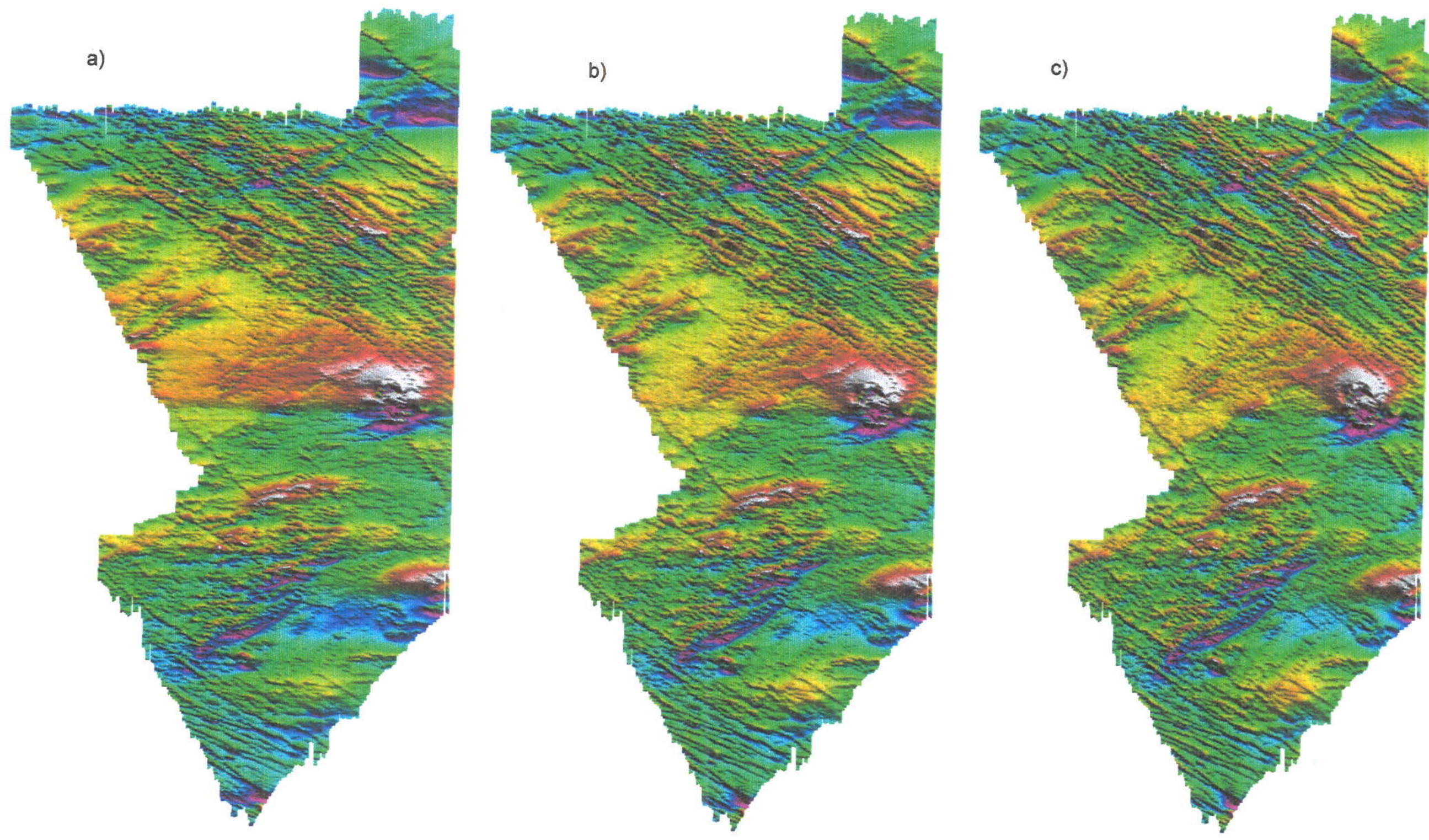

Figura 8.4 - Decorrugação da subárea 4 do PASPRJ: a) filtro co-seno direcional; b) filtros de Naudy e Fuller; c) filtro recursivo elíptico. 


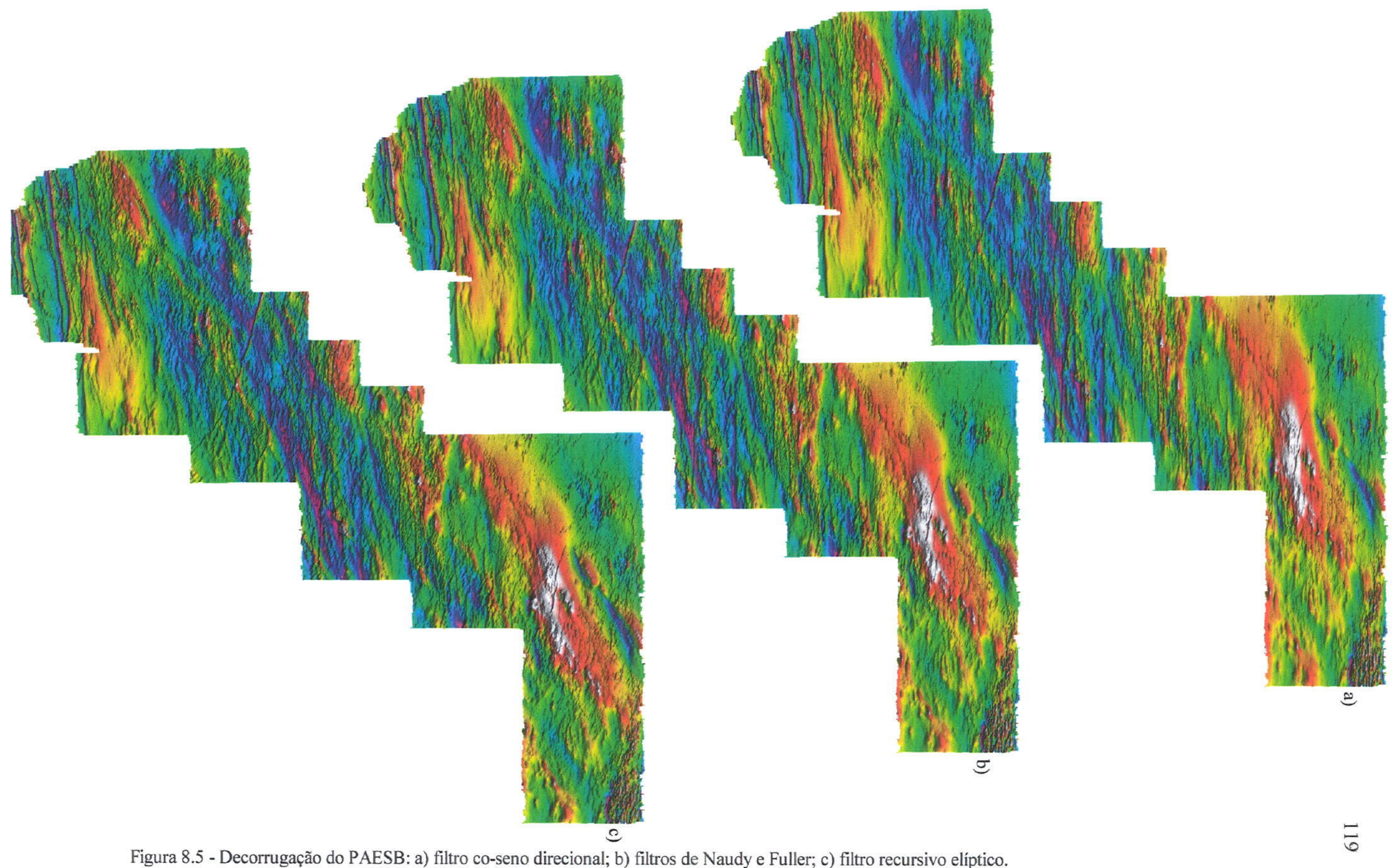

Figura 8.5 - Decorrugação do PAESB: a) filtro co-seno direcional; b) filtros de Naudy e Fuller; c) filtro recursivo elíptico. 
a)

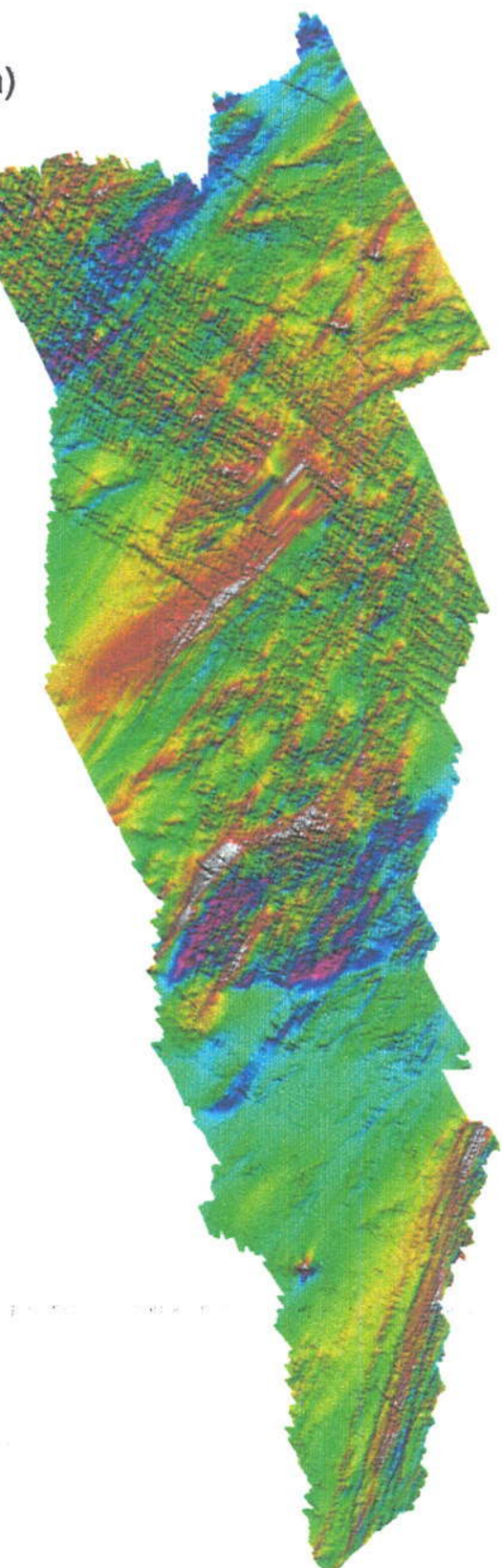

b)

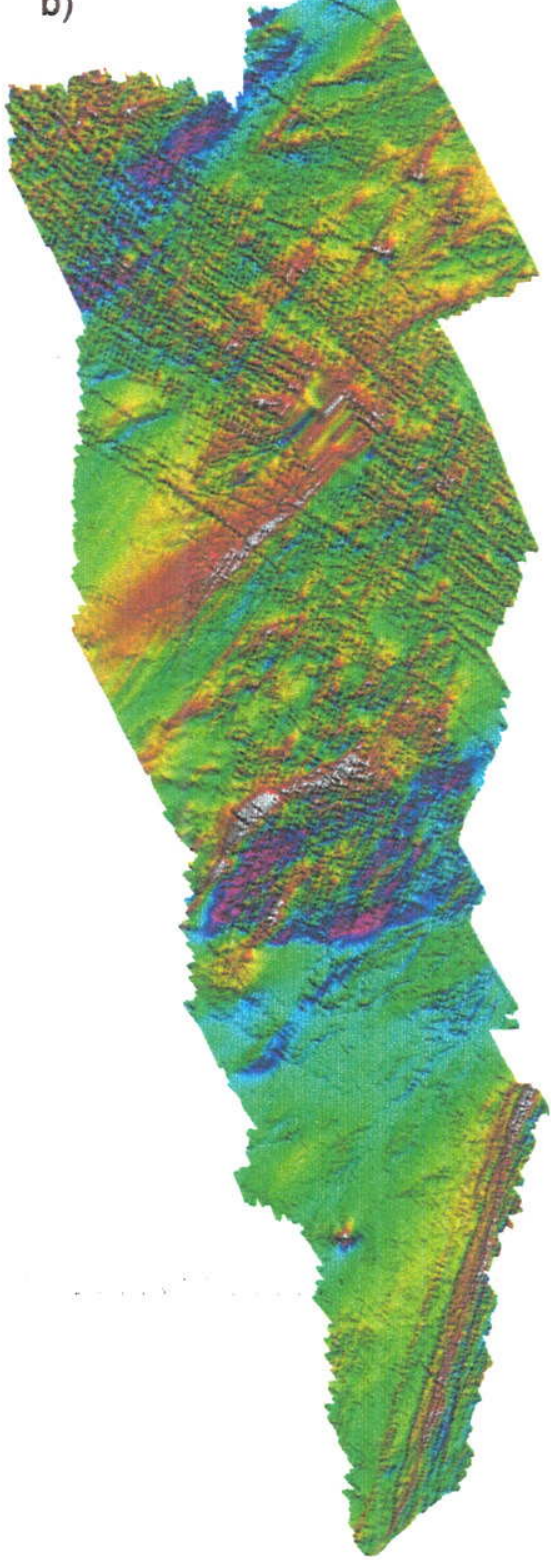

c)

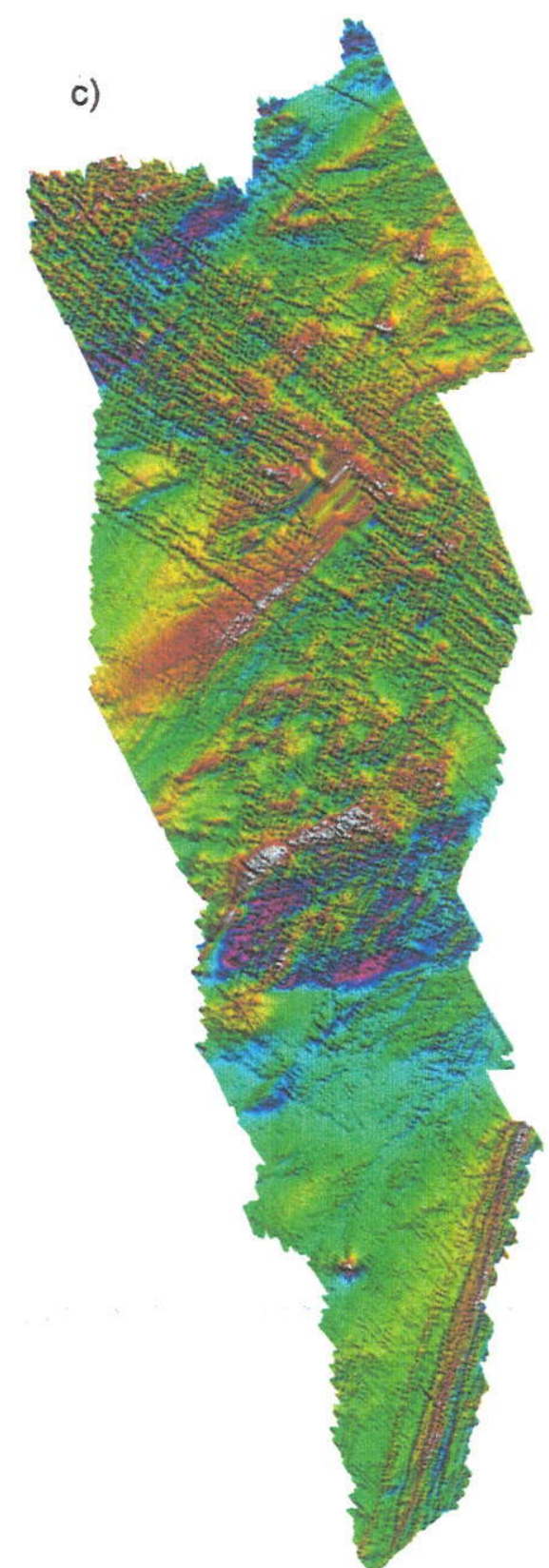

Figura 8.6 - Decorrugação do PASMS: a) filtro co-seno direcional; b) filtros de Naudy e Fuller; c) filtro recursivo elíptico. 


\section{CAPÍTULO 9 \\ O EMPREGO DE FASORES PARA A DISCRIMINAÇÃO DE COMPONENTES HARMÔNICAS E RUIDO}

\subsection{INTRODUÇÃo}

A transformada de Fourier é o método empregado com maior freqüência para a análise de séries temporais e espaciais, principalmente na tentativa de se identificar sinais harmônicos, mesmo aqueles de pequena amplitude, na presença de ruído. É prática comum que pequenos picos espectrais, projetados moderadamente acima do nível interpretado como sendo de ruído, sejam considerados como sinal harmônico. A menos do emprego de outras informações, baseando-se somente na análise visual do espectro, não se pode afirmar se estes picos espectrais são causados acidentalmente por uma interferência construtiva de ruído ou se são devidos a um sinal harmônico de pequena amplitude mascarado por ruído com amplitude elevada. $\mathrm{O}$ sinal harmônico pode estar presente apenas em partes isoladas das séries temporal/espacial, e não ao longo de toda a sua extensão, ou a sua fase pode apresentar variações temporais ao longo do registro do sinal. Esses dois efeitos têm como resultado a redução da amplitude da transformada de Fourier relativamente ao nível do rúdo. Desse modo, é necessário que se lance mão de outras técnicas de análise quando não há nenhuma informação a priori a respeito do comportamento espectral que se deve esperar a partir do sinal observado.

\subsection{OS FASORES}

A denominação fasor aplica-se a vetores que rotacionam com uma velocidade angular constante (Sheriff, 1991). A técnica da análise da trajetória dos fasores, que também é conhecida pelos nomes de Transformada de Fourier Gráfica ou Demodulação Complexa, tem sido aplicada em sismologia para a investigação da presença de sinais harmônicos em séries temporais e na análise de registros de gravímetros supercondutores (Zürn \& Rydelek, 1994), na análise de registros de marés terrestres (Zürn et al. 1995), e na análise de catálogos sísmicos (Rydelek \& Sacks, 1989), não sendo do conhecimento deste autor outras aplicações desta técnica, em geofísica, fora das áreas citadas. Schimmel et al (2002) introduzem a técnica de análise de fasores, em medicina, para a identificação de ciclos de temperatura em recém nascidos.

Na análise de fasores, para uma dada freqüência de teste soma-se vetorialmente no plano complexo as contribuições complexas (fasores) de cada uma das amostras, tomadas numa série amostrada a intervalos eqüidistantes, para a formação da transformada de Fourier. Essa representação gráfica gera um padrão, ou trajetória, que pode ser empregada para extrair informações sobre as propriedades do sinal, e que não são facilmente obtidas por outros métodos espectrais (Zürn \& Rydelek, 1994; Schimmel et al. 2002). 


\subsection{DESCRIÇÃO DO MÉTODO}

Seja dada uma série temporal $x_{k}, k=1, N$ amostrada a intervalos regulares, com intervalo de amostragem $\Delta t$. Supõe-se, a partir de alguma informação a priori ou por inspeção visual do espectro da série temporal, que um sinal com freqüência $f_{s}$ e freqüência angular $\omega_{s}=2 \pi f_{s}$ possa estar presente na série temporal. A contribuição de cada amostra quer para a transformada de Fourier ou para a trajetória do fasor é dada por (Zürn \& Rydelek, 1994):

$$
p_{k}\left(\omega_{s}\right)=x_{k} \exp \left(-i \omega_{s}(k-1) \Delta t\right)
$$

Essa contribuição pode ser entendida como um vetor ou fasor no plano complexo. A sua magnitude é dada por $x_{k}$, e a fase é representada pelo termo $\exp \left(-i \omega_{s}(k-1) \Delta t\right)$. Somando-se graficamente esses vetores, sucessivamente para $i=1$ até $N$, produz-se a trajetória dos fasores. A soma vetorial de todos os fasores é uma representação gráfica da transformada de Fourier da série temporal $x_{k}$ para a freqüência de teste $f_{s}$ :

$$
X\left(\omega_{s}\right)=\sum_{k=1}^{N} p_{i}
$$

Como a transformada de Fourier de uma série amostrada em pontos eqüidistantes é periódica no domínio da frequêencia, o emprego de freqüêencias de teste maiores do que a freqüência de Nyquist $f_{N}=1 /(2 \Delta t)$ é equivalente ao emprego da freqüência alias no intervalo entre $f_{s}=0$ e $f_{s}=f_{N}$.

A evolução temporal/espacial da trajetória dos fasores contém informação importante que é perdida se apenas o resultado final - a transformada de Fourier - for apresentado. Nos exemplos a seguir, são empregadas cores diferentes associadas a trechos distintos nas séries espaciais analisadas. A mesma convenção de cores é mantida na análise da trajetória dos fasores. Desse modo, torna-se possível discriminar quais porções da série espacial contêm a freqüência de teste.

Se a freqüência de teste for idêntica à freqüência de um pico espectral da série espacial, então a distância no plano complexo entre o ponto inicial (a origem no plano complexo) e o ponto final da trajetória (a magnitude da transformada de Fourier) é maior do que aquelas para freqüuencias de teste situadas na vizinhança daquele pico. Por outro lado, se a componente harmônica não estiver presente ao longo de toda a série espacial ou se a sua fase variar, então a soma vetorial dos fasores pode ser menor do que a soma de cada uma das suas componentes.

O fator exponencial complexo na equação (9.1) representa um fasor unitário que rotaciona um ângulo $\omega_{s} \Delta t$ em sucessivos intervalos $\Delta t$. $O$ fator $x_{k}$ define a magnitude do fasor no instante $k$. O ângulo entre os fasores rotaciona aproximadamente $2 \pi \mathrm{em} K$ intervalos sucessivos, onde $K=2 f_{N} / f_{s}$. Esta propriedade dos fasores resulta em figuras na forma de laço (loops) conforme mostrado nas figuras. 
Se a freqüência de teste for idêntica à freqüência $f_{0}$ do sinal harmônico, resulta-se numa trajetória retilínea para o deslocamento dos fasores, pois as mudanças de sinal e direção vão ocorrer em fase (Zürn \& Rydelek, 1994; Schimmel et al. 2002). Isto ocorre pois as grandes contribuições para o deslocamento sempre apontam na mesma direção, enquanto que as contribuições de pequena magnitude para o deslocamento tendem a ser ortogonais à direção da fase da componente harmônica. Para freqüências de teste ligeiramente diferentes da freqüência da componente harmônica presente no sinal, a trajetória de deslocamento dos fasores começa a se tornar ligeiramente curvada, dependendo a direção da curvatura do sinal da diferença entre a freqüências harmônicas e de teste. Uma vez que a curvatura aumenta com a diferença entre essas freqüências, pode-se usar a linearidade da trajetória do deslocamento dos fasores para se determinar com precisão a frequência do sinal presente na série $x_{k}$. A presença de mudanças abruptas na fase do sinal harmônico resulta numa mudança de direção da trajetória retilínea do deslocamento dos fasores.

Para uma série constante $x_{k}=c$, os fasores produzem polígonos com $K$ lados, e os seus diâmetros dependem do valor adotado para a constante. Se $K$ é inteiro, os polígonos são alinhados e fechados; se $K$ não é inteiro, os polígonos encontram-se sucessivamente rotacionados com relação aos anteriores.

\subsection{EXEMPLOS SINTÉTICOS}

Para exemplificar a potencialidade de emprego do método, a técnica descrita anteriormente foi aplicada a um sinal harmônico com frequiência $f_{0}$ de $50 \mathrm{~Hz}$ (Figura 9.1) sem a adição de ruído, e ao mesmo sinal só que corrompido por ruído branco (Figura 9.2). A Figura 9. la contém o sinal amostrado, com intervalo de amostragem de $0,001 \mathrm{~s}$ e freqüência de $50 \mathrm{~Hz}$. As Figuras 9.1 b até 9.1e apresentan a representação gráfica da trajetória dos fasores (em azul), calculadas respectivamente para as freqüências de teste $f_{s}$ de $30,49,50,51$ e $60 \mathrm{~Hz}$; nas mesmas Figuras está representado em magenta a direção da fase da transformada de Fourier para a freqüência de teste. Para as $f_{s}$ de 30 e $60 \mathrm{~Hz}$, distantes da freqüência $f_{0}$, observa-se que os fasores apresentam trajetórias cíclicas, indicando que as freqüências de teste não estão presentes no sinal analisado. Quando se empregam freqüências de teste de 49 e $51 \mathrm{~Hz}$, Figuras 9.1 c e 9.1 e, próximas à freqüência da componente harmônica presente no sinal, observa-se que a trajetória dos fasores apresenta um comportamento curvo. Este indicativo sugere que no sinal analisado existe uma componente harmônica cuja freqüência é próxima à freqüência de teste utilizada para gerar a trajetória analisada. Quando $f_{s}=f_{0}$, Figura 9.1d, obtém-se uma trajetória retilínea para a trajetória dos fasores, conforme citado anteriormente.

A Figura 9.2a apresenta o mesmo sinal da Figura 9.1a, só que corrompido pela adição de ruído branco. As Figuras $9.2 \mathrm{~b}$ a $9.2 \mathrm{f}$ foram geradas empregando-se as mesmas freqüências de teste adotadas na Figura 9.1. Constata-se, pelas Figuras $9.2 \mathrm{c}, 9.2 \mathrm{~d}$ e $9.2 \mathrm{e}$, que o método é robusto quanto à presença de ruído branco, e que a adição de ruído pouco afetou a trajetória dos fasores quando se emprega uma freqüência de teste correspondente à freqüência da componente harmônica presente no sinal. 
a)

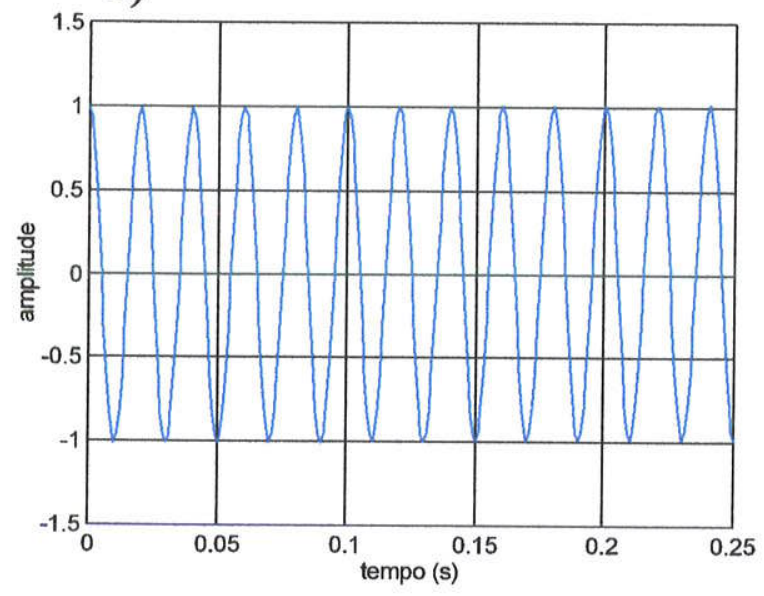

c)

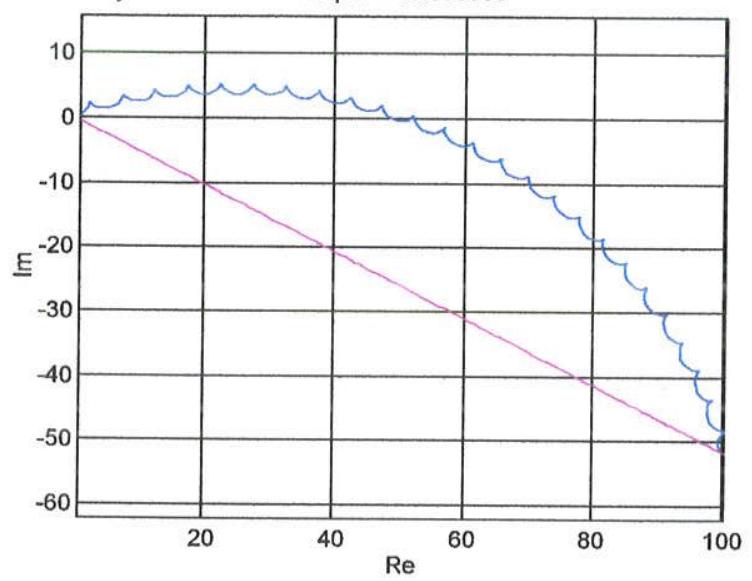

e)

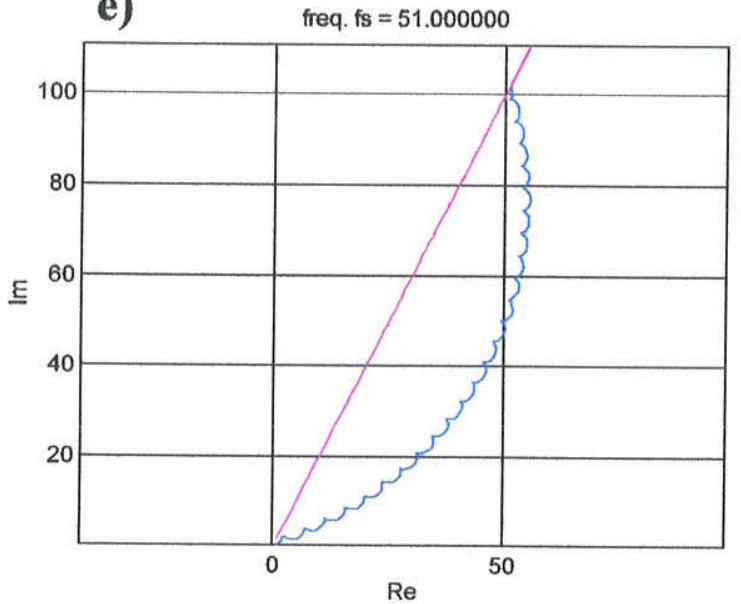

b)

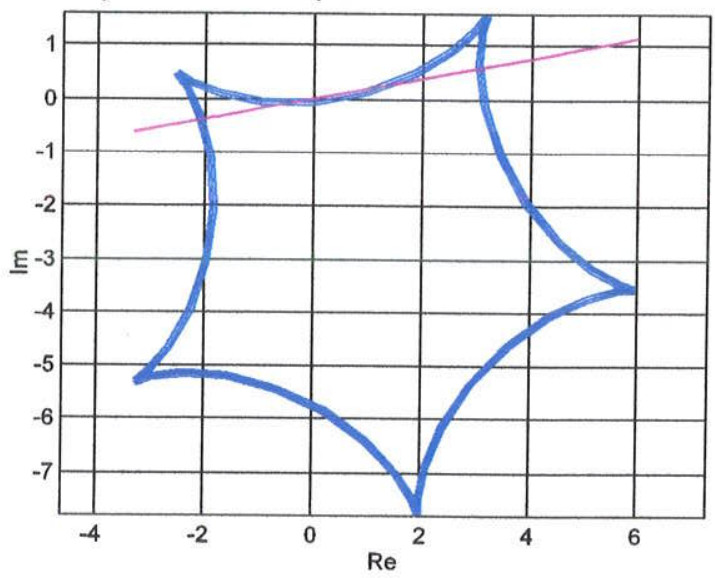

d)

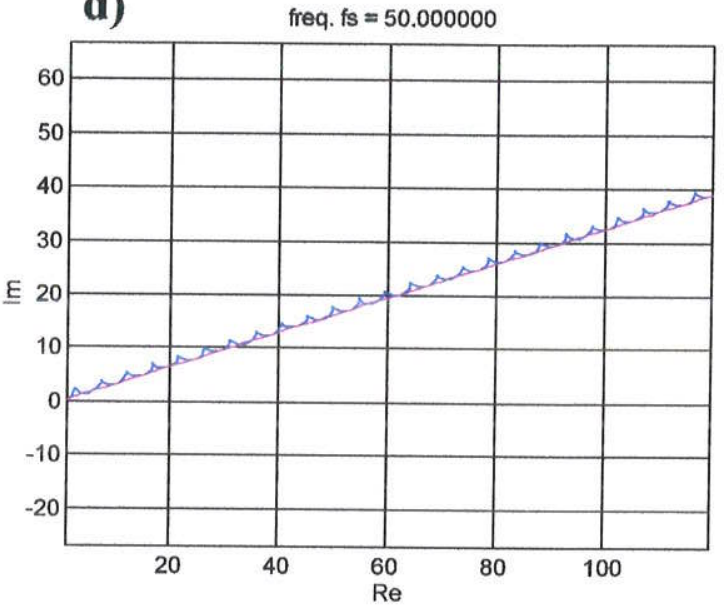

f)

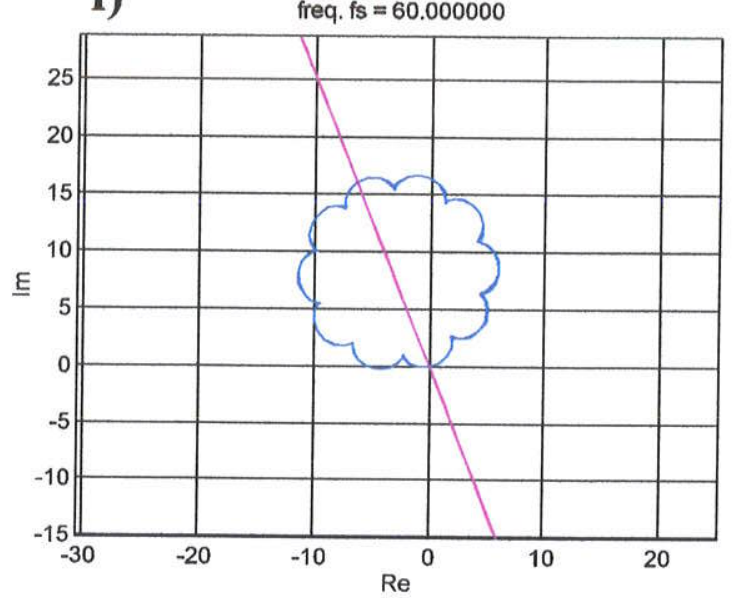

Figura 9.1 - Análise de fasores para um sinal sintético sem ruído:

a) sinal sintético com freqüência de $50 \mathrm{~Hz}$; trajetória dos fasores para as freqüências de teste de $30 \mathrm{~Hz}$ (b), $49 \mathrm{~Hz}$ (c), $50 \mathrm{~Hz}$ (d), $51 \mathrm{~Hz}$ (e), $60 \mathrm{~Hz}$ (f). 
a)

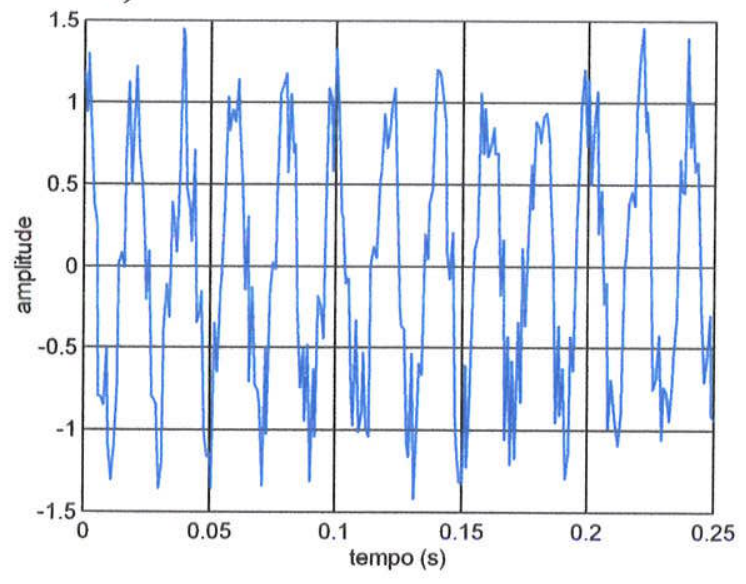

c)

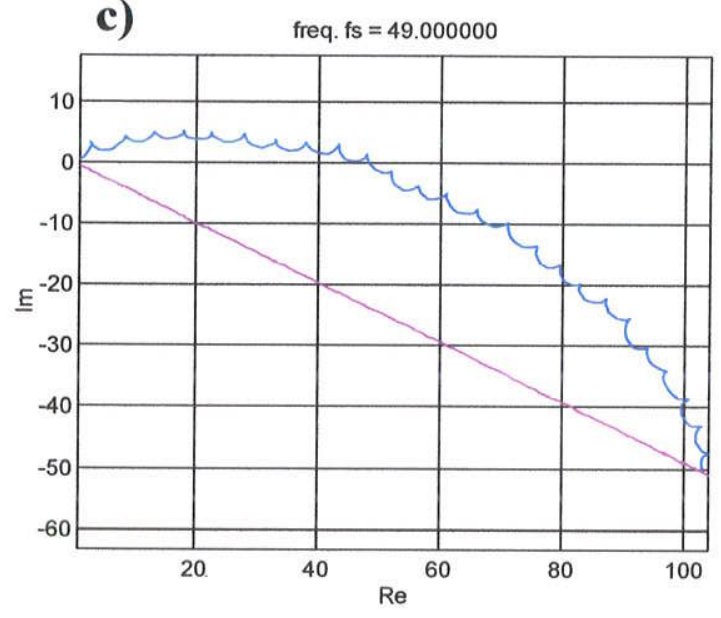

e)

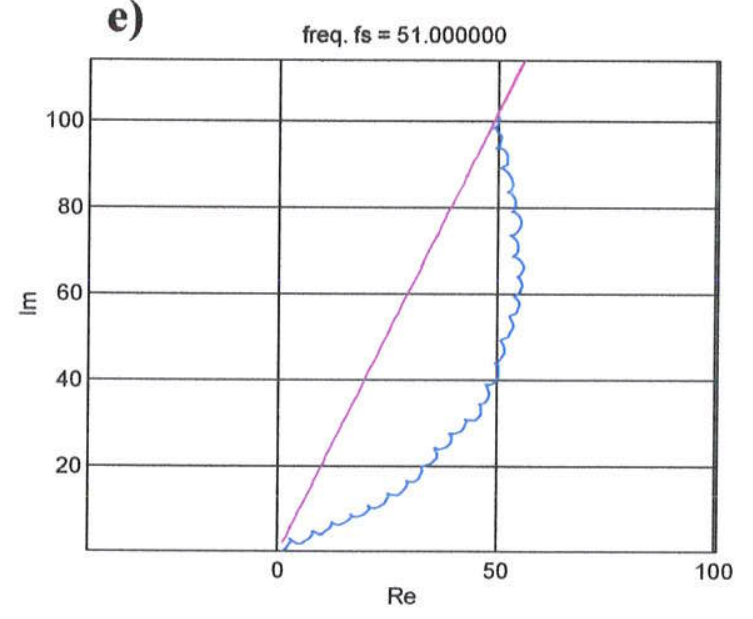

b)

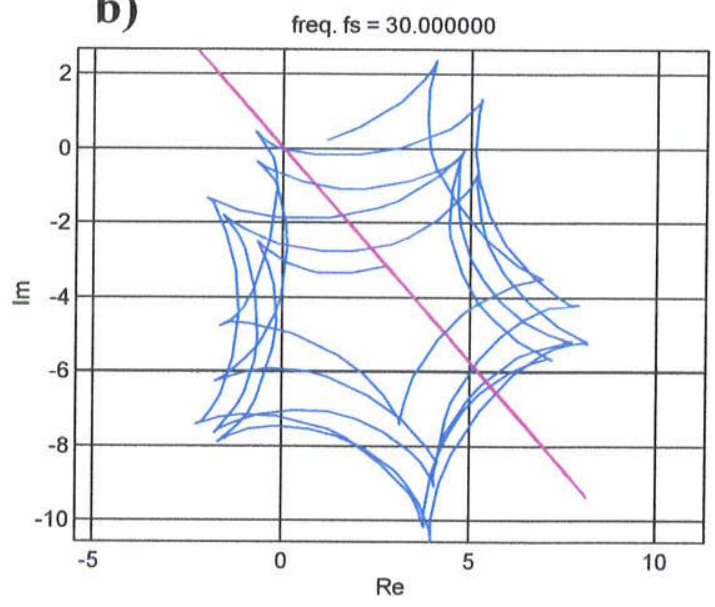

d)
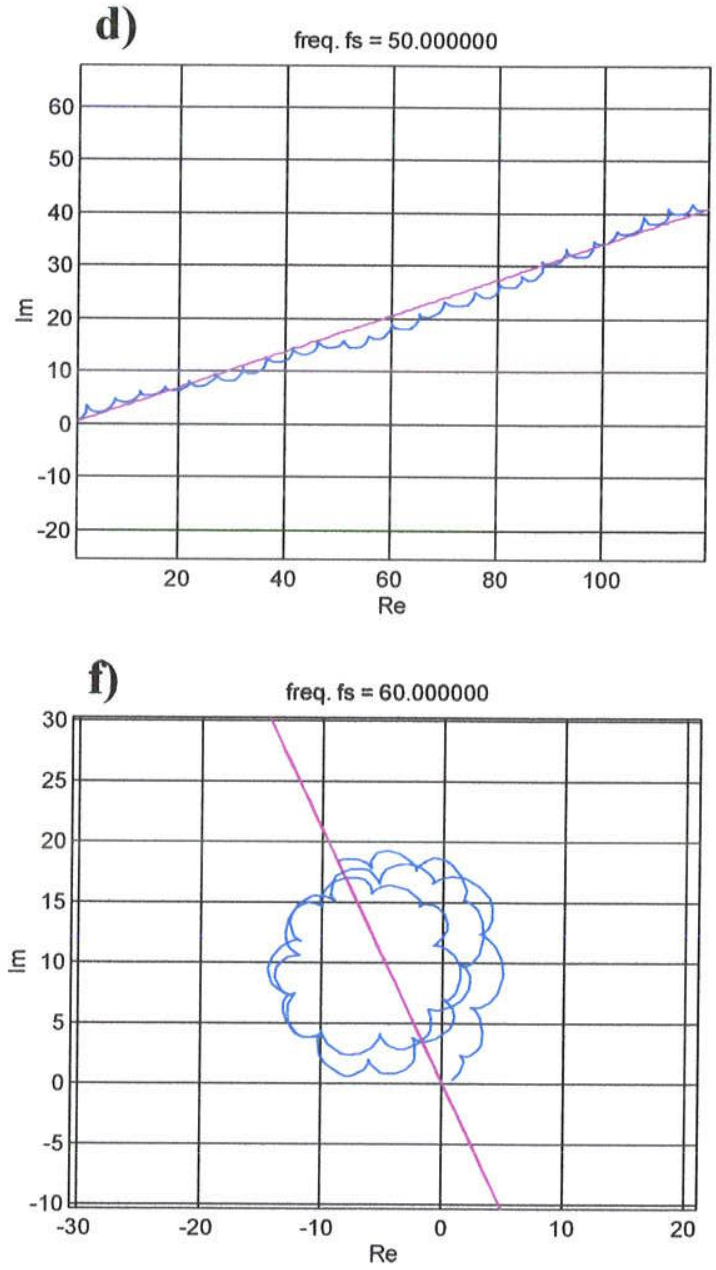

Figura 9.2 - Análise de fasores para um sinal sintético com ruído:

a) sinal sintético com freqüência de $50 \mathrm{~Hz}$ adicionado a ruído branco; trajetória dos fasores para as freqüências de teste de $30 \mathrm{~Hz}$ (b), $49 \mathrm{~Hz}$ (c) $50 \mathrm{~Hz}$ (d), $51 \mathrm{~Hz}(\mathrm{e}), 60 \mathrm{~Hz}$ (f). 


\subsection{CONSIDERAÇÕEs Gerais}

Conforme citado anteriormente, uma das dificuldades do emprego das técnicas tradicionais de análise de espectros de amplitude consiste em se determinar se um dado pico espectral corresponde, de fato, à existência de uma componente harmônica presente no sinal ou se ele é devido a uma interferência construtiva de ruído. Em outras situações pode-se estar interessado em determinar qual o nível de ruido branco presente no sinal analisado para, posteriormente, determinar-se qual a freqüencia de corte correta a ser aplicada a diversos tipos de filtros passa-baixa. Esta é uma escolha crítica, pois se for empregada uma freqüência de corte abaixo da correta, estará sendo eliminada uma porção importante do sinal onde residem informações de detalhe sobre a geometria dos corpos fontes de anomalia (Reid, 1980). Se a freqüência de corte adotada for maior do que aquela que define o nível de ruído branco, estará se permitindo que o sinal seja corrompido por ruído de alta freqüência. A presença deste tipo de ruído, certamente, vai influenciar o desempenho de diversas técnicas de processamento e inversão de dados aeromagnéticos, principalmente aquelas que fazem uso das derivadas do sinal (operações de nivelamento de dados, redução ao pólo, cálculo de susceptibilidade magnética aparente, etc.). A freqüência associada ao nível de ruído branco é aquela a partir da qual o espectro de amplitude do sinal apresenta-se horizontalizado, ou seja, é a freqüência a partir da qual todas as componentes espectrais contribuem igualmente para a formação do espectro (Bath, 1974; Sheriff, 1991). A identificação da freqüência associada a tal patamar pode não ser simples no caso de dados aeromagnéticos. Conforme pode ser visto na Figura 5.6, os espectros das linhas de vôo dos dados aeromagnéticos das subáreas dos Projetos Aerogeofísicos Extremo Sudeste do Brasil e São Paulo/Rio de Janeiro, apresentam:

a) um decaimento linear na porção de baixas freqüências, indicando a predominância de sinal sobre ruído;

b) uma região curva na porção de freqüências intermediárias, onde a influência do ruido já é maior do que na região anterior;

c) uma ultima região, na porção de freqüências mais elevadas, onde o espectro tende a se horizontalizar, caracterizando a predominância de ruído branco.

A identificação da freqüência exata onde ocorre a transição entre a porção em que predomina o sinal sobre o ruído para a porção em que predomina o ruído branco é subjetiva, e varia de intérprete para intérprete. A representação gráfica da trajetória dos fasores auxilia a identificação da região espectral em que ocorre a transição sinal/ruído, tornando esse procedimento menos subjetivo. Além disso, ela permite identificar em quais porções do sinal está presente a freqüência de teste analisada.

\subsection{AplicaÇão a Perfis Aeromagnéticos do Projeto São Paulo/Rio de Janeiro}

A Figura 9.3 apresenta a aplicação da técnica descrita anteriormente para uma linha de vôo típica da subárea 4 do Projeto Aerogeofísico São Paulo/Rio de Janeiro. A Figura 9.3a contém a anomalia magnética residual, representadas em 4 cores: em vermelho está a primeira porção do perfil, caracterizado por anomalias de médio comprimento de onda e de amplitudes moderadas; o segundo segmento do perfil, em verde, é caracterizado por anomalias magnéticas residuais com grande amplitude e com comprimentos de onda médios e pequenos; as duas 
a)
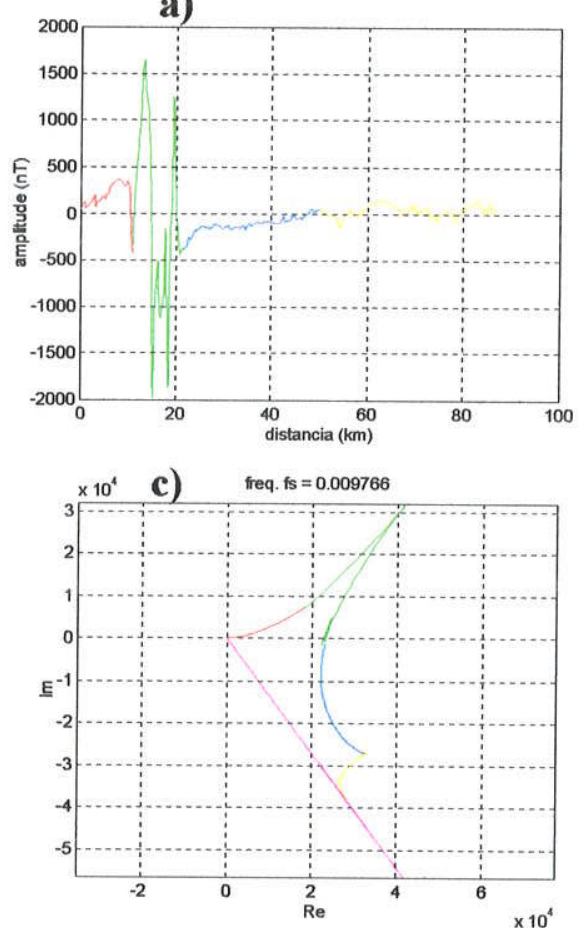

e) freq. $\mathrm{s}=0.732422$

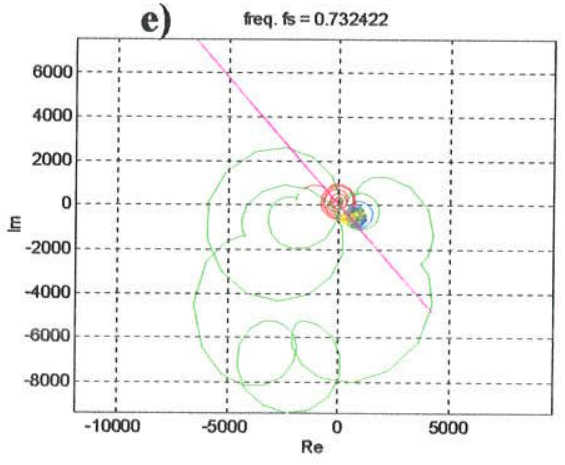

g) freq. fs $=0.947266$
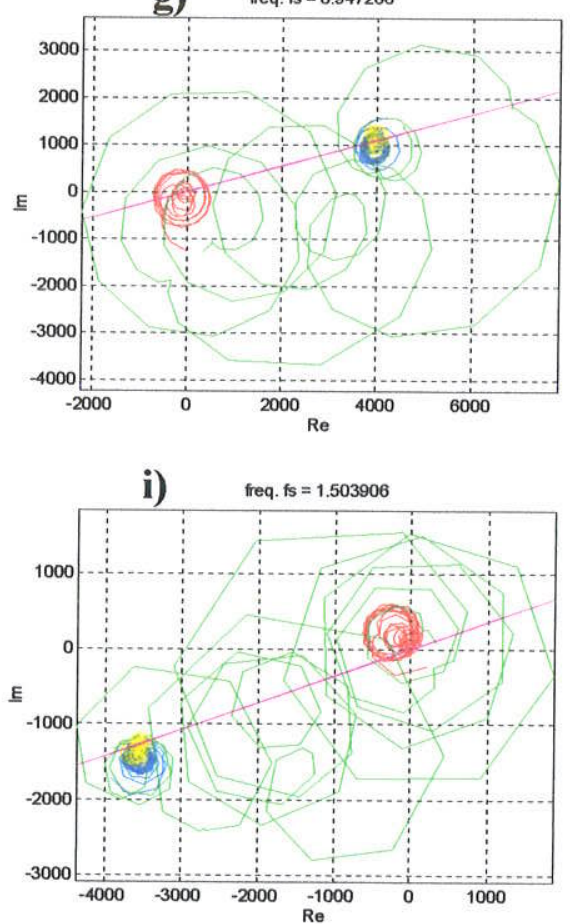

b)

127

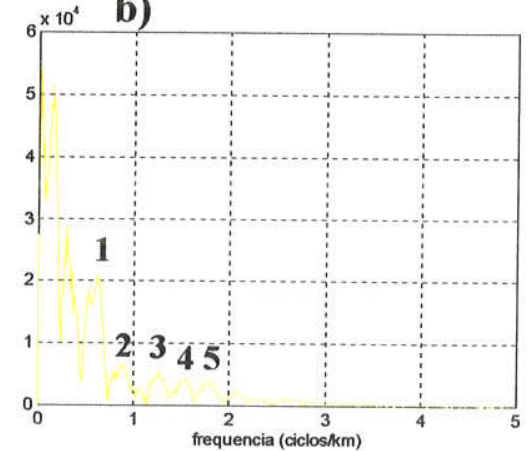

d) freq. $\mathrm{fs}=0.605469$
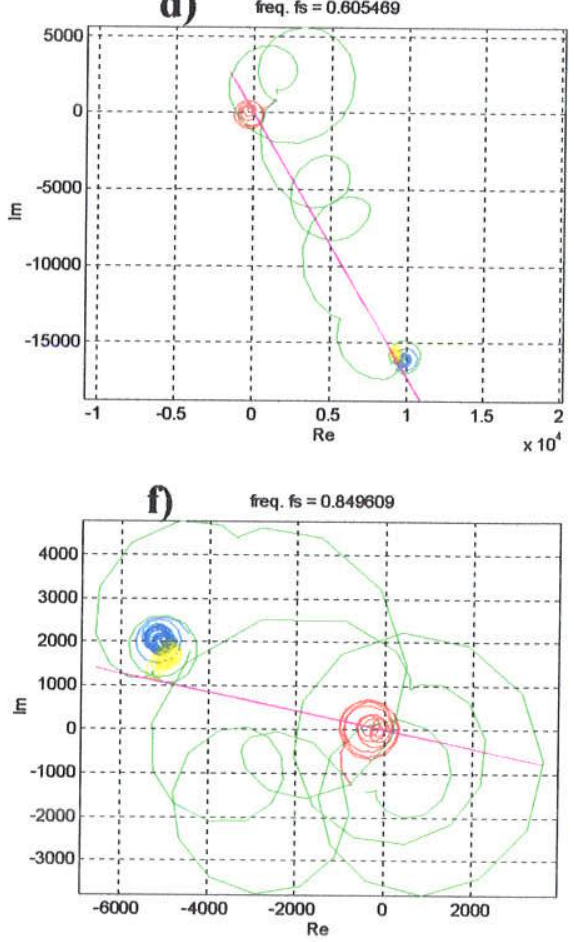

h) freq. $\mathrm{ts}=1.152344$
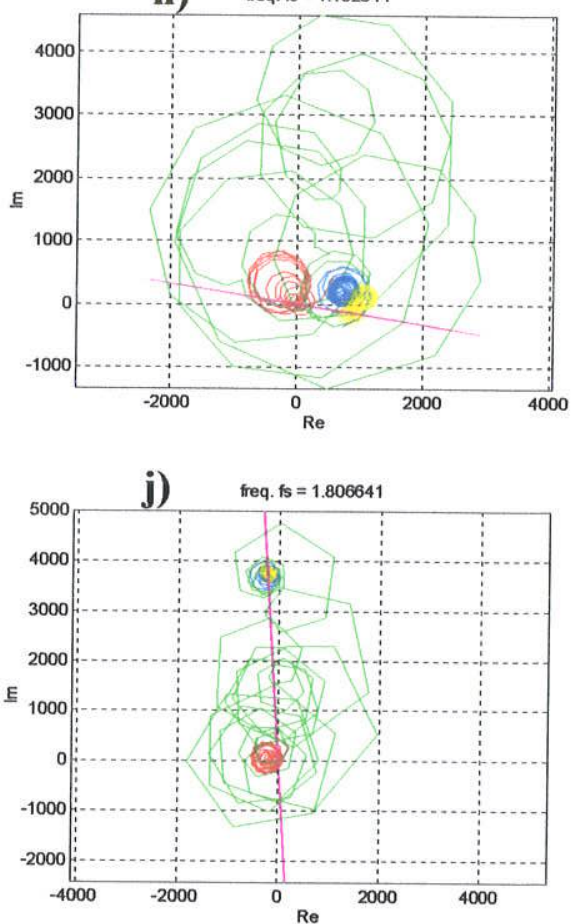

Figura 9.3 - Análise de fasores para um perfil aeromagnético da subárea 4 do PASPRJ: a) perfil aeromagnético; b) espectro de amplitude; trajetórias dos fasores para as freqüências de teste de: 0,00976 (c), 0,605469 (d), 0,732422 (e), 0,849609 (f), 0,947266 (g), $1,152344(\mathrm{~h}), 1,503906$ (i) e 1,806641 (j) ciclos/km. 
últimas porções do perfil, em azul e amarelo, apresentam, visualmente, anomalias de longo comprimento de onda e baixa amplitude, adicionadas a anomalias de curto comprimento de onda e com pequena amplitude.

A Figura 9.3b contém o espectro de amplitude da Figura 9.3a. Através da análise visual desse espectro, pode-se dizer que o ruído branco predomina para as freqüências acima de 2,5 ciclos $/ \mathrm{km}$, e que os 5 picos espectrais nele numerados correspondem a freqüências associadas a componentes harmônicas presentes no perfil aeromagnético. As Figuras 9.3c a 9.3j apresentam, respectivamente, a representação gráfica das trajetórias dos fasores para as freqüências de teste de $0,009766,0,605469,0,732422,0,849609,0,947266,1,152344$, $1,503906,1,806641 \mathrm{ciclos} / \mathrm{km}$. As duas primeiras freqüências, correspondem à porção de baixa freqüência do espectro; a terceira e a quarta freqüências fazem parte do pico espectral identificado por 1 na Figura 9.3b; as demais freqüências correspondem, respectivamente, aos picos espectrais identificados por 2, 3, 4 e 5 na Figura $9.3 b$.

Para a representação da trajetória dos fasores adota-se a mesma convenção de cores empregadas na Figura 9.3a. Assim, as trajetórias representadas em vermelho correspondem à trajetória do sinal representado em vermelho na Figura $9.3 \mathrm{a}$; as trajetórias representadas em verde correspondem à trajetória do sinal representado em verde na Figura 9.3a; e assim por diante. Os segmentos retilíneos na cor magenta representam a direção da fase da transformada de Fourier para as frequêencias de teste.

Através da Figura 9.3c, conclui-se que o perfil aeromagnético contém ao longo de toda a sua extensão freqüências próximas à freqüência de teste. Como pode ser observado, as trajetórias identificadas pelas cores vermelha, azul e amarela apresentam uma curvatura, o que indica que nos segmentos vermelho, azul e amarelo do perfil aeromagnético na Figura 9.3a estão presentes componentes harmônicas com freqüências próximas à freqüência de teste. Além disso, pode-se afirmar que a porção em vermelho no perfil aeromagnético contém componentes harmônicas mais próximas da freqüência de teste, do que as porções em azul e amarelo, uma vez que a trajetória em vermelho dos fasores apresenta-se menos encurvada do que as trajetórias em azul e amarelo.

Como as trajetórias dos fasores representadas pela cor verde apresentam um comportamento retilíneo, conclui-se que a freqüência de teste constitui-se de uma importante componente harmônica para a formação do sinal aeromagnético representado pela cor verde na Figura 9.3a. A inversão na direção dessa trajetória, formando dois segmentos retilíneos, indica que há uma mudança de fase da componente harmônica na porção representada pela cor verde na Figura 9.3a.

Para a freqüência de teste de $0,605469 \mathrm{ciclos} / \mathrm{km}$, Figura $9.3 \mathrm{~d}$, observa-se que as trajetórias dos fasores para os segmentos representados em vermelho, azul e amarelo, apresentam trajetórias circulares, indicando que não há nenhuma componente harmônica com frequêencia igual à frequiência de teste nos trechos em vermelho, azul e amarelo na Figura 9.3a. Ou seja, tomando-se como referência a freqüência de teste, pode-se afirmar que esses segmentos contêm apenas ruído. As trajetórias representadas pela cor verde, embora apresentem localmente trajetórias curvas, o seu comportamento global indica que elas sofrem um grande deslocamento ao longo da linha que representa a fase da transformada de Fourier (a sua fase é coerente com a fase da transformada de Fourier para a freqüência de teste). Isso indica que nesses segmentos predominam componentes harmônicas com freqüências próximas à freqüência de teste. 
As demais Figuras (9.3e a 9.3j) foram obtidas calculando-se as trajetórias dos fasores para as freqüências correspondentes aos picos espectrais numerados de 1 a 5 na Figura $9.3 \mathrm{~b}$. Como característica geral, independentemente da freqüência analisada, observa-se que as trajetórias apresentam comportamento cíclico, ou seja, no sinal referente ao perfil aeromagnético não existem componentes harmônicas com freqüências iguais ou próximas a essas freqüências de teste. Os picos espectrais assinalados no espectro de amplitude são devidos, portanto, a uma interferência construtiva de ruído. Ou seja, o ruído branco está presente em freqüencias mais baixas do que aquela estimada anteriormente, como sendo da ordem de 2,5 ciclos $/ \mathrm{km}$.

Esse é um comportamento importante que pode ser observado nas demais linhas de vôo localizadas na região do Vale do Ribeira. A frequêencia que indica a separação entre sinal e ruído geralmente situa-se abaixo de $1,0 \mathrm{ciclo} / \mathrm{km}$. Isso leva às seguintes considerações:

1) Os perfis aeromagnéticos da subárea 4 do PASPRJ foram executados com freqüências de amostragem de $10 \mathrm{ciclos} / \mathrm{km}$. Mesmo com esse nível de detalhamento na amostragem só é possível se identificar componentes harmônicas com freqüências de até 0,6 ciclos $/ \mathrm{km}$. As componentes com freqüências acima deste valor são consideradas como ruído. Era de se esperar que com tal frequiência de amostragem fosse possível se amostrar sinais com comprimentos de onda mais curtos sem que houvesse contaminação espectral. Como a análise da trajetória dos fasores não indica a presença desses comprimentos de onda pode-se supor que:

a) anomalia magnética não contém, de fato, essas componentes espectrais e, portanto, a freqüência de amostragem de 10 ciclos $/ \mathrm{km}$ é desnecessária para amostrar corretamente os comprimentos de onda existentes;

b) os corpos fontes de origem geológica podem estar gerando anomalias magnéticas cujos comprimentos de onda são menores do que o comprimento de onda de Nyquist (igual a 200 metros). Desse modo, com o emprego de uma freqüência de amostragem igual a 10 ciclos $/ \mathrm{km}$ não estaria sendo possível se amostrar corretamente os curtos comprimentos de onda, e o sinal medido estaria sendo contaminado espectralmente por essas componentes de maior freqüência, oriundas de corpos geológicos localizados e rasos;

2) Anjos \& Mourão (1988), após a geração da malha digital da subárea 4 do PASPRJ, aplicaram um filtro passa-baixa, com freqüência de corte de 2,0 ciclos $/ \mathrm{km}$. Este valor está muito acima do valor identificado de $0,6 \mathrm{ciclos} / \mathrm{km}$ como sendo representativo do limite entre sinal e ruido para as linhas de vôo do projeto. Como conseqüência, todo o ruído presente nas linhas de vôo com freqüência acima de 0,6 ciclos $/ \mathrm{km}$ e abaixo de 2,0 ciclos $/ \mathrm{km}$ vai contaminar espectralmente as malhas digitais geradas por Anjos \& Mourão (1988).

3) Durante o procedimento de homogeneização espectral, discutido anteriormente, foi sugerido o emprego de uma freqüência de corte de 0,5 ciclos $/ \mathrm{km}$. Essa freqüência foi obtida baseando-se exclusivamente em fatores geométricos que nortearam a execução do levantamento, ou seja, o espaçamento entre as linhas de produção. Deve-se notar que esse valor situa-se próximo do valor indicado anteriormente de 0,6 ciclos $/ \mathrm{km}$. Portanto, um eventual recobrimento aéreo de detalhe da área abrangida pelo levantamento São Paulo/Rio de Janeiro, na região do Vale do Ribeira, com um espaçamento menor entre linhas de vôo, não será capaz de fornecer informação espectral com mais detalhe do que aquela atualmente disponível, pois não há componentes harmônicas com frequiências maiores do que 0,6 ciclos $/ \mathrm{km}$ presentes ao longo das linhas de 
produção. Uma alternativa para se obter mais detalhes, além de se diminuir o espaçamento entre as linhas de vôo, consistiria, também, em se diminuir a altura dos perfis sobre o terreno e aumentar a taxa de amostragem, preferencialmente, dentro dos parâmetros estabelecidos por Reid (1980). 


\section{CAPÍTULO 10 COMENTÁRIOS E CONCLUSÕES}

Este trabalho tem por objetivo efetuar uma análise crítica e comparativa das técnicas de processamento e da consistência dos Projetos Aerogeofísicos Extremo Sudeste do Brasil, Serra do Mar Sul e São Paulo/Rio de Janeiro.

Muito embora os três projetos tenham sido executados aproximadamente na mesma época (entre 1975 e 1979), era de se esperar que eles empregassem metodologias contemporâneas de aquisição e de processamento, o que deveria resultar em dados com qualidade semelhante. Contudo, não é isso o que se observa; a qualidade dos dados dos três projetos é bem distinta. Particularmente, o PASMS é o projeto que apresenta os dados com a pior qualidade dentre os três projetos analisados. Talvez isso explique o porquê dos seus dados, apesar de abrangerem uma região com quase $500 \mathrm{~km}$ de extensão N-S, serem tão pouco utilizados pela comunidade acadêmica ou por empresas.

O PASMS, por ter sido executado a baixa altura sobre o terreno, numa região na qual ocorrem grandes desníveis topográficos, e por ter utilizado um sistema de navegação visual, apresenta os mais variados tipos de erro. Estes incluem:

- mau posicionamento das linhas de vôo - ora as linhas de produção se cruzam, ora encontram-se distanciadas até $4 \mathrm{~km}$ umas das outras, distorcendo, assim, a geometria das anomalias geofísicas;

- a identificação inadequada das coordenadas das fiduciais de controle - que fez com que erros de paralaxe passassem a afetar de modo distinto vários segmentos de uma mesma linha de vôo, distorcendo as formas das anomalias;

- a utilização de uma base cartográfica inadequada - que fez com que as anomalias geofísicas apresentassem erros de posicionamento, localizando-se até $20 \mathrm{~km}$ de distância dos corpos que as geram;

- a presença de fortes erros de nivelamento - que distorcem as anomalias na direção das linhas de vôo;

- grandes variações no intervalo de amostragem ao longo das linhas de vôo, no azimute e na altura das medidas -- tais erros, irreversíveis, comprometem a qualidade dos produtos finais, pois eles introduzem erros que tendem a contaminar espectralmente as medidas.

Alguns desses erros puderam ser corrigidos, como é o caso dos erros de paralaxe que afetam apenas trechos das linhas de vôo ou o caso da correção da base cartográfica do projeto. Com o desenvolvimento e a aplicação de metodologias inéditas a esses erros, as anomalias geofísicas passaram a coincidir com a localização dos seus respectivos corpos fontes, além disso, foi possível se atenuar muitas das distorções que afetam a geometria das anomalias. Outros tipos de erro, como os de nivelamento, só puderam ser atentados, pois os dados referentes às linhas de controle e da magnetometria não nivelada corrigida da variação diurna não foram preservados pela CPRM. A perda de tais dados impossibilita que sejam aplicadas as técnicas tradicionais de nivelamento de dados, pois estas necessitam das informações contidas nas linhas de controle. 
Foi desenvolvido um algoritmo inédito com a finalidade de se identificar a localização das fiduciais de controle de um levantamento aerogeofísico. Esse algoritmo apresentou um índice de $100 \%$ de acerto quando testado com os dados do PASMS, sendo capaz de identificar corretamente a localização de todas as fiduciais de controle selecionadas nos mapas de posição de linha de vôo. O desenvolvimento de tal algoritmo foi essencial para que se pudesse efetuar a correção dos erros de paralaxe que afetam apenas trechos das linhas de vôo.

A técnica de correção cartográfica do PASMS desenvolvida e apresentada neste trabalho mostrou-se superior ao emprego da técnica baseada na transformação afim, até então utilizada. O emprego da transformação afim para efetuar a correção cartográfica do PASMS é limitada em face da complexidade das distorções observadas. Ela é eficiente para ser utilizada em áreas restritas, de pequenas dimensões, nas quais as distorções são suaves. Contudo, ela é ineficaz para efetuar a correção global do PASMS. A metodologia aqui desenvolvida, baseada no ajuste de uma superfície de curvatura mínima às correções medidas, mostrou-se eficiente para efetuar a correção cartográfica global do PASMS. Ela foi testada com dados da porção norte do levantamento (região do Vale do Ribeira) e com dados da porção sul (região de Florianópolis). Ela foi capaz de efetuar adequadamente a correção do posicionamento dos dados dessas duas áreas, que se encontram separadas por uma distância da ordem de $300 \mathrm{~km}$. Após a aplicação dessa correção, as anomalias geofísicas passaram a coincidir com a informação geológica de superficie.

Muito embora o PASPRJ tenha sido executado sobre uma região quase tão desfavorável quanto o PASMS, ele não apresenta os severos erros de posicionamento que afetam as medidas do PASMS. Isso se deve ao fato do PASPRJ ter utilizado um sistema de navegação Doppler que, além de manter a aeronave na rota predefinida, controlou o sistema de aquisição de dados. Assim, as suas linhas de vôo apresentam um paralelismo muito bom, sendo executadas ao longo do azimute nominal (N-S). Além disso, as medidas do campo magnético apresentam pouca dispersão com relação à distância nominal de aquisição de dados ao longo dos perfis $(100 \mathrm{~m})$.

Apesar do PAESB ter utilizado o mesmo sistema de navegação visual (baseada em fotomosaicos) que foi empregada no PASMS, ele não apresenta erros de posicionamento de medidas tão intensos quanto o PASMS. Isso é devido ao fato da topografia na região do PAESB ser muito mais suave do que aquela encontrada na região do PASMS, o que favorece a navegação visual. A dispersão dos parâmetros de aquisição de dados do PAESB (distância entre fiduciais consecutivas, azimute das medidas, altura sobre o terreno) é muito menor do que aquela observada no PASMS. Contudo, elas são ligeiramente maiores do que aquelas observadas no PASPRJ. Isso indica que, mesmo em regiões topograficamente desfavoráveis, o emprego de um sistema digital de navegação é capaz de produzir medidas muito mais próximas dos parâmetros nominais do levantamento do que aquelas medidas que são obtidas ao se utilizar um sistema de navegação visual numa área topograficamente favorável (PAESB).

Vários são os tipos de erros que podem afetar as medidas aeromagnéticas. Alguns desses erros estão associados à aeronave que transporta o magnetômetro: interferência magnética causada pelos componentes da aeronave que apresentam magnetização permanente, indução magnética causada pelo movimento da aeronave através do campo magnético da Terra, interferências de altas frequiências causadas pelos sistemas elétricos de bordo, interferências de baixas e médias freqüências causadas pelos movimentos da aeronave. Esses erros atingem uma ampla faixa espectral e, se não forem adotadas medidas preventivas para atenuá-los, eles podem comprometer as medidas. Outros erros correspondem a variações temporais no campo 
geomagnético. Eles variam desde as pulsações (com períodos entre 1 e $300 \mathrm{~s}$, com amplitudes moderadas), passando pelas tempestades magnéticas (com períodos de horas e com amplitudes de dezenas de nanoteslas), pelas variações diurnas (com períodos de 24 horas e amplitudes de até $50 \mathrm{nT}$ ), até as variações mais longas, como as seculares (com variações graduais ao longo dos anos). As variações temporais de curto período só podem ser corretamente removidas dos dados se forem utilizados magnetômetros base instalados de modo adequado a se monitorar as variações geomagnéticas. Caso contrário, elas podem contaminar espectralmente as medidas efetuadas ao longo dos vôos. As variações temporais de períodos mais longos, por outro lado, podem ser atenuadas através de técnicas de nivelamento de perfis de dados.

As componentes do campo geomagnético, originadas no núcleo externo da Terra, e modeladas pelo IGRF ou pelo DGRF também devem ser removidas dos dados. Através de exemplo apresentado nesta tese, constata-se que existe uma diferença acentuada e não linear entre o IGRF (adotado pela Geofoto e pela CPRM para corrigir os dados) e o DGRF quando estes são calculados para uma mesma altitude ao longo da área dos três projetos. Como se sabe, a topografia na região estudada neste trabalho, apresenta grandes variações, principalmente nas áreas do PASPRJ e do PASMS, onde a superficie de vôo varia entre 110 e 1.810 metros acima do nível do mar. Devido ao gradiente vertical do campo magnético, espera-se que essas variações de altura desempenhem um papel importante nas correções dos dados. Recomenda-se que, no futuro, empregando-se um modelo topográfico digital adequado, seja analisado o comportamento dessas variações, aplicando-as aos dados, se necessário.

O modo heterogêneo como as medidas do campo magnético são feitas no transcurso de um aerolevantamento (pequeno espaçamento entre as medidas ao longo das linhas de vôo, e grande espaçamento entre linhas de vôo adjacentes) pode ocasionar uma contaminação espectral da malha digital interpolada se estiverem presentes nos perfis sinais com comprimentos de onda menores do que duas vezes o espaçamento entre as linhas de vôo (teorema da amostragem). Contudo, tem sido empregado rotineiramente aos dados dos projetos um filtro passa-baixa que corta os comprimentos de onda menores do que duas vezes o espaçamento entre os nodos da malha digital interpolada. Esse é um procedimento inadequado para ser utilizado com os dados oriundos das regiões dos projetos PAESB, PASMS e PASPRJ, pois conforme pode ser visto nos espectros das linhas de vôo, os dados amostrados apresentam um conteúdo espectral importante que não é removido pela filtragem que tem sido empregada. Desse modo, têm sido produzidas rotineiramente malhas digitais contaminadas espectralmente. Particularmente, as fontes de contaminação espectral de alta freqüência, são mais importantes na subárea 4 do PASPRJ do que nas subáreas 3 e 6 . Essas fontes de alta freqüência, muito provavelmente, estão associadas aos grandes lineamentos com orientação NW que ocorrem na subárea 4 e estão ausentes nas demais subáreas.

Tradicionalmente, têm sido empregadas técnicas de interpolação bidimensionais para se gerar as malhas digitais dos projetos PAESB, PASMS e PASPRJ. Tais técnicas incluem: curvatura mínima, krigagem e algoritmo Bigrid. Todas essas técnicas foram analisadas, sob o ponto de vista teórico, e aplicadas a uma área teste do PASPRJ. Visualmente não são notadas diferenças significativas nos resultados produzidos por elas. O teste de validação cruzada realizado mostrou que o algoritmo Bigrid foi aquele que, sistematicamente, produziu os menores resíduos de interpolação, seguido, respectivamente, pela krigagem ordinária e curvatura mínima. Deve-se ressaltar que o bom desempenho do algoritmo Bigrid deve ao fato dos perfis aeromagnéticos terem sido filtrados antes da interpolação dos dados, removendo-se as componentes com freqüência superior a $f_{N l}$. Resta salientar que essas técnicas de interpolação, muito embora sejam amplamente difundidas, em princípio, não são as mais adequadas para se 
interpolar dados de natureza tridimensional, como os dados do campo magnético, principalmente se esses dados forem medidos numa superfície variável, ao invés de serem medidos numa superfície plana. Recomenda-se que as técnicas de interpolação 3-D sejam aplicadas aos dados do PAESB e PASPRJ, confrontando os seus resultados com aqueles obtidos pelas técnicas tradicionais de interpolação $2-\mathrm{D}$, e verificando a viabilidade delas atenuarem, na prática, os efeitos dos erros de nivelamento, conforme foi demonstrado com o emprego de dados sintéticos. Quanto ao PASMS, ele não poderá ser alvo da interpolação 3-D pois os seus dados de magnetometria corrigida da variação diurna foram perdidos ao longo do tempo pelos órgãos responsáveis pela sua guarda.

As técnicas de filtragem de dados no domínio espacial, baseadas no emprego de filtros recursivos foram discutidas. Concluiu-se, após analisar as características dos filtros recursivos de Butterworth, Chebyshev dos tipos I e II, e elíptico, que este último seria o mais adequado para ser empregado nos processos de homogeneização espectral, atenuação de erros de nivelamento, e decorrugação de dados magnéticos. Ele foi implementado tanto na versão passabaixa quanto na versão passa-alta, produzindo resultados satisfatórios.

Com o objetivo de se tentar atenuar os erros de nivelamento que afetam os projetos PAESB e PASPRJ (este, de modo mais intenso), foram desenvolvidos programas capazes de efetuar três tipos de nivelamento de perfis de dados aeromagnéticos: nivelamento por reposicionamento do ponto de cruzamento, nivelamento por fechamento de loop, e nivelamento polinomial. A técnica de nivelamento por reposicionamento do ponto de cruzamento foi aquela que produziu os melhores resultados quando aplicada ao PASPRJ, seguida, respectivamente, pelo nivelamento polinomial e por fechamento de loop. Quanto ao PAESB, os melhores resultados foram obtidos com o emprego da técnica de nivelamento por reposicionamento das coordenadas do ponto de cruzamento e por fechamento de loop, enquanto o nivelamento polinomial apresentou resultados fracos. Visualmente, essas técnicas foram capazes de produzir resultados melhores do que aqueles obtidos com o emprego das técnicas até então utilizadas para o nivelamento dos dados desses projetos. Para que esses métodos de nivelamento pudessem ser implementados, foi desenvolvido um algoritmo inédito com a finalidade de identificar automaticamente o ponto de cruzamento entre as linhas de produção e as linhas de controle em levantamentos aerogeofísicos. $O$ algoritmo iterativo proposto converge rapidamente para a solução, economizando tempo de processamento.

A decorrugação e o micronivelamento de dados consistem em procedimentos que têm como objetivo remover das malhas digitais (decorrugação) e dos perfis de dados (micronivelamento) os erros residuais que ainda afetam os dados após a etapa de nivelamento dos perfis. Geralmente, tem-se utilizado a filtragem no domínio da freqüência (filtro co-seno direcional) para efetuar a decorrugação de malhas digitais. Contudo, conforme foi mostrado em exemplos, este tipo de filtro atenua não só os erros devidos ao nivelamento, como também atenua o sinal devido a fontes de natureza geológica ao longo de uma ampla faixa espectral. Com o emprego da filtragem espacial unidimensional às linhas e colunas das malhas digitais conseguiu-se gerar imagens menos distorcidas do que aquelas obtidas com a filtragem espectral. Particularmente, foi possível se obter um desempenho superior com a utilização de filtros recursivos do tipo elíptico ao invés de se empregar os filtros de Naudy e Fuller.

Tradicionalmente, a identificação de componentes harmônicas presentes em perfis de dados aeromagnéticos tem sido feita através da análise do espectro de amplitude dos dados. Neste trabalho, propõe-se o emprego da técnica de análise de fasores como ferramenta auxiliar 
na discriminação das componentes harmônicas presentes nos dados. Até então, em geofísica, esta técnica tinha sido experimentada em sismologia e na análise de registros de gravímetros supercondutores. Neste trabalho, esta técnica foi aplicada a perfís sintéticos sem e com ruído. Os resultados dessa análise mostram que a análise de fasores é robusta quando o sinal se encontra contaminado pela presença de ruído branco. Através da sua aplicação a perfis de dados reais, foi possível se identificar os trechos nos perfis em que predominam determinadas componentes harmônicas. Também, foi possível se identificar a ocorrência de mudança de fase no sinal. 


\section{Referências Bibliográficas}

Akima, H. - 1970 - A new method of interpolation and smooth curve fitting based on local procedures. Journal of the Association for Computing Machinery, vol. 17, no. 4 , p. 589-602.

Anjos, I.L.S. \& Mourão, L.M.F. - 1987 - Projeto Extremo Sudeste do Brasil, Relatório Final. Processamento dos dados. Texto, vol. 2, Companhia de Pesquisa de Recursos Minerais, Rio de Janeiro, 33 p.

Anjos, I.L.S. \& Mourão, L.M.F. - 1988 - Projeto São Paulo/Rio de Janeiro, Relatório Final. Processamento dos dados, Parte I - São Paulo. Texto, vol. 2, Companhia de Pesquisa de Recursos Minerais, Rio de Janeiro, 29 p.

Barritt, S.D. - 1993 - The African magnetic mapping project. ITC Journal, vol. 1993-2, p. 122-131.

Bath, M. - 1974 - Spectral analysis in geophysics. Elsevier, Amsterdan, 563 p.

Bhattacharyya, B.K. - 1966 - Continuous spectrum of the total-magnetic-field anomaly due to a rectangular prismatic body. Geophysics, vol. 31, no. 1, p. 97-121.

Bhattacharyya, B.K. - 1969 - Bicubic spline interpolation as a method for treatment of potential field data. Geophysics, vol. 34, no. 3, p. 402-423.

Billings, S. \& Richards, D. - 2002 - Quality control of gridded aeromagnetic data. Rio Tinto Exploration, Australia Region, 65 p.

Braggion Jr., I. - 1995 - Técnicas de geração de retículos para dados aeromagnéticos. Exame de Qualificação, Instituto de Astronomia, Geofísica e Ciências Atmosféricas, Universidade de São Paulo, 52 p.

Braggion Jr., I. - 1998 - O emprego de filtros elípticos à decorrugação de dados aeromagnéticos. In: Anais do $40^{\circ}$ Congresso Brasileiro de Geologia, Belo Horizonte, p. 393.

Braggion Jr., I. - 2002 - Uma nova metodologia para correção de erros de paralaxe: Aplicação ao Projeto Aerogeofísico Serra do Mar Sul. In: Anais do $41^{\circ}$ Congresso Brasileiro de Geologia, João Pessoa, p.636.

Briggs, I.C. - 1974 - Machine contouring using minimum curvature. Geophysics, vol. 39 , no. 1, p. 39-48.

Blum, M.L.B. - 1999 - Processamento e interpretação de dados de geofisica aérea no Brasil central e sua aplicação à geologia regional e à prospecção mineral. Tese de Doutorado, Instituto de Geociências, Universidade de Brasília, 229 p.

Casanova, P.G. \& Alvarez, R. - 1985 - Splines in Geophysics. Geophysics, vol. 50, no. 12, p. 2831-2848.

Cordell, L. - 1992 - A scattered equivalent-source method for interpolation and gridding of potential-field data in three dimensions. Geophysics, vol. 57, no. 4, p. 629-636.

Costa, A.F.U., Ramgrab, G.E. \& Vasconcellos, R. - 1990 - Interpretação do campo magnético na porção oriental do Escudo Sul-Rio-Grandense. In: Anais do $36^{\circ}$ Congresso Brasileiro de Geologia, p. 2439-2444.

CPRM - 1995 - Catálogo geral de produtos e serviços: Levantamentos Aerogeofísicos. Ministério das Minas e Energia, Companhia de Pesquisa de Recursos Minerais, Rio de Janeiro, $359 \mathrm{p}$.

Dampney, C.N.G. - 1969 - The equivalent source technique. Geophysics, vol. 34, no. 1, p. 39-53.

DNPM - 1984 - Inventário dos levantamentos aerogeofisicos executados pelo DNPM. Ministério das Minas e Energia, Departamento Nacional da Produção Mineral, Brasilia, $134 \mathrm{p}$. 
Evans, A.M. - 1995 - Introduction to mineral exploration. Blackwell Science Ltd, Oxford, $396 \mathrm{p}$.

Ferreira, F.J.F. - 1991 - Aerogamaespectrometria e aeromagnetometria de um trato ocidental do pré-Cambriano paulista. Tese de Doutorado, Instituto de Geociências, Universidade de São Paulo, 150 p.

Fitzgerald, D. - 1996 - Geophysical processing system and visualization tools. DFA Pty Ltd, Canberra, $304 \mathrm{p}$.

Foster, M.R., Jines, W.R. \& van der Weg, K. - 1970 - Statistical estimation of systematic errors at intersections of lines of aeromagnetic survey data. Journal of Geophysical Research, vol. 75, no. 8, p. 1507-1511.

Fraser, D.C., Fuller, B.D. \& Ward, S.H. - 1966 - Some numerical techniques for application in mining exploration. Geophysics, vol.31, no. 6, p. 1066-1077.

Fuck, R.F. - 2001 - An improved microlevelling algorithm. In: Anais do $7^{\circ}$ Congresso Internacional da Sociedade Brasileira de Geofísica, Salvador, p.582-585.

Geofoto - 1978a - Projeto Aerogeofisico Serra do Mar Sul: fase de aquisição de dados. Geofoto Aerofotogrametria, Rio de Janeiro, 93 p.

Geofoto - 1978b - Projeto Aerogeofisico Serra do Mar Sul: relatório final. Geofoto Aerofotogrametria, Rio de Janeiro, $48 \mathrm{p}$.

Ginde, S.V. \& Noronha, J.A.N. - 1998 - Design of IIR Filters. Virginia Polytechnic and State University, Blacksburg, $62 \mathrm{p}$.

Grauch, V.J.S. \& Campbell, D.L. - 1984 - Does drapping aeromagnetic data reduce terrain-induced effects? Geophysics, vol. 49, no. 1, p. 75-80.

Green, A.A. - 1983 - A comparison of adjustment procedures for leveling aeromagnetic survey data. Geophysics, vol. 48, no. 6, p. 745-753.

Hansen, R.O. - 1993 - Interpretive gridding by anisotropic kriging. Geophysics, vol. 58, no. 10 , p. 1491-1497.

Hansen, R.O. \& Simmonds, M. - 1993 - Multiple-source Werner deconvolution. Geophysics, vol. 58, no. 12, p. 1792-1800.

Hardwick, C.D. - 1984 - Important design considerations for inboard airborne magnetic gradiometers. Geophysics, vol. 49, no. 11, p. 2004-2011.

Herkommer, M.A \& Whitney, P.D. - 1994 - Minimizing misties in seismic data. Computers and Geosciences, vol. 20, no. 5, p.767-795.

Hinze, W.J. - 1990 - The role of gravity and magnetic methods in engineering and environmental studies. In: Ward, S. H., Ed., Geotechnical and Environmental Geophysics. Vol 1: Review and Tutorial, Soc. Explor. Geophys., p. 75-126.

Hogg, R.L.S. - 1989 - Recent advances in high sensitivity and high resolution aeromagnetics. In: Proceedings of Exploration '87. Ontario Geological Survey, Special Volume, p. 153-169.

Horsfall, K.R. - 1997 - Airborne magnetic and gamma-ray data acquisition. AGSO Journal of Australian Geology \& Geophysics, vol. 17, no. 2, p.23-30.

Hsu, S.K. - 1995 - XCORR: a cross-over technique to adjust track data. Computers and Geosciences, vol. 21, no. 2, p. 259-271.

Journel, A.G. \& Huijbregts, C.H. - 1978 - Mining Geostatistics. Academic Press, London, $600 \mathrm{p}$.

Krajewski, S.A. \& Gibbs, B.L. - 1994 - Computer contouring generates artifacts. Geotimes, vol. 39 , no. 4, p. 15-19.

Kulhánek, O. - 1976 - Introduction to digital filtering in geophysics. Elsevier, Amsterdam, $168 \mathrm{p}$.

Lewis, M. - 1993 - United Nations airborne geophysical activities in developing countries. ITC Journal, vol. 1993-2, p.132-139. 
Luyendyk, A.P.J. - 1997 - Processing of airborne magnetic data. AGSO Journal of Australian Geology and Geophysics, vol. 17, no.2, p.31-38. .

Matheron, G. - 1970 - La théorie des variables régionalisées et ses applications. Ecole Nationale Supérieure des Mines de Paris, Cah. Cent. Morphol. Math. Fontainebleau, no. 5, p. 1-212.

Mauring, E., Beard, L.P., Kihle, O. \& Smethurst, M.A. - 2002 - A comparison of aeromagnetic levelling techniques with an introduction to median levelling. Geophysical Prospecting, vol. 50, p. 43-54.

Mendonça, C.A. - 1992 - Interpolação de dados de campo potencial através de camada equivalente. Tese de Doutorado, Centro de Geociências, Universidade Federal do Pará, $177 \mathrm{p}$.

Mendonça, C.A. \& Silva, J.B.C. - 1994 - The equivalent data concept applied to the interpolation of potential field data. Geophysics, vol. 59, no. 5, p. 722-732.

Mendonça, C.A. \& Silva, J.B.C - 1995 - Interpolation of potential-field data by equivalent layer and minimum curvature: a comparative analysis. Geophysics, vol. 60 , no. 2 , p. $399-407$.

Metelo, M. - 1996 - Comunicação Pessoal.

Milligan, P.R. - 1995 - Short-period geomagnetic variations recorded concurrently with an aeromagnetic survey across the Bendigo area, Victoria. Exploration Geophysics, vol. 26, p. 173-178.

Minty, B.R.S. - 1991 - Simple micro-levelling for aeromagnetic data. Exploration Geophysics, vol. 22, p. 591-592.

Nadal, C.A., Ferreira, F.J.F., Stevanato, R. \& Rosier, F.A. - 1992 - Proposta de correção cartográfica do projeto aerogeofisico Serra do Mar Sul: um teste na folha Apiai (SG-22-X-V-1 / 1:250.000). In: Anais do $37^{\circ}$ Congresso Brasileiro de Geologia, São Paulo, p.220-221.

Naidu, P.S. \& Mathew, M.P - 1998 - Analysis of geophysical potential fields - A digital signal approach. Elsevier, Amsterdam, 298 p.

Naudy, H. \& Dreyer, H. - 1968 - Non-linear filtering applied to aeromagnetic profiles. Geophysical Prospecting, vol. 16, no. 2, p. 171-178.

Nelson, J.B. - 1994 - Leveling total-field aeromagnetic data with measured horizontal gradients. Geophysics, vol. 59, no. 8, p. 1166-1170.

Olea, R.A. - 1974 - Optimal contour mapping using universal kriging. Journal of Geophysical Research, vol. 79, no. 5, p. 695-702.

Olea, R.A. - 1975 - Optimum mapping techniques: using regionalized variable theory. Kansas Geological Survey, University of Kansas, Lawrence, 137 p.

Oppenheim, A.V. \& Schafer, R.W. - 1989 - Discrete-time signal processing. Prentice Hall Signal Processing Series. Prentice Hall, New Jersey, 879 p.

Parks, T.W. \& Burrus, C.S. - 1987 - Digital Filter Design. John Wiley \& Sons, New York, $342 \mathrm{p}$.

Paterson, N.R. \& Reeves, C.V. - 1985 - Applications of gravity and magnetic surveys: The state-of-the-art in 1985. Geophysics, vol. 50, no. 12, p. 2558-2594.

Peddie, N.W. - 1983 - International Geomagnetic Reference Field - its evolution and the difference in total field intensity between new and old models for 1965-1980. Geophysics, vol. 48, no. 12, p. 1691-1696.

Press, W.H., Flannery, B.P., Teukolsky, S.A., Vetterling, W.T. - 1990 - Numerical Recipes: The art of scientific computing. Cambridge University Press, Cambridge, $702 \mathrm{p}$.

Proakis, J.G. \& Manolakis, D.G. - 1988 - Introduction to Digital Signal Processing. Macmillan Publishing Co., New York, 944 p. 
Ray, R.D. - 1985 - Correction of systematic error in magnetic surveys: An application of ridge regression and sparse matrix theory. Geophysics, vol. 50, no. 11, p. 17211731.

Reid, A.B. - 1980 - Aeromagnetic survey design. Geophysics, vol. 45, no. 5, p. 973-976.

Rydelek, P.A. \& Sacks, I.S. - 1989 - Testing the completeness of earthquake catalogues and the hypothesis of self-similarity. Nature, vol. 337, p. 251-253.

Scherbaum, F. - 1996 - Of poles and zeros: fundamentals of digital seismology. Modern Approaches in Geophysics, vol. 15. Kluwer Academic Publishers, Amsterdam, $256 \mathrm{p}$.

Schimmel, M.; Waterhourse, J.; Marques, M.D. \& Weinert, D. - 2002 - Circadian and ultradian rhythmicities in very premature neonates maintained in incubators. Biological Rhythm Research, vol. 33, no. 1, p. 83-112.

Sheriff, R.E. - 1991 - Encyclopedic Dictionary of Exploration Geophysics. Society of Exploration Geophysicists, Tulsa, $376 \mathrm{p}$.

Silva, D.C. - 1994 - Espectrometria de raios gama aplicada na classificação de granitóides. Dissertação de Mestrado, Instituto de Astronomia, Geofísica e Ciências Atmosféricas, Universidade de São Paulo, 83 p.

Silva, D.C. \& Mantovani, M.S.M. - 1994 - Considerações sobre o projeto aerogeofisico Serra do Mar Sul. In: Anais do $38^{\circ}$ Congresso Brasileiro de Geologia. Boletim de Resumos Expandidos, Camboriu, vol. 2, p. 9-11.

Spector, A. \& Grant, F.S. - 1970 - Statistical models for interpreting aeromagnetic data. Geophysics, vol. 35, no. 2, p. 293-302.

Stevanato, R., Ferreira, F.J.F., Soares, P.C. \& Silva, F.V. - 1995 - Desempenho de métodos de interpolação espacial na composição de mapas aerogeofísicos. In: Anais do $4^{\circ}$ Congresso Internacional da Sociedade Brasileira de Geofísica, Rio de Janeiro, vol. 1, p. 252-255.

Telford, W.M.; Geldart, L.P.; Sheriff, R.E. \& Keys, D.A. - 1986 - Applied Geophysics. Cambridge University Press, Cambridge, 860 p.

Vasconcellos, R.M. - 1994 - Geofisica em Levantamentos Geológicos no Brasil. Companhia de Pesquisa de Recursos Minerais, Rio de Janeiro, 165 p.

Wachspress, E.L. - $\mathbf{2 0 0 0}$ - Evaluating elliptic functions and their inverses. Computers and Mathematics with Applications, vol. 39, p. 131-136.

Wynn, J.C. \& Bhattacharyya, B.K. - 1977 - Reduction of terrain induced aeromagnetic anomalies by parallel-surface continuation: A case history from the southern San Juan Mountains of Colorado. Geophysics, vol. 42, p. 1431-1449.

Xia, J. \& Sprowl, D.R. - 1991 - Correction of topographic distortion in gravity data. Geophysics, vol. 56, no. 4, p. 537-541.

Xia, J., Sprowl, D.R., Heljeson, D.A. - 1993 - Correction of topographic distortions in potential-field data: A fast and accurate approach. Geophysics, vol. 58, no. 4, p. 515-523.

Yamamoto, J.K. - 2001 - Avaliação e classificação de reservas minerais.Edusp, Fapesp, São Paulo, 226p.

Zürn, W. \& Rydelek, P.A. - 1994 - Revisiting the phasor-walkout method for detailed investigation of harmonic signals in time series. Surveys in Geophysics, vol. 15, p. 409-431.

Zürn, W.; Rydelek, P.A.; Polzer, G.; Weinbrecht, J. - 1995 - Identification of persistent harmonic signals using the phasor-walkout method. In: Proc. $12^{\text {th }}$ Int. Symp. on Earth Tides, Beijing, p. 279-288. 